Research Report

\title{
Authorities and Mechanisms for Purchased Care at the Department of Veterans Affairs
}

RAND Health

Sponsored by the U.S. Department of Veterans Affairs 
For more information on this publication, visit www.rand.org/t/rr1165z3

Published by the RAND Corporation, Santa Monica, Calif.

(C) Copyright 2015 RAND Corporation

RAND $^{\oplus}$ is a registered trademark.

\section{Limited Print and Electronic Distribution Rights}

This document and trademark(s) contained herein are protected by law. This representation of RAND intellectual property is provided for noncommercial use only. Unauthorized posting of this publication online is prohibited. Permission is given to duplicate this document for personal use only, as long as it is unaltered and complete. Permission is required from RAND to reproduce, or reuse in another form, any of its research documents for commercial use. For information on reprint and linking permissions, please visit www.rand.org/pubs/permissions.html.

The RAND Corporation is a research organization that develops solutions to public policy challenges to help make communities throughout the world safer and more secure, healthier and more prosperous. RAND is nonprofit, nonpartisan, and committed to the public interest.

The analyses upon which this publication is based were performed under a contract for the Department of Veterans Affairs. The content of this publication does not necessarily reflect the views or policies of the Department of Veterans Affairs, nor does the mention of trade names, commercial products, or organizations imply endorsement by the U.S. government. The author assumes full responsibility for the accuracy and completeness of the ideas presented.

\section{Support RAND}

Make a tax-deductible charitable contribution at www.rand.org/giving/contribute

www.rand.org 


\section{Authorship Credits}

\author{
Study Directors \\ Michael D. Greenberg \\ Caroline Batka \\ Communications Analyst \\ Lauren Skrabala
}

Michael D. Greenberg

Molly Dunigan

\author{
Veterans Choice Act Study Director \\ Carrie Farmer \\ Veterans Choice Act Study Co-Director \\ Susan Hosek
}

Chapter One: Introduction

Caroline Batka

Phil Carter

Chapter Two: Methods

Samantha Cherney

Caroline Batka

\section{Chapter Three: Authorities and Mechanisms for Purchased Care}

$\begin{array}{ccc}\text { Nicholas M. Pace* } & \text { Samantha Cherney } & \text { Lily Geyer } \\ \text { Geoffrey McGovern* } & \text { Joseph Thompson } & \text { Maya Buenaventura }\end{array}$

Chapter Four: VA Purchased Care Authorities and Mechanisms in Practice

$\begin{array}{ccc}\text { Molly Dunigan* } & \text { Parisa Roshan } & \text { Amy Grace P. Donohue } \\ \text { Samantha Cherney } & \text { Stephen Simmons } & \text { Caroline Batka } \\ \text { Joslyn Hemler } & \text { Eric Apaydin } & \\ \text { Jonathan Welch } & \text { Clara Aranibar } & \end{array}$

Chapter Five: Procurement and Episodes of Care
Susan Lovejoy*
Phil Carter
Michael D. Greenberg

Chapter Six: A Review of Whether the Secretary Needs New Authorities for Purchased Care

$\begin{array}{ccc}\begin{array}{c}\text { Michael D. Greenberg } \\ \text { Lynn E. Davis }\end{array} & \text { Caroline Batka } & \text { Nicholas M. Pace }\end{array}$

Chapter Seven: Alternative Government Health Care Payer Models
Francesca Pillemer*
Christine Buttorff
Amy Grace P. Donohue
Kayla Williams*
Eric Apaydin

Chapter Eight: Conclusions and Recommendations

Caroline Batka Michael D. Greenberg

*Denotes task leader 



\section{Preface}

Congress enacted and President Barack Obama signed into law the Veterans Access, Choice, and Accountability Act of 2014 (Public Law 113-146) ("Veterans Choice Act"), as amended by the U.S. Department of Veterans Affairs (VA) Expiring Authorities Act of 2014 (Public Law 113-175), to improve access to timely, high-quality health care for Veterans. Under "Title IIHealth Care Administrative Matters," Section 201 called for an independent assessment of 12 facets of VA's health care delivery systems and management processes (Assessments A-L): Veteran demographics and health care needs (A), health care capabilities (B), authorities and mechanisms for purchasing care $(\mathrm{C})$, access standards (D), appointment scheduling (E), inpatient clinical workflow $(\mathrm{F})$, staffing and productivity $(\mathrm{G})$, health information technology $(\mathrm{H})$, business processes for purchased care (I), pharmaceuticals and medical supplies (J), construction and capital management $(\mathrm{K})$, and leadership (L).

VA engaged the Centers for Medicare and Medicaid Services (CMS) Alliance to Modernize Healthcare (CAMH), a federally funded research and development center sponsored by CMS and operated by the MITRE Corporation, to serve as the program integrator and as primary developer of 11 of the 12 independent assessments. CAMH subcontracted with the RAND Corporation to conduct three assessments (A, B, and C). CAMH coordinated the assessments, prepared an integrated report for the overall study, and furnished the complete set of reports to the VA Secretary, the House and Senate Veterans Affairs Committees, and the Commission on Care on September 1, 2015. VA made the reports available to the public on its website at www.va.gov/opa/choiceact/factsheets_and_details.asp. This version has been copyedited and reformatted for ease of reading.

This report describes the results of an assessment of the policy and regulatory environment supporting private sector health care purchased by VA (Assessment C). It describes the legal authorities and operating mechanisms by which VA carries out its purchased care activity, related challenges and opportunities for VA, and insights regarding the question of whether the Secretary should have more, less, or different authority with regard to purchased care.

This research was conducted by RAND Health, a division of the RAND Corporation. Additional information about RAND can be found at www.rand.org. 



\section{Contents}

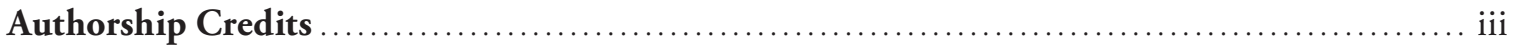

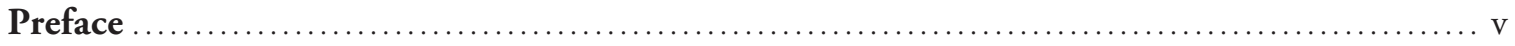

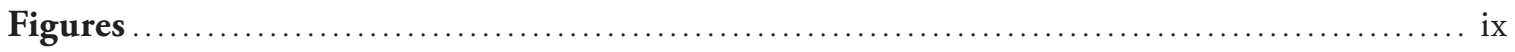



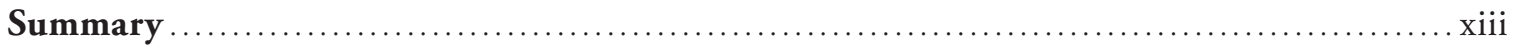

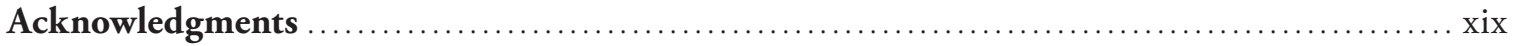



PART I

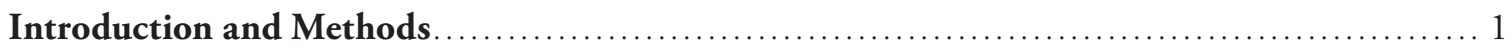

CHAPTER ONE

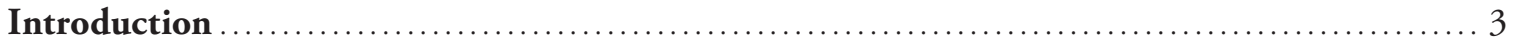

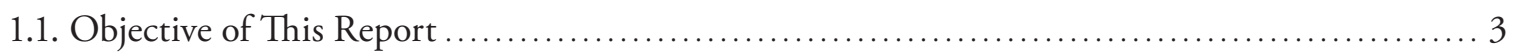







1.5. Organization of This Report................................................. 10

CHAPTER TWO

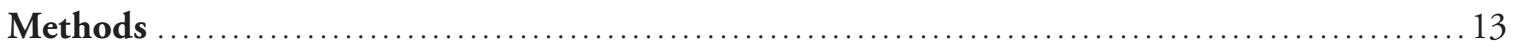

2.1. Statutory, Regulatory, and Legislative History Research and Analysis ...................... 13

2.2. Review of Relevant Published Literature .............................................. 13

2.3. Interviews with Expert Stakeholders ............................................. 14

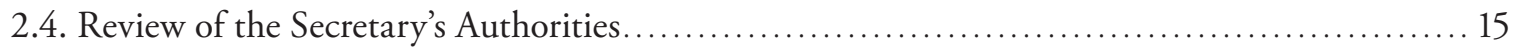

2.5. Review of Local VA Policy Documents ........................................... 15

2.6. Survey of VA Capabilities and Resources.............................................. 16

PART II

Current Authorities, Mechanisms, and Framework for VHA Purchased Care ................ 19

CHAPTER THREE

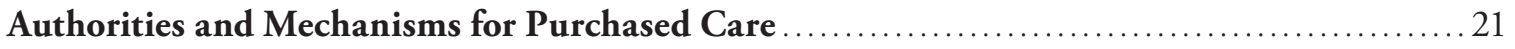

3.1. Pre-Veterans Choice Act Authority and Mechanisms................................ 22

3.2. Veterans Choice Act Authorities and Mechanisms ...................................... 39

3.3. Key Themes in Pre- and Post-Choice Purchased Care .............................. 50 
CHAPTER FOUR

VA Purchased Care Authorities and Mechanisms in Practice.............................. 57

4.1. Practical Challenges in the Administration of Purchased Care ................................ 57

4.2. Implementation of Purchased Care at the Facility Level Is Inconsistent...................... 76



CHAPTER FIVE

Procurement and Episodes of Care

5.1. VA Procurement in Purchased Care: Understanding the Framework Established by FAR

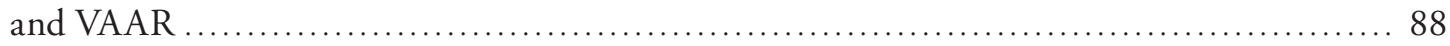

5.2. VA's Approach to "Episodes of Care" ................................................ 94

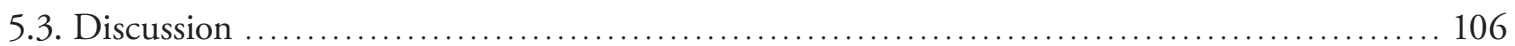

PART III

Considerations for Future VA Purchased Care Authorities and Mechanisms.

CHAPTER SIX

A Review of Whether the Secretary Needs New Authorities for Purchased Care ............ 111

6.1. Objectives for Policy Changes in Purchased Care .................................... 112

6.2. Steps to Implement Policy Changes and Implications for Authorities ..................... 114

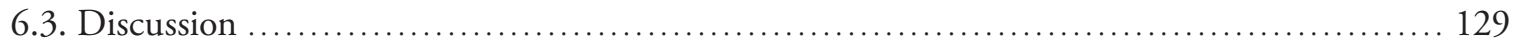

CHAPTER SEVEN



7.1. Key Similarities Across VA, TRICARE, and Medicare ............................... 132

7.2. Lessons for VA from TRICARE and Medicare .................................... 135

7.3. Experience with Third-Party Contracting for Purchased Care Administration............... 140

7.4. Discussion ....................................................................... 142

CHAPTER EIGHT

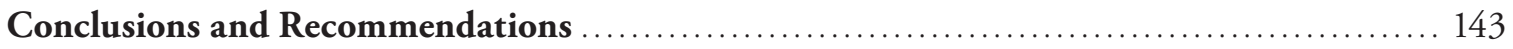

8.1. Summary of Assessment Findings ............................................... 143

8.2. Limitations of the Assessment........................................................ 146

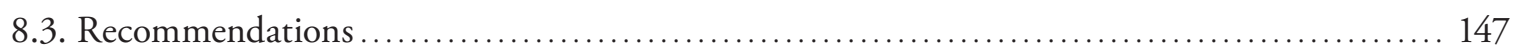

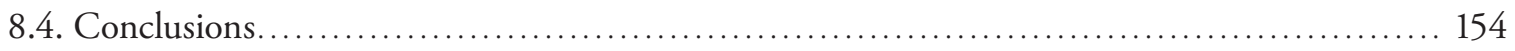

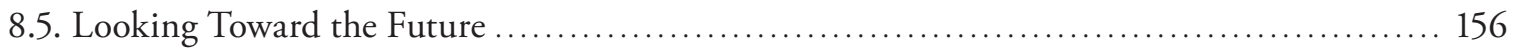

APPENDIXES

A. Growth in Purchased Care Utilization Rates and Authorizations .................... 159

B. Statutory and Regulatory Authorities for the Provision of Purchased Care

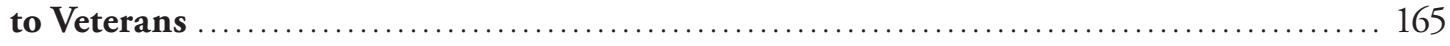

C. Responses to Request for Local VA Policy Documents and Data $\ldots \ldots \ldots \ldots \ldots \ldots \ldots \ldots \ldots$

D. Facility Survey Questions and Frequency Response Data $\ldots \ldots \ldots \ldots \ldots \ldots \ldots \ldots \ldots \ldots \ldots \ldots \ldots \ldots \ldots$

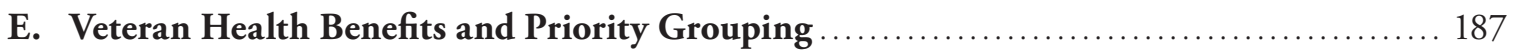

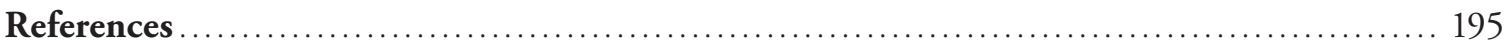




\section{Figures}

1-1. Timeline of VA Purchased Care Mechanism Development ........................ 5

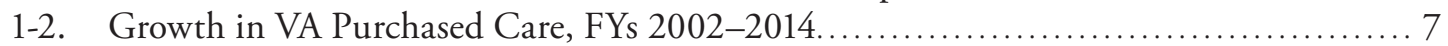

2-1. Local Purchased Care Policy Documents Received ................................ 15

4-1. Purchased Care Mechanisms in Practice .......................................... 58

4-2. Hierarchy for VA Care Referrals .......................................... 60

4-3. Facility Survey Data on Frequency of Electronic Record Sharing with Non-VA Providers .............................................................. 70

4-4. Facility Survey Statistics on Frequency of Data Collection Regarding Veteran Wait Times at Non-VA Facilities................................................ 72

4-5. Appointment Management Process Flowchart from One VAMC's SOP (April 2015)....79

4-6. Veterans Choice Notification Processing from One VAMC's SOP on the Veterans Choice Act Program (February 2015) ................................. 80

4-7. Reasons for Referral to Purchased Care ........................................ 83

5-1. Alternative Approaches to Purchased Care Strategy for Procurement .................... 93

5-2. Episode of Care Duration for Various Types of Care ........................... 98

5-3. Design Considerations for VA in Developing Episode-Based Payment Mechanisms ... 105

6-1. Objectives, Implementing Steps, and Implications for the Secretary's Authorities ...... 112

7-1. Spectrum of Provide-Versus-Purchase Care .................................. 132

8-1. VA's Approach to Informing Internal and External Stakeholders About Authorities... 151

A-1. Growth in VA Purchased Care, FYs 2002-2014.................................. 159

A-2. Purchased Care Utilization by VHA Enrollees, FYs 2002-2014 .................... 160

A-3. Purchased Care Utilization Across VAMC Sites, FYs 2012-2015 .................... 162

A-4. Total Purchased Care Authorizations and PC3 Authorizations Across Specific VAMC Sites, FYs 2013-2014 ................................................ 163

A-5. Frequency with Which VA Facilities Refer Veterans to Fee-Basis or Contracted Care .......................................................... 164

C-1. Local Purchased Care Policy Documents Received ............................. 173

C-2. Response Rates for Local Purchased Care Policy Documents ....................... 174

C-3. Distribution of Dates of Local VA Policies Received ............................... 175

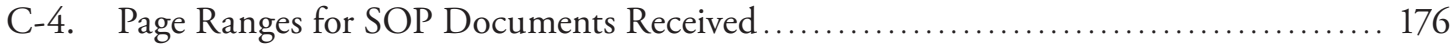





\section{Tables}

1-1. VA Purchased Care Rules for Eligibility, VA Discretion, Providers, and Payment ........ 6

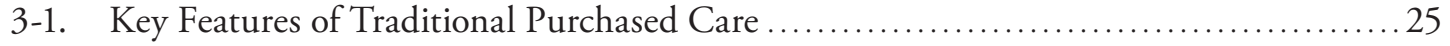

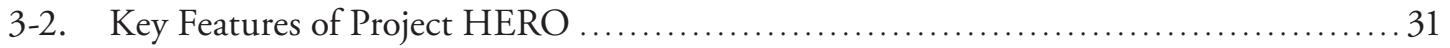

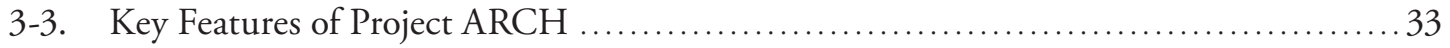

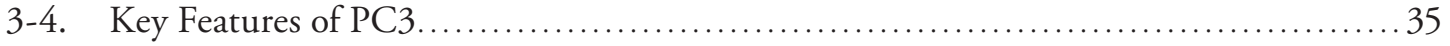

3-5. Key Features of the Veterans Choice Program .................................. 41

3-6. VA Discretion in Key Purchased Care Programs ................................. 51

3-7. Eligibility in Key Purchased Care Programs ........................................... 53

3-8. Veteran Input into Provider Choice in Key Purchased Care Programs .................... 53

3-9. Payments and Payers in Key Purchased Care Programs .............................. 54

3-10. Objectives for Utilizing Purchased Care ...................................... 55

4-1. Comparison of Purchased Care Eligibility Across Four Main Programs ................ 59

6-1. Objectives for Policy Changes in Purchased Care ................................. 113

6-2. Implementing Steps: Expand and Enhance Partnerships with Private Providers ....... 116

6-3. Implementing Steps: Modify Veterans' Eligibility for Purchased Care . .............. 118

6-4. Implementing Steps: Change the Way Purchased Care Is Managed ................. 121

6-5. Implementing Steps: Improve Contracting for Purchased Care .................... 126

7-1. Basic Program Structures of TRICARE, Medicare, and VA...................... 133

8-1. Provider Reimbursement Rates, by Purchased Care Mechanism ..................... 154

A-1. VA Spending and Utilization, by Purchased Care Category, FYs 2008-2012 ......... 160

B-1. Statutory Provisions Relevant to Purchased Care ................................... 166

B-2. Regulatory Provisions Relevant to Purchased Care............................... 171

C-1. Facilities Responding to Request for Data.................................. 178

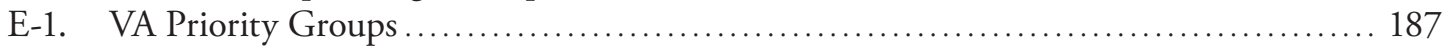

E-2. Key Features of Service-Connected Emergency Care ............................. 192

E-3. Key Features of Non-Service-Connected Emergency Care ........................ 193 



\section{Summary}

One of the core responsibilities of the U.S. Department of Veterans Affairs (VA) involves providing health care services to eligible Veterans. Although VA has traditionally carried out its health care role primarily by operating a national network of hospitals and other facilities, the agency also administers a purchased care function through which it pays for health care services from outside providers. VA's purchased care function has evolved primarily to address situations in which VA's direct-care resources are unable to offer needed services to Veterans. Moreover, the function is bounded by the fiscal context of a discretionary VA health benefit funded by a limited annual budget appropriation. ${ }^{1}$ Although purchased care has accounted for only a small fraction of VA's health care budget over the past decade, that fraction is growing. In the wake of the recent crisis in access to care through VA facilities, stakeholders and policymakers are revisiting the role and performance of VA purchased care. Specifically, they are considering whether modifications to VA's purchased care approach might be desirable, given broader goals of expanding access to care, enhancing trusted partnerships, and improving VA operations to deliver seamless and integrated support for the health of Veterans.

The Veterans Choice Act and the assessment mandate for this report were passed into law in the summer of 2014. Broadly, the act represented a congressional response to an acute access crisis in Phoenix, Arizona, and other parts of the country. In some important respects, the Veterans Choice Act spotlighted purchased care both as a device for ensuring Veterans' access to services and as a focal point for policy-makers' attention moving forward.

The assessment mandate for this report was established specifically by Section 201(a)(1)(C) of the Veterans Choice Act. That mandate called for a study to address "[t]he authorities and mechanisms under which the Secretary may furnish hospital care, medical services, and other health care at non-Department facilities, including whether the Secretary should have the authority to furnish such care and services at such facilities through the completion of episodes of care.”

\section{Purpose and Methods}

The purpose of this report is to respond to the assessment questions posed by Section 201(a)(1)(C) of the Veterans Choice Act. In particular, we describe the legal authorities and operating mechanisms by which VA carries out its purchased care activity, related challenges and opportuni-

1 As we discuss in the body of this report, the fiscal context for VA purchased care changed somewhat with the implementation of the Veterans Choice Act, particularly given the $\$ 10$ billion appropriation for the Choice program that was made under the act. 
ties for VA, and insights regarding the question of whether the Secretary should have more, less, or different authority for purchased care than he or she currently has. In addition, given the explicit language of the assessment mandate, we also evaluated VA's authority to purchase episodes of care and the relevance of "episodes" in VA's approach to the outsourcing of health care services.

Our research methods included a review and analysis of statutory, regulatory, and legislative history materials, as well as VA policy materials and related commentaries and guidance documents; a review of relevant secondary literature, commentary, and prior studies pertaining to VA's purchased care activity; consultation and interviews with expert stakeholders within VA and in relevant outside organizations and agencies; a forward-looking analysis of potential changes to VA authority; a survey of VA health care facilities; and the solicitation and analysis of local-level VA policy documents.

\section{Findings}

\section{VA Has a Complex Set of Authorities to Purchase Care, Reflecting Tension Among Implicit Aims}

Prior to the passage of the Veterans Choice Act in 2014, the Secretary of VA held long-standing authority to purchase care, scattered across many statutory and regulatory provisions. Although the basic grant of authorities to the Secretary is expansive in some respects, it is not unlimited. It involves significant controls on when, how, and for whom medical care may be purchased. These controls implicitly reflect several competing aims beyond simply making outside care available, including restricting costs and maintaining a balance between VA's provider and payer functions. In sum, not only are VA's authorities for furnishing purchased care complex and scattered, but they also embody more than one aim, and those aims operate in tension with each other.

In a related vein, the answer to whether the Secretary should have more or different authorities for purchased care is that it depends. More explicitly, it depends on what policymakers most want to accomplish through purchased care in the future. Different objectives for purchased care reform could easily lead to different conclusions about the need for revision to existing authorities.

\section{The Episode of Care Defines the "Unit" of VA Authorization and May Help Shape Purchased Care in Practice}

In Section 201(a)(1)(c) of the Veterans Choice Act, Congress posed the question of whether the Secretary should have the authority to furnish care at non-VA facilities through the completion of "episodes of care." The authorities for purchasing care tie into episodes primarily through program requirements for authorization (for example, as specified under the Veterans Choice Act). However, in principle, an episode conceptually bounds a clinical problem for which a Veteran might require outside services, so it might therefore make sense to outsource care as a coherent "unit." Future refinements in defining episodes of care, and an authority framework that allows the Secretary to adopt such refinements, may be critical to supporting VA's adoption of bundled payment and value-based purchasing mechanisms in the future. 
The Purchased Care Landscape Is in the Midst of Transformation

As of this writing (in summer 2015), numerous changes to VA's authorities and mechanisms for purchasing care were being proposed, planned, and implemented. These developments included new administrative pilots for administering the Choice and Patient-Centered Community Care (PC3) initiatives, modifications to the eligibility criteria under Choice, revisions to VA's procurement authority for purchased care, the extension of the Choice program and reallocation of funding, and the consolidation of existing purchased care mechanisms and initiatives under a unified programmatic umbrella. With these facets of purchased care authorities and practice in flux, the full landscape of VA purchased care is not just complicated, but dynamically so. Moreover, while the proposed policy changes seek to address many different problems and issues, their sheer multiplicity suggests the drawbacks of a piecemeal approach and the lack of guiding orientation and strategy for VA's purchased care enterprise as a whole.

\section{Recommendations for Purchased Care}

\section{Overall Strategy}

Define a Strategy for Purchased Care. Policy-makers and VA should articulate a clear strategy and set of goals for how purchased care should be used and how it fits into VA's broader health care mission. The strategy should also establish benchmarks for success in VA's adoption of purchased care reforms. Specifically, the strategy should provide a foundation and structure for purchased care authorities and procedures, as well as flexibility to support surge needs and Veteran-centered care.

Address Cost Control More Explicitly and Systematically. Existing purchased care authorities have established a set of indirect cost controls through eligibility requirements and other stipulations that limit the use of the discretionary health benefits. VA and policy-makers should address cost control in purchased care explicitly and directly through a more rigorous performance evaluation of existing purchased care contracts, better and more systematic data collection on purchased care costs, and stronger cost-control mechanisms, such as copays, deductibles, and utilization review.

Collect Better Data to Accurately Estimate the Demand for and Use of Purchased Care. In addition to strengthening its data collection on purchased care costs, VA should also strengthen its data collection on other aspects of purchased care processes and outcomes. At present, VA lacks systematic data on these various facets of purchased care, particularly at the local facility level. A stronger base of data and analysis could help VA to improve its monitoring of purchased care processes and improve outcomes for Veterans.

\section{Management Structure and Processes}

Develop a Stronger Management Structure for Purchased Care and Allocate Responsibility and Authority to the Most Appropriate Levels. VA purchased care activities require improved program management, with responsibilities assigned to organizations at the appropriate level of VA's administrative hierarchy. For example, referrals should be managed locally, while large contracts (such as those under Choice and PC3) should be managed centrally. VA leadership should issue clear policy and procedural requirements while facilitating appropriate flexibility in the field at the local level. 
Evaluate the Third-Party Contractors Administering PC3 and Choice. As the PC3 and Choice programs are fully implemented and continue to grow, VA should establish an ongoing process for evaluating third-party administrator (TPA) performance. VA should also assess the adequacy of the provider networks, the efficiency of claims and other processes, and Veteran experiences with the programs.

Develop Clear and Consistent Guidance and Training on VA's Authority to Purchase Care. Existing VA guidance pertaining to purchased care is scattered, sometimes outdated, and inconsistent in setting clear standards, leaving local facilities to develop their own policies and procedures. VA should create a consolidated manual on purchased care, together with associated training and external messaging that explains VA's authority to purchase care and that clarifies eligibility standards and processes to both inside and outside audiences.

Ensure That Purchased Care Contracts Include Requirements for Data Sharing, Quality Monitoring, and Care Coordination. VA has limited visibility into the quality of services that it purchases, and related standards and processes for coordinating care between VA and outside providers are inconsistent. To provide better oversight and ensure the high quality of purchased care services, both new and existing purchased care contracts with outside providers and TPAs should include appropriate requirements for data sharing, quality-of-care reporting, and care coordination.

Consider Adopting Innovative (but Tested) Ways to Purchase Care. TRICARE and Medicare offer useful lessons in how to purchase care efficiently. VA should consider incorporating some of these strategies, including outsourcing administrative functions and offering performance incentives to contractors.

\section{Authorities and Mechanisms}

Eliminate Inconsistencies in Current Authorities and Provide Flexibility for VA to Implement a Purchased Care Strategy. Policy-makers and VA should address and resolve specific points of tension and ambiguity in existing purchased care authorities, such as inconsistent standards for defining an episode of care, the subjective nature of some elements of 38 U.S.C. 1703 (the core statutory authority for VA purchased care), differences in definitions of geographic inaccessibility and wait time, and the conflict between the language and intent of what constitutes a "medical facility" for applying the 40 -mile rule under Choice. Congress and VA should also consider the more ambitious step of simplifying purchased care authorities and mechanisms generally, such as by seeking to consolidate and harmonize them. At least in principle, such a step could help reduce the complexity and ambiguity now associated with purchased care authorities and mechanisms.

Revise How Episodes of Care Are Defined to Better Accommodate Veterans' Needs. Under the Veterans Choice Act, VA is obligated to allow Veterans who use the Choice program to seek outside services through the completion of an episode of care, "but for a period not in excess of 60 days." The legal requirement for a fixed-term reauthorization of an episode runs contrary to evolving clinical practices and standards in the broader health care community. A revision of this authority could help improve the monitoring and coordination of episodes of care while reducing the administrative burden on VA staff and Veterans.

Adopt a Consistent Strategy for Reimbursement Rates Across Purchased Care Initiatives. Building VA purchased care networks in certain regions of the country may be difficult because some providers may not accept reimbursement rates at or below the rates set by Medicare. Current authorities generally set upper bounds on provider reimbursement rates but 
do not establish a floor. To address these types of reimbursement problems, we recommend that VA and policy-makers adopt a coherent strategy for setting reimbursement rates across VA purchased care initiatives, balancing cost and access considerations. In setting reimbursement rates, VA mechanisms and contracts for purchasing care should reflect the reality of local competitive market conditions. 



\section{Acknowledgments}

We gratefully acknowledge Molly Simmons for her research support and Dulani Woods, Teague Ruder, and Sam Hirshman for their data management support. We are grateful for the support and guidance from the project's management team, including Robin Weinick and Terri Tanielian, and the strong organizational support from Clare Stevens. We appreciate the comments provided by our reviewers, Daniel Ginsberg, Kenneth Kizer, Ross Anthony, Bernard Rostker, James Anderson, Jeffrey Wasserman, Paul Koegel, Peter Jacobson, and Susan Ridgely. We addressed their constructive critiques, as part of RAND's rigorous quality assurance process, to improve the quality of this report. We are grateful to Margaret Harrell for coordinating the quality assurance process for this project. We acknowledge the administrative support and assistance of Clara Aranibar in the preparation of this report. We also acknowledge the support of our MITRE colleague, Sandy Sinay, and her team. We are grateful to the individuals we interviewed and to those who prepared data for our analysis. 



\section{Abbreviations}

ARCH Access Received Closer to Home

$\mathrm{CAMH} \quad$ Centers for Medicare and Medicaid Services Alliance to Modernize Healthcare

C.F.R. Code of Federal Regulations

CHAMPUS Civilian Health and Medical Program of the Uniformed Services

CHAMPVA Civilian Health and Medical Program of the Department of Veterans Affairs

CMS Centers for Medicare and Medicaid Services

DoD U.S. Department of Defense

FAR Federal Acquisition Regulation

FQHC federally qualified health center

FY fiscal year

GAO U.S. Government Accountability Office

HCS healthcare system

HERO Healthcare Effectiveness Through Resource Optimization

HMO health maintenance organization

IHS Indian Health Service

MTF military treatment facility

NVCC Non-VA Care Coordination

PC3 Patient-Centered Community Care

PPO preferred provider organization

SOP standard operating procedure

TPA third-party administrator

U.S.C. U.S. Code

VA U.S. Department of Veterans Affairs 
xxii Authorities and Mechanisms for Purchased Care at the Department of Veterans Affairs

VAAR VA Acquisition Regulation

VAMC VA medical center

VHA Veterans Health Administration

VISN Veterans Integrated Service Network

VSO Veterans Service Organization 


\section{PART I Introduction and Methods}

This report is divided into three main parts. Each part is composed of several sections, which together address a common topic.

Broadly, this report summarizes the findings of a congressionally mandated study of U.S. Department of Veterans Affairs (VA) purchased care, responding specifically to three basic questions posed by Congress:

- What authorities and mechanisms does VA have to purchase care?

- Does VA have the appropriate authorities and mechanisms to purchase care?

- Should VA have the authority to purchase care through the completion of episodes of care?

In answering these research questions, we undertook an extensive investigation of VA's current authorities and mechanisms for purchasing care, as well as of potential changes and alternative models that stakeholders and policy-makers might consider in the future. Parts II and III of this report deal with the current landscape and future possibilities for VA purchased care, respectively.

Part I of this report offers an introduction to our assessment task and to our methods of research and analysis in carrying out this study. We provide here an overview of the broader context of our research and mandate, including how purchased care fits into the larger health care mission, organization, and recent history of VA. We also discuss the message, audience, and purpose of this report. 

One of VA's core functions involves providing health care services to eligible Veterans. Although VA has traditionally carried out this role primarily by operating a national network of hospitals and other facilities, the agency also administers a purchased care function, through which it pays for health care services from outside providers. VA purchased care evolved primarily to address situations in which VA's direct-care resources were unable to offer needed services. Although purchased care has accounted for only a small fraction of VA's health care budget over the past decade, that fraction is growing. In the wake of the recent crisis in access to care at VA facilities, stakeholders and policy-makers are now revisiting the role and performance of VA purchased care. Specifically, they are considering whether modifications to VA's purchased care approach might be desirable, given broader goals of expanding access to care, enhancing trusted partnerships, and improving VA operations to deliver seamless and integrated support.

The Veterans Access, Choice, and Accountability Act of 2014 (Veterans Choice Act) and the assessment mandate for this report were passed into law in the summer of 2014. According to some commentators, the act was a congressional response to misconduct and mismanagement in the VA health care system, in which delayed access to services was allegedly associated with the deaths of dozens of Veterans and falsified wait-time data collected at the VA medical center (VAMC) in Phoenix, Arizona.

The access crisis in Phoenix and other parts of the country led Congress to require a series of corrective actions under the Veterans Choice Act. Perhaps most notably, the legislation established the new Choice program, an initiative to increase access to purchased care for eligible Veterans who met new enrollment, wait-time, and driving-distance criteria. Another major provision of the Veterans Choice Act served to reorganize payment authority and budgeting for purchased care, shifting responsibility from VAMCs to the Veterans Health Administration's (VHA's) Chief Business Office. Both measures under the act reflect policy-makers' view of purchased care as an important tool for ensuring comprehensive access to medical services by Veterans.

\subsection{Objective of This Report}

Pursuant to Section 201(a)(1)(C) of the Veterans Choice Act, Congress mandated an independent assessment of VA specifically to address "[t]he authorities and mechanisms under which the Secretary may furnish hospital care, medical services, and other health care at non-Department facilities, including whether the Secretary should have the authority to furnish such care and services at such facilities through the completion of episodes of care." 
The first clause of the assessment mandate broadly addresses the legal and policy contours under which VA is empowered to provide health care services at non-VA facilities. We interpreted the phrase health care at non-Department facilities as synonymous with purchased careor actions taken by VA to pay for outside medical services for Veteran beneficiaries, rather than providing service directly through VA-employed or VA-contracted providers and at VA-owned or VA-contracted facilities. ${ }^{1}$ Although the language of the Veterans Choice Act mandate could be interpreted more broadly to encompass other aspects of VA practice related to the delivery of health care services, such as facility leasing, the primary focus of this assessment is on purchasing health care for Veterans from non-VA sources and on the authorities and mechanisms that support this practice.

The second clause of the assessment mandate asks whether the VA Secretary should have the authority to furnish health care services at non-VA facilities through the completion of episodes of care. At present, VA has established a patchwork of policies, programs, and mechanisms to furnish health care at non-VA facilities. Thus, for this assessment, we were asked to assess the various elements of the purchased care system and to envision what the array of laws, programs, and policies might look like in the future. The language of the Veterans Choice Act mandate asks a forward-looking, normative question about VA authority and implicitly invites comment on an array of potential policy changes to the VA purchased care landscape. The mandate also invites specific comment on episodes of care and their relationship to other aspects of VA authority and purchased care in practice.

One additional aspect of the assessment mandate deserves particular note: the focus on authorities and mechanisms. We interpreted authorities to refer to the statutory and regulatory framework that empowers VA to purchase care, while we interpreted mechanisms to refer to uncodified VA policies and to the actual practice by which VA carries out its purchased care activity. In essence, the mandate involved addressing several basic research questions about purchased care:

1. What authorities and mechanisms does VA have to purchase care?

2. Does the Secretary have the appropriate authorities and mechanisms to purchase care?

3. Should the Secretary have the authority to purchase care through the completion of episodes of care?

\subsection{Historical Evolution of VA Purchased Care}

The landscape of VA purchased care authorities is complex, largely because the act of purchasing medical services is inherently complicated. Purchasing care minimally involves screening Veterans to determine when outside referrals for services may be appropriate, initiating those referrals, and establishing contractual relationships with outside providers. It also involves defining the scope of authorization for outside care in specific situations, monitoring the services provided, sharing records appropriately and coordinating care with non-VA providers,

\footnotetext{
1 Note that purchased care, as we define it here, may also include actions taken by VA to obtain services from outside care providers at non-VA facilities without directly paying for them, as through strategic resource-sharing arrangements between VA and the U.S. Department of Defense (DoD). With this being said, much of our focus is specifically on VA's role and authority as a payer for outside services. Hence, we use purchased care as an umbrella term in describing the scope of this assessment.
} 
and paying claims for outside services. VA purchased care does not involve just a single function and mechanism, but rather a whole series of interlocking ones. For the system to operate effectively, all the parts must work together efficiently and consistently.

As shown in Figure 1-1, VA has had the core statutory authority to purchase care for decades. We characterize this authority, originally established by what is currently 38 U.S.C. 1703 and programs enacted thereunder, as traditional purchased care. Over the years, VA has purchased inpatient and outpatient services through a mix of individual authorizations and contracts with outside providers at external facilities. As with health care services provided through VA directly, purchased care has evolved to cover both service-connected conditions and non-service-connected conditions. There was a similar expansion in coverage with regard to the purchase of or reimbursement for emergency care services. In part as a response to the recent conflicts in Iraq and Afghanistan, VA has been compelled to apply and refine its purchased care tools to meet increased demand. For example, in 2001, Project HERO (Healthcare Effectiveness Through Resource Optimization) was instituted as a pilot program designed to enhance the coordination of care delivered by both VA and external providers. Project ARCH (Access Received Closer to Home) was originally fielded as a pilot program to increase the coordination and cost-effectiveness of care provided to rural Veterans, and the pilot was continued under the Veterans Choice Act. PC3 (Patient-Centered Community Care, sometimes referred to as PCCC) was subsequently created to further expand access and was based on lessons learned from the prior pilot programs.

Each of the multiple VA purchased care programs and initiatives that exist today has different criteria for Veteran and provider eligibility, different guidelines for VA discretion to

Figure 1-1

Timeline of VA Purchased Care Mechanism Development

\begin{tabular}{lll|l}
\multicolumn{1}{c|}{$1970 \quad 1980$} & 1990 & 2000 & 2010 \\
\hline $\begin{array}{l}\text { Traditional purchased care } \\
\text { (originally est. 1957) }\end{array}$ & \\
\hline $\begin{array}{l}\text { Emergency care } \\
\text { (service-connected condition) }\end{array}$ & & \\
\hline $\begin{array}{l}\text { Emergency care } \\
\text { (non-service-connected condition) }\end{array}$ & \\
\hline Project HERO & & \\
\hline Project ARCH & & \\
\hline PC3 & \\
\hline Choice & \\
\hline
\end{tabular}

NOTES: Dashed arrows indicate mechanisms established prior to the start of the figure's timeline or anticipated to continue indefinitely. The vertical red line indicates when this analysis took place (2015). RAND RR1165z3-1.1 
furnish care, ${ }^{2}$ and different rules governing payment. Table 1-1 compares four primary mechanisms involved in providing purchased care.

Unsurprisingly, the multiplicity of mechanisms and programs in purchased care has sometimes created confusion and inefficiency. Although a single purchased care provider might deliver care through more than one of these mechanisms, the corresponding reimbursement rates, requirements for record sharing, and other conditions of participation vary by mechanism.

Individual Veterans may be eligible to receive purchased care through multiple mechanisms. For Veterans and VA staff, determining the appropriate route to access purchased care is sometimes difficult. Referring VAMCs must select from among these options according to one or more goals, including optimizing ease of access, lowering costs, leveraging preexisting contractual relationships with providers, and optimizing Veteran choice.

As of this writing (in summer 2015), about 10 percent of VA's annual health care budget went to purchased care. VHA's Chief Business Office estimated that purchased care costs in fiscal year (FY) 2014 totaled $\$ 5.6$ billion, after steady and significant increases year after year (Figure 1-2; VA, 2014c). Other VA sources have provided different estimates of purchased care expenditures during this time frame, with VA Deputy Secretary Sloan Gibson testifying before the Senate Veterans' Affairs Committee on May 12, 2015, that VA had spent more than $\$ 8.5$ billion on purchased care in FY 2014 (Exploring the Implementation and Future of the Veterans Choice Program, 2015). The difference in these estimates is likely because Deputy Secretary Gibson included Civilian Health and Medical Program of Veterans Affairs (CHAMPVA) costs in his totals. Using another metric of purchased care utilization, Deputy Secretary Gibson noted that Veterans completed 55.04 million appointments at VA facili-

Table 1-1

VA Purchased Care Rules for Eligibility, VA Discretion, Providers, and Payment

\begin{tabular}{|c|c|c|c|c|}
\hline Feature & $\begin{array}{l}\text { Traditional VA } \\
\text { Purchased Care }\end{array}$ & $\mathrm{ARCH}$ & PC3 & Choice \\
\hline Eligibility & $\begin{array}{l}\text { VA not able to } \\
\text { furnish necessary } \\
\text { care (per } 38 \text { U.S.C. } \\
\text { 1703) }\end{array}$ & $\begin{array}{l}\text { Driving time to VA } \\
\text { facilities (pilot sites } \\
\text { only) }\end{array}$ & $\begin{array}{l}\text { VA not able to } \\
\text { furnish necessary } \\
\text { care }\end{array}$ & $\begin{array}{l}\text { Wait time, } \\
\text { geographic distance } \\
\text { to VA facilities }\end{array}$ \\
\hline $\begin{array}{l}\text { Does corresponding } \\
\text { authority permit or } \\
\text { compel VA to furnish } \\
\text { care at non-VA } \\
\text { facilities? }\end{array}$ & "may" & "shall" & "may" & "shall" \\
\hline Providers & $\begin{array}{l}\text { Contract/ } \\
\text { agreement }\end{array}$ & Network & Network & Medicare-eligible ${ }^{a}$ \\
\hline $\begin{array}{l}\text { Typical } \\
\text { reimbursement rate }\end{array}$ & $\begin{array}{l}\text { VA fee schedule, } \\
\text { Medicare rate, or } \\
\text { contracted rate }\end{array}$ & $\begin{array}{l}\% \text { of or full } \\
\text { Medicare rate }\end{array}$ & $\%$ of Medicare rate & $\%$ of Medicare rate \\
\hline
\end{tabular}

a Health care providers from DoD, the Indian Health Service (IHS), and federally qualified health centers (FQHCs) would also be qualified under Choice.

2 Some VA authorities specify that VA shall furnish care, while others specify that VA may furnish care. In this context, shall represents VA authority and a congressional mandate to provide or pay for the care required, as long as the eligibility criteria are met. May implies greater discretion on VA's part, in that VA has the authority to furnish the necessary care but not a specific mandate to do so. 
Figure 1-2

Growth in VA Purchased Care, FYs 2002-2014

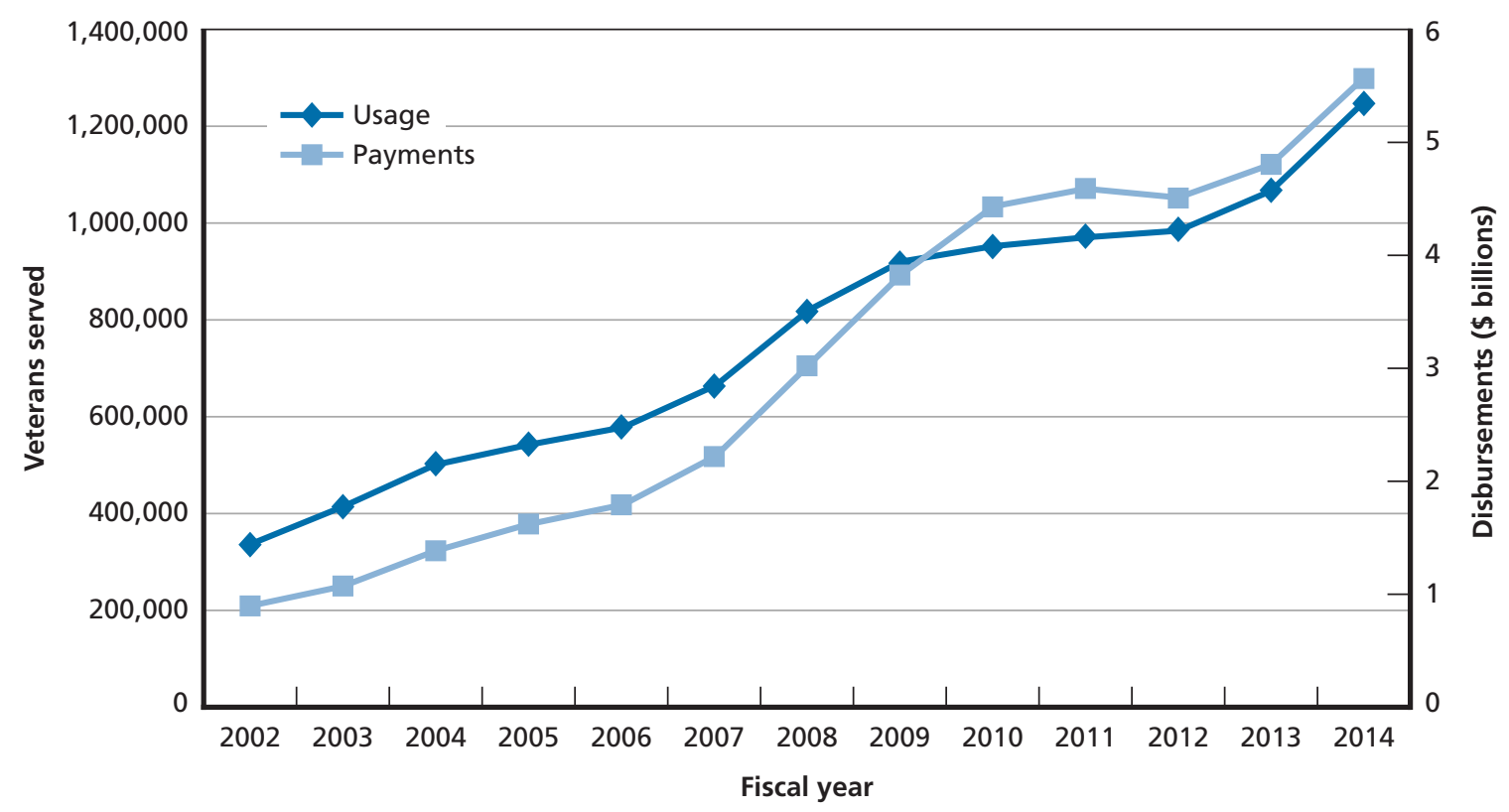

SOURCE: Data obtained through a request to the VHA Chief Business Office, May 12, 2015, and originally derived from VA Central Office fee payment files.

RAND RR1165z3-1.2

ties and 16.2 million appointments in the community (through purchased care) in FY 2014 (Exploring the Implementation and Future of the Veterans Choice Program, 2015).

Rising expenditures over the past decade reflect only one of the ways in which purchased care has evolved. The research for this assessment began in November 2014. Since that time, there have been major changes to VA's authorities and mechanisms for purchasing care. For example, as required by the Veterans Choice Act, VA mailed "Choice Cards" to Veterans to seek care in the community, reorganized the VHA Chief Business Office, and consolidated the purchased care budget. In addition, in April 2015, VA promulgated a revised regulation that changed its interpretation of the access standard used to determine Veterans' eligibility for the Choice program from a geodesic line to driving distance using the fastest route (VA, 2015d). ${ }^{3}$ This roughly doubled the number of Veterans eligible to receive care in the community under the Choice program (Exploring the Implementation and Future of the Veterans Choice Program, 2015).

This assessment represents the status of VA purchased care as of early in 2015. There were many changes to the purchased care landscape that were implemented, planned, or proposed while we were writing this report. The changes to the Veterans Choice Act mentioned above were just a few examples. Throughout this report, we have attempted to incorporate and address the most recent developments in purchased care authority and mechanisms as of May 2015.

3 We discuss this change in more detail in Chapter Three of this report. 


\subsection{Overview of VA Purchased Care Funding}

Beyond the programs and mechanisms of VA purchased care, it is also helpful to recognize that purchased care is bounded by some basic features of VA's structure as an agency. Perhaps most important, VA health benefits are notably not a legal entitlement or a benefit to which Veterans are automatically entitled and for which the government must pay. Rather, Veterans may obtain VA health care services according to a priority scheme for eligibility established by Congress. ${ }^{4}$ In addition, VA's capacity to provide health care benefits is limited by its annual appropriations allocated by Congress. ${ }^{5}$ As such, VA's health care mission involves not only providing health care services with "integrity, commitment, advocacy, respect, and excellence"6 but also doing so while simultaneously keeping expenditures under a restrictive resource ceiling.

This basic funding reality for VA's health care operations is central to understanding purchased care. One historical implication is that dollars spent on purchased care by local VA facilities have sometimes been viewed as a direct offset to funding available for other local health care purposes. From this perspective, purchased care may sometimes involve a resourcing trade-off against strengthening the capacity of VA's own provider facilities. While this is beyond the focus of this report to address in depth, ${ }^{7}$ for stakeholders concerned with VA health care more broadly, the potential for a resourcing trade-off between VA direct care and purchased care is an important consideration for the future.

Another implication of VA's funding constraint is that some of the basic features of purchased care are implicitly tied to limiting spending. Such features include eligibility and authorization requirements for purchased care, Veteran copays, requirements for outside provider reimbursement rates, and restrictions on who can participate as an outside provider. ${ }^{8}$ Collectively, these have the effect of giving VA more control and influence in restricting purchased care expenditures. Achieving an optimal balance between access and quality on one hand and cost control on the other presents a fundamental challenge for VA in purchased care.

The discretion to purchase care has traditionally resided with VA rather than Veterans. This has changed somewhat under the new Choice program, which confers more power on eligible Veterans to elect to pursue purchased care, as well as a direct mandate for VA to pay for that care when wait-time or driving-distance criteria are met. Together, these features of the Choice program are likely to enhance access, but with the implicit trade-off of reducing VA control over related expenditures. ${ }^{9}$ Here again, purchased care involves striking a balance between the competing aims of enhancing Veteran choice and access and containing related costs.

\footnotetext{
4 We describe the priority scheme for enrollment for health care benefits in Appendix E of this report.

5 As we discuss in Chapter Three, funding for purchased care in particular shifted somewhat with the Veterans Choice Act, which established a specific reserve of $\$ 10$ billion to cover costs associated with the Choice program established by the act.

6 These are the five core values articulated by VA as an implicit part of its mission statement (VA, 2014b).

7 Note that a separately mandated assessment under the Veterans Choice Act addressed issues of VA health care capacity and focuses more directly on this particular issue (see RAND Health, 2015b).

8 We discuss these features in more detail in Chapters Three, Four, and Seven of this report.

9 Regarding the latter point, it is noteworthy that the Veterans Choice Act established a $\$ 10$ billion funding pool for benefits under the Choice program. Thus, although the congressional mandate for Choice program benefits has the effect of reducing VA's control over costs, the budget mechanism and additional resourcing serve to balance that.
} 
All of these considerations spotlight the importance of VA's funding context in shaping the operation of purchased care. Purchased care fulfills a limited function within VA's health care mission, and it does so primarily through discretionary funding from Congress. Recent changes to purchased care under the Veterans Choice Act invite some reflection on this context and on how changes to the context might influence the balance between access, choice, and cost containment in the future.

\subsection{Scope of This Report}

The contents of this report adhere closely to the assessment mandate posed by Congress in Section 201(a)(1)(C) of the Veterans Choice Act. To address components of that mandate, we undertook a broad investigation of VA purchased care authorities, policies, and mechanisms.

Authorities and mechanisms are terms drawn directly from the assessment mandate in Section 201(a)(1)(C) of the Veterans Choice Act. We interpreted each of these terms in accordance with its plain meaning and in view of the act's objectives. Here again, authorities refers broadly to federal law, the powers and responsibilities delegated by Congress to the Secretary, and formal rule-making undertaken by the Secretary, consistent therewith. Mechanisms, by contrast, is a less formal term. We construed mechanisms to include (uncodified) VA programs and initiatives, VA guidance documents and policies, and VA operating practices for furnishing purchased care. Generally speaking, mechanisms are not formally codified by law and regulation, but they nevertheless reflect VA practice and VA's efforts to furnish purchased care consistent with the framework established by formal authorities. Both concepts are central to understanding the landscape of VA purchased care.

Although we describe laws and regulations pertaining to VA purchased care in detail in Chapters Three and Four of this report, it is important to emphasize that this report is not intended to offer an academic review of the law or a legal treatise. ${ }^{10}$ Rather, this report was written for a broader policy audience (including Congress and VA, as well as other interested stakeholder groups) and in direct response to the assessment mandate in Section 201(a)(1)(C) of the Veterans Choice Act. VA purchased care is a complicated topic, and a discussion of the statutory and policy issues surrounding VA purchased care requires an understanding of the legal framework that defines it. However, the law also reflects an underlying set of policy objectives and economic relationships that are the substance of purchased care, both as it exists today and as policy-makers might choose to refashion it in the future. This report aims to speak to this broader policy context, not just the legal aspects of it.

It is equally important to highlight what is beyond the scope of this report. As we noted earlier, the assessment mandate of Section 201(a)(1)(C) refers to the phrase "care at nonDepartment facilities." For the purposes of this report, we interpret this phrase as being largely synonymous with purchased care. However, the same phrase could be interpreted in other

\footnotetext{
${ }^{10}$ It is also important to emphasize that this report does not offer formal legal advice to VA or to Congress. Formal legal advice can only be given by licensed attorneys operating within the scope of their professional practice in response to legal consultation sought by a client. The RAND Corporation is not a law firm and is unable to give formal legal advice. If the sponsors of this report would like to receive legal advice, they would need to consult internally with their own counsels or seek assistance from an independent law firm.
} 
ways. VA facility leasing, for example, involves "care at non-Department facilities." ${ }^{11}$ Likewise, it could also include VA's relationship with DoD to provide health care services to Veterans. Although we do touch on the latter topic in some parts of this report, we do not address it at length. VA and DoD have a unique, long-standing collaborative relationship that has been the subject of intense scrutiny and comment elsewhere (see, for example, Military Compensation and Retirement Modernization Commission, 2015).

More generally, VA purchased care authorities and policy are closely tied to many other aspects of VA's health care mission, structure, and operations. For example, the types of health care services purchased by VA are implicitly determined by the contours of the agency's health care benefit, since the latter defines the services that Veterans may be eligible to receive. Likewise, Veterans' ability to obtain purchased care services is contingent on initial eligibility to receive VHA benefits. Other examples of collateral features that have some relevance to purchased care include the anatomy of VA's national infrastructure of health care facilities, the structural and command relationship between VA's local facilities and its regional and national administrative offices, and the composition and evolution of VA's internal provider capabilities. We do not address these ancillary aspects of VA in much detail in this report, though they do shape the VA purchased care landscape in various ways. Some of these topics were addressed by other mandated assessments under the Veterans Choice Act.

One additional scoping note deserves particular mention here. Veterans' eligibility for health benefits, broadly construed, is outside the scope of this report to address. However, VA's purchased care authority does involve an important interaction with Veteran eligibility: the Secretary's discretion to purchase services when VA facilities are unable to provide those services directly versus the Secretary's obligation to provide care to specific categories of Veterans as designated by statute. ${ }^{12}$ In Chapter Three of this report, we discuss the tension between these two basic authority provisions and the implications for actual practice in VA purchased care.

\subsection{Organization of This Report}

This report is organized into three parts. Part I includes this introductory chapter and an overview of our study methods (Chapter Two). Part II focuses broadly on authorities and mechanisms for VA purchased care and includes sections on these authorities and mechanisms prior to and since the passage of the Veterans Choice Act (Chapter Three) and in practice (Chapter Four), along with a discussion of procurement and episodes of care (Chapter Five) to help frame a strategy for VA purchased care going forward. The report concludes with Part III, which examines potential reforms to VA purchased care practice (Chapter Six) and alternative government payer models (Chapter Seven); it also presents our overall conclusions and recommendations (Chapter Eight). This report includes five technical appendixes providing additional background and detail on rates of VA purchased care utilization and authorizations (Appendix A); statutory and regulatory authorities for the provision of VA purchased care (Appendix B); characteristics of the policy documents received through our request for data on VA purchased care in practice at the local level (Appendix C); pertinent questions included

11 VA facility leasing is a focus of other assessment mandates in the Veterans Choice Act in Section 201(a)(1)(K) and (a) (2)(B) (see McKinsey, 2015b, and RAND Health, 2015b).

12 We refer here to 38 U.S.C. 1703 and 1710, respectively. See the discussion in Chapter Three of this report. 
in the 2015 Survey of VA Capabilities and Resources that was fielded to all VAMCs, as well as data on responses to those questions (Appendix D); and information on VA health benefits and priority groups, to provide a fuller picture of the context in which VA purchased care mechanisms operate (Appendix E). 

Consistent with the assessment questions posed by Congress, our research methods included statutory, regulatory, and legislative history research and analysis. We supplemented this analysis with a review of the published literature, including commentary and prior studies of VA's purchased care activity, consultations and interviews with expert stakeholders representing VA and other agencies and organizations, a review of local-level VA policy and procedural documents, and a survey of VA facilities. This chapter reviews each of these approaches in more detail.

\subsection{Statutory, Regulatory, and Legislative History Research and Analysis}

The primary research methodology involved cataloging and analyzing statutes and regulations related to VA purchased care, along with associated legal commentary and cross-references from those materials. Much of the authority for VA purchased care appears in various provisions in Title 38 of the U.S. Code (U.S.C.), while corresponding regulations appear in Title 38 of the Code of Federal Regulations (C.F.R.). We conducted an initial review of these primary legal sources to identify the provisions that were relevant to this assessment; we then used the themes drawn from these provisions to structure our analysis of VA purchased care authorities in Chapter Three. We also reviewed and analyzed the relevant provisions under the Veterans Choice Act. Where appropriate, we consulted legislative history materials to better understand the interpretation and intentions of Congress with regard to the Veterans Choice Act and relevant pieces of legislation affecting how VA furnishes purchased care. We also searched and reviewed relevant case law.

\subsection{Review of Relevant Published Literature}

Beyond our direct research on statutes and regulations, we also reviewed the published literature on VA's purchased care authorities and programs. Specifically, we searched for pertinent reports published by the U.S. Government Accountability Office (GAO), the Congressional Budget Office, and the Congressional Research Service; by previous independent commissions and panels that have studied or commented on VA purchased care practices; and by entities within VA, including the central offices, VHA, and the Office of Inspector General. We also sought to identify, retrieve, and review copies of all publicly available VA policy documents pertaining to purchased care, including directives, manuals, and guidance documents. Finally, 
our review considered findings published in scholarly papers and commentaries, which we accessed through several databases, including PubMed and the Index to Legal Periodicals.

\subsection{Interviews with Expert Stakeholders}

To construct a more complete picture of VA policies and mechanisms pertaining to purchased care in practice, we conducted a series of interviews and background discussions with a range of VA personnel and representatives from other stakeholder groups. Interviews were formal meetings during which we asked questions informed by prior background discussions with other stakeholders. These meetings were guided by research protocols and formal consent documents. Interviewees were informed that their responses would not be attributed to them in any way. Interview questions probed stakeholders' professional experiences with and perspectives on VA purchased care authorities and mechanisms. Background discussions were informal meetings and were not guided by research protocols. These discussions, which focused on basic facts and the structure of VA purchased care authorities and mechanisms, were used to inform the development of research protocols for the formal interviews.

Interviewees included VA officials and administrators spanning a variety of offices at VA headquarters, as well as senior officials at VAMCs and Veterans Integrated Service Networks (VISNs). Outside of VA, we spoke with representatives from seven Veterans Service Organizations (VSOs); officials with the third-party administrators (TPAs) responsible for administering the PC3 and Choice programs; subject-matter experts from the Congressional Budget Office, the Congressional Research Service, GAO, and other organizations; and congressional staff of several committees with responsibility for Veterans' affairs. Within these varied categories, we selected interviewees who had considerable familiarity with and expertise on the issues surrounding VA purchased care, drawing on our own prior knowledge and familiarity with these stakeholders and on the recommendations of the respondent organizations and interviewees themselves. Although we make no claims about the representativeness of the opinions proffered by our interviewees, we made a concerted effort to talk to a diverse selection of individuals with expertise on the issues pertaining to this study and ensured that we spoke to individuals who would have differing perspectives and opinions.

Over the course of several months, we conducted a total of 41 conversations with both individual stakeholders and small groups. These interviews were both telephonic and in person. The majority of interviews were one hour in length, though a small number were conducted in conjunction with Assessment B, on health care capabilities (RAND Health, 2015b), and thus were slightly longer. Of those, 11 were background discussions with subject-matter experts and VA officials that served to increase our knowledge of the subject material and help refine our formal interview protocols. The remaining 30 were formal interviews. ${ }^{1}$ Because many of these conversations were with small groups of interviewees, we ultimately collected input and insights from more than 50 individuals. Recognizing the methodological risks of overreliance on a relatively small sample of qualitative interviews, we bolstered our utilization of these data through triangulation with a variety of other qualitative and quantitative methods, as described elsewhere in this chapter.

1 RAND's Human Subjects Protection Committee approved this research. 


\subsection{Review of the Secretary's Authorities}

To investigate the authority implications associated with a range of different possible future changes to purchased care, we employed a method derived from scenario analysis. Starting from a set of potential objectives that VA and Congress might bring to changing purchased care, we defined a series of illustrative implementing steps that they might choose to pursue, which are broadly responsive to one or more of these objectives. We then analyze the implications for authority - specifically, the need for legislative action, formal rule-making by VA, or revisions to VA guidance or policy documents - for each potential implementing step. The objectives and implementing steps were developed through discussions with a panel of experts, as well as through a review of the literature and from interviews with stakeholders.

\subsection{Review of Local VA Policy Documents}

As described in Assessment B (RAND Health, 2015b), VA health care facilities are overseen by overlapping management structures. At the basic level, VA's 21 VISNs manage all resources within their service areas. On top of that, "administrative parents" oversee clusters of health care facilities. We requested policy documents related to purchased care from all of VA's 141 administrative parents, a management mechanism responsible for care in a group of health care facilities. ${ }^{2}$ We specifically requested written documentation (i.e., policies or guidance) on when, how, and for whom VA purchased care is contracted at the local, facility level (as distinct from national-level policies). We clarified that the purpose of the request was to understand local variation in the implementation of national policy. In response to our solicitation, we received a total of 664 files from 78 VAMCs and one VISN (see Figure 2-1).

Figure 2-1

Local Purchased Care Policy Documents Received



NOTE: SOP = standard operating procedure.

RAND RR1165z3-2.1

2 According to VHA Handbook 1006.02, VHA Site Classifications and Definitions, an administrative parent is defined as a "collection of all the points of service that a leadership group (Medical Facility Director, Deputy Medical Facility Director, Chief of Staff, Associate or Assistant Director, and Nurse Executive) manages. The points of service can include any institution where health care is delivered. All the data originating from these points of service roll up to a single station number representing the administrative parent for management and programmatic activities” (VA, 2013b, p. 1). 
We reviewed and categorized the documents we received into three categories: (1) descriptions of SOPs related to purchased care $(\mathrm{n}=265)$, (2) detailed VAMC site descriptions $(\mathrm{n}=49)$, and (3) organizational charts $(n=149)$. We did not receive any policy documents from 22 of the VA administrative parent organizations to which the data request was issued. The overall response rate to the request was 86 percent. We calculated response rates for each of the document categories: 49 percent for SOPs, 30 percent for site descriptions, and 67 percent for organizational charts.

Not all of the policy documents were dated, but among those that were (205 of the 664 total documents), the vast majority predated the August 2014 passage of the Veterans Choice Act and the November 2014 establishment of the Choice program. Those dates ranged from January 2008 to April 2015, with the majority issued in 2012 and 2013. Moreover, the majority of the documents issued after the establishment of the Choice program were quite short and less useful for describing variations in key policies, processes, and SOPs pertaining to purchased care. For instance, many were simply one-page documents containing screenshots showing how to enter a purchased care consult request into various computing systems, with little or no accompanying text.

To assess the local policy documents, we coded the SOPs received by the following criteria: date; their level of detail in describing VA purchased care policies and procedures; number of pages; terminology used to refer to a non-VA care provider; authorities cited; level of detail; whether they encouraged the use of VA purchased care, or, alternatively, staying within the VA system; which VA staff were listed as responsible for various steps in the VA purchased care referral and authorization processes; and whether and to what extent they discussed "episodes of care." We then used the themes extracted through this coding exercise to draw preliminary conclusions about how purchased care decisions are made at the local level. Additional detail on our request for data and our assessment of the documents received is provided in both Chapter Four and Appendix C of this report.

\subsection{Survey of VA Capabilities and Resources}

The 2015 Survey of VA Capabilities and Resources was fielded as part of RAND's assessment in response to the mandate in Section 201(a)(1)(B) of the Veterans Choice Act (RAND Health, 2015b). The survey was designed to identify clinically meaningful delays in care for seven illustrative clinical populations and for primary care more generally. The survey's sample frame was all of VA's 141 administrative parents (again, local health care systems with at least one hospital and its affiliate clinics), and the field period for the survey was two and a half weeks (May 7-26, 2015).

We included seven questions in the survey. Three of these questions concerned referrals for VA purchased care, two asked about how episodes of care are defined in practice, and two asked about various internal processes and practices at the VAMC level (including data collection) and the use of the Non-VA Care Coordination (NVCC) program. Response options varied; there were two yes/no questions, two questions asking about the frequency of various practices, one question asking respondents to rank the options by importance, and two questions asking the respondent to select the best answer from several provided responses. Each question also included a small comment box in which the respondent could elaborate on his or 
her answer. Additional details of the survey's fielding, full text of the survey questions pertaining to purchased care, and response data are presented in Appendix D of this report.

We received survey responses from 117 out of 141 administrative parents — an 83-percent overall response rate. ${ }^{3}$ However, several respondents chose to exit the survey before answering every question, leaving 111 respondents answering those questions pertaining specifically to this assessment (a 79-percent response rate). In analyzing survey responses, we explored respondents' estimates of the frequency of referrals to purchased care, as well as the reasons for these referrals. We also assessed respondents' feedback about their knowledge of and experiences with episodes of care and electronic record sharing.

3 VHA Handbook 1006.02 defines an administrative parent as a "collection of all the points of service that a leadership group (Medical Facility Director, Deputy Medical Facility Director, Chief of Staff, Associate or Assistant Director, and Nurse Executive) manages. The points of service can include any institution where health care is delivered. All of the data that originate from these points of service roll up to a single station number representing the administrative parent for management and programmatic activities" (VA, 2013b, p. 1). 



\section{PART II Current Authorities, Mechanisms, and Framework for VHA Purchased Care}

This part covers three chapters: Chapter Three, "Authorities and Mechanisms for Purchased Care"; Chapter Four, "VA Purchased Care Authorities and Mechanisms in Practice"; and Chapter Five, "Procurement and Episodes of Care." These chapters describe the current landscape of purchased care authorities and mechanisms.

These three chapters also describe the strengths and challenges of VA purchased care implementation on the ground. The first chapter in this part (Chapter Three) examines features of the laws governing purchased care and the evolution of the various purchased care mechanisms. Its purpose is to offer policy-makers a detailed view of the inner workings of VA's purchased care authorities to facilitate understanding of the existing laws. Those descriptions lay the foundation for Part III, in which we discuss possible future authorities and mechanisms for VA's purchased care. Existing authorities were developed over time in a piecemeal fashion. Future changes to purchased care authorities should consider the potential detriment of further incremental development without the guidance of a centralized strategy or supporting mechanisms. Chapter Four provides a detailed discussion of purchased care mechanisms in practice, derived from analysis of multiple primary data sources collected specifically for this study. The chapter describes the strengths and shortfalls of purchased care mechanisms and offers findings and recommendations aimed at VHA management and reform. Chapter Five concludes with framing material that describes some of the critical elements underlying VA's purchased care authority and mechanisms, including procurement policies, definitions of episodes of care, and the health benefits structure. 



\section{Authorities and Mechanisms for Purchased Care}

\section{Overview of Methods and Data for Authorities and Mechanisms for Purchased Care}

- We traced the history of authorities and mechanisms for VA purchased care through a review of relevant statutes, regulations, VA policies, and associated guidance documents.

- Supporting the legal analysis, we reviewed in detail the provisions of Title 38 of the U.S. Code and of legislative initiatives governing VA purchased care prior to the Veterans Choice Act. We also reviewed data on purchased care programs implemented prior to the passage of the Veterans Choice Act, including key features of those programs and VA's role thereunder.

- We examined changes to VA purchased care implemented by, and under, the Veterans Choice Act.

Although the Choice program received considerable attention in 2014 and was considered a novel mechanism for using non-VA facilities and providers to meet Veterans' medical needs, similar authority had already been in place for nearly six decades. ${ }^{1}$ Such explicit authority was necessary for acquiring medical services from external providers because VA operates within considerable statutory and regulatory limits. Given that this underlying authority is based on myriad legislative initiatives, each addressing different concerns for different Veteran populations at different times and under different conditions, understanding what is and is not permitted under current law can be a daunting task.

The mandate for this study (Section 201 of the Veterans Choice Act) called for an examination of the "authorities and mechanisms under which the Secretary may furnish hospital care, medical services, and other health care at non-Department facilities." For our purposes, authority can be understood partly as the set of statutes passed by Congress, which define, guide and constrain VA purchased care activity. ${ }^{2}$ In addition, authority also includes regula-

\footnotetext{
1 The key legislative foundations for purchased care prior to the Veterans Choice Act are as follows: Veterans' Benefits Act of 1957 (Pub. L. 85-56, Sec. 501); the Veterans Health Care Expansion Act of 1973 (Pub. L. 93-82, Sec. 106); Consolidated Omnibus Budget Reconciliation Act of 1985 (Pub. L. 99-272, Sec. 19012, 1986); the Veterans' Health Care Eligibility Reform Act of 1996 (Pub. L. 104-262); and the Veterans Millennium Health Care and Benefits Act (Pub. L. 106-117, 1999). The use of non-VA facilities and providers actually dates back prior to the original establishment of the agency.

2 Federal statutes sometimes involve direct mandates to executive branch agencies and also sometimes involve a delegation of power and discretion to agencies. As we describe in this section, some of the core statutory authorities for VA purchased care involve considerable discretion for the Secretary in determining when and how to apply them. Note that pursuant to Chevron v. National Resources Defense Council (467 U.S. 837, 1984) and as a general matter of administrative law, the courts typically defer to a federal agency in the interpretation of its own empowering statutes, so long as the agency interpretation is not unreasonable.
} 
tions promulgated by VA, consistent with its authorizing statutes, which also operate with the force of law. Relevant regulations and rules can also be promulgated by other federal agencies. Together, statutes and regulations establish the legal framework within which VA carries out its purchased care functions.

Another important focus of our analysis involves examining the mechanisms by which VA carries out its activities in practice. Beyond the formal legal authority embodied in statutes and regulations, VA and other executive branch agencies also exercise considerable interpretive discretion in carrying out their functions on a day-to-day basis. A mechanism refers to the specific means by which an agency acts, or intends to act, within the bounds of its authority. For example, a mechanism might involve a program that is created with government facilities, personnel, and funding, such as for the provision of basic medical services through VHA facilities. Some aspects of VA's operating policies and practices are recorded in internal guidance documents, handbooks, or directives that provide direction for staff when carrying out VA business. Other aspects of VA's operating practices may not be written down at all or may be described through a range of other types of documents of narrowly focused application, such as a contract entered into by VA with an outside health care provider.

In this chapter, we describe the authorities and mechanisms that have been available to the Secretary for furnishing medical care to Veterans in non-VA facilities and from non-VA providers. We first review those that were in in place prior to the passage and implementation of the Veterans Choice Act. We provide an overview of programs developed in light of such authority, such as the traditional approach utilized by VA under 38 U.S.C. 1703 for preauthorized inpatient and outpatient services, reimbursement for emergency care provided to Veterans by non-VA resources, certain types of contracting authorities that provide VA with the ability to establish formal relationships with certain entities for sharing or purchasing health care resources, the acquisition of specialized services or the provision of purchased care to specialized Veteran populations, and four key initiatives that have helped shape delivery in the current environment. We then address the Veterans Choice Act, attendant changes to VA's authority in this area, and the features of the Choice program. This chapter concludes by comparing the authority and mechanisms of all of these programs, both before and after the Veterans Choice Act. Additional detail on the legal and regulatory provisions relating to VA purchased care can be found in Appendix B.

We note that over the years, externally provided medical care has been referred to in a number of ways by Congress, VA, and others, under such labels as "Non-VA Outpatient Fee Care," "Non-VA Care Coordination," "Fee Care," "Fee Basis Care," "Purchased Care," "NonDepartment Care," "Fee Program," "Preauthorized Care," "Non-VA Care," and "Non-VA Medical Care" (see, for example, VHA Directive 1601, [VHA, 2013a, p. 1]). In this report, we generally refer to externally provided medical care simply as purchased care in the broadest sense to characterize health care professionals and facilities that are not part of VA and the care they provide, regardless of the underlying authority, purpose, or circumstances of such utilization.

\subsection{Pre-Veterans Choice Act Authority and Mechanisms}

While what constitutes purchased care may seem relatively straightforward, the concept covers a wide-ranging set of circumstances with different goals, mechanisms, and target Veteran populations. For the purposes of this discussion, purchased care available just prior to the passage 
of the Veterans Choice Act can be divided into two categories. The first is broad-based external services. This type of care is generally available to any eligible Veteran, covers the widest variety of medical and dental services, and can involve treatment in inpatient, outpatient, and emergency settings (though we describe it more fully elsewhere in this chapter, the Veterans Choice Act's Choice program is intended to deliver broad-based external services as well). The second category is specialized external services. These services involve the use of purchased care resources to address the needs of specific subsets of Veterans, sometimes to provide specialized services available only from selected types of health care providers. While specialized external services can address critical aspects of an individual Veteran's health needs, broad-based external services are most relevant to a discussion of authorities and mechanisms for furnishing care at non-VA facilities if the underlying goal is to increase access for Veterans generally. The following sections provide a brief overview of the authorities for both broad-based and specialized external services, though we generally focus on the former. ${ }^{3}$

\subsubsection{Broad-Based External Services}

\subsubsection{Traditional Authority Under 38 U.S.C. 1703}

The core statutory authorities for broad-based external services can be found in the U.S. Code at Title 38, Section 1703, as implemented by VA regulations set forth in the C.F.R. at Title 38, Sections 17.52-17.56. We characterize this authority as that for "traditional purchased care" because it has been the primary means of utilizing non-VA facilities and providers since the late 1950s. VA is authorized under 38 U.S.C. 1703 to contract for medical and dental care when VA facilities are "not capable of furnishing economical hospital care or medical services because of geographical inaccessibility" or when VA facilities "are not capable of furnishing the care or services required." If either condition is met, the types of care that can be authorized include the following:

- Hospital care or medical services for the treatment of a service-connected disability, a disability that led to a discharge or release from service, or any disability of a Veteran who has a total and permanent service-connected disability (38 U.S.C. 1703(a)(1))

- Medical services for the treatment of a Veteran with a service-connected disability rated at 50 percent or more, a Veteran who has already received medical care for a disability but requires additional medical services to complete treatment, or certain types of Veterans whose medical condition precludes appropriate treatment in VA facilities (38 U.S.C. $1703(\mathrm{a})(2))$

- Emergency hospital care or medical services in situations that pose a serious threat to the life or health of a Veteran who is already receiving nursing home care in a non-VA facility or already receiving medical services in a VA facility (38 U.S.C. 1703(a)(3))

\footnotetext{
3 It should be noted that we do not treat community-based outpatient clinics as specific providers of non-VA medical care for Veterans. Though such clinics may be owned and staffed by VA or may lease space that is also staffed by VA, some do include contracted facilities and personnel, often provided through a health care management organization. Nevertheless, there are no fundamental restrictions on Veterans obtaining health care services through a community-based outpatient clinic. The Veteran does not have to seek prior authorization nor make any upfront payment of out-of-pocket expenses (at least not for services similar to those received at a traditional VAMC), and all such clinics are affiliated with a specific VAMC in terms of administrative responsibility. As such, we characterize community-based outpatient clinics in the same manner as any other VA medical facility.
} 
- Hospital care for female Veterans (38 U.S.C. 1703(a)(4))

- Hospital care, or medical services in place of hospital care, for Veterans outside of the contiguous 48 states (38 U.S.C. 1703(a)(5))

- Diagnostic services needed to determine eligibility or appropriate course of treatment at an outpatient clinic for medical services in place of hospital care (38 U.S.C. 1703(a)(6))

- Outpatient dental services, treatment, and appliances for former prisoners of war (38 U.S.C. $1703(\mathrm{a})(7))$

- Diagnostic services for determining eligibility for a VA benefit or service (38 U.S.C. $1703(\mathrm{a})(8))$.

The legislative grant of power to VA to contract with outside providers is broader than it might appear from the granulated categories in the statute. A key provision in the enabling statute is the one that addresses medical services for the treatment of any disability of a Veteran who has already received VA medical care but nevertheless requires additional medical services to complete treatment (38 U.S.C. 1703(a)(2)(B)). What widens the reach of Section 1703 is that the terms disability and medical services have expansive meanings under Title 38 of the U.S. Code. Under 38 U.S.C. 1701(1), a disability is defined as any "disease, injury, or other physical or mental defect" (rather than the more common conceptualization of an impairment that limits one or more major life activities); thus, any Veteran who is already receiving VA medical services for nearly any type of medical condition would clear at least one statutory threshold for external health care provision. Moreover, 38 U.S.C. 1701(6) defines medical services in a very broad way, going beyond examination, treatment, and rehabilitation to include surgical services, dental services and appliances, optometric and podiatric services, preventive health services, and noninstitutional extended care services. The language of 38 U.S.C. 1703 allows the use of external services for any Veteran if (1) he or she has already been seen by VHA providers and (2) it can be determined that non-VA resources are required to address the Veteran's medical needs in some way (assuming that there is a lack of capacity on VA's part to furnish the care at all or to do so economically as a result of geographic inaccessibility). Table 3-1 describes key aspects of the authorities and mechanisms related to the traditional authority under 38 U.S.C. 1703 for purchasing care. ${ }^{4}$

38 U.S.C. 1703 states only that the VA Secretary "may contract" with external providers, not that the Secretary must. As such, VA has considerable discretion to define the circumstances under which it will pay for such services, and it can place additional conditions on external provider utilization if it so desires (and it has done so in the past).

VA-promulgated regulations implementing 38 U.S.C. 1703 are found at 38 C.F.R. 17.5217.56, "Use of Public or Private Hospitals." These regulations impose additional requirements on Veteran eligibility and describe the circumstances under which the use of non-VA resources would be appropriate. Notably, 38 C.F.R. 17.52 states that any such exercise of authority under 38 U.S.C. 1703 would be possible only through contracts with non-VA facilities or, when "demand is only for infrequent use," the use of "individual authorizations." In other words, VA must have a contract in place before an external resource can be used, or, in the absence of such

\footnotetext{
4 We refer to the purchased care authorities granted by 38 U.S.C. 1703 and programs established thereunder as traditional purchased care.

5 We have been informed that VA is moving away from the use of term individual authorizations; instead, VA will refer to these as other forms of agreements.
} 
Table 3-1

Key Features of Traditional Purchased Care

\begin{tabular}{ll}
\hline Feature & \multicolumn{1}{c}{ Description } \\
\hline Situational eligibility & $\begin{array}{l}\text { VA not capable of furnishing ... } \\
\text { (1) economical care/services because of "geographical inaccessibility" or } \\
\text { (2) required care/services }\end{array}$
\end{tabular}

Status eligibility

Many conditions and situations qualify, but two may be most commonly utilized:

(1) treatment of any service-connected disability/condition; or

(2) treatment of any disability if

(a) Veteran was previously seen by VHA providers and

(b) non-VA resources are required to complete treatment

VA discretion to utilize or pay for non-VA care

Provider qualifications or requirements

Veteran input into provider choice

Additional requirements for inpatient treatment

Additional requirements for outpatient treatment

Payments

Direct payer of provider

Medical record sharing requirements

Coverage

First year implemented or authorized

Status

Key statutes or laws

Key regulations
VA may employ if eligibility criteria are met

None, as long as

(a) existing contract is in place, or

(b) individual authorization is granted in instances where need is infrequent

None specifically authorized

VA or other federal facility must not be "feasibly available," defined as when

(1) "urgency" of condition,

(2) "relative distance," or

(3) treatment required

makes use of external resource "necessary or economically advisable."

Stay is limited to the time needed to stabilize/improve condition

None

If inpatient, "prospective payment system similar to that used in the Medicare program"; in practice, this means

(1) the non-VA hospital rate

(2) the VA cost-to-charge rate

If outpatient,

(1) the amount described on any contract or negotiated agreement, or

(2) if no contract or agreement exists but there is an applicable "Medicare rate," the lower of

(a) the "Medicare rate,"

(b) the "repricer" rate, or

(c) the amount that the provider bills the general public;

(3) If no contract or agreement exists and there is no applicable "Medicare rate," the lower of

(a) the local VA fee schedule;

(b) the "repricer" rate, or

(c) the amount that the provider bills the general public

VA

Implemented programmatically

National

1957, though authority most similar to current form was enacted in 1986

Active

38 U.S.C. 1703

38 C.F.R. $17.52-17.56$ 
an existing relationship, it must issue an explicit authorization for an individual Veteran for a particular course of treatment. Furthermore, 38 C.F.R. 17.53 restricts inpatient treatment by external providers to instances in which any VAMC or other federal facility where the Veteran could conceivably be seen is "not feasibly available" - in other words, when (1) the "urgency of the applicant's medical condition," (2) "the relative distance of the travel involved," or (3) "the nature of the treatment required" makes the use of an external provider rather than a VA resource "necessary or economically advisable." In addition, the authorization is limited to the "period of time required to stabilize or improve the patient's condition to the extent that further care is no longer required to satisfy the purpose for which it was initiated."

\subsubsection{Emergency Services}

Services under 38 U.S.C. 1703 are often referred to as "preauthorized care" because the Veteran must receive explicit permission from VA prior to visiting external health care professionals or facilities or else risk being personally liable for the costs of services rendered. In a crisis situation, however, obtaining appropriate VA approval prior to arriving at a hospital's emergency department or calling for paramedics may be impractical or put the Veteran's life or health at risk. Two key statutes provide the legislative authority for VA payment of external emergency care without prior approval, differing by whether or not the event was related to a service-connected condition. ${ }^{6}$

The first of these statutes is 38 U.S.C. 1728, under which VA will reimburse a Veteran for the costs of emergency treatment (or pay the provider directly) as long as the event was related to a service-connected disability (either directly or indirectly) or the Veteran had a serviceconnected total disability. While the statute does say that the VA Secretary "shall" reimburse, any reimbursement will be "under such regulations as the Secretary prescribes." tions can be found at 38 C.F.R. 17.120-17.121, with Section 17.120 limiting 38 U.S.C. 1728 reimbursement to claims "timely filed" by Veterans. Furthermore, the emergency must be one in which "a prudent layperson would have reasonably expected that delay in seeking immediate medical attention would have been hazardous to life or health," thus "placing the health of the individual in serious jeopardy, serious impairment to bodily functions, or serious dysfunction of any bodily organ or part." Moreover, any VA or other federal facilities providing health care to Veterans that could have theoretically provided emergency services must not have been "feasibly available," and any attempts to use them would "not have been reasonable, sound, wise, or practicable" or the treatment authorization "had been or would have been refused."

The other main avenue to reimbursed external emergency care is 38 U.S.C. 1725, which does not require a Veteran to have a service-connected disability. The enabling statute, created as part of the Veterans Millennium Health Care and Benefits Act (which is why payments for

\footnotetext{
6 There is also additional authority in the U.S. Code for utilizing non-VA emergency care. First, 38 U.S.C. 1703(a)(3) authorizes the use of non-VA resources in emergencies posing a serious threat to the life and health of Veterans in nursing homes or while receiving treatment at VA facilities. In addition, Section 1703(a)(2)(B) and its associated regulations address situations in which VA can preauthorize the use of external emergency resources and when the emergency involves treatment already being received by the Veteran. Second, 38 U.S.C. 1728(a)(4) covers emergency services provided to Veterans participating in a vocational rehabilitation program. Our discussion in this section focuses on the perhaps more common circumstances constituting an emergency-one in which prior approval would not be practical, involving a condition not previously treated by VA, and the Veteran is not in a nursing home, participating in a vocational rehabilitation program, or at a VA health care facility at the time of emergency.

7 The original version of this statute, the Veterans Health Care Expansion Act of 1973 (Pub. L. 93-82), Section 106(a), indicated only that VA may reimburse.
} 
non-service-connected emergency services under this provision are popularly known as "Mill Bill" reimbursements), does have some important restrictions, however. ${ }^{8}$ The Veteran must be enrolled and have received some type of VA health care in the previous two years (though not necessarily related to the conditions that led to the emergency) and be otherwise "personally liable" for the charges. The personal liability requirement means that the Veteran has (1) no entitlement to any health care plan or contract (such as private health insurance, Medicare or Medicaid benefits, or workers' compensation benefits) that might cover some part of the charges and (2) no recourse against any "third party" (such as an automobile liability carrier following a motor vehicle collision, an employer, or an employer's insurance carrier) that could pay the entire bill for services. Put another way, VA must essentially be the resource of last resort to cover the costs of the emergency care. ${ }^{9}$ The statute's provisions are clarified by 38 C.F.R. 17.1000-17.1008. Section 17.1002 generally mirrors the language in 38 C.F.R. 17.120 for assessing the reasonableness of service-connected emergency claims. It also contains a version of the "feasibly available" and "prudent layperson" standards described earlier with regard to defining a true emergency and whether a VA facility should have been used instead.

Appendix E includes a more complete overview of the key features of these two types of emergency care authorities for purchased care.

\subsubsection{Related Contracting Authorities}

External services provided to Veterans under 38 U.S.C. 1703, 1725, and 1728 are often acquired on an ad hoc basis; in other words, a Veteran has a medical issue that requires only one or perhaps just a handful of contacts with specific non-VA health care professionals or facilities, and the Veteran may be the only patient (or one of just a handful of patients) treated by the professional or facility whose services would ultimately be paid for or reimbursed by VHA. In such instances, VHA receives a statement from the provider or a request for reimbursement from the Veteran that itemizes the costs of each service delivered and indicates whether the circumstances and the services rendered are appropriate uses of non-VA care according to statutes and regulations. If so, VHA pays the bill. ${ }^{10}$ Increasingly, however, VA appears to be moving away from such a "fee-for-service" model requiring individual authorizations toward one in which external care is delivered by health care providers who have an existing and ongoing relationship with the agency and the costs of services delivered are determined in advance. The three main vehicles for establishing such relationships beyond the traditional fee-for-service approach-purchased care contracts, sharing agreements with DoD, and sharing agreements with VA's "academic affiliates" - are described in the following sections. It should be kept in mind, however, that these three contracting vehicles do not constitute an expansion of basic VA authority to purchase care for Veterans, beyond that in 38 U.S.C. 1703, 1725, and 1728.

\footnotetext{
8 Pub. L. 106-117 (1999). This original enabling statute was later amended by Pub. L. 110-387 (2008) and Pub. L. 111-137 (2010), with both amendments easing the requirements somewhat for reimbursing emergency care.

9 When a third party is responsible for paying part of emergency services (such when a Veteran is 50-percent responsible for a motor vehicle accident), VA will act as a secondary payer and cover only the Veteran's share of the expense (38 U.S.C. $1725(\mathrm{c}))$.

10 When there is no existing contract or agreement in effect (as might be the case when external health care is sought only on an occasional fee-for-service basis), 48 C.F.R. 801.670-3 (part of the VA Acquisition Regulation [VAAR]) allows certain officials at VA medical facilities to order medical, dental, and ancillary services when the amount authorized is less than $\$ 10,000$. In such situations, 48 C.F.R. 813.307(c) and 48 C.F.R. 853.213 describe the forms that must be executed when ordering the services under the simplified procedures for VA acquisition set forth in 48 C.F.R. 873.101-873.118.
} 


\subsection{Purchased Care Contracts}

The "sharing of medical facilities, equipment, and information" by VA is addressed by 38 U.S.C. 8151-8158. The key statute of interest here in terms of purchased care is 38 U.S.C. 8153, which allows VA-when it determines that it is "in the best interest of the prevailing standards of the Department medical care program" - to "make arrangements, by contract or other form of agreement for the mutual use, or exchange of use, of health-care resources between Department health-care facilities and any health-care provider, or other entity or individual." Although this language may seem to imply a reciprocal agreement in which VA offers its services in exchange for those provided by others, in actuality, the statute is commonly used as the basis for directly purchasing services and supplies from a wide range of health care providers. ${ }^{11}$ Examples include contracting for dialysis services, organ transplants, anesthesia services, diagnostic radiology, and psychiatric care.

Section 8153(a)(3)(B) allows VA to enter into such commercial medical care contracts, which may involve services delivered over a relatively long period of time and for considerable sums of money, through the use of certain "simplified" contracting rules "without regard to any law or regulation that would otherwise require the use of competitive procedures for procuring the resource" (48 C.F.R. 873.101-873.118). 38 U.S.C. 8153 plays a key role in recent initiatives that VA has rolled out to deliver purchased care, with third parties essentially administering all aspects of the referral, including choosing the providers, scheduling appointments, processing claims, and coordinating care. The language of the statute permits VA wide latitude to contract with managed care organizations and other entities that oversee (or directly employ) entire networks of providers.

VA contracting for outside health services under Section 8153 implicates the area of law pertaining to government procurement activities more generally. In Chapter Five of this report, we discuss VA contracting for purchased care generally, and related authorities, in much greater detail.

\subsection{DoD Sharing Arrangements}

Another statute concerning the acquisition of external services is 38 U.S.C. 8111, under which VA and DoD can enter into arrangements for utilizing each other's medical care facilities and providers: "The Secretary of Veterans Affairs and the Secretary of Defense shall enter into agreements and contracts for the mutually beneficial coordination, use, or exchange of use of the health care resources of [their respective Departments]." Unlike 38 U.S.C. 8153, which can be used with any public or private provider, Section 8111 focuses exclusively on DoD as VA's intended partner. Moreover, the flow of services and products under Section 8111 has been in both directions, with VA "selling" (i.e., treating DoD patients and seeking reimbursement later) and "buying" (i.e., sending VA patients to DoD). Nevertheless, compared with other means of acquiring external health care, VA's use of existing DoD facilities and personnel is a minor contributor to the overall cost of addressing the medical needs of Veterans at slightly more than $\$ 100$ million per year. ${ }^{12}$ Issues related to the physical distribution of such facilities (which may not be located near population centers) and potential interruptions due to secu-

\footnotetext{
11 As described later, VA often enters such reciprocal agreements with DoD and certain academic institutions.

12 In FY 2013, for example, DoD purchased $\$ 152$ million in services and goods from VA; in turn, DoD provided \$119 million in medical resources to VA (VA, 2015b, p. 200). To put these numbers into perspective, VHA's Chief Business Office's estimate of total spending in FY 2014 for all purchased care was $\$ 5.6$ billion (VA, 2014c).
} 
rity concerns or DoD priorities may limit the utility of these arrangements for VA (see GAO, 2008).

\subsection{Academic Affiliate Sharing Arrangements}

The authorization under 38 U.S.C. 8153 to establish sharing agreements and other relationships with external entities offers minimal guidance on which entities should be prioritized. That said, 38 U.S.C. 7302 separately mandates VA to "carry out a program of education and training of health personnel" in cooperation with schools of "medicine, osteopathy, dentistry, nursing, pharmacy, optometry, podiatry, public health, or allied health professions." Section 8153(a)(3)(A) reflects that policy by allowing the use of noncompetitive sharing agreements (in other words, sole-source contracts) with affiliated academic institutions, such as medical schools, teaching hospitals, and associated clinical practices. The enhanced ability to enter into sole-source contracts without competitive bidding, in combination with VA's underlying mission to "assist in providing an adequate supply of health personnel to the Nation" (38 U.S.C. 7302(a)), has been an important factor in the growth of arrangements with academic affiliates. While the program is primarily one in which non-VA health care professionals (such as medical school residents) receive training at VA facilities, VA purchases more than $\$ 1$ billion in services each year from their academic affiliates (for example, a VA patient may be sent to a medical school for certain radiological services).

\subsubsection{Specialized External Services and Specialized Veteran Populations}

There are many other programs that could be characterized as VA purchased care, since they also rely on external providers and resources to deliver health care to Veterans. However, their utility as a means of expanding a wide range of health care services to Veterans generally is limited. These programs include, for example, agreements to reimburse IHS and Tribal Health Program health facilities for services provided to American Indian and Alaska Native Veterans; ${ }^{13}$ the authority under 38 U.S.C. 7409 to enter into contracts with medical and nursing schools, "clinics," or "any other group or individual" for the provision of "scarce medical specialist services"; and the Foreign Medical Program under 38 U.S.C. 1724, which is used to reimburse medical expenses incurred by Veterans with service-connected disabilities who require treatment while residing or traveling abroad. Appendix E includes a comprehensive list of these programs.

\subsubsection{Pre-Veterans Choice Act Initiatives}

VA has implemented a series of programmatic mechanisms in recent years with various goals, such as better utilizing purchased care resources, containing costs, enhancing the coordination of care, and addressing the needs of underserved Veterans. These programs' origins range from congressional mandates to internally developed VA initiatives. Some seem to have been specifically directed at various concerns that have been raised regarding purchased care generally, while others were intended to be the primary templates for VA's purchased care activities in the future.

13 IHS, part of the U.S. Department of Health and Human Services, provides health services to members of federally recognized American Indian and Alaska Native tribes. VA reimburses IHS and the Tribal Health Program for care provided to Veterans through reimbursement agreements authorized under 38 U.S.C. 8153. 
The following discussion addresses four such programs: a pilot to explore using provider networks for purchased care in certain VISNs (Project HERO), expanded eligibility rules for certain rural Veterans in selected locations to also employ provider networks (Project ARCH), a nationwide rollout of a provider network approach (PC3), and a more centralized approach to administering purchased care (NVCC). ${ }^{14}$

In the discussion below, we use some key terminology in explaining these purchased care initiatives. By provider, we mean any health care professional or facility that might render medical services to Veterans in connection with one of the programs described in in this chapter. By network, we mean a group of providers who have executed agreements with the same organization to deliver medical care under predetermined rules and conditions. Such an organization is a network administrator and may be a preferred provider organization (PPO), insurer, employer, TPA, health maintenance organization (HMO), or health plan. A provider who agrees to join the network is said to be "participating" as an "in-network provider." A provider who does not join the network but nevertheless is utilized for purchased care services is said to be an "out-of-network provider." Generally, network administrators and the providers within that network are independent of each another and not agents (or principals), employers (or employees), or other legal representatives. The predominate type of network administrator in VA's current purchased care programs is a TPA.

We also use the term contractor for any organization or individual under contract with VA to deliver some type of medical service. For example, in some of the programs described in this section, a network administrator makes its network of providers available to VA under contract to supply medical services. Thus, a network administrator can be characterized as a type of contractor. ${ }^{15}$ The term contractor can also be applied to a medical facility that delivers contracted medical services to VA, typically using its own employees. Individual providers can also contract with VA (and, as such, can be contractors). Still another type of contractor would be any organization that has contracted with VA to provide administrative services for VA purchased care, such as claims administration.

\subsubsection{Project HERO}

Project HERO was created in response to a House Conference Committee report issued in connection with the 2006 Military Quality of Life and Veterans Affairs Appropriations Act (Pub. L. 109-114). While Project HERO is no longer an active initiative, we describe it here because many of its features were subsequently used as a model for later programs, in particular PC3 (Jones, 2012). The committee report urged VA to explore new medical case management strategies, though what VA ultimately implemented was less an exercise in fully managed care than a means of enhancing the existing purchased care program (House Report 109-305, 2005, pp. 43-44; Panangala, 2010, p. 4). The pilot program went live in January 2007 and was tested in VISNs 8, 16, 20, and 23. It employed provider networks under contract to VA for

\footnotetext{
14 Not included in the discussion in this section are demonstration projects for expanding access for rural Veterans authorized by Section 307 of the Caregivers and Veterans Omnibus Health Services Act of 2010 (Pub. L. 111-163). Among the projects contemplated by Congress were partnerships between VA and the IHS, the U.S. Department of Health and Human Services, and the Centers for Medicare and Medicaid Services (CMS), among other agencies, for non-VA facilities and providers. That said, it appears that the primary vehicle for expanding access for this Veteran population has been the use of grants to fund enhanced transportation to both VA and non-VA medical facilities for highly rural Veterans, as described in 38 C.F.R. 17.700-17.730. Because these grants simply facilitate rather than authorize or direct the use of non-VA providers, we do not include them here as a relevant recent initiative.

15 We have been informed that VA's currently preferred term for a TPA is contractor.
} 
supplemental referrals when similar care was not available at local VAMCs or VA clinics. The goal, according to one observer, was to make "contracted providers virtual, high-quality extensions of VHA" (American Legion, n.d.). VA contracted with Humana Military Healthcare Services, Inc. (for medical services) and Delta Dental (for dental services) to operate as network administrators. These contracts terminated in September 2012 and March 2013, respectively. Table 3-2 describes Project HERO's features.

VA fee staff (in consultation with the contractor) would determine whether referral to Project HERO was appropriate, assuming all other criteria for purchased care were satisfied. That determination would be driven by (1) whether the specialty required was one offered by the HERO contractor and (2) whether the HERO provider selected by the contractor was located within a "reasonable distance" of the Veteran. ${ }^{16}$ If both criteria were met, the contractor would be responsible for contacting the Veteran to set up an appointment. The contractor

Table 3-2

Key Features of Project HERO

\begin{tabular}{|c|c|}
\hline Feature & Description \\
\hline Situational eligibility & Same as for traditional purchased care \\
\hline Status eligibility & $\begin{array}{l}\text { Same as for traditional purchased care, though specialty required must also be } \\
\text { one offered by a HERO contracted provider }\end{array}$ \\
\hline $\begin{array}{l}\text { VA discretion to utilize or pay } \\
\text { for non-VA care }\end{array}$ & Same as for traditional purchased care \\
\hline $\begin{array}{l}\text { Provider qualifications or } \\
\text { requirements }\end{array}$ & $\begin{array}{l}\text { (1) Provider must be part of the HERO network (which may impose additional } \\
\text { credentialing requirements); and } \\
\text { (2) Provider is located within a "reasonable distance" from the Veteran }\end{array}$ \\
\hline $\begin{array}{l}\text { Veteran input into provider } \\
\text { choice }\end{array}$ & $\begin{array}{l}\text { Presumably limited; HERO contractor sets up appointment with provider within } \\
\text { network }\end{array}$ \\
\hline $\begin{array}{l}\text { Additional requirements for } \\
\text { inpatient treatment }\end{array}$ & Same as for traditional purchased care \\
\hline $\begin{array}{l}\text { Additional requirements for } \\
\text { outpatient treatment }\end{array}$ & Same as for traditional purchased care \\
\hline Payments & $\begin{array}{l}\text { Presumably at or below the amounts allowed for traditional purchased care; } \\
\text { reportedly a negotiated percentage of local Medicare rates }\end{array}$ \\
\hline Direct payer of provider & HERO contractor \\
\hline $\begin{array}{l}\text { Medical record sharing } \\
\text { requirements }\end{array}$ & Contractually required \\
\hline Coverage & VISNs $8,16,20$, and 23 \\
\hline $\begin{array}{l}\text { First year implemented or } \\
\text { authorized }\end{array}$ & 2007 \\
\hline Status & Final contracts expired March 2013 \\
\hline Key statutes or laws & Same as for traditional purchased care \\
\hline Key regulations & Same as for traditional purchased care \\
\hline
\end{tabular}

16 While a reasonable distance standard was not specifically defined, as a matter of practice, the contractor would inform VA staff whether the available network provider was more than 50 miles from the Veteran's residence. If so, VA staff would have the option of canceling the HERO referral and using another means to supply the required care. The distance standard appears to be the result of an internal VA business practice rather than a formal feature of Project HERO (Panangala, 2010, p. 11). 
would also act as the conduit for exchanging clinical information between VA and the provider, both before and after the service was provided. ${ }^{17}$ Payments to providers were simplified, coming from the contractor rather than the U.S. Department of the Treasury. ${ }^{18}$ Presumably, such payments would not exceed those allowed under existing statutory and regulatory authority for purchased care. Reportedly, however, providers were paid a "negotiated percentage" of CMS rates, according to "local market rates where the services are provided" (Panangala, 2010, p. 12). As compensation for managing the provider network and administering the payment and information exchange, the contractor was paid a value-added fee equivalent to just under 8 percent of total billings in FY 2009 (Panangala, 2010, p. 13, Table 2).

\subsubsection{Project $A R C H$}

Project ARCH is an effort to explore a more patient-centered approach to the use of purchased care in a coordinated, cost-effective manner. ARCH is the result of Section 403 of the Veterans' Mental Health and Other Care Improvements Act of 2008 (Pub. L. 110-387), which required VA to test the subsidization of health care costs for rural Veterans in locations other than those testing Project HERO. ${ }^{19}$ The pilot program was first fielded in 2011 as a three-year test in rural VAMCs and focused on selected medical services. ${ }^{20}$ The services would be provided "through contracts," presumably in contrast with individual payments to external providers for fee-based care. VA selected the Cary Medical Center (in Maine) and Humana Veterans Health Services (all other sites) to act as the initial network administrators. The pool of providers available under ARCH was limited to those who had executed agreements with the network administrators (VHA Chief Business Office, 2014). The Veterans Choice Act extended $\mathrm{ARCH}$ an additional two years, and it now has a termination date of August 2016. ${ }^{21}$

The congressional mandate included a clear expansion of the eligibility rules set forth for traditional purchased care, albeit only for a geographically defined set of Veterans (Table 3-3). A Veteran living in one of the pilot sites would be eligible for ARCH under one of the following conditions: (1) the Veteran's home was more than 60 minutes driving time from the nearest VA primary health care service facility (if the Veteran was seeking primary care); (2) the Veteran lived more than 120 minutes driving time from the nearest VA facility offering acute hospital care (if acute medical care was sought); or (3) the Veteran lived more than 240 minutes driving time from the nearest tertiary care VA health care facility (if tertiary care was sought). The original enabling statute determined eligibility based on distance rather than time, so the maximum travel criteria to the three facility types were 60 miles, 120 miles, and 240 miles,

\footnotetext{
17 As a contractual requirement, the network administrator sent the medical record of the treatment back to the originating VAMC (Panangala, 2010, p. 7).

18 The contractor would seek reimbursement from VA at a later point.

19 Authority for the pilot program was later amended by Section 308 of the Caregivers and Veterans Omnibus Health Services Act of 2010 (Pub. L. 111-163).

20 The program was officially called the Pilot Program of Enhanced Contract Care Authority for Health Care Needs of Veterans in Highly Rural Areas. The pilot was implemented in VISNs 1, 6, 15, 18, and 19 (Caribou, Maine; Farmville, Virginia; Pratt, Kansas; Flagstaff, Arizona; and Billings, Montana). Under the Veterans' Mental Health and Other Care Improvements Act of 2008, VA had the discretion to include other VISNs in the program, but it appears not to have done so.

21 The extension gives VA the ability to rely on existing ARCH contracts or to enter into new ones, presumably including those now utilized for the Choice program.
} 
Table 3-3

Key Features of Project ARCH

\begin{tabular}{|c|c|}
\hline Feature & Description \\
\hline Situational eligibility & $\begin{array}{l}\text { (1) If seeking primary care, Veteran must reside more than } 60 \text { min. driving time to } \\
\text { nearest VA primary health care facility; or } \\
\text { (2) If seeking acute hospital care, must reside more than } 120 \text { min. driving time to } \\
\text { nearest VA acute hospital care facility; or } \\
\text { (3) If seeking tertiary care, must reside more than } 240 \text { min. driving time to nearest } \\
\text { VA tertiary care facility. }\end{array}$ \\
\hline \multirow[t]{2}{*}{ Status eligibility } & $\begin{array}{l}\text { Veteran must be } \\
\text { (1) residing in a pilot site; and } \\
\text { (2) currently enrolled for VA health care }\end{array}$ \\
\hline & Services required must be offered by an $\mathrm{ARCH}$ contracted provider \\
\hline $\begin{array}{l}\text { VA discretion to utilize or pay } \\
\text { for non-VA care }\end{array}$ & $\begin{array}{l}\text { VA shall provide covered health services to eligible Veterans (if electing) through } \\
\text { ARCH provider contracts (assuming qualified providers are available) }\end{array}$ \\
\hline $\begin{array}{l}\text { Provider qualifications or } \\
\text { requirements }\end{array}$ & $\begin{array}{l}\text { Provider must be part of an ARCH network or facility; VA determines whether } \\
\text { provider is "qualified" }\end{array}$ \\
\hline $\begin{array}{l}\text { Veteran input into provider } \\
\text { choice }\end{array}$ & Presumably limited to providers within $\mathrm{ARCH}$ network \\
\hline $\begin{array}{l}\text { Additional requirements for } \\
\text { inpatient treatment }\end{array}$ & Presumably none if Veteran is otherwise eligible \\
\hline $\begin{array}{l}\text { Additional requirements for } \\
\text { outpatient treatment }\end{array}$ & Presumably none if Veteran is otherwise eligible \\
\hline Payments & $\begin{array}{l}\text { Reportedly a negotiated percentage of local Medicare rates for four sites } \\
\text { managed by a vendor, while full Medicare rates for the site directly contracting } \\
\text { with VA }\end{array}$ \\
\hline Direct payer of provider & ARCH contractor \\
\hline $\begin{array}{l}\text { Medical record sharing } \\
\text { requirements }\end{array}$ & Mandated by statute \\
\hline Coverage & Certain rural VAMCs in VISNs $1,6,15,18$, and 19 \\
\hline $\begin{array}{l}\text { First year implemented or } \\
\text { authorized }\end{array}$ & 2011 \\
\hline Status & $\begin{array}{l}\text { Now scheduled to terminate in August } 2016 \text { as a result of a Veterans Choice Act } \\
\text { extension }\end{array}$ \\
\hline Key statutes or laws & $\begin{array}{l}\text { Pub. L. 110-387, Sec. 403; Pub. L. 111-163, Sec. 308; Pub. L. 113-146, Sec. 104; Pub. } \\
\text { L. 113-175, Sec. } 409\end{array}$ \\
\hline Key regulations & None that can be identified \\
\hline
\end{tabular}

respectively. That language was subsequently changed by Section 308 of the Caregivers and Veterans Omnibus Health Services Act of 2010 (Pub. L. 111-163). ${ }^{22}$ The original statute also included language that would have expanded the pilot program to Veterans who lived within the driving limits but who nevertheless faced "such hardship or other difficulties in travel to the nearest appropriate Department health care facility that such travel is not in the best interest of the veteran, as determined by the Secretary pursuant to regulations prescribed for pur-

22 Nevertheless, the language in the current version of the statute continues to use the phrase driving distance rather than driving time, even though eligibility is based on minutes of driving. 
poses of this subsection." The subsequent revision dropped that alternative eligibility definition (Pub. L. 111-163).

Eligibility is based primarily on the patient's status as a "highly rural" Veteran, determined by a simple drive-time test related to the specific medical need rather than "geographic inaccessibility" or other Section 1703 criterion. VA calculated drive times for every Veteran in each of the pilot sites, so eligibility had essentially been determined before the program was under way. ${ }^{23}$ That said, the Veteran's VA provider would still need to determine that a service available under ARCH was needed, even if the Veteran met one of the drive time criteria. In addition, Veteran participation is voluntary and could be withdrawn if other types of purchased care were preferred or if the Veteran were willing to tolerate drive times exceeding the ARCH-qualifying standards.

Besides simply offering purchased care to Veterans with geographical access limitations, ARCH mandates that the care be provided on a timely basis. Section 104 of the Veterans Choice Act requires that medical appointments under ARCH be "scheduled not later than 5 days after the date on which the appointment is requested" and "occur not later than 30 days after such date." It is not clear what the consequences might be if an appointment is not delivered within these limitations, however.

One important aspect of ARCH is that it was funded by VA's Office of Rural Health rather than the VAMC where the consults originated. ${ }^{24}$ In FY 2012, for example, the office allocated \$35 million for ARCH-related needs (Veterans' Rural Health Advisory Committee, 2012, p. 3). In FY 2015, funding for ARCH, like for all VA purchased care, was moved to the VHA Chief Business Office budget. ${ }^{25}$ Thus, referrals to purchased care throughout the ARCH experience would have had a minimal direct impact on a VAMC's budget, essentially eliminating any significant financial disincentive at the local level to use non-VA providers. In contrast, funds expended for purchased care as part of Project HERO were sourced from the VISNs where the pilot programs operated. ${ }^{26}$ Another important aspect involves provider reimbursement rates. In four of the five $\mathrm{ARCH}$ sites, the managing organization made arrangements with its network providers to pay, as was true under Project HERO, negotiated percentages of Medicare rates (Tester, 2014). But because Cary Medical Center in Maine directly contracted with VA as a provider, 100 percent of applicable Medicare rates were paid (Dickson, 2014; Non-VA Care: An Integrated Solution for Veteran Access, 2014).

\subsubsection{PC3}

PC3 (Patient-Centered Community Care, sometimes referred to as PCCC) was created by VA in 2013 based on what was learned from Project HERO and other pilot/demonstration programs. The first contracts with regional health care networks TriWest Healthcare Alliance and Health Net Federal Services were awarded in September 2013 for the delivery of external health care in a manner similar to a private employer's TPA for managing health care benefits. This particular initiative was being fully rolled out when the Veterans Choice Act was passed.

\footnotetext{
23 The Veteran would nevertheless have to "submit to [VA] an application . . containing such information as [VA] shall specify for purposes of the pilot program" (Project ARCH, n.d.).

24 While management of ARCH originated in VHA's Chief Business Office, the Office of Rural Health reportedly assumed operational oversight in October 2011 (Veterans' Rural Health Advisory Committee, 2012, p. 3).

25 See Section 106(b) of the Choice Act.

26 In FY 2009, for example, Project HERO payments were 0.43 percent of total budgets for the relevant VISNs.
} 
A key point to keep in mind is that PC3 (like Project HERO) does not provide any expanded authority for VA to utilize non-VA resources (see Table 3-4). ${ }^{27}$ It simply addresses administrative aspects of existing authority, such as that available under 38 U.S.C. 1703 related to geographical inaccessibility or when VA facilities are incapable of furnishing the care that the Veteran requires. VAMC staff determine whether PC3 resources are appropriate.

The initial focus was on medical and surgical services other than primary care, dialysis, and mental health, but the program has been expanded over time to include inpatient specialty care, outpatient specialty care (such as home infusion therapy), certain types of emergency care, and some care for newborns of enrolled female Veterans. In August 2014, the program was expanded considerably, at least in terms of potential scope, when primary care was added (see VA Office of Public and Intergovernmental Affairs, 2014). That said, PC3 remains a program

Table 3-4

Key Features of PC3

\begin{tabular}{|c|c|}
\hline Feature & Description \\
\hline Situational eligibility & Same as for traditional purchased care \\
\hline Status eligibility & $\begin{array}{l}\text { Same as for traditional purchased care, though specialty required must also be } \\
\text { one offered by a PC } 3 \text { contracted provider }\end{array}$ \\
\hline $\begin{array}{l}\text { VA discretion to utilize or } \\
\text { pay for non-VA care }\end{array}$ & Same as for traditional purchased care \\
\hline $\begin{array}{l}\text { Provider qualifications or } \\
\text { requirements }\end{array}$ & $\begin{array}{l}\text { (1) Provider must be part of the PC3 network; and } \\
\text { (2) Provider is located within a "reasonable distance" from the Veteran. }\end{array}$ \\
\hline $\begin{array}{l}\text { Veteran input into provider } \\
\text { choice }\end{array}$ & $\begin{array}{l}\text { Presumably limited; PC3 contractor sets up appointment with provider within } \\
\text { network }\end{array}$ \\
\hline $\begin{array}{l}\text { Additional requirements for } \\
\text { inpatient treatment }\end{array}$ & Same as for traditional purchased care \\
\hline $\begin{array}{l}\text { Additional requirements for } \\
\text { outpatient treatment }\end{array}$ & Same as for traditional purchased care \\
\hline Payments & $\begin{array}{l}\text { Presumably at or below the amounts allowed for traditional purchased care; } \\
\text { reportedly a negotiated percentage of local Medicare rates }\end{array}$ \\
\hline Direct payer of provider & PC3 contractor \\
\hline $\begin{array}{l}\text { Medical record sharing } \\
\text { requirements }\end{array}$ & Contractually required \\
\hline Coverage & National \\
\hline $\begin{array}{l}\text { First year implemented or } \\
\text { authorized }\end{array}$ & 2013 \\
\hline Status & Active \\
\hline Key statutes or laws & Same as for traditional purchased care \\
\hline Key regulations & Same as for traditional purchased care \\
\hline
\end{tabular}

27 In contrast, Project ARCH had a congressional mandate expanding Veteran eligibility beyond that set forth in 38 U.S.C. 1703,1725 , and 1728 . 
in the early stages of implementation, and, while the country has already been divided across two administrators (TriWest and Health Net), provider networks are still being developed.

One characteristic that distinguishes PC3 from purchased care (at least before the advent of the relatively recent NVCC program discussed subsequently) is its concerted effort to provide current clinical information about a patient to the health care provider at the time of service, regardless of whether the Veteran is treated by a VA or external provider. In addition, PC3 providers are required to schedule an appointment within five days of initial contact and hold the appointment within 30 days of receiving authorization, with the patient being seen within 20 minutes of arrival. There are also contractually imposed requirements regarding turnaround times for returning medical documentation (14 days for outpatient and 30 days for inpatient). Like the practice adopted during Project HERO, the health care professional or facility must be located within a "reasonable distance" of the Veteran (Health Net Federal Services, n.d.-a).

As discussed in greater detail in Chapter Four, TriWest and Health Net act as TPAs of provider networks. Individual health care professionals and entities register with the TPAs to become preferred in-network providers. ${ }^{28}$ When VA staff decide that referral to a PC3 provider is warranted, a request is sent to the appropriate TPA, which, in turn, sends an authorization to a network provider (TriWest Healthcare Alliance, n.d.). After treating the Veteran, the provider sends a claim to the TPA (or, in some instances, the claims processing vendor appointed by the TPA). As required in the network provider agreement, to be paid, the claim must be accompanied by the medical record of the treatment (see, for example, TriWest Healthcare Alliance, 2015c, p. 15). If the provider believes that additional or different treatment is needed, it must contact the TPA for a supplemental authorization. Ultimately, the TPA seeks bulk reimbursement from VA for all PC3 payments it has made.

Another important aspect that differs from traditional purchased care is that providers in the TPA networks (outside of Alaska) receive amounts that are, on average, less than the full Medicare reimbursement rates-reportedly 94.5-97.5 percent for medical and surgical services and 92-97 percent for skilled home health (Robinson, 2014; VA Office of Inspector General, 2015, pp. 11-12). The rate is contractually set, and some providers have agreed to even lower levels of reimbursement. ${ }^{29}$

PC3 is VA's preferred mechanism for external medical services, though actual utilization (as far as we could determine) is far smaller than other paths to VA purchased care. VA materials suggest that in cases of geographical inaccessibility or a lack of availability of services through VHA, a PC3 authorization should be used unless direct contracting with providers is a "definitively" better method:

Local contracts may be used on an exception basis. The intent is to purchase all services included in PC3 through the resultant contracts. However, a local VAMC may contract directly if needed services are not covered by PC3 or if the local contract can definitively provide benefits above and beyond those offered by PC3. (VHA Chief Business Office, 2014, emphasis added)

\footnotetext{
28 The Assessment I report, on business processes, details the responsibilities of PC3 providers (Grant Thornton, 2015).

${ }^{29}$ For example, the EmpowerChiro preferred provider application states, "Provider agrees to accept a percentage discount off the current applicable Medicare Fee Schedule, as updated from time to time, as follows: $85 \%$ of Medicare" (EmpowerChiro, 2014, Exhibit 1).
} 


\subsubsection{NVCC}

NVCC (Non-VA Care Coordination Program), the current administrative mechanism for many aspects of VA purchased care, was first rolled out as a pilot program in VISNs 11, 16, and 18 and later system-wide. Again, we note that NVCC is not an expansion of VA's ability to use non-VA medical care resources. Rather, it can be viewed as a change in internal business processes, especially with regard to standardizing referrals to external providers. Some aspects of NVCC administration now apply to all VA purchased care delivery, including PC3, Project $\mathrm{ARCH}$, and the Choice Program, but the program's primarily role at the outset was to standardize procedures related to external medical care under 38 U.S.C. 1703, 1725, and 1728.

Again, it is challenging to characterize the process by which purchased care is provided under NVCC because policies, guidance, and lines of authority have changed frequently. One key difference from past practices is that VA Central Office staff now play a larger role in coordinating the delivery of external services to the Veteran: Not only does VHA make the referral, but it also sets up the appointment (see Chapter Four for a more detailed discussion). As of January 2014, the process for obtaining an authorization for external care appeared to begin with the submission of a non-VA care consult, presumably by a VA health care professional who has been working with the Veteran. ${ }^{30}$ That consult was then reviewed for the Veteran's administratively eligibility for external health care and whether the proposed services were medically necessary. If approved, NVCC staff would determine which purchased care option would be most appropriate (e.g., individual authorization or referral to the PC3 network), an authorization would be issued and sent to the Veteran, and a separate authorization would be sent to the provider along with information about the services being authorized, the time frame for the services, and other guidance.

NVCC also marked a fundamental change how provider claims are processed. Previously, responsibility for reviewing claim eligibility and moving the paperwork was at the local level, with "fee staff" (personnel charged with claims processing and other purchased care duties) based at each VAMC. The VHA Chief Business Office is now in the process of consolidating these tasks so that only a small number of sites will be used to handle purchased care paperwork (though fee staff at individual VAMCs will continue to perform this function for the foreseeable future). When there is no preexisting contract or negotiated agreement with the provider, claims are paid in accordance with 38 C.F.R. 17.55 and 17.56, which closely follow Medicare guidelines. ${ }^{31}$ With a preexisting arrangement, the reimbursement is at the negotiated rate.

There has also been a focused effort under NVCC to track the flow of clinical documentation from external providers and add it to the Veteran's electronic medical record. ${ }^{32}$ Finally, there is more standardized guidance to field the inevitable requests for appeal and to ensure compliance with statutory and regulatory requirements for the provision of external care.

NVCC continues to be VA's primary avenue for managing external care, at least in the near future. Indeed, the Veterans Choice Act clearly anticipates that the NVCC process will

\footnotetext{
30 This description draws heavily on VA Form 10-7078/10-7079 (VA, 2014a). Presumably, the VA health care professional has been designated by the facility's chief of staff and by VHA's Chief Business Office as an official authorized to approve purchased care consults. See VHA (2013b, 2013c).

31 If not applicable, the 75 th percentile methodology described earlier would be used.

32 Authorizations under NVCC put the provider on notice that submission of the medical record would be a prerequisite for payment. See VA Form 10-1079 (VA, 2014a).
} 
provide the administrative structure for the Choice option: "The Secretary shall coordinate, through the Non-VA Care Coordination Program of the Department of Veterans Affairs, the furnishing of care and services under this section to eligible veterans." As a result, NVCC staff will determine whether a Veteran would be best served by the Choice Program, PC3, fee-forservice preauthorized medical services, or another option.

\subsubsection{Available Guidance for VA Purchased Care Prior to the Veterans Choice Act}

The bulk of broad-based external services prior to the Veterans Choice Act were the result of decisions made at the VAMC level to authorize a Veteran to go outside of VA for nonemergency medical or dental care. It is difficult to describe the decision-making process because the guidance available to VAMC staff evolved over time and was not always consistent or up to date. Although the identification of controlling statutes and regulations is straightforward, internal VHA policies and procedures that define the day-to-day applications of the VA purchased care program appear to have developed piecemeal over time. In theory, staff should have been able to turn to VHA's main operation manual (Manual M-1, "Operations, Part I, Medical Administration Activities)—specifically, Chapter 18 ("Outpatient Care-Fee") and Chapter 21 ("Authorized Non-VA Hospitalization in the United States"). They would also be able to draw guidance from VHA Directive 1601 (VHA, 2013a). However, as VA's Office of Inspector General noted in 2009,

VHA does not have a centralized source of comprehensive, clearly written, current policies and procedures for the Fee Program. Instead, fee supervisors and staff rely on an assortment of resources including the CFR, Manual M-1, other VHA directives, procedure guides that contain some policy, technical guides for the VistA Fee system, training materials, and informal guidance, such as conference call minutes. (VA, Office of Inspector General, 2009, p. 10)

Our own summary review of publicly available VA guidance materials describing purchased care mechanisms is broadly consistent with the foregoing observation. The last published update to Chapters 18 and 21 in Manual M-1 appears to have occurred in 1995. Although much has changed in VA purchased care, and in the broader U.S. health care landscape, in the last 20 years, each of these legacy chapters offers guidance to VHA staff on when, how, and under what terms they may seek to purchase outside health care services. While VHA Directive 1601 (“Non-VA Medical Care Program”) dates from 2013, its short summary of the rules for Veteran eligibility for purchased care services lack the level of detail needed for assuring consistency in practices across VISNs and VAMCs. VA Directive 1663 ("Health Care Resources Contracting-Buying" [VA, 2006]) does provide guidance on contracting practices in purchased care and describes the roles and responsibilities of various local and regional officials in carrying out such contracting, but it has not been updated in nine years.

The shortcomings here are obvious. Despite the fact that there has been significant development in VA purchased care authority and mechanisms since these documents were published, important aspects of VA purchased care practice in 2015 are simply not included in these documents. Consequently, local VA officials seeking relevant purchased care guidance would need to look in more than one place to find it, and some aspects of current VA practice may not be captured in published guidance at all. Moreover, the content of the chapters in Manual M-1 in particular is simultaneously noteworthy for being detailed and fairly technical 
in some respects (e.g., concerning "Invoice Processing" under the "Fee-Basis System"), while leaving considerable discretion to local officials in other respects (e.g., concerning "When to Make Contracts" with non-federal hospitals).

Taken together and in context, even these limited materials suggest that relevant VA guidance pertaining to purchased care is scattered, outdated in parts, and inconsistent in setting clear standards for local VA officials to follow. Our subsequent findings in Chapter Four suggest that local VAMCs have indeed struggled with ambiguity in seeking to develop their own local policies and procedures for purchased care.

\subsection{Veterans Choice Act Authorities and Mechanisms}

With broad bipartisan support, Congress passed the Veterans Choice Act in August 2014 in part to address widely reported issues related to wait times at VA facilities. The act covered many areas related to Veterans' medical care, along with such topics as housing loans, awards and bonuses available to VA employees, educational benefits, medical facility leases, and the removal of certain VA senior executives. The key centerpiece of the act, however, is the provisions that concern the delivery of medical services to Veterans through the use of non-VA entities, a topic primarily covered by Section 101 and implemented through what is popularly known as the Choice program. As its title implies, the act was intended to give Veterans additional options when confronted by lengthy delays in obtaining appointments with VA health care providers or challenged by difficulties in traveling to VA facilities. Reports often portrayed the new act as providing Veterans with markedly expanded discretion to select a local doctor or other caregiver, free from the bureaucratic constraints that had led to a headline-grabbing scandal earlier in the year. ${ }^{33}$

In the sections that follow, we highlight the key changes to VA purchased care triggered by the legislation. We conclude our review of authorities and mechanisms by drawing comparisons across the purchased care initiatives previously discussed and the Choice program. Additional detail on the legal and regulatory provisions relating to non-VA care can be found in Appendix B of this report.

Amendments to the Veterans Choice Act were made by Section 409 of the Department of Veterans Affairs Expiring Authorities Act of 2014 (Pub. L. 113-175), Section 242 of the 2015 Consolidated and Further Continuing Appropriations Act (Pub. L. 113-235), and Section 3 of the 2015 Construction Authorization and Choice Improvement Act (Pub. L. 114-19). Unless noted, these amendments did not significantly change the language or meaning of any of the Veterans Choice Act sections cited here.

Also of interest for this discussion are certain regulations promulgated by VA in response to the Veterans Choice Act's mandate that interim final rules implementing Section 101 be published within 90 days of enactment (Sec. 101(n)). On November 5, 2014, such rules were indeed published in the Federal Register, creating nine new sections in Title 38 of the Code of

\footnotetext{
33 For example, Representative Bradley Byrne of Alabama said in a blog post, "[U]nder most circumstances, our local veterans can now choose to visit a specialist or hospital of their choosing close to home. I cannot overstate how much this freedom of choice will mean to our veterans" (Byrne, 2014).

According to Representative Tim Huelskamp of Kansas, "Thousands of Kansas Veterans who live further than 40 miles from a VA facility - or those who have to wait more than 30 days for care-will soon be able to call their local doctor and get their healthcare needs met" (Huelskamp: Kansas vets to receive their Choice card soon, 2014).
} 
Federal Regulations specifically addressing the Choice program. ${ }^{34}$ We reference the regulations in the November 2014 interim final rule here only when they differ in some meaningful fashion from the language used in the Veterans Choice Act.

\subsubsection{Basic Eligibility}

Under the Veterans Choice Act, a Veteran's eligibility for the Choice program is a function of both the Veteran's status and his or her personal situation (Table 3-5). The status component can be satisfied if the Veteran was already enrolled in VA's patient enrollment system as of August 1, 2014, or if he or she is a recently discharged combat Veteran under certain circumstances (Sec. 101(b)(1)). ${ }^{35}$ The situational component under the act as originally adopted required that the Veteran meet one of the following requirements:

1. The Veteran was unable to schedule an appointment with VA for hospital care or medical services within VHA's "wait-time goals."

2. The Veteran resides more than 40 miles from any VA medical facility.

3. The Veteran resides more than 20 miles from any VA medical facility if his or her state of residency lacks a VA medical facility providing hospital care, emergency services, or inpatient surgical care.

4. The Veteran resides 40 miles or less from any VA medical facility but either is required to travel by air or water or is faced by an "unusual or excessive burden" in accessing those facilities due to "geographic challenges" as defined by VA (Sec. 101(b)(2)). ${ }^{36}$

Some of the conditions attached to situational eligibility have important implications for the size of the eligible Veteran population. Sec. 101(s)(1) of the Veterans Choice Act provides a default definition for VHA's wait-time goal: not more than 30 days from the date a Veteran requests hospital care or medical services from VA. ${ }^{37}$ However, the law also provided an option for VA to use a different standard if it submitted a report to Congress setting forth different wait-time goals within 60 days of the act's passage (Sec. 101(s)(2)). Such a report was submitted on October 3,2014, establishing a standard that, while nominally holding to the default 30-day period, markedly changed the points at which the clock may start to tick:

Unless changed by further notice in the Federal Register, the term 'wait-time goals of the Veterans Health Administration' means not more than 30 days from either the date that an appointment is deemed clinically appropriate by a VA health care provider, or if no such clinical determination has been made, the date a Veteran prefers to be seen for hospital care or medical services. In the event a VA health care provider identifies a time range when care

\footnotetext{
34 This refers to Expanded Access to Non-VA Care Through the Veterans Choice Program, 79 Fed. Reg. 65571-01, November 5, 2014, amending 38 C.F.R., Part 17. Section 101 in the Veterans Choice Act is addressed primarily in 38 C.F.R. $17.1500-17.1540$.

35 A recently discharged combat Veteran presumably would have to sign up for the patient enrollment system before participating in the Choice program.

36 Eligibility based on non-road travel or geographic challenges does not apply to Veterans residing in Guam, American Samoa, or the Philippines.

37 Under VA's interim final rule, the request for care or services from which the 30 days is measured must be affirmatively communicated to a VA employee who is responsible for scheduling appointments or to a VA health care provider (38 C.F.R. 17.1505).
} 
Table 3-5

Key Features of the Veterans Choice Program

\begin{tabular}{|c|c|}
\hline Feature & Description \\
\hline Situational eligibility & $\begin{array}{l}\text { The Veteran ... } \\
\text { (a) was unable to schedule appointment within "wait-time goals"; } \\
\text { (b) resides more than } 40 \text { miles from any VA medical facility; } \\
\text { (c) resides more than } 20 \text { miles from any VA medical facility if state lacks a VA } \\
\text { "standard" level inpatient facility; } \\
\text { (d) is required to travel by air or water to all VA medical facilities within the } 40 \\
\text { mile limit; or } \\
\text { (e) has "unusual or excessive burden" due to "geographic challenges," } \\
\text { "environmental factors," medical conditions, or other VA-defined factors }\end{array}$ \\
\hline Status eligibility & $\begin{array}{l}\text { Veteran must be } \\
\text { (1) already enrolled in VA's patient enrollment system as of Aug. 1, 2014; or } \\
\text { (2) a recently discharged combat Veteran under specific circumstances }\end{array}$ \\
\hline $\begin{array}{l}\text { VA discretion to utilize or pay } \\
\text { for non-VA care }\end{array}$ & $\begin{array}{l}\text { Hospital care and medical services shall be furnished to an eligible Veteran at the } \\
\text { election of such Veteran }\end{array}$ \\
\hline $\begin{array}{l}\text { Provider qualifications or } \\
\text { requirements }\end{array}$ & $\begin{array}{l}\text { Provider must .. } \\
\text { (1) participate in Medicare; } \\
\text { (2) meet or exceed the credentials and licenses required of those within VA; } \\
\text { (3) submit verification of credentials and licenses annually; } \\
\text { (4) have entered into agreements with VA or TPAs of program; and } \\
\text { (5) be "accessible" to the Veteran }\end{array}$ \\
\hline $\begin{array}{l}\text { Veteran input into provider } \\
\text { choice }\end{array}$ & $\begin{array}{l}\text { Presumably limited to providers who have previously entered into agreements } \\
\text { with VA or TPAs of program and who VA judges to be "accessible" to the Veteran }\end{array}$ \\
\hline $\begin{array}{l}\text { Additional Requirements for } \\
\text { Inpatient Treatment }\end{array}$ & Presumably none if Veteran is otherwise eligible \\
\hline $\begin{array}{l}\text { Additional Requirements for } \\
\text { Outpatient Treatment }\end{array}$ & Presumably none if Veteran is otherwise eligible \\
\hline Payments & $\begin{array}{l}\text { Rates are to be negotiated, but may not be more than } \\
\text { (a) Medicare fee schedule rates; } \\
\text { (b) a negotiated rate greater than Medicare rates but only for Veterans residing } \\
\text { in a "highly rural area"; } \\
\text { (c) the rates available under the NVCC formula but only if the Medicare fee } \\
\text { schedule is not applicable; or } \\
\text { (d) an alternative set of rates in certain locations }\end{array}$ \\
\hline Direct payer of provider & Choice contractor \\
\hline $\begin{array}{l}\text { Medical record sharing } \\
\text { requirements }\end{array}$ & Mandated by statute \\
\hline Coverage & National \\
\hline $\begin{array}{l}\text { First year implemented or } \\
\text { authorized }\end{array}$ & 2014 \\
\hline Status & Scheduled to terminate in August 2017 \\
\hline Key statutes or laws & $\begin{array}{l}\text { Pub. L. 113-146, Sec. 101; Pub. L. 113-175, Sec. 409; Pub. L. 113-235, Sec. 242; Pub. } \\
\text { L. 114-19, Sec. } 3\end{array}$ \\
\hline Key regulations & 38 C.F.R. $17.1500-17.1540$ \\
\hline
\end{tabular}

a Health care providers from DoD, IHS, and FQHCs would also be qualified under the Choice program. 
must be provided (e.g., within the next 2 months), VA will use the last clinically appropriate date for determining whether or not such care is timely. The Department anticipates that the Under Secretary for Health periodically will consider changes to the wait-time goals of the Veterans Health Administration as appropriate. (VA, 2014c; see also 79 Fed. Reg. 62519-62520)

As such, the standard for situational eligibility under the Veterans Choice Act, if based solely on delay, would first depend on whether a VA provider had made a clinical determination of when necessary medical services or hospitalizations would be appropriate. If no such determination has been made, the clock starts on the Veteran's preferred date of service. ${ }^{38}$ When the determination involves a specific date, the period begins on that date. When the determination involves a range, the period begins on the last day of the range. Under the revised time goals, the original default standard described in the act would be in effect only when there was no clinical determination of time frame and the Veteran requested that the appointment be scheduled for the same day VA was contacted.

Another important question regarding the potential Veteran uptake in the Choice program involves what constitutes a VA medical facility for the purposes of calculating the distance standard. According to the Veterans Choice Act, the "term 'facility of the Department' has the meaning given the term 'facilities of the Department' in section 1701 of title 38, United States Code" (Sec. 2(1)). The statute defines facilities as "(A) facilities over which the Secretary has direct jurisdiction; (B) Government facilities for which the Secretary contracts; and (C) public or private facilities at which the Secretary provides recreational activities for patients receiving care under section 1710 of this title" (38 U.S.C. 1701(4)). Conceivably, this definition could include a parking lot operated by VA, though the Veterans Choice Act narrows the application to "medical facility of the Department." Thus, the VA facility providing medical services or products closest to the Veteran would be the end point in the distance assessment. The key issue here is that the Veterans Choice Act does not distinguish between medical facilities that meet a Veteran's specific needs (in other words, the reason for requesting the appointment) and medical facilities that do not provide the necessary care. ${ }^{39}$ For example, the Veterans Choice Act specifically mentions "a community-based outpatient clinic" as one type of medical facility considered for the 40-mile test. A Veteran who needs hospitalization and inpatient surgery could fail to meet the distance test set forth in Section 101(b)(2)(B) if such a clinic were within 40 miles of his or her residence, even though the closest VA hospital where the surgery could be performed was 100 miles away.

Notably, the July 28, 2014, conference report accompanying H.R. 3230 (the bill that was eventually enacted as the Veterans Choice Act) and jointly issued by the bill's managers in the House and Senate assumed that VA would not use technical proximity to block access to the Choice program if the facility did not provide the necessary services: "The Conferees do not intend the 40-mile eligibility criteria included in this section to preclude veterans who reside less than 40 miles from a VA facility from accessing care through non-VA providers,

\footnotetext{
38 A threshold issue here would be VA's interpretation of the phrase "the date a Veteran prefers to be seen" as used in the interim rule. It is not clear whether such a preference is completely up to the Veteran's discretion (e.g., any day and time that is convenient for the Veteran) or whether it is constrained by the dates and times eligible providers are actually available.

39 In contrast, the corresponding criterion for Veteran eligibility under Project ARCH is the distance from the type of medical facility from which the patient is seeking services.
} 
particularly if the VA facility the veteran resides near provides limited services" (House Report 113-564, 2014, p. 55). Nevertheless, VA has stated that it lacked options under the Veterans Choice Act on the issue of any facility versus a facility that provides the actual care required: "Absent a statutory change, VA does not believe that it has the flexibility to adopt an alternative approach" (VA, 2014c, p. 2).

It should be noted that VA's final interim rule does narrow the definition of medical facility from the potentially broader usage found in the Veterans Choice Act. Currently, 38 C.F.R. 17.1505 states, "VA medical facility means a VA hospital, a VA community-based outpatient clinic, or a VA health care center. A Vet Center, or Readjustment Counseling Service Center, is not a VA medical facility." The comments to the final interim rule noted, "We have included these types of VA facilities because they provide medical care or hospital services that may be provided as part of the Program." However, VA documents routinely refer to a fourth category of medical facility beyond hospitals, community-based outpatient clinics, and health care centers: outpatient clinics that are not community based (for example, the Sierra Foothills Outpatient Clinic in Auburn, California; the Johnson County/Radiation Oncology VA Clinic in Overland Park, Kansas; and the Zachary and Elizabeth Fisher Medical and Dental Clinic in Great Lakes, Michigan). ${ }^{40}$ It is unclear how these facilities would factor into the distance calculations.

At least for calculating distances, medical facility is defined more narrowly in the special case in which a Veteran's state of residence does not have a VA medical facility capable of providing hospital care, emergency care, and inpatient surgical services rated by VA as "standard" in complexity. In such cases, a 20-mile criterion is used, and the facility must meet the hospital/emergency/standard surgical competence test. However, the Veteran's specific need is not a consideration here with regard to facility type, and, moreover, the 20-mile rule is likely to affect only a small percentage of the Veteran population. ${ }^{41}$

How the distance between residence and facility is measured is also critical to the size of the eligible Veteran pool.42 The Veterans Choice Act did not describe how to calculate mileage from a Veteran's residence for the purpose of determining Choice eligibility, only that the test involves varying criteria, such as "more than 40 miles," "more than 20 miles," or "40 miles or less." The July 28, 2014, conference report for H.R. 3230 stated that it was "the Conferees' expectation that VA will use geodesic distance, or the shortest distance between two points" (House Report 113-564, 2014, p. 55). VA's interim final rule met that expectation by promulgating regulations related to the Veterans Choice Act using straight-line distance (i.e., "as the crow flies") (38 C.F.R. 17.1510(e)). Such an interpretation might have meant that a Veteran who lived 70 miles driving distance from a VA medical facility would not satisfy the test if the

\footnotetext{
40 In California, for example, there are nine VAMCs, one VA health care system, 36 community-based outpatient clinics, and 24 facilities characterized simply as "outpatient clinics." Of the latter group, only one is clearly a health care center. Presumably, the outpatient clinic group excluding any health care centers would not qualify as "a VA hospital, a VA community-based outpatient clinic, or a VA health care center.” See VA (2010).

41 Only Alaska, Hawaii, and New Hampshire are currently without any VA inpatient surgical facilities rated at standard complexity (VHA, 2014a).

42 A threshold issue here is what constitutes a Veteran's “residence.” Although the Veterans Choice Act does not address this issue, VA's interim final rules define it as the legal residence or personal domicile at the time the Veteran is seeking external medical care through the Choice program (38 C.F.R. 17.1505).
} 
facility was 30 miles away by helicopter. ${ }^{43}$ Reacting to criticisms from multiple quarters, VA announced on March 24, 2015, that it intended to issue an interim rule so that "this criterion will change to the driving distance calculation between the Veteran's home and the nearest VA medical facility," adding, "VA believes that revising the calculation will still be in the spirit of the law and allow improved access for Veterans" (VA, 2015c). It did so a month later, announcing that it would use driving distance to determine eligibility for the Choice program (VA, 2015d). In May 2015, Congress eliminated any remaining uncertainty about this aspect of the 40-mile rule calculation with an amendment to the Veterans Choice Act calculating the mileage "based on distance traveled" (Pub. L. 114-19, Sec. 3(a)(1)).

Finally, VA was originally given considerable discretion in how it would define "geographic challenges" with regard to Veteran eligibility based on "unusual or excessive burden" in accessing medical facilities 40 miles or less from a Veteran's residence. ${ }^{44}$ The interim final rule essentially equated "geographic" with geological or topological—specifically, "a body of water (including moving water and still water) or a geologic formation that cannot be crossed by road" (38 C.F.R. 17.1510(b)(4)). The May 2015 congressional amendment to the Veterans Choice Act retained the geographical challenge test for eligibility based on burden, but it also expanded the potential factors to include environmental ones ("such as roads that are not accessible to the general public, traffic, or hazardous weather"), a medical condition ("that impacts the ability to travel"), and any "other factors, as determined by the Secretary" (Pub. L. 114-19, Sec. 3). The change broadened the range of possible interpretations available to VA, and, conceivably, the time needed to travel to VA facilities on clogged urban highways or by public transit could be taken into account. ${ }^{45}$

\subsubsection{Elections and Providers}

The Veterans Choice Act intends that when a recently separated combat Veteran signs up for the patient enrollment system, when a Veteran is unable to schedule an appointment within the wait-time goal maximum, or when a Veteran becomes eligible under criteria related to travel, he or she be provided with information about the availability of Choice-related care (Sec. 101(g)). Once eligible, a Veteran, at his or her election, can receive the types of hospital care and medical services that would normally be furnished by VA via health care providers participating in the Medicare program, any FQHC (for example, a nonprofit community health center), DoD, or IHS (Sec. 101(a)(1)). ${ }^{46}$ As indicated previously, the process would be managed through VA's existing NVCC program, and VA is charged with ensuring that the Veteran's appointment with the external provider occurs within VA's wait-time goals (Sec. 101(a)(3)).

\footnotetext{
43 The commentary in the supplementary information section of the interim final rule indicated that there was "strong support for this interpretation" because the conference report accompanying the Veterans Choice Act noted that in "calculating the distance from a nearest VA medical facility, it is the Conferees' expectation that VA will use geodesic distance, or the shortest distance between two points" (79 Fed. Reg. 65577, citing House Report 113-564, 2014, p. 55).

44 “[A]s determined by the Secretary," per Section 101(b)(2)(D).

45 The Assessment B report examines many elements related to Veterans' geographic access to care, and how various alternative standards affect determinations of access (RAND Health, 2015b).

46 FQHCs are facilities that qualify for enhanced reimbursement and other benefits under Medicare and Medicaid. They must meet several service and quality criteria, including offering a sliding fee scale, engaging in continuous quality assurance, and providing services to underserved populations (Health Resources and Services Administration, n.d.).
} 
Under the original language of the Veterans Choice Act, Veterans who are unable to obtain a timely appointment with a VA provider have the following options: (1) keep the appointment despite the delay, (2) be placed on a prioritized waiting list for available VA services, or (3) elect to use external providers and obtain an authorization to receive care for "for a period of time specified" by VA (Sec. 101(c)(1), as modified by Pub. L. 113-175, Section 409(a)(1)(A)). If the eligible Veteran chooses the external provider option, he or she also has the ability, at least in theory, to select a specific provider (Sec. 101(a)(2)). The Veterans Choice Act's original language did not grant this option to Veterans who are eligible for external care solely on the basis of distance and other travel challenges. VA's final interim rule was intended to fill "this gap in the law by providing these Veterans the same opportunity to select a particular provider as Veterans eligible based upon the wait-time standard. Eligible Veterans may nevertheless choose not to make such a selection, and in such a situation, those Veterans will be referred to an eligible entity or provider identified by VA.” Accordingly, 38 C.F.R 17.1515(a) makes no distinction between time- and travel-based Veterans when it comes to available elections.

While the Veterans Choice Act (as interpreted by the interim final rule) appears to suggest that the specific choice of provider is essentially up to the Veteran as long as the provider falls under one of the four allowed categories, in actuality, a much narrower set of external health care resources is available. ${ }^{47}$ Focusing here on private providers and FQHCs (rather than DoD or IHS providers), participation in Medicare is an initial requirement. Another requirement is that the provider must meet or exceed the credentials and licenses of VA providers and submit verification of these qualifications annually (Sec. 101(i)).

The provider pool is even more limited than the set of health care professionals who accept Medicare and who possess the necessary qualifications. An important characteristic of the Veterans Choice Act is the existence of "agreements" between VA and providers, suggesting that some preexisting legal relationship must be in place before a provider can render services to an eligible Veteran and expect reimbursement (Sec. 101(d)(1)). ${ }^{48}$ Such an agreement anticipates that the provider would be willing to accept no more than standard Medicare program reimbursement rates for Choice-related services, except in situations involving Veterans residing in counties with a population density under seven persons per square mile (Sec. 101(d)(2) (B)). The technical amendments to the Veterans Choice Act through the Department of Veterans Affairs Expiring Authorities Act of 2014 added to Section 101(d)(1)(A) an explicit preference for using existing agreements with providers before entering into new ones:

Before entering into an agreement pursuant to this subparagraph, the Secretary shall, to the maximum extent practicable and consistent with the requirements of this section, furnish such care and services to such veterans under this section with such entities pursuant to sharing agreements, existing contracts entered into by the Secretary, or other processes available at medical facilities of the Department. (Pub. L. 113-175, Sec. 409(a)(2))

\footnotetext{
47 VA's interim final rule states that while an eligible Veteran may specify a desired non-VA entity or provider for Choice services, in actuality, the entity or provider must meet certain requirements set forth in the regulations to be eligible to participate in the program (38 C.F.R. 17.1515(b)). If the Veteran does not specify an eligible provider or entity, VA will make the decision.

48 Indeed, the title of Section 101 describes its purpose as "[e]xpanded availability of hospital care and medical services for veterans through the use of agreements with non-Department of Veterans Affairs entities."
} 
Given that VA already had extensive contracts with TriWest and Health Net for PC3, the amended language opened the door to having these two TPAs effectively become the functional administrators of the Choice program. ${ }^{49}$ If a health care provider wishes to be classified as Choice-eligible, it would have to either join an existing TriWest or Health Net network or enter into a special provider agreement with a Choice TPA. At least for the short run, a Veteran's ability to select a specific provider would, as a practical matter, be limited to those already a part of one of the existing networks.

The interim final rule addressed another aspect to Choice program provider eligibility not discussed at length in the Veterans Choice Act: accessibility from the perspective of the Veteran (38 C.F.R. 1530(c)). The Veterans Choice Act indicated only that Veterans eligible due to appointments exceeding wait-time goals "may select a provider . . . from among the entities ... that are accessible to the veteran," without actually defining what accessibility involved (Sec. 101(a)(2)). Besides expanding the scope for this section to include Veterans eligible due to distance, the interim final rule noted that the amount of time the Veteran would have to wait for an appointment with a provider, the provider's qualifications, and the distance from the Veteran's residence to the provider's facilities would all be taken into account in VA's unilateral decision about whether a provider is appropriately accessible to the Veteran. The interim final rule does not specify the exact criteria for making such assessments, though the comments to the rule indicate that "VA will consider these factors together," balancing competing interests and "the preference of the veteran," and make "accessibility determinations on a case-by-case basis” (79 Fed. Reg. 65580).

Prior to receiving any external care, the Veteran must inform VA of any other medical benefit plans, contracts, or agreements (other than through Medicare, Medicaid, or TRICARE) that might provide coverage (Sec. 101(e)(1), (4)). VA, in turn, discloses these details to the external provider, along with information about any non-service-connected disability that could result in payments or benefits from collateral sources (such as workers' compensation, insurance recoveries related to motor vehicle accidents, victim compensation funds, or health care plans) (Sec. 101(e)(2), (3)(C)). Such information is required because the external provider is responsible for first seeking reimbursement from collateral sources or health plans, and the Choice program is secondarily responsible to the extent that the rate does not exceed the allowable amounts (Sec. 101(e)(3)(A), (B)). The act does not address the issue of primary or secondary responsibility when the payments or benefits are related to a service-connected disability, but the interim final rule states that VA is solely responsible for covering hospital care or medical services for a service-connected disability (38 C.F.R. 17.1535(b)(2)).

The final interim rule also aligned the Veterans Choice Act's provisions with VA's existing but informal policy of not requiring copays from a Veteran at time or point of service but, rather, only after VA has processed provider billings and determined the net amount owed (38 C.F.R. 17.108(b), (c); 38 C.F.R. 17.110(b)(4), (b)(3)).

\subsubsection{Scope of Care}

A Choice authorization to receive care at non-VA facilities can cover more than just a single visit to an external doctor or hospital. The Veterans Choice Act requires VA to allow a Veteran to obtain "hospital care and medical services from [the non-VA] health care provider through the

49 Every state and the District of Columbia is already assigned to either TriWest or Health Net. 
completion of the episode of care," which includes "all specialty and ancillary services deemed necessary as part of the treatment recommended in the course of such hospital care or medical services" (Sec. 101(h)). The Veterans Choice Act does not define episode of care, though it does limit the provision of care from any health care provider under a single Choice authorization to a maximum of 60 days (Sec. 101(h)). Thus, whatever the Veterans Choice Act considered an episode of care to be, Choice would only cover the first 60 days thereof without follow-up authorizations. See Chapter Five for a more detailed discussion of the legal contours of episodes of care as currently defined by VA authority. See also Chapter Four for a discussion of how this concept is applied locally and its practical implications for purchased care administration.

\subsubsection{Program Application}

Choice is a very recent initiative. Despite a clear congressional desire to roll out the program as a fully featured option for Veterans within a few months of the act's passage, key rules and agency practices are still evolving and undoubtedly will continue to do so for the foreseeable future. The April 2015 decision to measure the distance between a Veteran's residence and a VA medical facility according to highway mileage provides an excellent example of the dynamic nature of the program's implementation. Materials describing how Choice works in practice may be out of date as soon as they are made available, and the specific policies and procedures used by one VA location may differ from those used by another as the system moves toward a unified, stable approach. That said, we can nevertheless describe in broad terms our interpretation of how the Choice program operates.

The process begins with a VA health care provider deciding that a course of treatment or a particular service is needed. A Veteran who wishes to take advantage of the Choice program initially calls a hotline that connects him or her with a representative of either TriWest or Health Net (depending on the location). At that point, the representative will confirm basic eligibility according to distance, appointment delay, or other criteria. ${ }^{50}$ If eligibility is confirmed, the types of services available depend on the type of eligibility. Veterans who meet only the wait-time criteria can use Choice solely for the service that could not be scheduled within the time standard. Veterans who meet distance or other residence-based criteria can use Choice providers for any services that are "clinically necessary" (VA, 2014d). The TPA determines clinical necessity (VHA, 2015a, p. 9). The Veteran is then asked for the name and address of his or her preferred non-VA provider (if one is preferred), though, ultimately, that choice is limited to participating providers. The TPA representative then formally authorizes the referral and schedules the appointment with a Choice provider.

Providers who are interested in becoming eligible for Choice are informed that "VA has expanded its Patient-Centered Community Care (PC3) contracts with Health Net Federal and TriWest Healthcare Alliance to include implementing the Choice Program," noting that Choice "supplements PC3 and allows coverage for more services for eligible Veterans and provides Veterans more flexibility in their choice to receive care in the community or through VA" (VA, 2014e). They are told that existing members of either PC3 network are already eligible to participate in Choice. Moreover, if a provider is interested in joining a PC3 network (and thus becoming automatically eligible for Choice participation), it must execute a contract with TriWest or Health Net. If it would prefer to remain independent from a PC3 network, it must

50 Some of the information used by TPAs to confirm Veteran eligibility is periodically received from VHA. 
nevertheless execute an out-of-network provider agreement with one of the two TPAs. Such agreements require the provider to meet Medicare conditions for participation and coverage, accept Medicare rates, and submit a copy of the Veteran's medical record to the TPA after services are rendered.

Review of the Health Net and TriWest web portals for provider inquiries suggests that there is little pressure to choose a PC3 contract rather than a Choice provider agreement and that the process for executing a provider agreement is not particularly onerous. ${ }^{51}$ That said, the selected path to provider eligibility (via a PC3 network agreement or an out-of-network provider agreement with a TPA) does have important economic implications. Recall that PC3 network providers are paid about 3 to 8 percent less than full Medicare reimbursement rates. Presumably, those operating independently under a Choice out-of-network provider agreement (assuming that less-than-Medicare reimbursement rates were not required to enter into the agreement) would incur no such loss. ${ }^{52}$ It should be noted that the rules for calculating rates under Choice vary depending on whether a contract or provider agreement is in effect, the location of the services provided, and a number of other factors. For example, there is a specific authorization for the use of "the Alaska Fee Schedule of the Department of Veterans Affairs" for the Choice Program in Alaska, and in states like Maryland, where an all-payer model agreement between the state and CMS is in place, the reimbursement rates are those in effect under the agreement. ${ }^{53}$

Not surprisingly, given its connection to PC3 administration, the Choice process from the provider's perspective is similar to that under PC3. An eligible provider (either selected by the Veteran or assigned by the TPA) receives the care authorization from the TPA (TriWest Healthcare Alliance, n.d.). When the authorization is based on excessive wait times, it is accompanied by clinical/consultation information provided by VA; when patient eligibility is based on distance, supplementary information is included. Unlike PC3 and other VA purchased care programs, the provider is responsible for initially billing any health plan or other collateral source for initial reimbursement. Any residual claim (and any claim without another payment source that could be considered primary) would be then presented to the TPA or the TPA's payment processing vendor. The Veterans Choice Act specifically requires providers to supply VA with electronic medical records describing the treatments rendered (Sec. 101(l)). In addition, provider agreements with the network contractor are likely to require the submission of medical records prior to payment for services rendered. ${ }^{54}$

It is important to remember that the Choice program is a stopgap approach taken to address the circumstances that led to the passage of the Veterans Choice Act. In the words of VA Secretary Robert A. McDonald, "The Choice Program is a new, temporary benefit allowing some Veterans to receive health care in their communities rather than waiting for a VA appointment or traveling to a VA facility" (McDonald, 2014b). Moreover, it is a supplement

\footnotetext{
51 For Health Net's portals, see Health Net Federal Services (n.d.-b, n.d.-c, \& n.d.-d). For TriWest's, see TriWest Healthcare Alliance (2014, 2015a, \& 2015b).

52 A sample Health Net Choice program provider agreement-presumably one that would not be required for health care professionals and facilities already associated with Health Net through the PC3 program-indicates that the default rate of reimbursement would be "Rate Agreed Upon: 100\% of Medicare rates," and, when there is no published Medicare rate, it would be "Rate Agreed Upon: 100\% of the VA fee schedule rate" (Health Net Federal Services, 2014).

53 See, for example, Pub. L. 113-235, Sec. 242.

54 See, for example, Section 9 in Health Net's participation agreement (Health Net Federal Services, 2014).
} 
to existing VA purchased care authorities and not a replacement. As the commentary to VA's regulations implementing the Veterans Choice Act specifically noted,

Nothing in this rulemaking modifies VA's existing authority to furnish non-VA care, such as under 38 U.S.C. 1703, 1725, 1728, 8111, or 8153. The requirements of those statutes and their implementing regulations continue to apply, and VA will use those authorities when appropriate. Any veteran currently receiving non-VA care who is eligible for the Program will be provided the opportunity to elect to participate in the Program or to continue being provided care under VA's other authorities. (79 Fed. Reg. 65571)

\subsubsection{Other Changes to VA Purchased Care Triggered by the Veterans Choice Act 3.2.5.1. Lines of Authority}

The Veterans Choice Act addressed a number of areas that relate to the use of external medical care providers and facilities not necessarily tied to the Choice program. One involves the lines of authority for all VA purchased care. Traditionally, VHA's Chief Business Office had nominal control over all aspects of care provided externally, while VISNs maintained operational authority and responsibility. Nevertheless, it was the VAMCs that handled the day-to-day administration of purchased care, with staff at each center essentially having an independent hand when authorizing, managing, and paying for such care. The arrangement was said to provide "flexibility to meet local needs," though some have commented that the "decentralized nature of this program produces inefficiency" (AMVETS, Disabled American Veterans, Paralyzed Veterans of America, \& VFW, 2013, p. 168). Some critics were more direct in their assessments of the existing arrangement, noting that this "highly decentralized mode of operation across VA hospitals and networks is a primary factor in the [VA purchased care] program's inefficient operations and high payment error rates," which was marked by significant variation in "organizational alignment, staffing, grade profiles, education, training, proficiency certification, performance standards and performance expectations" (National Academy of Public Administration, 2011). In addition, because payments to non-VA providers came out of VAMC budgets, the conference report accompanying the Veterans Choice Act noted that there were built-in disincentives when authorizing the use of external care, a situation that "in some cases has led to the determination of eligibility as subject to facility budget considerations rather than to the determination of what is best for the veteran” (House Report 113-564, p. 60).

Section 106 of the Veterans Choice Act was an attempt to address these concerns. Within a few months of the act's passage, VA was required to transfer all authority to pay for externally provided care from the VISNs and VAMCs to VHA's Chief Business Office (Sec. 106(a) (1)). VISN and VAMC employees who were tasked with claims processing, appeals, clinical reviews, and other functions associated with VA purchased care programs would be transferred (at least on paper) to an independent division of VHA's Chief Business Office known as "Chief Business Office Purchased Care." 55 To reduce direct financial disincentives for VAMC provider staff when making external referrals, Section 106(b) provided that all funding for VA purchased care would be handled by the Chief Business Office rather than the VISNs and VAMCs where the services would actually be obtained.

55 It appears that some NVCC care coordination functions will remain at local VAMCs and other VHA facilities. 


\subsubsection{Prompt Payment}

Some criticisms lodged against VA purchased care programs prior to the passage of the Veterans Choice Act related to delays in processing claims and reimbursing external providers. Congress moved to address these criticisms through the act.

In theory and more broadly, the Prompt Payment Act (codified at 31 U.S.C. 3901-3907) is designed to discourage federal agencies from such tardiness when they owe monies under federal contracts. The Prompt Payment Act requires the government to pay valid invoices on commercial obligations that are properly submitted within specific time frames; if the agency fails to do so, it must pay interest to the contractor and, in some instances, penalties. ${ }^{56}$

While some federal agencies fall outside of these requirements, VA does not. Internal guidance acknowledges VA's responsibilities under the act: "VA will follow the Prompt Payment Act for accepting goods, establishing the payment due date, and calculating any applicable discounts or interest required for procurement contracts, vendor payments, and utility payments per 5 C.F.R. Part 1315 and other regulatory guidance" (VA, 2013a, p. 2). However, VA has traditionally interpreted the applicable statutes and regulations as exempting purchased care invoices from interest and penalties when payment is delayed. VA's position was that the Prompt Payment Act "applies to payments incurred as the result of a procurement contract," which means "any enforceable agreement, rental and lease agreement, purchase order, delivery order, requirements-type (open-ended) service contract, or blanket purchase agreement between VA and a vendor" (VA, 2013a, p. 19). While the definition of a procurement contract is broad and would presumably cover instances in which VA purchased care is acquired through competitive bids for long-term services (such as contracting for establishing one of the PC3 networks), VA nevertheless asserted that payments "for medical and dental services which fall under non-VA care and are not covered in a contract or sharing agreement" are specifically exempt from these protections (VA, 2013a, p. 20). Under this view, an individual authorization for purchased care under 38 U.S.C. 1703 (and the subsequent invoice VA would receive from the non-VA provider or facility) would not trigger Prompt Payment Act requirements.

The Veterans Choice Act took steps to clearly tie Prompt Payment Act requirements to VA purchased care invoicing. Section 105(a) states that it is the "sense of Congress" that VA comply with the prompt payment regulations set forth at 5 C.F.R. 1315 et seq., though it continued to characterize the underlying relationship as contractual. ${ }^{57}$ Moreover, Section 106(a) required VA (presumably VHA's Chief Business Office) to establish "a system to process and pay claims" from non-VA providers and mandated that the claims system be compliant with the Prompt Payment Act statutes.

\subsection{Key Themes in Pre- and Post-Choice Purchased Care}

In this section, we examine the four current methods for acquiring external health care for Veterans outside of emergency settings: three programs that rely primarily on established provider networks (Project ARCH, PC3, and the Choice program) and one "fee-for-service" mechanism

\footnotetext{
56 Regulations implementing the act are found at 5 C.F.R. 1315.1-1315.20. The Assessment I report, on business processes, details the issues surrounding these interest penalty payments (Grant Thornton, 2015).

57 Prompt Payment Act regulations would come into play only with regard to "health care pursuant to contracts entered into with non-Department of Veterans Affairs providers."
} 
that can essentially utilize any eligible health care professional or facility (traditional purchased care). Note that the descriptions of these programs reflect our best assessment of how they work in practice, not simply what has been legally mandated by applicable statutes and regulations. The descriptions focus on services provided by physicians and inpatient facilities, as other types of services and products - such as clinical laboratory work, ambulances, dialysis, outpatient facilities, anesthesia, dental, pharmaceuticals, and ambulatory surgical centers-may operate under special rules for calculating payments and other criteria that would significantly increase the complexity of any cross-program comparison.

The basic statutory requirement for providing hospital, nursing, and domiciliary care for Veterans at VA facilities can be found in 38 U.S.C. 1710. That statute directs the VA Secretary to furnish certain types of care to specific classes of eligible Veterans (e.g., those with serviceconnected disabilities) and grants discretionary authority to the Secretary for providing medical care contingent on the availability of resources and facilities. ${ }^{58}$

With this mandate to provide care at VA facilities as background, the traditional authority for going outside VA-38 U.S.C. 1703-establishes the authority by which the Secretary "may contract with non-Department facilities" to furnish certain types of medical care and services (Table 3-6). The interplay of the two statutes-one mandating care at VA facilities for some groups of Veterans and one permitting contractual arrangements to provide care at non-VA facilities - is the foundation for VA's current and historical programs for externally provided care.

A key point on the interaction between 38 U.S.C. 1703 and 1710 is important to recognize. Section 1710 includes a mandate that "the Secretary shall furnish hospital care and medical services which the Secretary determines to be needed," particularly to Veterans in specified groups. One question that arises is, how does the statutory mandate for VA to provide care under Section 1710 interact with the Secretary's discretion to purchase services under Section 1703? The answer is complicated. When read together, these two statutory provisions imply that for Veterans entitled to receive care under Section 1710, the Secretary has an obligation to provide that care, and if unable to do so through VA, the Secretary would then presumably have an obligation to exercise his discretion to purchase care from the outside. However,

Table 3-6

VA Discretion in Key Purchased Care Programs

\begin{tabular}{ll}
\hline Program & \\
\hline Traditional purchased care & VA may employ if eligibility criteria are met \\
ARCH & $\begin{array}{l}\text { VA shall provide covered health services to eligible Veterans (if electing) through } \\
\text { ARCH provider contracts (assuming qualified providers are available) }\end{array}$ \\
PC3 & Same as for traditional purchased care \\
Choice & $\begin{array}{l}\text { Hospital care and medical services shall be furnished to an eligible Veteran at the } \\
\text { election of such Veteran }\end{array}$ \\
\hline
\end{tabular}

\footnotetext{
58 Specifically, the statute requires the Secretary to "furnish hospital care and medical services which the Secretary determines to be needed to any veteran for a service-connected disability; and to any veteran who has a service-connected disability rated at 50 percent or more" (38 U.S.C. 1710(a)(1)(A and B)). In addition, " the Secretary may, to the extent resources and facilities are available, ... furnish hospital care, medical services, and nursing home care which the Secretary determines to be needed" (38 U.S.C. 1710(a)(3)).
} 
the wording of both statutes gives the Secretary discretion in making threshold judgments, including the determination of need for care under Section 1710 and VA's inability to provide care directly under 1703. Whether in practice VA has fully met this obligation in the way that it historically carried out purchased care, however, is open to debate. ${ }^{59}$

Choice moves the pointer ever further, with a clear mandate upon VA to utilize non-VA resources when certain conditions are met. However, as our earlier description of the regulatory environment in which Choice operates suggested, that "shall" comes with important modifiers in terms of who can be used as providers and the circumstances in which the external care will be provided. Note that Choice was not groundbreaking in regards to providing the Secretary with an unambiguous charge to utilize purchased care under specific conditions; the congressional authority establishing Project ARCH contained equally strong language, albeit applicable only for a fraction of the Veteran population.

As Table 3-7 suggests, the rules for Veteran eligibility across all four programs are a complicated mix of distance, time, medical conditions, travel challenges, issues related to local internal VA capabilities, issues related to statewide VA facility types, and Veteran residency. Navigating this jigsaw puzzle of rules would be difficult enough for administrative law attorneys, but for a Veteran whose primary concern is receiving adequate care on a timely basis, and not legal scholarship, the challenges would be formidable. Project ARCH has the least ambiguous (from the perspective of the Veteran) definition of what constitutes eligibility (requiring a certain amount of driving time depending on the facility desired), and traditional purchased care under Section 1703 is the most ambiguous (requiring knowledge of VA's internal ability to furnish economical care). Some of Choice's rules regarding eligibility are straightforward, but, given the current debate over what constitutes a "medical facility" for the purpose of measuring distance, there is still some confusion even among well-informed stakeholders.

Veterans are clearly provided with greater discretion to choose a provider under the Choice program than under the other three purchased care programs (Table 3-8), but, given that the provider pool is essentially restricted to those with preexisting relationships with the TPAs administering Choice, assertions made at the time of the act's passage that eligible Veterans could go to any doctor of their choosing markedly overstated the actual situation. This condition could change with the continued rollout of Choice, though the VA-defined requirement of "accessibility" could further narrow Veteran discretion.

These programs also differ dramatically with regard to what providers might receive for treating Veterans (Table 3-9). As discussed in Chapter Four, these differences may play a significant role in program uptake, if indeed the payment rules reduce the pool of available providers and services in a region. There does appear, however, to be some flexibility built into the rules, and, ultimately, provider reimbursement levels may be driven more by market forces than statutory and regulatory mandates.

The statutory and regulatory references described here suggest several potential reasons for allowing Veterans to obtain care outside of VA (Table 3-10). In some cases, the underlying objective originates with VA, such as when it considers the use of outside providers to be in its economic self-interest or a way to avoid having to develop a capacity that may have little ongo-

\footnotetext{
59 As we noted in the introduction to this report, the lead-up to the passage of the Veterans Choice Act in 2014 involved a crisis in access to services through some VA facilities. Presumably, some or all of the Veterans denied timely access to care ought to have been given access to purchased care as an alternative, based on a superficial reading of Sections 38 U.S.C. 1703 and 1710 .
} 
Table 3-7

Eligibility in Key Purchased Care Programs

\begin{tabular}{|c|c|c|}
\hline Program & Situational Eligibility Rules & Status Eligibility Rules \\
\hline $\begin{array}{l}\text { Traditional } \\
\text { purchased } \\
\text { care }\end{array}$ & $\begin{array}{l}\text { VA not capable of furnishing ... } \\
\text { (1) economical care/services because of } \\
\text { "geographical inaccessibility" or (2) required } \\
\text { care/services }\end{array}$ & $\begin{array}{l}\text { Many conditions and situations qualify, but two } \\
\text { may be most commonly utilized: (1) treatment } \\
\text { of any service-connected disability/condition } \\
\text { or ( } 2 \text { ) treatment of any disability if }(a) \text { Veteran } \\
\text { was previously seen by VHA providers and (b) } \\
\text { non-VA resources are required to complete } \\
\text { treatment }\end{array}$ \\
\hline $\mathrm{ARCH}$ & $\begin{array}{l}\text { (1) If seeking primary care, must reside more } \\
\text { than } 60 \text { min. driving time to nearest VA primary } \\
\text { health care facility; ( } 2 \text { ) if seeking acute hospital } \\
\text { care, must reside more than } 120 \text { min. driving } \\
\text { time to nearest VA acute hospital care facility; } \\
\text { or ( } 3 \text { ) if seeking tertiary care, must reside } \\
\text { more than } 240 \text { min. driving time to nearest VA } \\
\text { tertiary care facility. }\end{array}$ & $\begin{array}{l}\text { Veteran must be (1) residing in a pilot site } \\
\text { and ( } 2 \text { ) currently enrolled for VA health care. } \\
\text { Services required must be offered by an } \mathrm{ARCH} \\
\text { contracted provider }\end{array}$ \\
\hline PC3 & Same as for traditional purchased care & $\begin{array}{l}\text { Same as for traditional purchased care, though } \\
\text { specialty required must also be one offered by a } \\
\text { PC3 contracted provider }\end{array}$ \\
\hline Choice & $\begin{array}{l}\text { The Veteran ... (a) was unable to schedule } \\
\text { appointment within "wait-time goals"; (b) } \\
\text { resides more than } 40 \text { miles from any VA medical } \\
\text { facility; (c) resides more than } 20 \text { miles from any } \\
\text { VA medical facility if state lacks a VA "standard" } \\
\text { level inpatient facility; (d) is required to travel } \\
\text { by air or water to all VA medical facilities within } \\
\text { the } 40 \text { mile limit; or (e) has "unusual or excessive } \\
\text { burden" due to "geographic challenges," } \\
\text { "environmental factors," medical conditions, or } \\
\text { other VA-defined factors }\end{array}$ & $\begin{array}{l}\text { Veteran must be (1) already enrolled in VA's } \\
\text { patient enrollment system as of Aug. 1, 2014, or } \\
\text { (2) a recently discharged combat Veteran under } \\
\text { specific circumstances }\end{array}$ \\
\hline
\end{tabular}

Table 3-8

Veteran Input into Provider Choice in Key Purchased Care Programs

\begin{tabular}{ll}
\hline Program & \\
\hline Traditional purchased care & None specifically authorized \\
ARCH & Presumably limited to providers within ARCH network \\
PC3 & $\begin{array}{l}\text { Presumably limited; PC3 contractor sets up appointment with provider within } \\
\text { network }\end{array}$ \\
Choice & $\begin{array}{l}\text { Presumably limited to providers who have previously entered into agreements } \\
\text { with VA or TPAs of program and who VA judges to be "accessible" to the Veteran }\end{array}$ \\
\hline
\end{tabular}

ing utility. In other cases, it is the Veteran's preferences or interests that are at stake, such as the inconvenience or expense of accessing medical care in highly rural areas. The line between the two sets of interests is not a clear one, and even when an authority allows the Veteran to see a much closer non-VA physician, VA's interests are nevertheless in play, because VA would ultimately be responsible for covering the costs of traveling to a VA facility.

What is clear from Table 3-10 is that VA has never been given unfettered discretion by Congress to purchase external health care. In every instance, the authority to do so is limited in some way, sometimes by objective criteria (such as minimum distance from the closest VA medi- 
Table 3-9

Payments and Payers in Key Purchased Care Programs

\begin{tabular}{|c|c|c|}
\hline Program & Payment Rules & Payer Rules \\
\hline $\begin{array}{l}\text { Traditional } \\
\text { purchased } \\
\text { care }\end{array}$ & $\begin{array}{l}\text { If inpatient, "prospective payment system similar to that used in the Medicare } \\
\text { program"; in practice this means (1) the Non-VA hospital price rate or ( } 2 \text { ) the } \\
\text { VA cost-to-charge rate. If outpatient, (1) the amount described on any contract } \\
\text { or negotiated agreement, or ( } 2 \text { ) if no contract or agreement exists but there } \\
\text { is an applicable "Medicare rate," the lower of (a) the "Medicare rate," (b) the } \\
\text { "repricer" rate, or (c) amount the provider bills general public; (3) If no contract } \\
\text { or agreement exists and there is no applicable "Medicare rate," the lower of (a) } \\
\text { the local VA fee schedule, (b) the "repricer" rate, or (c) amount the provider bills } \\
\text { general public }\end{array}$ & VA \\
\hline $\mathrm{ARCH}$ & $\begin{array}{l}\text { Reportedly a negotiated percentage of local Medicare rates for four sites } \\
\text { managed by a vendor; full Medicare rates for the site directly contracted with VA }\end{array}$ & $\begin{array}{l}\mathrm{ARCH} \\
\text { contractor or } \\
\text { facility }\end{array}$ \\
\hline PC3 & $\begin{array}{l}\text { Presumably at or below the amounts allowed for traditional purchased care; } \\
\text { reportedly a negotiated percentage of local Medicare rates }\end{array}$ & PC3 contractor \\
\hline Choice & $\begin{array}{l}\text { Rates are to be negotiated, but may not be more than ... (a) Medicare fee } \\
\text { schedule rates; (b) a negotiated rate greater than Medicare rates but only for } \\
\text { Veterans residing in a "highly rural area"; (c) the rates available under the } \\
\text { traditional purchased care formula but only if the Medicare fee schedule is not } \\
\text { applicable; or (d) An alternative set of rates in certain locations }\end{array}$ & $\begin{array}{l}\text { Choice } \\
\text { contractor }\end{array}$ \\
\hline
\end{tabular}

cal facility) and sometimes by narrowing the pool of potential patients (such as Veterans with service-connected disabilities). There are likely many reasons for these legislative constraints, such as controlling costs, discouraging VA from shifting from its traditional role as a specialized health care provider into a health care payer, or ensuring that resources for purchased care are targeted toward specific goals. Whatever the reason, Congress has repeatedly declined to grant VA with unrestricted ability to spend department funds in this area as it sees fit.

Additional layers of constraint on purchased care use are essentially self-imposed by VA. Regulations it has promulgated often serve to more narrowly define the circumstances in which Veterans are eligible to receive care from external sources than what the underlying statutory authority required. Regulations also have been used to place additional restrictions upon the qualifications of providers who might be eligible to deliver such services and to limit the scope and duration of any treatment given during the course of a referral. Ultimately such regulations provide VA with powerful tools to control when, where, and how it utilizes outside medical services.

Given that they have been developed over many decades, it is not surprising that these authorities are marked by an array of eligibility requirements and, sometimes, idiosyncrasies. ${ }^{60}$ Over the years, revisions to the basic authority for purchased care provided by 38 U.S.C. 1703, as well as the expansion of permissible uses of external resources brought about by Project ARCH and the Veterans Choice Act, have created a complex structure for service delivery. Table 3-7 provides a hint of this intricate maze of statute and regulation that has developed over time at least with regard to situational and status eligibility requirements. Navigating that maze is not only a challenge for Veterans, but it can also be a challenge for VA staff, especially given that key sources for guidance do not always reflect the most current legal framework for purchased care.

60 One example is a specific provision in 38 U.S.C. 1703 allowing VA to use non-department facilities when a female Veteran is in need of hospital care. The authorization appears to date back to the 1950s. No similar authority exists for male Veterans. 
Table 3-10

Objectives for Utilizing Purchased Care

\begin{tabular}{|c|c|c|}
\hline Area of Concern & Congressional Approach & Authority Provided \\
\hline $\begin{array}{l}\text { VA does not have expertise or } \\
\text { facilities to provide needed care. }\end{array}$ & $\begin{array}{l}\text { Provide VA with limited discretion } \\
\text { to determine whether it has the } \\
\text { capacity to deliver needed services. }\end{array}$ & $\begin{array}{l}\text { Authorizations issued under } 38 \text { U.S.C. } \\
1703\end{array}$ \\
\hline $\begin{array}{l}\text { VA has expertise or facilities } \\
\text { required, but external provision } \\
\text { would be economically } \\
\text { advantageous to VA. }\end{array}$ & $\begin{array}{l}\text { Provide VA with limited discretion } \\
\text { to determine whether it has the } \\
\text { capacity to deliver needed services } \\
\text { economically. }\end{array}$ & $\begin{array}{l}\text { Authorizations issued under } 38 \text { U.S.C. } \\
1703\end{array}$ \\
\hline $\begin{array}{l}\text { VA has expertise or facilities } \\
\text { required, but wait time for Veteran } \\
\text { would be excessive. }\end{array}$ & $\begin{array}{l}\text { Allow Veteran to use non-VA } \\
\text { resources if an appointment cannot } \\
\text { be scheduled within wait-time } \\
\text { standards. }\end{array}$ & $\begin{array}{l}\text { Eligibility for Choice program based } \\
\text { on whether appointment can be } \\
\text { scheduled within VA-defined time } \\
\text { standards }\end{array}$ \\
\hline $\begin{array}{l}\text { VA has expertise or facilities } \\
\text { required, but Veteran's life or } \\
\text { health requires immediate delivery } \\
\text { of services. }\end{array}$ & $\begin{array}{l}\text { Allow Veteran to use non-VA } \\
\text { resources in emergency situations. }\end{array}$ & $\begin{array}{l}\text { Reimbursements under } 38 \text { U.S.C. } 1725 \\
\text { and } 1728\end{array}$ \\
\hline $\begin{array}{l}\text { VA has expertise or facilities } \\
\text { required, but travel time or effort } \\
\text { for Veteran to access care would be } \\
\text { excessive. }\end{array}$ & $\begin{array}{l}\text { Allow Veteran to use non-VA } \\
\text { resources when he or she meets } \\
\text { objective distance, time, or } \\
\text { geographic criteria. }\end{array}$ & $\begin{array}{l}\text { Qualification under Project } \mathrm{ARCH} \\
\text { for residing more than } 120 \text { minutes } \\
\text { driving time from needed acute care } \\
\text { facility }\end{array}$ \\
\hline $\begin{array}{l}\text { VA has expertise or facilities } \\
\text { required, but Veteran would prefer } \\
\text { alternative provider. }\end{array}$ & $\begin{array}{l}\text { Allow Veteran option of using VA } \\
\text { providers or going outside VA, } \\
\text { but only if certain conditions are } \\
\text { met; offer limited pool from which } \\
\text { providers can be chosen. }\end{array}$ & $\begin{array}{l}\text { Optional use of Choice program } \\
\text { providers under Veterans Choice Act }\end{array}$ \\
\hline $\begin{array}{l}\text { VA has expertise or facilities } \\
\text { required to some degree, but } \\
\text { demand for specific services exceeds } \\
\text { supply. }\end{array}$ & $\begin{array}{l}\text { Allow contracting to augment } \\
\text { available pool of providers. }\end{array}$ & $\begin{array}{l}\text { Agreements under } 38 \text { U.S.C. } 7409 \text { to } \\
\text { purchase services from local medical } \\
\text { schools }\end{array}$ \\
\hline $\begin{array}{l}\text { Use of collaborative arrangement } \\
\text { for sharing resources is believed to } \\
\text { further VA mission. }\end{array}$ & $\begin{array}{l}\text { Permit the use of reciprocal } \\
\text { agreements allowing VA to treat } \\
\text { other entities' patients, and vice } \\
\text { versa. }\end{array}$ & $\begin{array}{l}\text { Sharing agreements with DoD under } \\
38 \text { U.S.C. } 8111\end{array}$ \\
\hline $\begin{array}{l}\text { Development of sustainable/widely } \\
\text { available expertise or facilities } \\
\text { believed to be a less-than-optimal } \\
\text { use of VA resources. }\end{array}$ & $\begin{array}{l}\text { Carve out specific conditions or } \\
\text { treatments for facilitated access to } \\
\text { external resources. }\end{array}$ & $\begin{array}{l}\text { Treatment of children with spina } \\
\text { bifida under } 38 \text { U.S.C. 1813(b) }\end{array}$ \\
\hline
\end{tabular}

This overview of purchased care authorities and mechanisms before and after Choice program implementation demonstrates that existing statutes do provide the Secretary with authority to use a multitude of purchased care options to accomplish the mission of serving Veterans. However, various restrictions on the use of these resources create a convoluted pool of criteria that can limit how external providers are used if VA so chooses. Statutory limitations and VA's interpretive rulemaking could both benefit from clarification to facilitate the more effective and efficient use of VA purchased care. 



\section{Overview of Methods and Data for Authorities and Mechanisms for Purchased} Care in Practice

We assessed barriers and challenges to purchased care in practice by:

- Reviewing documentation from 79 VA facilities, describing their purchased care policies and processes at the local level

- Reviewing relevant VA policy documents and guidance at the national level, as well as related secondary literature

- Conducting and analyzing data from stakeholder interviews

- Analyzing relevant data from the Survey of VA Capabilities and Resources.

As discussed in Chapter Three, VA can purchase care through a series of different mechanisms. Figure 4-1 illustrates the array of purchased care mechanisms in use as of the writing of this report (summer 2015). In Chapter Three, we explained how differences in purchased care programs' key elements create inherent challenges to implementation by VA. This chapter discusses VA purchased care authorities and mechanisms in practice and how the multiple programs for purchasing care may contribute to confusion and inefficiency within VA.

Whereas Chapter Three primarily addressed the federal authorities and mechanisms by which VA purchases care, in this chapter, we focus on challenges in the implementation of purchased care and on the experiences of local VA facilities and personnel in striving to overcome them. We drew on our review of the relevant literature, as well as original data gleaned from stakeholder interviews and the Survey of VA Capabilities and Resources. We also examined the balance between standardization and flexibility in local VAMC and VISN purchased care policies, procedures, and training, drawing on original source materials we received from VA and the Survey of VA Capabilities and Resources. During that process, we identified models that could inform revisions to various local policies in purchased care. This chapter highlights leverage points for policymakers to consider that would help to streamline the administration and practice of purchased care in the future.

\subsection{Practical Challenges in the Administration of Purchased Care}

Several reports have highlighted serious problems with the administration of the traditional VA purchased care programs, including improper payment of fee claims, administrative inefficiencies, and inconsistent procedures (see, e.g., VA Office of Inspector General, 2009, 2010, 
Figure 4-1

Purchased Care Mechanisms in Practice




and 2012). Another criticism leveled was the lack of coordination or care management with regard to Veterans' use of fee care services, potentially leading to inappropriate follow-up care, medication errors, and readmissions (Jones, 2012).

To assess the barriers and challenges to purchased care in practice, we reviewed documentation from 79 VA facilities describing their purchased care policies and processes at the local level. We also reviewed relevant data from the 2015 Survey of VA Capabilities and Resources, which assessed clinically meaningful delays in care for the seven illustrative clinical populations chosen for Assessment B (RAND Health, 2015b) and for primary care. ${ }^{1}$ In addition, we conducted stakeholder interviews and reviewed related literature on local implementation and federal oversight of VA purchased care. Our assessment of purchased care program administration examines eligibility criteria, reimbursement and billing, quality of care, issues with TPAs and provider networks, coordination of care, and centralization and oversight versus local discretion and flexibility.

\subsubsection{Eligibility Criteria and the Hierarchy of Purchasing and Referral Options}

As shown in Figure 4-1, VA obtains (preauthorized) outside care through several channels, including the traditional VA purchased care mechanism, VA partner agencies, Project ARCH, PC3, and Choice. Eligibility for purchased care varies across these pathways. Through NVCC, local medical facilities determine which mechanism to use to purchase care for each patient referred. That determination is based primarily on the Veteran's eligibility for each of the purchased care programs. Table 4-1 summarizes the eligibility criteria for the four main purchased care programs; these criteria are discussed in greater detail in Chapter Three of this report.

As discussed in Chapter Three, Project ARCH is a pilot program offered only in rural VAMCs in VISNs 1, 6, 15, 18, and 19. The pilot is set to end in August 2016. Thus, for most VISNs, both currently and in the long term, ARCH eligibility is not a relevant consideration. However, at present, for Veterans living in the five VISNs participating in the pilot, driving time criteria for participating in ARCH is an additional consideration.

The other purchased care mechanisms have overlapping distance and access eligibility requirements. Under Choice, Veterans who are eligible based on 40-mile access criteria may request purchased care.

As shown in Figure 4-2, there is also a specified hierarchy intended to determine VA health care referrals. Direct VA health care is broadly the option that VHA prefers Veterans to utilize first. Current guidance then directs purchased care referrals first to other federal

Table 4-1

Comparison of Purchased Care Eligibility Across Four Main Programs

\begin{tabular}{|c|c|c|c|c|}
\hline Feature & $\mathrm{ARCH}$ & PC3 & $\begin{array}{c}\text { Traditional Purchased } \\
\text { Care }\end{array}$ & Choice \\
\hline Eligibility & $\begin{array}{l}\text { Driving time to VA } \\
\text { facilities (pilot sites } \\
\text { only) }\end{array}$ & $\begin{array}{l}\text { VA not able to furnish } \\
\text { necessary care }\end{array}$ & $\begin{array}{l}\text { VA not able to furnish } \\
\text { necessary care }\end{array}$ & $\begin{array}{l}\text { Wait time, geographic } \\
\text { distance to VA facilities }\end{array}$ \\
\hline
\end{tabular}

1 See Chapter Two and Appendix D for additional detail on the survey's administration and the questions about purchased care. 
Figure 4-2

Hierarchy for VA Care Referrals

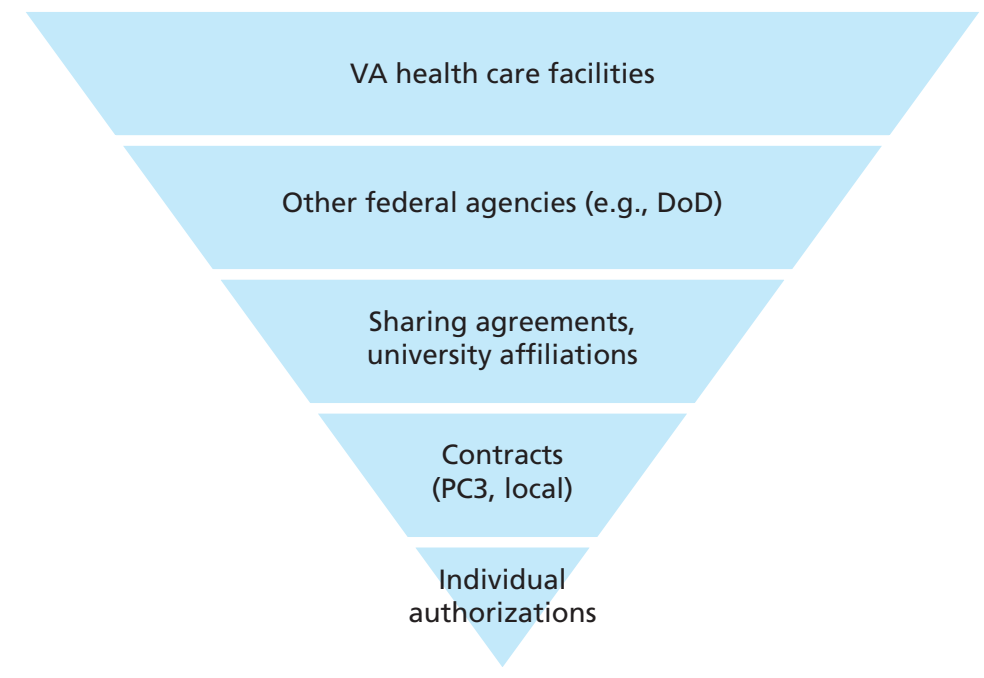

SOURCE: Robinson (2014).

RAND RR1165z3-4.2

agencies, ${ }^{2}$ then to affiliated academic medical centers, then to contracts (including PC3 and Choice), and then to individual authorizations.

Notwithstanding this programmatic hierarchy for outside referrals, complex judgments by VA administrators may still be involved in deciding which purchasing mechanism to use, given the context of care for a specific Veteran. As noted in Chapter Three, the various programmatic options differ not only with regard to basic eligibility criteria but also along other parameters, including payment levels, provider qualifications, and additional, situational eligibility requirements. Taken collectively, and given the likelihood that access to willing outside providers may be more readily available under some pathways than others, the selection of the "correct" purchasing pathway may not be reducible to a simple algorithm. As one VA official we interviewed said, "It isn't that VA staff aren't familiar [with the various purchased care programs], it's that they don't know which program to use first."

As of this writing, purchased care eligibility criteria and the referral hierarchy did not appear to be getting simpler, though VHA's Chief Business Office was strengthening its guidance for navigating program eligibility. ${ }^{3}$ In 2015, stakeholders were actively discussing a range of possible changes to the hierarchy for purchased care. According to one senior VA stakeholder interviewed, the hierarchy is intended to shift in June 2015, based on new VA guidance that will assert that no new individual provider agreements should be made. By implication, referrals would go to academic affiliates first, then to PC3, and then to existing contracts with providers, while individual authorizations would disappear from the hierarchy as a purchasing

2 As we discussed earlier in Section 3.1.1.3.2 of this report, VA has specific authority to enter into collaborative agreements with DoD for the sharing of medical facilities and providers. In addition, VA also has the authority to collaborate and/or contract with other several other federal agencies to obtain outside services, notably including the IHS and FQHCs. Sections 101 and 102 of the Veterans Choice Act address both of these outside agencies, and Section 101 explicitly identifies them as being eligible to receive Choice referrals.

3 According to one interviewee. 
option. In contrast, recent congressional testimony by a different VA official described new legislation being proposed by VA that is specifically intended to protect individual authorizations as a procurement practice for purchased care (Murray, 2015). Yet another recent testimony before the Senate Veterans' Affairs Committee suggested a different possible shift to the purchased care referral hierarchy, under which Choice would become the default option for purchased care going forward (Exploring the Implementation and Future of the Veterans Choice Program, 2015).

At present, it seems fair to conclude that the future direction of these policies is unclear. In the meantime, purchased care referrals under the existing framework involve navigating a complex set of eligibility criteria, with significant ambiguity for VA officials in determining the appropriate pathway for purchasing care and referring Veterans in specific cases.

\subsubsection{The Role of NVCC in Navigating Eligibility Criteria}

We heard somewhat conflicting views about NVCC in stakeholder interviews. Several VAMC and VISN officials provided positive feedback on the program, praising NVCC as a critical mechanism for routing Veterans to the appropriate care and navigating the complex maze of eligibility criteria. One VAMC interviewee noted Veterans' appreciation of the fact that, under NVCC, VA is responsible for coordinating all steps of the patient's medical treatment or services, from scheduling the appointment through completion of care. Similarly, some believed that NVCC had standardized the referral process for purchased care. As one VISN interviewee put it, "The loop is phenomenally tight." Others cited the standardization brought about by NVCC as being useful in aiding the VAMCs and VISNs and in monitoring problems in the referral process.

Still other stakeholders critiqued what they perceived as an overriding of the successful NVCC process by new purchased care mechanisms, such as PC3 and Choice. VA interviewees stated that the standardization in referral processes established through NVCC did not extend to PC3 or Choice. As one VISN interviewee noted, "NVCC is a great program. It provides great care, and serves Veterans well. It's timely, and provides continuity of care. PC3 has done nothing but fracture the NVCC process."

However, other interviewees spoke of challenges they perceived to be associated with NVCC. One senior VA official with significant expertise in NVCC processes spoke of the complexities surrounding NVCC, specifically the backlog of cases resulting from understaffing and high workloads. This official reported an average monthly workload of 1,600 appointments. Compounding this problem are apparent communication and information-sharing challenges that NVCC personnel encounter as they attempt to interact with VA personnel and external medical providers of purchased care; each office or entity may have a distinct information-technology structure of its own. The same senior VA official commented that already overburdened NVCC personnel must rely on fax machines to transmit the majority of documentation between different providers' offices and spend a significant amount of time resending documents and calling providers to track down documentation that was, in many cases, already sent. This official also noted that while NVCC personnel receive official VA training on scheduling, standardized guidance on NVCC-specific training is lacking. As

a result, staff training in NVCC-specific processes tends to be "locally developed, like a lot of VA [practices].”

The literature points to other potential problems with NVCC. An inspection of one VAMC by the VA Office of Inspector General's Office of Healthcare Inspections found 
improper "batch closings" of more than 1,500 NVCC requests for external clinical care in April 2014, done solely to meet a May 1, 2014, administrative deadline. Moreover, the inspection found that the same facility had problems scheduling timely appointments under NVCC, missing VHA's 90-day goal every month for five months (VA Office of Inspector General, 2014a).

\subsubsection{Reimbursement Rates and Claims Processing Issues}

Variability in reimbursement rates to providers under different purchased care mechanisms has also hampered implementation. A criticism frequently levied against PC3 is that provider reimbursement rates, which, in some areas, are lower than those under Medicare, might discourage participation (Dickson, 2014). Indeed, concerns about low PC3 reimbursement rates and their effect on provider participation led Congress to mandate an explicit extension of Project $\mathrm{ARCH}$ so that care for Veterans already in the system would not be disrupted when PC3 was launched at the ARCH sites.

These concerns were supported by a March 2015 letter to Secretary Robert McDonald from the American College of Physicians, which noted that negotiated reimbursement levels in both PC3 and the Choice program operated as a disincentive to provider participation. "In order to encourage participation by non-VHA physicians and other healthcare professionals in the [Veterans Choice Act] Program, payment rates should be no lower than those provided under the Medicare program" (American College of Physicians, 2015). Moreover, the National Association of Community Health Centers (2015) has argued that reimbursement rates under Choice should not be calculated on the basis of what was available under PC3, which it asserted was wrongfully being used as the default standard if a provider participated in both programs.

These concerns were echoed in the interviews conducted for this assessment. The Veterans Choice Act states that, except in certain specified situations, the rates shall be no higher than those paid to providers under Medicare for similar services, but there is no similar language that prevents a provider from being offered less than full Medicare rates as part of network participation negotiations. Some interviewees were concerned that health care providers had little financial incentive to sign on to VA purchased care networks, especially in affluent regions and in areas where "concierge medicine" (as one VAMC director phrased it) is on the rise. ${ }^{4}$ Indeed, in such areas, even Medicare rates are substantially lower than the market rates that a provider can command, adding an extra challenge to efforts to expand purchased care. The same VAMC director who mentioned concierge medicine explained that there is "variance between what is reimbursable and what [some outside providers] can command in their individual markets. It's quite a variance, and, in some cases, it's ... hard to reconcile." It is important to note that these are individual perceptions. An evaluation of VA's purchased care networks, once they are fully established under PC3 and Choice, will be needed to determine their adequacy and the trade-offs between negotiated payment rates and access to providers.

Several past reports have indicated the pervasiveness of improper claims payments and their potential impact on non-VA providers' willingness to continue serving Veterans. ${ }^{5}$ A 2009

4 Concierge medicine refers to primary care practices in which patients pay annual retainers to receive enhanced, more customer-oriented care.

5 According to Assessment I, on business processes, the most significant barrier to timely and accurate payments of claims is technological. Non-VA providers submit relatively few electronic claims, negatively affecting accuracy and timeliness (Grant Thornton, 2015). 
study conducted by VA's Office of Inspector General determined that the outpatient component of the traditional purchased care program improperly paid 37 percent of outpatient fee claims by making duplicate payments, paying incorrect rates, and making other, less frequent payment errors, such as paying for the wrong quantity of services (VA Office of Inspector General, 2009, p. 4). It also found that, for 80 percent of outpatient fee claims, VAMCs did not follow requirements for justifying and authorizing fee services. A subsequent study by the same office in 2010 found that VHA improperly paid 28 percent of preauthorized inpatient fee claims. It also found that VAMC staff did not properly authorize inpatient fee care because VHA policies did not provide adequate guidance for determining eligibility or because fee staff did not understand the guidance that was available (VA Office of Inspector General, 2010, p. 3). ${ }^{6}$ Others have criticized the lack of updated automated processes for claims handling by VA under the traditional purchased care program, noting that the primary application being used to handle claims from non-VA providers is more than two decades old (AMVETS, Disabled American Veterans, Paralyzed Veterans of America, \& VFW, 2013, p. 167). The problems noted go beyond mere inefficiencies in handling paperwork, some stakeholders argue; there have been "serious concerns about past due claims payments from VA and the economic realities that will force community providers to stop serving Veterans without timely payments" (Jones, 2012). Indeed, a March 2014 GAO report indicated that delays in claim processing under the traditional purchased care program were a major issue for some non-VA hospitals. According to the report, staff at one VA facility believed that these delays had lasted years in some cases. ${ }^{7}$ To our knowledge, as of this writing, VA had not performed any systematic evaluations of the timeliness and quality of contractor claims processing for the relatively new PC3 and Choice programs. However, Assessment I, on business processes (Grant Thornton, 2015) provides an evaluation of these issues.

To the extent that Medicare rates (or sub-Medicare rates) and delayed claims payments are unattractive to outside providers, purchased care mechanisms that otherwise seek to address internal VA capacity shortfalls may be unsuccessful in building a robust outside provider capacity. The TRICARE program, the health benefit plan for active-duty and retired military personnel and their dependents, also maintains a national network of civilian providers who are paid largely at Medicare rates. At the end of FY 2014, the TRICARE network totaled 434,300 physicians and other providers, and beneficiary access to community care was similar to or higher than in private sector plans (Defense Health Agency, 2015, p. 62). As of June 2015, both TriWest and Health Net were still building their networks. Once this initial effort is complete, VA can evaluate network adequacy as TRICARE does.

Reacting to claims processing challenges and backlogs, Section 106 of the Veterans Choice Act directed a reorganization of claims processing to consolidate this function under the management of VHA's Chief Business Office, as discussed in detail below. The success of that reorganization and its ultimate impact on claims processing speed remain to be seen. ${ }^{8}$ Policymakers might at least consider whether similar direct legislative intervention could be helpful in improving any aspect of reimbursement, including both claims processing and purchased

\footnotetext{
6 Two years later, similar issues were still in play. See VA Office of Inspector General (2012).

7 This GAO report was about Millennium Act claims in particular, but it echoes statements made more generally (GAO, 2014d).

8 Assessment I (Business Process) notes that this is a step in the right direction and recommends complete centralization and standardization of the claims processing function.
} 
care provider rates. For example, current VA purchased care law generally sets upper bounds on provider reimbursement rates but establishes no floor. ${ }^{9}$ When ensuring an adequate pool of participating providers is perceived to be an important component of a policy to address a particular problem (such as lengthy wait times), Congress could discourage the use of VA initiatives that result in reimbursements smaller than what the Medicare fee schedule allows. The broader policy issue to consider is the resulting trade-off: Authorities and policies that reduce purchased care expenditures may be desirable for controlling cost, but they sometimes may be undesirable when they make participating in purchased care less attractive to outside providers. Future policy discussions will need to determine the appropriate trade-offs.

Although provider reimbursement rates and procedures are a key component of VA purchased care provision, most SOPs we reviewed did not discuss this issue. Instead, they focused on authorization, referral, and appointment management. Given the recent shift and the lack of guidance of budgetary authority from VAMCs to VHA's Chief Business Office, VAMC personnel could be confused, at least in the near term, about responsibilities and procedures for provider reimbursement. The Assessment I report echoes this sentiment, noting that non-VA care procedures for processing claims are complex and confusing, and claims clerks must execute a number of complicated processes and tasks on a daily basis (Grant Thornton, 2015).

\subsubsection{Reimbursement for Emergency Services}

Most of the time when medical care is provided outside of VA, the patient may be unaware of issues related to invoicing, claim verification, and provider payment. That is not the case for emergency services, for which a Veteran is unlikely to have obtained an official authorization from VA prior to seeking emergency help at a local hospital or clinic. The latter situation puts the onus on the Veteran to pay the bill and seek reimbursement from VA for his or her emergency care (or to seek an assurance that VA will take care of the bills as they are received). Commenting on the complexities of complying with the conditions set forth in 38 U.S.C. 1725 and 1728 to avoid significant financial responsibility, one group of VSOs has asserted that the "laws prescribing VA coverage of non-VA emergency care services places an extraordinary burden on Veterans, requiring that they be educated on convoluted and burdensome administrative criteria not typically found in private health-insurance plans" (AMVETS, Disabled American Veterans, Paralyzed Veterans of America, \& VFW, 2013, p. 67).

\subsubsection{Financing and Payment}

Section 106 of the Veterans Choice Act consolidates purchased care financing in VHA's Chief Business Office rather than at the local level. Congress included this provision in the act in an effort to shift financial decision-making for outsourcing care from the local facilities to the central administration and encourage the use of non-VA care mechanisms. Although referrals still must be made at the local level, this was seen as one lever available to Congress to help increase

\footnotetext{
9 Under Section 101(d)(2)(B) of the Veterans Choice Act, for example, provider reimbursement rates generally cannot be higher than the Medicare fee schedule rates (unless the care involves Veterans residing in counties with population densities of less than seven persons per square mile). In the context of outpatient services under Section 1703 purchased care, however, reimbursements can be based on the terms of any existing contract or agreement between the provider and VA. If no such contract or agreement exists, it would be the lower of the Medicare rate, the rate available through repricing (where contractors give VA discounted health care through a network of providers), or the amount the provider bills the general public for similar services.
} 
the utilization of purchased care. As one senior VA official put it, "Choice was a reaction to us not using our mechanisms as often as we should." A congressional official confirmed this sentiment: "We know that VA has the authority to provide non-VA care, but they don't use it. We want to know how to get the VA to use non-VA care authorities."

However, this initiative has met with varying levels of support across different stakeholder groups. Of the nine VISN/VAMC interviews conducted, seven interviewees commented on the centralization of purchased care funding, and all had negative impressions of the change. One VISN director articulated that it caused payments to be late, which, in turn, affected relations with community providers. The interviewee's VISN reportedly had a 95-percent payment rate within 30 days prior to the policy change; after financing was centralized at VHA's Chief Business Office, according to the interviewee, the payment rate dipped to 80 percent. That said, a congressional official was optimistic and suggested that the reshuffle would ultimately help improve the timeliness of claims processing and reimbursements across the VHA enterprise.

Another concern among local and regional VA officials was that the centralization of financing would overincentivize the use of purchased care. Previously, when local officials managed their purchased care budgets, there was an incentive to bring services back in house to sustain internal workloads. According to one high-level VA Central Office official, "The centers were used to knowing how much money they had, to constrain how many patients they sent out. Now, we are finding that they are sending people out because they aren't under budget constraints." Other local officials worried that the new process would hamper their budget planning. One VISN examined historical care provisions to determine how much purchased care a VAMC was likely to need in the coming year, according to the director of a facility in that VISN. Having a clear expectation of the extent to which purchased care might be required helped the VISN to build a smarter budget. Steps are reportedly being taken to carry out this function in collaboration with the relevant VA central offices, the contractors, and the VISNs/ VAMCs, but it is too early to determine how widespread or effective this approach has been.

On the other hand, several VSO representatives interviewed for this study supported the shift in budget authority and heralded the consolidated financing as a much-needed change. In the words of one VSO official, "Before, the facilities could decide [how much to spend on non-VA care]. Now, the reliance on non-VA care does not have financial impact on their ability to provide capacity because it's coming from Chief Business Office. It's a step forward and removes a barrier for access to non-VA care.”

\subsubsection{Quality of Care Concerns}

The quality of the care provided by VA is often raised as a major reason for Veterans to stay within the system. The review of the evidence on VA quality of care in the Assessment B report (RAND Health, 2015b) showed that VA health care quality was good overall on many measures and domains compared to non-VA comparators. Studies have found that a key aspect of VA's quality of care is the cultural competency of its providers. For example, a RAND report on the cultural competency of non-VA mental health providers found that only 13 percent were equipped to serve a Veteran population (Tanielian et al., 2014, p. 18). ${ }^{10}$ The Assessment B

10 While not all the factors examined in the report are relevant to providers of medical care, aspects such as "knowledge, attitudes, and behaviors with respect to military and veteran culture" (Tanielian et al., 2014, p. 20) speak to cultural competency beyond the mental health profession. 
report details the ways in which VA's culture is well suited to providing care to Veterans. ${ }^{11}$ In addition to a better understanding of military culture, VA providers understand the specific health needs of Veterans. Illnesses and injuries, such as traumatic brain injury, polytrauma, exposure to hazardous materials, and chronic pain, are more common among Veterans than in the general population (Johnson et al., 2013). Because VA screens Iraq and Afghanistan Veterans for traumatic brain injury, a VA practitioner might be better equipped than a physician at a non-VA facility to identify the symptoms of the condition. Assessment A, on demographics, describes the unique health care challenges facing Veterans and notes that VA providers treat a sicker population than civilian providers (RAND Health, 2015a).

Several interviewees expressed concerns tied to inconsistent oversight and quality of care across purchased care providers. Some stakeholders indicated a need for performance metrics and data collection so that VA could track community providers' performance. For instance, one VISN director suggested that VA loses control over quality when Veterans seek health care in the community. An official working for another government health program took a similar stance, noting that VA would have to decide whether assessing the quality of care provided to Veterans by non-VA providers is part of its business model. While interviewees tended not to raise quality of care concerns with regard to traditional purchased care, several stakeholders interviewed, including both VISN and VSO officials, expressed concern about the potential dilution of quality standards due to VA's limited oversight when it relies on contractors under PC3 and Choice. One VISN official noted that quality of care concerns were more prevalent with programs like PC3 than with NVCC: "NVCC is a great program, provides great care, and serves Vets well. It's timely, and provides continuity of care. PC3 has done nothing but fracture the NVCC process." Meanwhile, a VSO official acknowledged, "I don't know how indepth [VA] can go in vetting those providers who want to sign on. If they vet them fairly well and they get top-notch service, fine. If they just sign them up to get numbers, that could be a problem." A VISN official acknowledged that a theoretical benefit of PC3 is that the provider networks are supposed to maintain certain levels of quality that are in line with VA standards. However, he felt that his VISN did not receive adequate data or reporting on quality of care under PC3. Overall, this official was skeptical about the extent of oversight of quality of care in PC3-affiliated clinics. Other interviewees explained that the goal should be to give Veterans the same quality of care outside the VA system through purchased care mechanisms as they are guaranteed within it.

Similarly, interview participants discussed the importance of the quality of choices, as opposed to just their quantity. One VSO official said, "It's less about having choice, and more about 'what are the choices?' If the choice is between two bad choices, then having a choice doesn't make a difference." Put another way, "Should a Veteran be able to make a bad choice?" Other interviewees, conversely, argued that quality of care is not as important as access to care, which is what the Veterans Choice Act aims to address.

\subsubsection{Issues with the Use of Third-Party Administrators and Implementing Provider Networks}

There have been concerns about how VA coordinates with the TPAs to determine Veteran eligibility under both PC3 and the Choice program. Reportedly, there is lag time between when a Veteran attempts to make an appointment with VA but is unable to do so within the

11 The report also notes that VA culture may result in discrimination toward and uneven utilization by certain subgroups. 
required time frame and when VA provides that information to the TPA. As a result, if a Veteran attempts to contact the TPA to set up a new appointment with an external provider, he or she may be told that the TPA has not yet received authorization to schedule the appointment, even though the Veteran is already eligible under wait-time requirements (VFW, 2015a, p. 4).

As we discussed earlier, another concern is that some clinicians may be unwilling to accept Choice patients at Medicare reimbursement rates. One requirement described as problematic stipulates that providers submit a report on the care provided within 14 days of the date of service. We were told that the industry norm is 30 days, though we could not confirm this. The Prompt Payment Act, with which the Veterans Choice Act requires VAMCs to comply, has hamstrung VA's abilities to recover medical documentation from non-VA providers in a timely fashion. As VAMC directors explained it, the act does not allow VA to withhold payment pending receipt of the report on care, and, therefore, it disincentivizes providers from sending back the documentation. However, other interviewees noted that providers are not paid until medical documentation is returned and accepted by VA, which frequently rejects such documentation, thus delaying payment to providers. This discrepancy in reported experiences is notable and worthy of further investigation. Furthermore, VA's reliance on networks of eligible providers for PC3 and, where possible, Choice has been called into question. Veterans who are eligible for the Choice program can acquire purchased care only from non-VA providers who are in the PC3 networks or willing to sign an agreement to provide the care outside the network. Both TPAs indicated that they will try to enter into agreements with providers Veterans prefer to see, but this is not always possible. Asserting that the Veterans Choice Act "makes clear that veterans may choose from any eligible entity, not merely from those with whom VA happens to contract," some lawmakers have argued that a "limited list of non-VA providers makes the provision of care at VA's choice, not the veteran's" (McDermott, 2014).

One media account reported that Veterans attempting to use their Choice card at a public regional health center were being turned away. The health center had been told that it would take the TPA 90 days to review and approve the health center's application, submitted in midJanuary 2015 (Kidston, 2015). Veterans cannot seek service from a civilian provider using their Choice cards as proof of coverage; they must have a referral for the service, and the provider must sign an agreement. We heard repeatedly that many Veterans did not understand how to use their Choice cards. Following an inquiry from the senator representing the state in the case in question, the health center's application was approved a week later. Other potential providers have noted that "hospitals have experienced difficulties getting in touch with [the Choice TPAs], receiving answers to their questions about the program, and interpreting communications, particularly pre-authorizations," arguing that a better approach would be to allow "VA to consider allowing hospitals to contract directly with their local VA facilities," rather than requiring "all non-VA medical care provided under the program to be implemented through contracts with either Health Net Federal or TriWest Healthcare Alliance" (American Hospital Association, 2015). It is unclear whether these problems reflect the unusually short implementation period in the Veterans Choice Act or a longer-term issue related to contracting out network development.

VAMC and VISN officials cite these challenges as one underlying reason for low utilization of the Choice program. Eight of the nine senior VAMC and VISN officials interviewed 
noted that use of the Choice program had been minimal so far. ${ }^{12}$ According to these interviewees, the prevailing perception at the VAMC/VISN director level was that the low utilization of the Choice program thus far was primarily due to serious lack of development in the provider networks formed by Health Net and TriWest. We note, however, that the Veterans Choice Act prioritizes the Veteran's provider of choice and does not require use of a network provider. Although some aspects of the low utilization problem are not necessarily something for which VA can reasonably be held responsible-for example, the overall lack of health care providers in rural areas and the statutory caps on reimbursement rates-VAMC and VISN interviewees believed that two elements of the Choice program contributed to the current situation: negotiated rates that drop below the Medicare schedule (or below existing market rates, in affluent areas where those rates are substantially higher than Medicare rates) and the requirements associated with joining the provider networks. In contrast, a Health Net official noted, "There has never been support for PC3... . The volume has not materialized under PC3 because there has not been accountability" for adhering to VA guidance on using PC3 and Choice before the traditional program. This view is supported by recent testimony of Deputy Secretary of Veterans Affairs Sloan Gibson before the House Veterans' Affairs Committee:

PC3 ... [is] still a new program and it's still a very small percentage. ... [A]s I mentioned in my statement we've been referring veterans for care in the community for years. Folks are used to doing that a certain way, there are providers that are used to referring their patients to [outside providers] on a routine kind of basis and so that's what's being over-utilized. ... . Choice was designed to help accelerate access to care to make care in the community more available to veterans. That is precisely what we've been trying to do. We've just been using traditional channels to accomplish that as opposed to being able to get all the system and veterans and providers in place to do it through Choice. (Gibson, 2015)

The Health Net official also cited the requirements associated with the Choice program, reporting that providers state, "If you are going to pay us low, that's okay, as long as you don't require all this extra stuff. You can't have it all."

In addition, interviewees pointed out that joining the network does not guarantee availability for VA referrals. Doctors may agree to join the network, but some may have limited or no availability to see Veterans. One VAMC director told us, "A number of specialists that have signed up have very little capacity. It's an important component, especially in rural areas." Moreover, according to the same interviewee, some of the specialists who signed up to serve Veterans are geographically inaccessible. Choice (and PC3) are still being implemented, but when the programs stabilize, VA will need to evaluate where and for what services purchased care will be effective in augmenting VA's in-house capacity to supply timely, high-quality care to Veterans.

Although the majority of VAMC and VISN interviewees felt that the provider networks were too small, one VISN director and one VAMC director expressed optimism that the networks would grow over time, through cooperation with the TPAs and outreach in the community. Moreover, three VAMC directors and one VISN director noted that their relationships with the TPAs had been generally positive. The TPAs indicated that their networks are expanding quickly and they are working with VA central offices, VISNs, and VAMCs in their

12 The issue was not directly addressed in the ninth interview. Utilization data on the Choice program to date is presented later in this chapter. 
areas to shape the networks according to local needs and to improve communication and ensure clarity on the documentation required to make referrals. Ultimately, the interviews point to the need to evaluate the TPAs and the provider networks in a systematic and comprehensive manner. Because the interviewees with both negative and positive views emphasized that the networks were very new and still being built, ongoing evaluation and analysis would prove extremely beneficial.

\subsubsection{Challenges in Coordinating Care}

The literature on purchased care cites the lack of coordination or care management for Veterans who use purchased care services as being sufficiently problematic as to potentially lead to inappropriate follow-up care, medication errors, and readmissions (Jones, 2012). Coordinated care management has been raised as a concern under multiple non-VA care programs. For instance, analysts have criticized PC3 in the past as creating "a national contract for a network of providers to deliver medical and surgical services without critical care coordination elements" such as those found in the discontinued Project HERO, making the program "nothing more than a discounted fee network, with no added benefits for Veterans" (Jones, 2012).

One seemingly critical step in coordinating Veteran care across VA and non-VA providers is ensuring the seamless transfer of Veteran health information from VA facilities to local health care providers in electronic format. As described in the Assessment B report (RAND Health, 2015b), VA has actively pursued electronic health information exchange through its Veteran Lifetime Electronic Record initiative but faces a complex set of technical and other challenges that plague health information exchange more generally (Hosek \& Straus, 2013). VA has gradually increased the number of civilian providers who participate in the Veteran Lifetime Electronic Record initiative, but the technical requirements and level of effort required to meet federal standards for secure exchange of health information pose significant barriers to participation for most providers. The facility survey included a question on this issue, asking VAMC chiefs of staff, "How often does your local health care system share records with non-VA health care providers in electronic format?" The survey specified that respondents should use their best judgment to answer this question, and they were not required to pull data from their administrative parent records to answer. Response options included "all of the time," "most of the time," "some of the time," and "none of the time." As expected, electronic record sharing with non-VA providers is fairly rare, with nearly half of respondents answering "none of the time," 40 percent responding "some of the time," and only small fractions responding "most of the time" or "all of the time" (see Figure 4-3).

Stakeholder interviews further illuminated views on coordinated care management under purchased care. For instance, a VSO official asked how VA will address cases in which a Veteran receives all of his or her care outside VA: "How can VA do case management on those folks? Will there be health case managers? Will it be part of the job of primary care? I don't know what mechanism they have in place for patients who may be seen entirely outside VA, that's a new paradigm. ... The last thing we need is poor care coordination that leads to longterm declines." Such care coordination is the responsibility of VHA, not of the Veteran; however, the unintended consequence of poor care coordination is that Veterans must either take it upon themselves to coordinate their own care or suffer from a lack of care coordination. Other VSO officials have made public statements to this effect, noting that the Veterans themselves are "assumed to lead the sharing of information and communication between private providers and VA when receiving VA-purchased care, particularly through Fee [traditional purchased] 
Figure 4-3

Facility Survey Data on Frequency of Electronic Record Sharing with Non-VA Providers

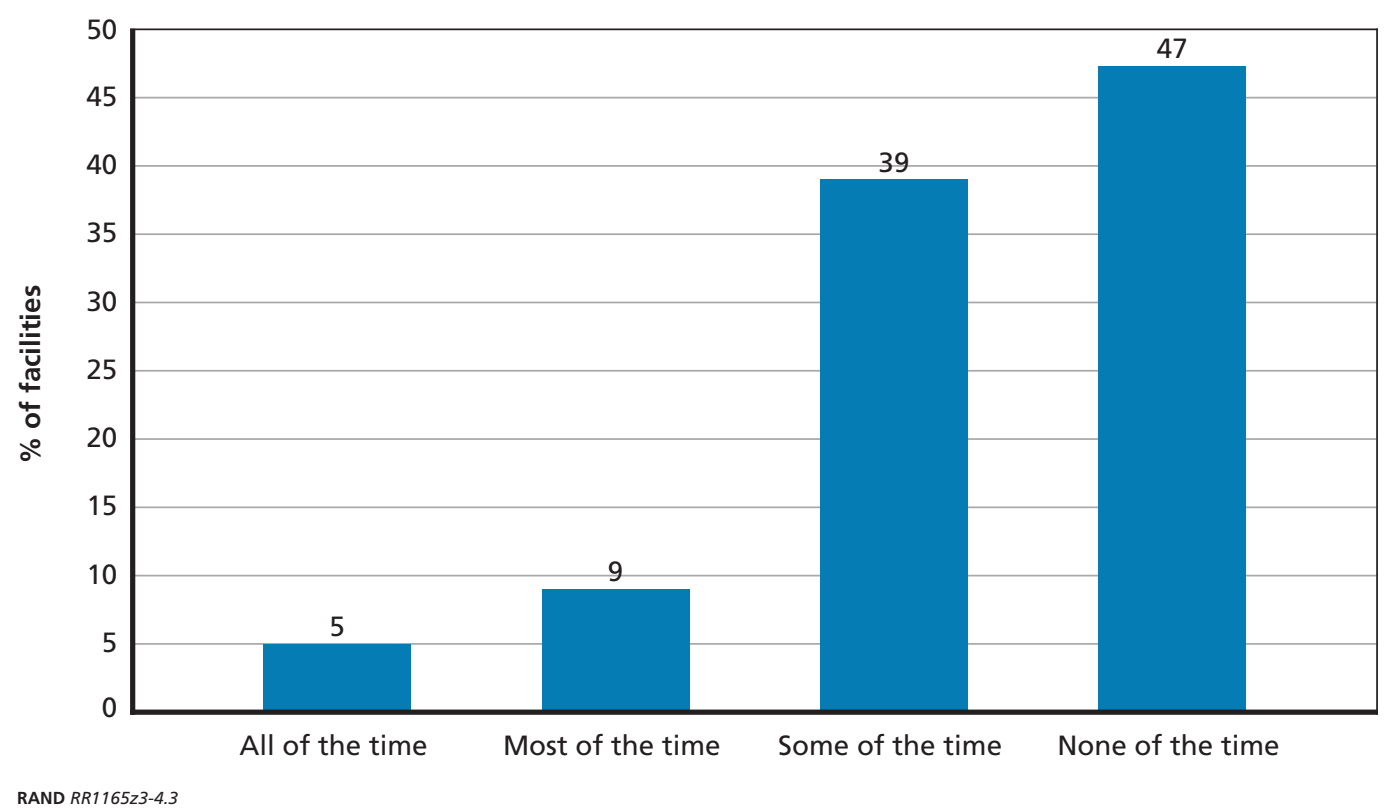

Care" and arguing, "VA has the obligation to lift the burden from veteran patients who are bridging the fragmented and disconnected care the Department buys from the private sector" (AMVETS, Disabled American Veterans, Paralyzed Veterans of America, \& VFW, 2013, p. 166). Ideally, there would be a "single care/case manager responsible for assisting and coordinating the veteran and his or her care purchased or provided directly by VA." The need for coordinated care was said to be "especially critical for chronically ill and complex patients, such as those with cancer, diabetes, chronic obstructive pulmonary disease, and end-stage renal disease," as these were the types of patients who have multiple comorbid conditions in addition to the one that led to the consultation. In the future, VA may be able to adopt care management approaches that have been shown to be effective in Medicare or employer health plans or to develop its own approaches. ${ }^{13}$ Chapter Five further discusses this issue in the context of episodes of care.

One factor indelibly related to coordination of care and electronic transfer of records to non-VA providers is the communication of information-both to patients and between providers. In many of the SOPs we reviewed, the delegation of responsibility for communicating information to both the Veteran and the non-VA provider is unclear. One VAMC's SOP for the NVCC program, for example, simply says that an NVCC administrative team member will contact the Veteran and the non-VA provider but does not say which staff member or provide guidance for employees to make this determination. Furthermore, the SOP says that the Veteran will be contacted by telephone but does not explain what the conversation should entail. At the other end of the spectrum, several VAMCs have promulgated-either as separate

\footnotetext{
13 Note that there are weaknesses in the Medicare model. One interviewee explained that care coordination has long been problematic under Medicare. VA must keep these drawbacks in mind.
} 
SOPs or as appendixes - scripts for staff to follow when calling Veterans to guarantee satisfactory interaction between the Veteran and VAMC staff.

\subsubsection{Centralization and Flexibility in Purchased Care Administration}

The balance between flexibility and standardization at the VISN and VAMC levels was a key issue that received considerable attention in our interviews. A VAMC director suggested that, from the outset, those who wrote the Veterans Choice Act recognized that there would not be complete standardization and consistency in its implementation across VA: "It's hard to write one global directive that can be universally implemented. . . There was general guidance on implementation, and each VISN would implement practices that would most efficiently implement the law."

Other interviewees spoke of the benefits and costs of both flexibility and standardization. Several local VA officials echoed the phrase, "If you've seen one VA facility, then you've seen one VA facility." The lack of standardization across VAMCs is a point of pride for some VA officials; for others, it is a point of great concern.

Although a frequently stated objective is to maintain an appropriate level of standardization and centralization across VAMCs and VISNs, there is a recognized need for flexibility in (and localization of) certain decision processes. For instance, one VISN director expressed the hope that the claims process would be standardized across facilities and across VISNs but assumed that there was not much variation currently. This interviewee also indicated that standardization should be the priority for this function. Flexibility may be acceptable when it comes to contacting the patient, but "the majority of the time, we strive to be standardized." Another VAMC director commented on the benefits of standards and accountability mechanisms in the Federal Acquisition Regulation (FAR) that are available under traditional purchased care but said, "I'd like to have a little bit more freedom locally to be able to reach out and implement some of those arrangements ... in an efficient, legal, and effective way."

Interviewees highlighted the benefits of the greater standardization provided by the Veterans Choice Act. When asked about the act's strengths, one senior VA official responded that it establishes uniformity for interpreting authorities and implementation. This interviewee felt that the way purchased care was approached prior to the Veterans Choice Act did not give Veterans enough input or choice when using purchased care and that rules regarding who was referred for outside care were not consistently applied. For example, one VISN might have required a Veteran to drive 100 miles to receive care. Another VISN might have required the Veteran to seek care closer to home. VSO representatives also appreciated the greater standardization that the Veterans Choice Act provides. They felt that the thresholds for waiting "too long" or being "too far" were no longer nebulous. Instead, the distance and access metrics are written into statute, and Veterans can better understand purchased care offerings. That said, Choice is currently a temporary program with a capped budget, and not all Veterans are eligible. Criteria for referring patients for purchased care through other mechanisms are still at the discretion of local VA officials.

\subsubsection{Need for Better Data Collection}

A review of the facility survey findings speaks to another administrative shortcoming indicating that VA could benefit from further attention to collecting critical data at the local level. The survey included a question asking VAMC chiefs of staff, "How often does your local health care system collect data about how long Veterans wait for appointments with non-VA 
health care providers?” Interestingly, one in four respondents answered that they never collect these data, and only one in seven reported collecting these data routinely. Most respondents answered that they collect data on wait times outside VA some or most of the time (see Figure 4-4). Given the focus on minimizing Veteran wait times within VA in an attempt to ensure overall quality of care, it seems reasonable to expect that VA would similarly track the wait times for Veterans who are referred out to non-VA providers for various reasons. However, it appears that there is no such systematic tracking.

A study conducted by the National Academy of Public Administration in 2011 provides support for the finding that VA's data collection efforts are minimal, observing that VHA had a "limited understanding of the services" it was paying for under the program as well as the costs to purchase external care (National Academy of Public Administration, 2011, p. 6).

More recent GAO reports also highlight a need for improved data collection on purchased care for the dual purposes of oversight and cost-effectiveness analysis. As discussed in detail in Chapter Five, there are various concerns with data collection mechanisms supporting identification of episodes of care. GAO found that, consequently, VA cannot compare the cost-effectiveness of purchasing care to direct care for episodes of care (GAO, 2013a). However, as discussed in the Assessment B report (RAND Health, 2015b), data are inadequate for estimating the costs of providing either individual services or episodes of care in VA facilities, and, further, there are significant methodological challenges involved in comparing VA and private-sector costs. GAO has also noted that the deficiency of purchased-care data systems hinders both the accuracy of reimbursement and the ability to audit those payments, at least in the traditional program (Williamson, 2015). VA reported that, in FY 2016, it would analyze the costs of purchased care by episode of care after the overhaul of data systems is finished (Williamson, 2015).

Figure 4-4

Facility Survey Statistics on Frequency of Data Collection Regarding Veteran Wait Times at NonVA Facilities

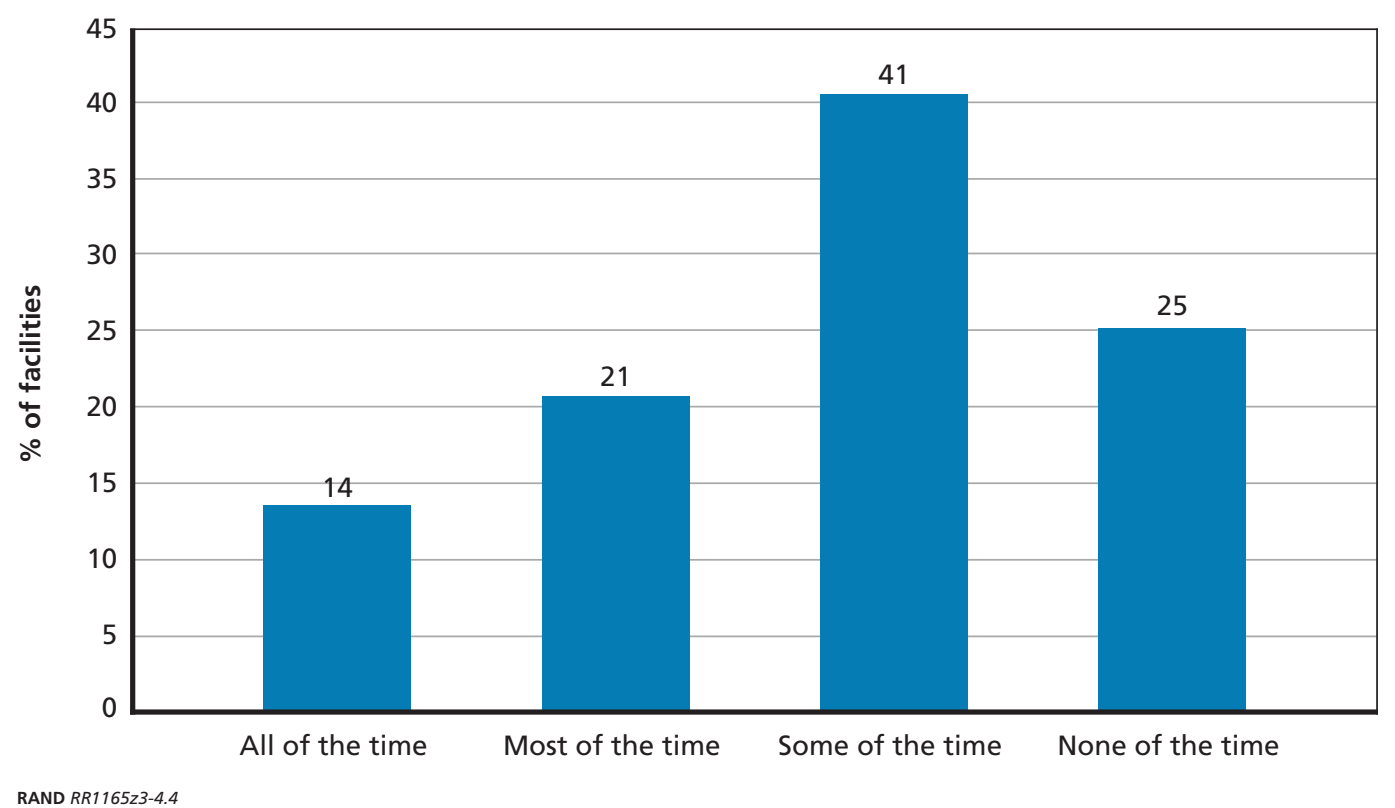

RAND RR1165z3-4.4 
These assessments by the National Academy of Public Administration and GAO align with our conclusion that more systematic data collection ought to be embedded in purchased care processes and both VA and their contractors should have the capability to analyze these data as needed to plan for and operate the purchased care program cost-effectively. A strong base of data and analysis will allow for ongoing monitoring of purchased care outcomes (access, quality, coordination, cost) over time and target improvements to enhance outcomes.

\subsubsection{The Veterans Choice Act and VA's Role Going Forward}

In November 2014, VA anticipated that 440,794 eligible Veterans would seek authorization for non-VA medical care under the Veterans Choice Act annually and that, in response, 187,000 eligible entities and health care providers would furnish hospital care and medical services. ${ }^{14}$ By mid-March 2015, four months after Choice program implementation, VA reported that 45,990 Veterans had requested Veterans Choice Act authorizations, resulting in some 45,000 appointments scheduled under the program (VA, 2015b). Another report estimated that about 27,000 Veterans received an appointment (rather than simply requesting one) over roughly the same period (Hegseth, 2015). Although actual uptake was significantly lower than originally predicted, with about 11,500 Veterans per month making requests in the four months after the interim final rule's publication, compared with an anticipated average of 37,000 per month over the course of the year, it should be remembered that the Veterans Choice Act benefit card distribution was staggered, with many-perhaps most—Veterans not receiving cards until January 2015.

In May 2015 testimony before the Senate Veterans' Affairs Committee, an official from Health Net-one of the two TPAs responsible for implementing the Veterans Choice Act program—cited slightly different utilization rates for the Choice program:

Since the inception of the Choice program in November through the beginning of May, 2015, we have answered about 550,000 calls, with the vast majority of these calls coming from Veterans seeking information on Choice or requesting an authorization for care. About 30,000 Veterans have opted-in to the Choice Program with almost two-thirds eligible based on wait time. About 16,500 authorizations have been made for wait list eligible Veterans and nearly 10,000 authorizations have been issued for mileage-eligible Veterans. With the recent change in eligibility criteria based on driving distance, we expect a significant increase in demand for care for mileage eligible Veterans. (Hoffmeier, 2015, p. 6)

When interpreting these data, it is important to keep in mind that Health Net serves only a portion of the Veteran population eligible under the Veterans Choice Act, with TriWest acting as the TPA for the remainder of eligible Veterans. For TriWest's part, president and CEO David J. McIntyre, Jr., noted in May 2015 testimony before the Senate Veterans' Affairs Committee,

In the six months the [Veterans Choice] program has been operational, TriWest has processed over 40,000 authorizations for care. And we have seen growth in the use of the program every month with the exception of a slight drop between January and February of this year. In November 2014, we processed approximately 2,600 authorizations (more than

14 VA's interim final rule submission in response to the Paperwork Reduction Act of 1995 (79 Fed. Reg. 65582-65583), November 2014. 
the first month of operation under PC3). By April 2015, the number was 10,600; growth of nearly 400\%. (McIntyre, 2015, p. 7)

Perhaps the most controversial aspect of the program has been a February 2, 2015, request in the White House's FY 2016 budget to reallocate some of the $\$ 10$ billion in funds earmarked by Congress for the Choice program to other needs within VA (Kime, 2015). At the time, a VA spokesperson argued that the lack of uptake was "a strong indication that [Choice] is not the veteran's preferred choice" and that Veterans "would prefer to remain in the VA" for health care services (Kime, 2015). It was also argued that VA has "no ability to shift resources between Choice Programs and VA-provided care" to provide timely health care to all Veterans, especially in light of "anecdotal indications from veterans and their representatives that they would prefer to get their care in VA facilities from the medical professionals they have" (Kime, 2015). In contrast, others have argued that any underutilization was the result of how the program was rolled out and the "confusion" that accompanied its implementation (Kime, 2015). In response to the request to move funds out of the Choice program if any surplus remains, the primary sponsor of the Veterans Choice Act said that the plan is a "complete non-starter, which I will not support" (Hicks, 2015).

Ultimately, given that the Veterans Choice Act has been in effect for only a short period and uptake has been slower than expected, it is difficult to predict the full effects of the Choice program and the long-term implications for VA's role as a health care provider and for Veterans' experiences in seeking care.

One overarching theme in our interviews was that the Veterans Choice Act might be an opportunity for VA to determine how it defines its broader role in directly providing care going forward. Unprompted, several VSO officials, as well as at least one senior VA official and one TPA official, discussed the degree to which the Veterans Choice Act represents the first step on a "slippery slope"15 toward more purchased care. However, other interviewees had both positive and negative reactions to this idea.

Many interviewees expressed concern that the Veterans Choice Act and a potential increase in purchased care use could "lead to a dilution of quality of care in the VA health care system and could fail to leverage key strengths of the VHA."16 The primary concern among these interviewees was that the Veterans Choice Act could signal the beginning of more outsourcing of care that will replace direct VA care offerings. While some believed that purchasing care was a good approach, others had reservations. They spoke of a cultural shift in moving from VA/military to private medical providers and were concerned that non-VA providers were not well informed about the medical consequences of military service and lacked the cultural competency to care for Veterans. Furthermore, these interviewees felt that the cost of training non-VA providers on these issues outweighed the financial and logistical benefits of referring Veterans out for care. One VSO official who supported the Veterans Choice Act also expressed concerns about the second- and third-order effects of the Choice program associated with an ever-increasing amount of care being provided outside of VA. His view was that Veterans have unique care needs due to service-connected injuries and therefore rely heavily on VA care.

\footnotetext{
15 In this case, the "slippery slope" refers to a vast increase in the use of purchased care over time that will follow after the Veterans Choice Act and its resulting surge in purchased care.

16 Beyond RAND's interviews for the purposes of this study, this idea has been discussed in outside reports and literature. See, for example, Panangala (2010).
} 
Several interviewees discussed VA's duty to provide care. According to one senior VA official, "VA still owns that care in the community. There is connection and importance there. There is a distinction that we are responsible in a global sense. . . When you contract, some of that responsibility may be severed."

Several interviewees noted that Veterans consistently expressed a preference for VA care, with this preference being especially strong among those who were already in the system. One VSO official stated, "The majority of Veterans we hear from are happy with their care. Once they can get into the VA, they get top-notch care. It's an issue of getting into the VA." More than one VSO official told us that Veterans "feel comfortable with their VA doctor, they feel safe, they feel understood there." Reasons cited included the quality of care, providers' familiarity with the distinct and complex needs of Veterans, and a sense of camaraderie.

The attraction of the VA system extends beyond issues of quality, familiarity with Veterans' specialized needs, and camaraderie, however. Several interviewees raised the point that Veterans may choose to remain within the VA system because it is familiar and known to them. One VSO official noted that Congress may have overestimated the number of Veterans who will choose purchased care. The VSO official said, "Particularly the older guys who've been going to the VA for 20 years, they don't want to go anyplace else. . . . Better the devil you know than the devil you don't know." A VISN director concurred with this point, stating, "We haven't seen the [Veterans] Choice Act be successful. Most Vets want to stay within our system of care. We don't see Vets elect to go into the community when offered." Building on this reasoning, a VAMC director suggested that Veterans might prefer VA over outside providers because they are confused about the Veterans Choice Act and its offerings:

They are happy with the services that are provided in our telehealth clinics and in our facility, so, for us, that's a great compliment to the services that we provide. So, as far as Choice goes, the premise is great. It works in our areas for our Veterans that are able to utilize it effectively, but for the majority of our folks, it can be confusing and frustrating for them to access that care.

The preference of Veterans for VA care is somewhat supported by recent data. Two recent surveys compiled by the VFW show that just under half of the Veterans surveyed reported that when they were offered the choice to use purchased care, they nevertheless elected to stay in the VA system (VFW, 2015b, p. 3).

\subsubsection{Overcoming the Practical Challenges in Purchased Care}

In sum, the day-to-day administration of purchased care presents a series of challenges for VA officials. Resolving those challenges will be pivotal to the future success of purchased care and ought to be a high priority for VA to undertake. More specifically, a robust purchased care program will require adequate reimbursement rates to ensure provider participation, avoiding delays in processing claims submitted by outside providers, ensuring sufficient network depth and administrative coordination with the TPAs, consistent oversight of quality in outside services purchased, coordination of care and communication of information to and between patients and providers, and data collection efforts in support of these various aims.

Building on these granular steps, VA could strengthen its purchased care operations by developing a strategic plan, by implementing stronger training for its personnel, and by systematically collecting data on various aspects of purchased care operations in order to care- 
fully monitor performance. In principle, these tools could help to articulate clear policy and procedural requirements for VA personnel to follow while clarifying performance expectations and oversight in purchased care, as well as applicable sanctions for local noncompliance with standards.

At the end of this chapter, we summarize our empirical findings on facility-level implementation of purchased care, how this is currently organized, and the balance of power that it represents between local and centralized authority within VA.

\subsection{Implementation of Purchased Care at the Facility Level Is Inconsistent}

\subsubsection{Organization of Purchased Care Within VAMCs}

Not only do VA facilities' non-VA care policies and procedures vary, but their categorization and placement of purchased care administration within their organizational structures also differ. As noted above, RAND received 253 organizational charts from VAMCs and VISNs across the country as part of our request for purchased care policies. Of these 253 organizational charts, just 12 organizations identified a separate purchased care function or office on their organizational chart. One of them was at the VISN level, while 11 were from facilities. The dates of these 12 charts varied widely, from January 2012 to February 2015. Nine predated the implementation of the Veterans Choice Act in November 2014; three were dated after implementation. Offices relevant to purchased care at these organizations also went by a variety of names.

In the 12 organizations examined, purchased care offices reported through a variety of management channels. Two offices reported to the VAMC associate director for patient care services, three to the VAMC associate director, one to the VAMC assistant director of facility support, two to the VAMC chief of staff, and one to the VISN deputy network director. Little standardization appeared to exist in purchased care reporting chains within the organizations examined.

To gain a better understanding of where purchased care offices are located within the organizations, we recorded the degrees of separation between the office and the VAMC for the ten charts with this information. For example, if the purchased office reported to the associate director who reported to the VAMC director, we counted two degrees of separation. If the office reported to a manager who reported to the associate director, who then reported to the VAMC director, RAND counted three degrees of separation. On average, we found 2.5 degrees of separation between the facility director and the purchased care office across those 12 organizations listing a separate non-VA care function or office on their organizational chart.

\subsubsection{Variation in Length, Terminology, and Tone in Local and Regional Policy Guidance and Standard Operating Procedures}

Documents received through our request for data indicated a lack of standardization in purchased care referral and authorization processes and procedures across facilities. Of the 240 SOPs, 57 SOPs were highly detailed, 86 SOPs were moderately detailed, and 94 SOPs were minimally detailed.

Moreover, there was little consistency in the terminology used to describe purchased care across these SOPs: some were specific to particular purchased care mechanisms (such as either 
the Veterans Choice Act program or PC3), while others referred to "non-VA care," "purchased care," "fee basis," "fee authority," "community based services," or "non-VA fee consults." Still others referred to specific services, such as dialysis, home health services, mammograms, and physical therapy. These service-specific SOPs are discussed in greater detail below. Most SOPs contained a section delineating responsibilities for particular staff members to fulfill in the purchased care referral and authorization process, but they varied widely both in terms of the staff positions listed and the responsibilities of each staff member.

Variations in the permissiveness and tone of purchased care SOPs across the VAMCs provide another working hypothesis to explain the wide variation in utilization described in Appendix A, though such local-level policies may have ultimately been shaped by the knowledge of overarching budgetary constraints in a given region. We coded all SOPs received through the request for their apparent focus/tone pertaining to utilizing internal VA care if at all possible, as opposed to being permissive regarding utilization of purchased care. The results were strikingly varied, with 70 SOPs containing language focused on keeping Veterans within the VA system and utilizing purchased care only as a temporary, last-resort option. Meanwhile, 102 SOPs were much more permissive in tone regarding the utilization of purchased care. Although these 102 SOPs still tended to note that purchased care was to serve only as a temporary solution, they were set up to facilitate the ease of use of the purchased care mechanism(s) in question. The remaining SOPs were deemed to be too neutral in tone to code either way. Nonetheless, the variation in tone across VAMCs regarding how permissive to be when authorizing purchased care services provides one possible explanation for the variation in the actual use of purchased care mechanisms across sites and among local SOPs.

\subsubsection{Variation in Purchased Care Procedures Across Medical Services}

A review of the SOPs received through our request also revealed the existence of a number of stand-alone policies for authorizing purchased care for certain medical services. Stand-alone policies were discovered for dialysis, physical therapy, home health services, and mammograms. A follow-up interview with a senior VA official clarified that each of these services has unique exterior requirements that necessitate more explicit guidance on procedures. For dialysis, there is a national contract for purchasing care that applies not only to VA but also to other national-level care providers, such as Medicare and Medicaid. Stand-alone policies are most likely developed in an effort to ensure that VA is following procedures and is in compliance with this contract. Home health, on the other hand, is ordered differently from typical purchased care. Therefore, the methodology is separate. For mammograms, there are specific time frame guidelines for reporting cancer-screening results. Because many VA facilities lack mammography machines, it appears that separate protocols are drafted to ensure compatibility with these strict timeline requirements. From our discussions with VA officials, it appears that separate stand-alone policies are required when specific care anomalies are known. However, due to the lack of standardization even in these stand-alone policies across different facilities and regions, it would be worthwhile for VA Central Office officials to explore whether efficiencies might be gained by promulgating a single, national stand-alone policy for each of the services in question and mandating that all local facilities adopt these as their own. 


\subsubsection{Potential Models for Improving Local-Level Standard Operating Procedures for Purchased Care}

Many of the SOPs received through the request for data described highly specific processes and specialties, were lacking in detail, or-conversely-were overwhelmed by minutiae. A good number of SOPs provided a modicum of detail about staff responsibilities and the procedure, but not enough to serve as a useful reference for employees. Approximately 57 of the 240 SOPs were coded as having a high level of detail. Out of those, around 15 VAMCs have promulgated SOPs that, in our judgment, may serve as models for replication.

We used several primary criteria in judging the quality of purchased care SOPs:

- Clarity and logical organization, judging that only those SOPs that clearly delineate staff responsibilities are likely to be used by employees in the field

- Effect use of visual and graphic features as an aid and illustration to accompany the text

- Applicability to a broad range of services

- Adherence to national guidance and use of valuable features from national manuals, handbooks, and directives

- References to the authorities, regulations, and manuals, along with explanations of why certain policies and practices are in place and how the various programs fit together and better serve Veterans.

Many of the best SOPs share several features and are organized in the same way, with the following sections: Purpose, Policy, Definitions, Responsibilities, Procedures, and References. Having headings of any sort is useful in breaking up dense text and simplifying the reader's task. An employee can skip right to the Procedures section when determining what action to take. The presence of similar section headings across the SOPs increases internal coherence across the various programs, as well as the different VAMCs. Many of the inferior SOPs are also organized this way, but they lack the substance and detail of the better documents. Several of the best SOPs also contain attachments and appendixes, such as flowcharts and screenshots.

The best SOPs cover the full range of purchased care operations, so that staffers are not required to refer to different documents for each service and specialty. For example, one VAMC's SOP from May 2012 applied to “outpatient/inpatient non-VA services." Following a brief statement of purpose and, in some, definitions of key terms, these SOPs lay out the responsibilities of relevant staffers. Although some SOPs use full sentences, the SOPs that use bulleted lists were easier to follow (VA Central Western Massachusetts Health Care System, 2012). In the best SOPs, the guidance in the Procedures section is presented in the form of bulleted step-by-step instructions that clearly indicate which staffer is responsible for the task. Some SOPs combine responsibilities and procedure into one section. If clearly done, this can be a good approach. Many well-written SOPs do not indicate who is responsible for the task at hand, thus diminishing their utility. The strong SOPs also include references to various authorities, including statutes, regulations, Chief Business Office directives, VHA handbooks, and various VHA guides and webpages.

Some of the best SOPs include useful appendixes and attachments. One VAMC's 2015 SOP for non-VA purchased care consultations includes a number of helpful flowcharts describing the following: referral review, appointment management, hospital notification, clinical review for emergency claims, and administrative appeals (see example in Figure 4-5). Staffers can use these for quick and easy reference. 
Figure 4-5

Appointment Management Process Flowchart from One VAMC's SOP (April 2015)

New appointment scheduling

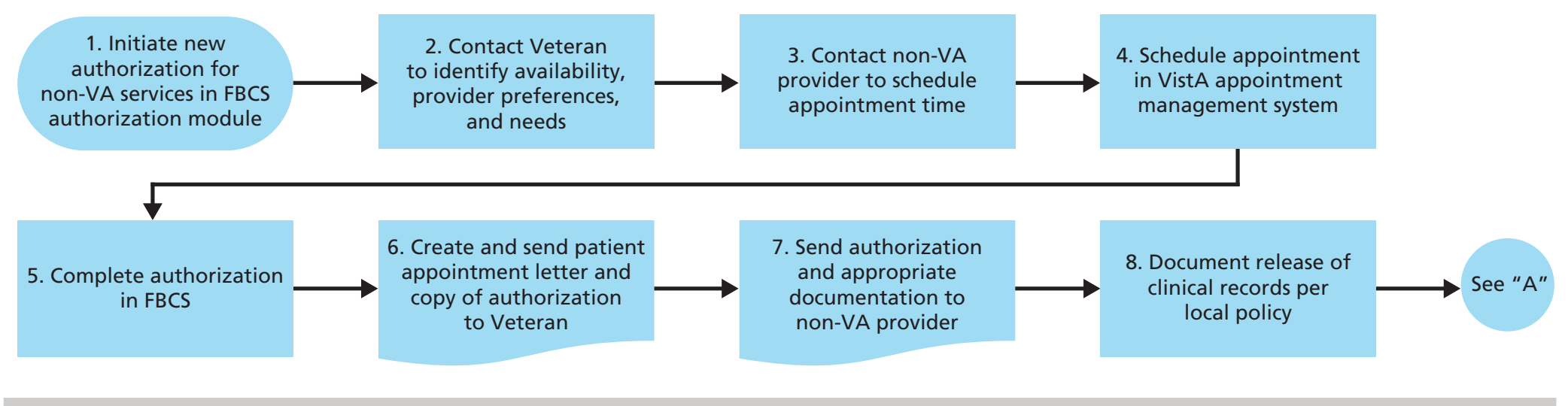

Post-appointment follow-up

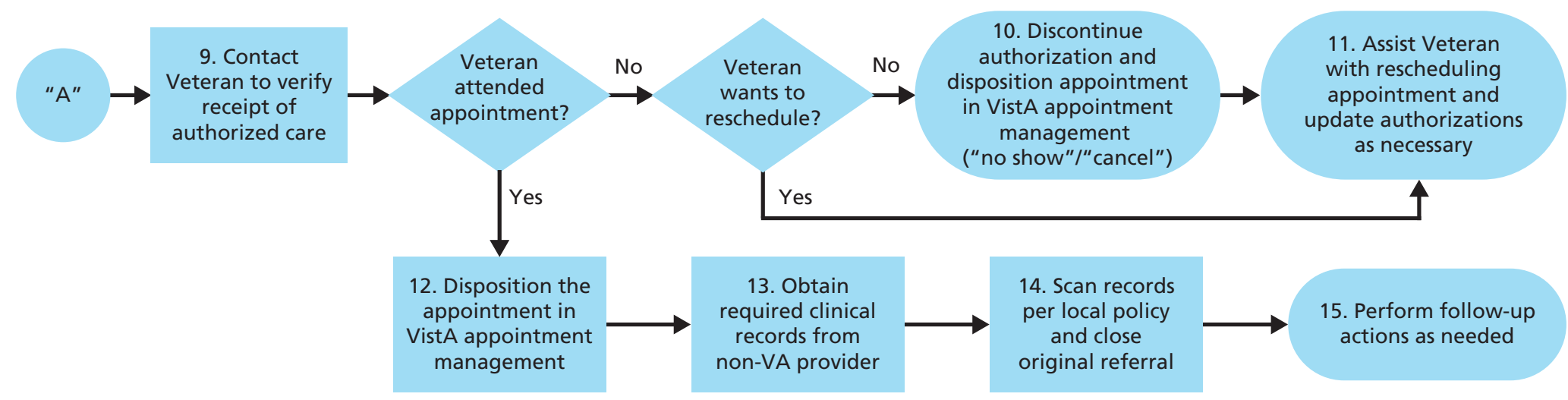

NOTE: FBCS = Fee Basis Claims System.

RAND $R R 1165 z 3-4.5$ 
Another useful appendix was included in another VAMC's purchased care SOP, showing a table of the responsible approval officer, by title, for each purchased care service. Rather than creating different SOPs for multiple specialties, this VAMC created one comprehensive document, and indicated the areas of minor distinction. Some SOPs attach additional relevant SOPs so that all the information is one place. For example, one VAMC's SOP for consult management also includes the procedure for consult tracking.

The SOP shown in Figure 4-6 also includes computer instructions, sample patient letters, and various other useful attachments.

Another element that is included in some, but not all, of the best SOPs is an acknowledgement of the need for Veteran-centered, high-quality care. Although this is presumably an implied goal of the VAMCs, it can be beneficial for the SOP to state this somewhere. Often, it is mentioned only in passing. One VAMC's SOP, for example, mentioned that NVCC is an "initiative to create a more Veteran-centered environment." It would likely improve the quality of all SOPs to include a short statement, perhaps in the Policy or Purpose section.

To summarize, the best SOPs apply to all purchased care procedures. While the best SOPs' main guidance is broadly written, the documents offer references to directions for specific care and services that deviate from the general guidance. Including references to more information about process steps and concrete examples of work procedures and work products, like computer instructions and sample patient letters, is very helpful. Other best practices include step-by-step design, effective use of flow-charts and graphics, and bulleted lists that connect relevant staffers to associated responsibilities.

\subsubsection{Integration of VHA Chief Business Office SOPs Into Local Procedures}

Some of the SOPs that may serve as models share similarities with SOPs created by VHA's Chief Business Office. For example, the Chief Business Office wrote a process guide to help

Figure 4-6

Veterans Choice Notification Processing from One VAMC's SOP on the Veterans Choice Act Program (February 2015)



RAND RR1165z3-4.6 
VAMCs with "Appointment and Clinical Documentation Management" (VHA Chief Business Office, 2013a). It contains a useful flowchart illustrating the appointment management procedure, which is also included in one VAMC's SOP. Other SOPs have Procedures sections that are very similar to the Chief Business Office documents.

Although the strong SOPs do share similarities with those from the VHA Chief Business Office and often borrow language, content, and graphics, there are also many areas in which the local documents diverge. As noted above, SOPs received through the request for data varied widely by VAMC or VISN, and very few cite or mirror national guidance. Statutory authority for purchased care is often cited, but the implementation of such authority varies widely by SOP. Sometimes, this is because local documents include more detail, describe the same action items differently, or address multiple procedures in one document. The result is a confusing landscape that lacks clarity.

The several SOPs that do cite VA Chief Business Office guidance could serve as exemplars for local facilities' potential to usefully integrate national guidance into their own local-level SOPs. Several VAMCs apparently utilize SOPs for NVCC appeals that very closely mirror the systematic Chief Business Office guidance on the subject and encourages readers to use a National Fee Program Office appeals management web tool for the process. One such VAMC also cited these materials in its SOP on hospital notification and instructed readers to use both Computerized Patient Records System and Fee Basis Claim System software. This guidance appears to be quite detailed, but National Fee Program Office materials were not available for comparison. This VAMC also has a very detailed, nationally influenced SOP on the purchased care referral review process.

Similarly, one VAMC uses an SOP for appointment management that very closely mirrors Chief Business Office guidance, including instructions to use national Fee Basis Claim System and VistA software. This VAMC also cites Chief Business Office guidance in several other SOPs, including those concerning appeals management and pre-/post-appointment phone calls. Another VAMC's guidance on fee-basis care also cites Chief Business Office material and directs readers to a Computerized Patient Records System template for fee-basis consults. Unfortunately, the cited Chief Business Office document, "Series 1601F: Fee Service," was not provided in response to the request for data, so we cannot analyze further similarities between it and the VAMC SOP in question.

The above SOPs not only cite national guidance, but they are also clearly influenced by it. Many follow national SOP steps closely, if not exactly. These exemplar local SOPs use nationally created software, and this ensures that their processes and the outputs and data from such processes are standardized. Given the apparent benefit of standardization and the high quality of the Chief Business Office documents, it would be worthwhile for VA to consider mandating their adoption by local VAMCs.

\subsubsection{Referral and Authorization Processes}

The following sections describe the referral and authorization processes in theory and in practice. The referral and authorization processes are difficult to implement, given the number of different purchased care programs, the variations in Veteran eligibility for each, and the different prescribed methods and individuals involved in referrals for each programs. We find that the referral and authorization processes differ in theory and in practice. Based on our research, on-the-ground practices reflect greater consideration of availability of clinical services than consideration of Veterans' driving times and geographic access. 


\subsubsection{The Referral Process in Theory}

In theory, the referral process for purchased care ought to be clear and easily understandable, based on eligibility factors and availability of services offered through the purchased care mechanisms.

For traditional purchased care, ${ }^{17}$ this process would begin with a VAMC clinician requesting an authorization (or "consult") for outside services for a patient. The clinician would include a justification for the request, based on either the VAMC's inability to furnish the care or its inability do so economically or due to geographic inaccessibility. The VAMC chief of staff, or a designee, would then review the request and authorize it if appropriate. "Fee staff," those employees at the VISN or VAMC level who are tasked with administering the program, would review the request. After this review, the fee staff would notify the Veteran that the request had been authorized. At this point, the Veteran would be able to select a provider, assuming that one was not already designated in the authorization. Assuming that the provider agrees to provide the services at the reimbursement rate offered, then fee staff would schedule the appointment, and the Veteran would then go to that appointment and receive the outside care.

The referral process is slightly different under Project ARCH (Altarum Institute, 2015, Exhibit 12-27), which involves a TPA contractor (Humana). According to ARCH procedures, the VA medical provider acts as a gatekeeper to the program. The medical staff treating the Veteran are notified of basic drive-time eligibility, and they then assess whether referral to a network provider is appropriate. If so, the next step is to determine whether the Veteran is interested in participating. If the Veteran is indeed interested, then an authorization is sent to Humana's local ARCH network manager, who sets up the appointment with a participating provider.

Under PC3, a referral is to be made in instances of geographical inaccessibility or a lack of availability of services within VHA, unless interagency sharing agreements or direct contracting would be definitively superior. Where fee staff determine that a referral through PC3 is appropriate, a request is then sent through VHA's Chief Business Office to the appropriate TPA, which then sends the authorization and confirmation of eligibility to a network provider or, if a network provider is not available, arranges for the care with a non-network provider (TriWest Healthcare Alliance, 2015c). The PC3 contractor is responsible for scheduling the appointment with the Veteran.

Under the Choice program, selected Veterans may be eligible based on either wait time or travel distance criteria (Sec. 101(g)). VA then provides eligible Veterans with information about the Choice program and available providers thereunder. ${ }^{18}$ If the Veteran elects to receive external care, an authorization is sent to the PC3 TPA for his or her area, who generally follows the same process as under PC3 for referral to a network or non-network provider. The law specifies that, under the Choice program, the Veteran may select a provider of his or her choosing, ${ }^{19}$ and the TPA arranges for the care with that provider if possible.

\footnotetext{
17 The process description is adopted from Appendix A in VA Office of Inspector General (2009), as well as the transcript from a hearing before the House Veterans' Affairs Committee, Subcommittee on Health, "VA Fee Basis Care: Examining Solutions to a Flawed System" (2012).

18 Per our discussion in Chapter Three, eligible providers under the Choice program include those participating in Medicare, any FQHC, DoD, or IHS (Veterans Choice Act, Sec. 101(a)(1)).

19 Subject to fairly extensive limitations and restrictions, as we describe at greater length in Chapter Three.
} 


\subsubsection{How and Why Referrals Are Made in Practice}

When we examined the purchased care referral process in practice at the facility level, we found variation in how and why referrals were made and significant variation in the processes that were used to make referrals.

The Choice program legislation focuses on Veterans' geographic accessibility and distance to care and appointment availability in determining eligibility for purchased care. In our survey of VA facilities, VAMC Chiefs of Staff reported that most referral decisions were made based on availability of clinical services altogether at the facility (Figure 4-7). Approximately three-quarters of respondents ranked "lack of clinical services available at VA facilities" as the most important reason for referral to purchased care.

We also found variability in the processes for authorizing purchased care referrals. As we described in the previous section, our review of VA facilities' SOPs revealed substantial variation in management structure, policies and procedures, adherence to national SOPs, level of detail, and format.

Another issue raised in the literature and illustrated in our data analysis is that purchased care referral and authorization processes tend to be complicated and entail delays (Altarum Institute, 2015, p. 3). In light of the differences revealed in our review of the SOPs, it is possible that delays could occur due to confusion regarding various staff members' responsibilities with regard to ensuring timely authorizations and/or due to the complexities of the procedures themselves and the number of staff members who are required to sign off on a single authorization. For instance, in one facility, the Community Care Consult Unit is responsible for ensuring that requested clinical services are received in a timely manner. In theory, this means that they should be responsible for the timeliness of authorizations as well, but the SOP document does not explicitly state this. Meanwhile, in another facility, the SOP outlines a specific set of steps to be followed by officials responsible for purchased care authorizations-including

Figure 4-7

Reasons for Referral to Purchased Care




the chief of the service requesting the referral, the Fee Basis section, and the Chief Business Office-and states, "Procedures are to be established to assure processing of applications for fee-basis care does not exceed 10 days." Yet, the fact that Veterans may have to wait ten days simply to be authorized to utilize purchased care despite the specificity of this policy highlights the problem of authorization delays.

The American College of Physicians, reacting to the Veterans Choice Act, argued that multiple cycles of authorizations for purchased care constitute a process that "can easily become a burden to the treating clinician and their staff, as well as the veteran," recommending that VA "consider reducing or eliminating authorization for treatment provided to eligible veterans from approved non-VHA clinicians who have established a record of effective and efficient care" (American College of Physicians, 2015). Eliminating the authorization step altogether may not be possible, but involvement of multiple levels of VA management along with the TPA may not add value, especially if it can be monitored effectively.

\subsubsection{Lack of Standardization in Staff Training}

Another key area in which standardization appears to be lacking in spite of a need for it is in the training of VA staff in purchased care processes. The Veterans Choice Act required that VA implement the program unusually quickly; VA awarded the TPA contracts just two months before the program start date. VA staff, who had only just been introduced to the PC3 and NVCC programs, had to quickly familiarize themselves with Choice. Interviewees pointed out that the Choice program is complicated and confusing, and in the wake of the Choice Card mailings, VA personnel had to deal with many calls and inquiries from confused Veterans. VA did not have time to institute a standardized formal training program before implementation, and, to our knowledge, one has yet to be developed. One VAMC director described the situation as "a good example of rolling something out without doing the appropriate training." Among the VAMC directors we asked about training, some were unsure what, if any, training was provided. One director with some knowledge about training stated that explanatory documents were created at the national and regional levels to familiarize staff with the Veterans Choice Act, and designated "Choice Champions" visited at least some clinics to offer assistance and knowledge.

Of the materials received through our request for data, supplemented by a number of training materials that we downloaded from the VA Intranet, only a handful appear to be part of a formal training program. In fact, of the 62 documents to which we had access that were at least tangentially related to training, only three are components of any formal purchased-care training. Two are national in scope and are training presentations, virtually identical in content, created by the National Non-VA Care Program Office, VHA's Chief Business Office, and the Clinical Business System Office, about the NVCC model and processes. These lengthy and comprehensive presentations are useful with regards to the referral review, appointment management, and hospital notification processes, containing templates, screenshots, and detailed instructions. A third document is the only document from a local VAMC in the materials and is a slideshow presentation from a kickoff briefing introducing the NVCC program.

We received a number of Chief Business Office process guides covering various elements of the NVCC program, such as appointment management, referral review, hospital notification, and administrative appeals. As process guides, these documents are all formatted the same way, with information about key individuals involved, a high-level process overview, a step-by-step procedure, and appendixes. Another useful national document that may have 
been used locally is the NVCC Manager's Guide, which contains an overview of processes, templates (and when to use certain templates, which is lacking in other guides), tools, and information about managing the program and Computerized Patient Records System setup.

We also received 10 fact sheets published by various VA Central Office departments, including VHA's Chief Business Office, Health Information Management (HIM), and the National Non-VA Medical Care Program Office. Some are useful introductions to new programs, such as NVCC; helpful explanations of complicated issues, such as "episodes of care"; and guides about how to fill out certain forms. Although these fact sheets do not appear to be part of a training program, they can help convey new and important information to staff. However, the extent to which these VHA Central Office documents are circulated to relevant staff at the local level is unclear.

Many of the other materials to which we had access are more straightforward policy documents: VHA directives, memos, and handbooks. Based on the materials analyzed, it appears that training is not provided at the local level nor mandated by the VHA Central Office and is, therefore, not standardized at VA facilities across the country.

In addition to the paucity of formal training provided to VA staff, some interviewees noted that employees at TriWest or Health Net call centers also lacked training, often providing incorrect or misleading information to Veterans, leading to further confusion. One VAMC director explained that "there have been some issues as far as a Veteran would call [the TPA] one time they'd get one piece of information and if they' $\mathrm{d}$ call another time, they might have something different said." This interviewee also noted, however, that such issues were more common at the beginning of the Veterans Choice Act, and that the TPAs have been providing more reliable information to Veterans more recently.

This impression is supported by the May 2015 testimony of David J. McIntyre, Jr., president and CEO of TriWest, before the Senate Veterans' Affairs Committee, in which he noted that the lack of time to properly train TriWest staff in Veteran call centers was a major shortcoming of the rollout of the Choice program:

First and foremost, we suffered from a lack of training time. We had less than two weeks to hire and train hundreds of people just to answer phone calls from Veterans and describe or explain a complex new program. It is no understatement to say that most who worked to get [the Veterans Choice Program (VCP)] up and operational worked 100-hour weeks during that 30-day period . . . in order to understand what was envisioned by the law and then design the approach and stand-up operations. Given the brief amount of time to do all that was required, one of the greatest challenges was to gain a solid base of understanding of this valuable new benefit, and get the operation design set so that we could sufficiently explain both to others. And, we were not alone in that challenge. Among those most impacted, beyond the Veterans we were all aiming to serve, were the new staff in [our] call centers, as they had only five to seven days in which to grasp the information versus the typical two to three week period one ought to provide. I am sure others, including VA, struggled with the same.

Obviously, the lack of training led to less than optimal customer experiences. Information provided to Veterans was at times inaccurate or confusing. And some Veterans were left frustrated. I want to apologize for that. But, in apologizing, I also want to reassure this Committee that we did everything in our power to train and educate this new team in the very short period of time we were allotted. In the end, it was simply not enough time. And, 
we are doing our best to stay on top of making sure that our staff has the right knowledge base of the program in order to provide solid customer service . . even as this program continues to be refined, creating a need for re-training. (McIntyre, 2015)

The need for improved training and SOPs extends into the traditional purchased care program contracting, insofar as the program continues to be important for purchased care. In recent congressional testimony, GAO echoed VA's need for improved training among contract administrators and recommended that VA revise training for contracting officers' representatives to include developing and overseeing service contracts (Williamson, 2015). Furthermore, GAO called for VA to revamp SOPs for contracting officers' representatives to ensure that they have the appropriate workload based on their availability, qualifications, and training. It also recommended that VA increase oversight of contracting officers and their representatives (Williamson, 2015).

\subsection{Discussion}

In this chapter, we sought to investigate and analyze a series of implementation barriers to VA purchased care, in large part through the experience of local VA facilities and personnel in striving to overcome them. Drawing on our findings from stakeholder interviews, a request for local purchased care policy documents from VA facilities, and a facility survey that included seven questions pertaining to local purchased care practice, we identified a series of related challenges for VA and its personnel. These challenges range from difficulties in claims processing and reimbursement, to concerns about the oversight of quality in purchased care services, to the fundamental tension between central control and local flexibility in carrying out purchased care policies and operations. Our findings reflect an important set of potential leverage points for policy-makers to consider using in seeking to streamline and improve the administration of VA purchased care in the future.

Our findings speak to the considerable variability in local practices for purchased care and the difficulty that VAMCs and VISNs have faced in developing their own policies for carrying out purchased care activities. More specifically, we found that the organization of local purchased care operations is highly varied, and that local SOPs for purchased care, when available at all, are considerably diverse in their content and level of detail. We also found that authorization and referral practices, coordination of care through electronic record sharing, and staff training efforts represent three specific areas in which variability of practices and/or lack of standardization may be detracting from the efficiency and effectiveness of purchased care operations. Moreover, we found a lack of systematic data collection and performance monitoring at the local level, an issue which could — if remedied-help to ameliorate the potentially negative effects of the lack of standardization in local practices.

The findings in this chapter highlight some important opportunities to improve VA purchased care by effectively implementing procedures to ensure that local facilities and personnel understand and can effectively carry out their purchased care tasks. In Chapter Five, we examine the broader strategy for VA purchased care and some of the key leverage points for VA purchased care at the national level going forward. 


\section{Overview of Methods and Data for Procurement and Episodes of Care}

- We examined the key statutory provisions governing VA's procurement of purchased care, including applicable sections of the U.S. Code, the Federal Acquisition Regulation, and supplemental acquisition regulations, including the Veterans Affairs Acquisition Regulation.

- We separately traced VA procurement strategy for different types of service purchases (small, individual purchases and large, bundled purchases) to illustrate how the regulations are applied, as well as their implications for different strategies.

- We examined how episodes of care are used to define clinical courses of treatment, in part through a review of the literature from the wider health care sector.

VA purchased care is complex and multifaceted. As we discuss elsewhere in this report, policymakers might reasonably consider many different aspects of purchased care as possible targets for future revision. ${ }^{1}$ Nonetheless, it is important to acknowledge that the basic parameters for VA purchased care are tightly bound to several other aspects of VA's institutional mission, operations, and authority. For example, it is difficult to imagine a discussion of purchased care that does not acknowledge the intimate link between VA's health care benefit structure and VA's activities as a purchaser. ${ }^{2}$ The scope and structure of the health benefit serves to define what VA can purchase and for whom. Although it is beyond the scope of this report to address in detail, many plausible future revisions to VA purchased care might go hand in hand with future revisions to the health benefit package for Veterans.

Two other key elements of VA authority and policy are similarly foundational to the operation of purchased care. These include VA procurement rules, which influence the way that contracting is carried out, and the definition of episodes of care, which could have farreaching ramifications both for contracting and for units of purchase. Each of these elements helps to set the stage for purchased care activity and to bound VA's purchased care operations. Moreover, each of these elements is potentially transformational. Shifting them could deeply change what VA would be purchasing, as well as the terms on which any such purchase transactions might take place.

In the future, VA procurement of outside health care services based on bundled payment and revised episode of care standards could look very different from current practice, with an

\footnotetext{
1 On this point, see particularly Chapter Six for an assessment of a wide range of future possible policy changes that might be undertaken in VA purchased care.

2 See Appendix E for a brief summary of the major structural features of the VA health benefit.
} 
emphasis on new types of aggregated purchasing arrangements, performance-based contracting, and risk-shifting between VA and outside providers. These kinds of changes could become pivotal to VA's health care operations, especially if policy-makers decide to strengthen VA's emphasis on serving as a payer, rather than as a direct provider, of medical services. Analyzing the implications and possibilities requires a more conceptual discussion than that undertaken in Chapter Three.

For VA stakeholders and policy-makers, these elements present a unique challenge and opportunity, which goes beyond a basic analysis of authority. Much of our discussion of VA purchased care so far has focused on questions of what and how: What has VA been authorized to do, and how has VA carried out its mandate? This chapter touches on why foundational changes to procurement and to episode-of-care standards might be useful strategic pathways for VA to explore. Our discussion focuses on corresponding possibilities for purchased care strategy in the future and the reasons why stakeholders might choose to transform the landscape of VA purchased care along these lines.

In the sections that follow, we describe and explain VA procurement authority, episodeof-care standards, and how these elements contribute to VA's broader purchasing policy. We conclude with some observations regarding that strategy and considerations that stakeholders should bear in mind in any future reforms that touch on procurement and episodes of care.

\subsection{VA Procurement in Purchased Care: Understanding the Framework Established by FAR and VAAR}

\subsubsection{An Introduction to VA Contracting Authority}

One of the key mechanisms for VA in carrying out any purchased care activity is contracting, or the process for entering into an agreement with a TPA or, in the traditional VA purchased care program, an outside provider entity for delivering health care services in exchange for payment from VA. As we discussed in Chapter Three, core provisions of authority establish that VA may purchase services for Veterans once a series of designated eligibility criteria are met. VA has established mechanisms under NVCC to carry out the front-end processes of purchased care, particularly around local referrals and authorizations for outside services. Collectively, these mechanisms and authorities establish when VA may purchase care (and when Veterans receive it) and how the front end of this process is carried out by VA. An equally important piece involves the contractual relationship between VA and the outside providers from whom it purchases care. Without payment and contracting, there can be no access for Veterans to outside providers or services, regardless of whether VA theoretically has the power to act as a payer or whether Veterans have the right to access care at non-VA facilities. Statutes, regulations, and policies may create the overall framework for VA to act as a payer, but government contracts provide the actual mechanism by which care is purchased for Veterans. When it comes to contracting with outside providers and actually purchasing services from them, what kinds of authorities and restrictions govern VA practice?

In Chapter Three, we described the key statutory provision for VA purchased care contracting under 38 U.S.C. 8153 . This provision gives the Secretary the power to engage in contracting to purchase health care services from outside providers, when he or she determines this to be appropriate. Section 8153 also states that VA is explicitly required to conduct its purchase of health care services and resources "in accordance with all [federal] procurement laws and 
regulations." ${ }^{3}$ Notably, however, when VA seeks to purchase medical services from a formally affiliated institution (like an academic medical center), it may do so without regard to any requirements for competitive procedures (or bidding) that would otherwise apply under federal law (per 38 U.S.C. 8153(a)(3)). Also, VA may purchase services from nonaffiliated entities under simplified procurement procedures, the latter to be formally promulgated and published by VA (also per 38 U.S.C. $8153(\mathrm{a})(3)$ ).

Federal laws and regulations on procurement, including but not limited to Title 41, U.S. Code (Public Contracts), code sections applicable to each agency within their own titles of the U.S. Code, the Federal Acquisition Regulation (FAR), and agency supplemental acquisition regulations, provide additional detailed guidance on contracting and procurement. FAR is codified in Title 48 of the C.F.R., and it involves a set of rules designed to establish "uniform policies and procedures for acquisition by all executive agencies" (FAR 1.101). In turn, VA (like many other executive branch agencies) has published its own supplementary set of rules on acquisition, which elaborate on FAR. VA's rules are called the Veterans Affairs Acquisition Regulation (VAAR) and are also codified in Title 48 of the C.F.R. Taken together, FAR and VAAR establish an elaborate set of definitions, policies, processes, and technical standards that regulate many different aspects of VA contracting practice. These include descriptions of different types of contracts (such as cost-type and fixed-price contracts), requirements for competitive bidding, ${ }^{4}$ definitions and standards for contractor qualifications, rules for contract financing and guidelines for contractor cost accounting, guidelines for government review of contractors' pricing, guidelines for the selection and appointment of government contracting officers, and processes for termination and settlement of contracts. Many of the detailed requirements of FAR and VAAR are complex and are beyond the scope of this report. Despite this complexity, the basic intent behind FAR and VAAR is simple: "The vision for the Federal Acquisition System is to deliver on a timely basis the best value product or service to the [government] customer, while maintaining the public's trust and fulfilling public policy objectives" (FAR 1.102(a)).

A few basic features of the acquisition rules in FAR and VAAR are important to note, particularly with regard to VA purchased care. First, the requirements for fixed-price contracting under FAR depend on the size (or dollar value) of the contract. Part 13 of FAR establishes a set of simplified acquisition procedures that apply to contracts for amounts under the simplified acquisition threshold, which is defined at $\$ 150,000$ (per FAR 2.101). ${ }^{5}$ Contracts falling under the simplified acquisition procedures are exempt from a series of federal laws that would otherwise apply and are subject to streamlined standards for solicitation and competitive bidding (as described under FAR Subpart 13.1). For VA, simplified acquisition procedures for health care resources are elaborated under VAAR at 48 C.F.R. Part 873. Particularly noteworthy is

\footnotetext{
3 See particularly 38 U.S.C. 8153 at subsections (a)(3)(A), (B), and (C).

4 The FAR and VAAR requirements for competitive contracting flow from statute, including the Competition in Contracting Act of 1984, which is codified in relevant part at 41 U.S.C. 253.

5 In addition to the standard simplified acquisition threshold, federal law allows simplified acquisition procedures for higher-priced contracts when in support of contingency operations (as that term is defined by DoD) or for procurements related to defense against (or recovery from) nuclear, chemical, biological, or radiological attack. See 41 U.S.C. 1903. For these types of urgent procurements, FAR sets a simplified acquisition threshold of $\$ 300,000$ for domestic procurements and \$1 million for overseas procurements. See FAR 2.101 (Definitions); see also FAR Subpart 18.2 (Emergency Acquisition Flexibilities).
} 
VAAR Section 873.104, which establishes that contracts for services with provider institutions that are formally affiliated with VA (for example, academic medical centers) may be entered into on a sole-source basis and without publication and written justification requirements, notwithstanding contrary provisions that would otherwise apply under FAR and VAAR. This is consistent with VA's statutory authority under 38 U.S.C. 8153(a)(3)(A) to pursue such solesource contracts with affiliated health providers.

Beyond the simplified acquisition procedures described above, another important set of contracting rules in FAR pertains to purchases that fall below the micro-purchase threshold, which is defined as $\$ 3,000$ (FAR 2.101). ${ }^{6}$ For these purchases, an even more simplified and streamlined set of contracting requirements applies (under FAR Subpart 13.2). In essence, those requirements allow for purchasing without competitive bidding, and with only limited additional requirements for documentation and verification of price reasonableness (FAR 13.203). Contracting for services under the micro-purchase threshold can be carried out through any of several different purchase methods, including (fixed-price) purchase orders and commercial purchase cards (per FAR Subpart 13.3).

When VA acts to purchase medical services from the private sector, it must work within the framework set forth by federal statute and regulation, including FAR and VAAR. Within this framework, there are many taxonomies for organizing contracts, such as cost-type versus fixed-price contracts, ${ }^{7}$ commercial items versus noncommercial items, and goods versus services. However, to understand VA's authorities to purchase medical care, the most important parameter is the size of a contract, which under federal law and regulation dictates the level of formal process necessary to enter into, administer, and terminate such a contract. Large, highvalue contracts involve extensive and formal requirements under FAR and VAAR. Smaller contracts, falling under the simplified acquisition threshold, are subject to a somewhat streamlined process and fewer requirements. ${ }^{8}$ In some cases, such as when VA is purchasing services from a small disadvantaged business or medical services from an affiliated institution, VA may leverage additional flexible authorities to set aside contracts for a limited range of bidders or use contracting procedures that involve less than full and open competition. For the smallest contracts, those falling below the micro-purchase threshold, there are even fewer formal

6 As with simplified acquisitions generally, there exists a set of urgent authorities for use in making micro-purchases when the head of an agency determines that a micro-purchase is to be used in support of a contingency operation or relates to defense or recovery from nuclear, chemical, biological, or radiological attack. Upon such a determination by the head of an agency (in this case, the Secretary of Veterans Affairs), FAR raises the micro-purchase threshold to $\$ 15,000$ for domestic purchases and to $\$ 30,000$ for overseas purchases. See FAR 13.201; FAR 2.101.

7 See FAR Part 16 (Types of Contracts), for a taxonomy of government contracts based primarily on the cost basis of the agreement-i.e., whether fixed-price or cost-reimbursable. Even within these types there are many subtypes, such as the differences between cost-plus-fixed-fee and cost-plus-award-fee contracts. Depending on the type of contract, a government contract may have different terms and conditions.

8 Another important type of contract involves those awarded to special disadvantaged businesses, including Veteranowned small businesses and service-disabled Veteran-owned small businesses. These contracts can be issued for a range of purposes and for goods or services. However, an agency may set aside contracts during the procurement process specifically for bids by these types of businesses. See FAR Subpart 19.5 (Set-Asides for Small Business) and FAR Subpart 6.2 (Full and Open Competition After Exclusion of Sources). In addition, an agency may award a sole-source contract to a Veteran-owned or special disadvantaged business. Within this category, there are specific statutory and regulatory authorities enabling (or, in some cases, requiring) VA to set aside contracts or make sole-source awards available to such businesses. See FAR 19.1405 (Service-Disabled Veteran-Owned Small Business Set-Aside Procedures) and FAR 19.1406 (Sole-Source Awards to Service-Disabled Veteran-Owned Small Business Concerns); see also Sec. 308, Veterans Benefits Act of 2003 , Pub. L. 108-183 (December 16, 2003). 
requirements and more flexibility on the part of VA and its contracting officers in carrying out those arrangements.

\subsubsection{Procurement and Contracting Strategy for Purchased Care}

In practice, VA contracting for purchased care can take several different forms, consistent with the federal procurement framework established under FAR and VAAR. For example, the PC3 relationships with Health Net and TriWest represent one form of such contracting: large-scale, cost-type contracts with government contractor TPAs to purchase an indefinite amount of care for many Veterans on an indefinite delivery schedule over a period of years. However, the TPAs can use agreements instead of formal contracts with providers who are willing to join the network or provide care on a case-by-case basis. Alternatively, a local VAMC might purchase a specific medical service for a specific Veteran at a local non-VA facility via a purchase order under the FAR micro-purchase threshold, with very streamlined requirements for making that purchase under FAR. Both of these forms of contracting related to purchased care occur within VA, but each has different contracting and purchasing processes. The different tiers of contracting authority and the multiplicity of contracting options may reflect the fact that it can sometimes be advantageous to local VA facilities to have a very simple process for entering into small purchase contracts in the field, while VHA Central Office is simultaneously working to strengthen a much broader contractual framework for purchasing care on a regional and national basis. This is particularly true if there is no appropriate network provider; this discussion focuses on situations in which the network is not a preferred solution.

These contracting alternatives highlight the fact that VA procurement for purchased care is complex. Beyond the technical requirements of FAR and VAAR that contribute to the complexity of purchased care, the multiplicity of VA contractual alternatives add to the complication. In addition, VA must decide how to define the units of service being purchased and, consequently, the most appropriate way to structure contracts for carrying out those purchases. For example, to the extent that large amounts of outside health care services are being procured in small increments, less than $\$ 3,000$ each, as through purchase orders under the micro-purchase threshold, that might well represent one expedient way for VA to purchase care. Could a series of similar purchases from the same outside provider be lumped together contractually into a larger, more strategic procurement, in a manner that would surpass the micro-purchase threshold, and thereby require a more rigorous and demanding contractual process under FAR and VAAR? Likewise, could one envision an even more aggregated, macro-level contracting framework for purchased care, under which VA would move away from purchasing individual services locally on a fixed-price basis and instead toward bundled purchasing of services in large quantities from networks of private providers, using contract types (such as cost plus award fee or cost plus incentive fee) that appropriately incentivize performance?? Or could VA innovate even further in its contracting and procure aggregated bundles of medical service under an indefinite quantity contract in which the basis of payment is the outcome achieved, rather than

\footnotetext{
9 Note that FAR Subpart 16.4 deals at length with "Incentive Contracts" and introduces these as an alternative to fixedprice contracts when "required supplies or services can be acquired at lower costs and, in certain instances, with improved delivery or technical performance, by relating the amount of profit or fee payable under the contract to the contractor's performance."
} 
the services acquired, similar to what CMS and private health providers have begun to adopt?10 The answer to all of these questions is, perhaps.

Ultimately, one of the tensions of VA contracting for purchased care involves the level of formality that ought to apply under FAR and VAAR. The full requirements of FAR and VAAR are intended to ensure rigor in the contracting process, through competitive bidding; tight management controls; and appropriate standards for notice, evaluating bids, qualifying contractors, and other factors. To the extent that concerns have arisen about waste, inefficiency, or unresponsiveness in VA purchased care contracting or about local contract terms that are insufficient to ensure the quality of care being purchased, in principle, tighter requirements under FAR and VAAR might be helpful to address these problems. On the other hand, the downside to full formality under FAR and VAAR is that contracts carried out thereunder become more burdensome for outside providers to enter into and potentially less attractive to participate in, at least on a local basis and for small quantities of service. Where VA has a legitimate reason and need to purchase small quantities of service locally for individual Veterans and there is no network provider who can provide timely care, it may be considerably easier to do so through the streamlined rules under the micro-purchase threshold. Outside providers may be more open to direct contracting, which can involve terms more similar to the terms they would encounter in the commercial market for health care services. Put another way, VA may obtain the benefit of competitive rigor (and whatever price or quality advantages that this confers) when it structures large purchased care contracts under the full weight of FAR and VAAR, while obtaining the alternative benefits of flexibility and greater attractiveness to local providers when using purchase orders for small quantities of service.

In Volume I of VA's FY 2016 Budget Submission to Congress, VA included a specific legislative proposal to update its purchased care authority, particularly with regard to provider agreements and contracting (VA Office of Budget, 2015). Citing outdated and scattered authorities which "in some cases have created confusion and uncertainty," VA proposed a legislative update that would "streamline and speed the process for purchasing care for an individual Veteran that is not easily accomplished through a more complex contract with a private provider." Full language of the proposal was not available as of this writing (summer 2015), but VA described its intent as "preserving key protections that would be found in full FAR-based contracting, while providing the benefits of a more streamlined and less complex practice that is more likely to appeal to solo practitioners or small healthcare providers." Taken at face value, it appears that the VA proposal seeks to protect and enhance flexibility in purchased care contracting for some services at the local level, where the Secretary believes that there are meaningful advantages to this practice.

In contrast to this proposal are some of the future possibilities for VA contracting, particularly in a world where VA becomes much more active as a purchaser and more innovative in shifting toward payment models based on bundled purchasing. As we discuss later in in this chapter, new definitions of "episodes of care" are now being developed outside of VA, and various outside payer and provider organizations are actively working to build new contracting models that leverage these definitions to support bundled purchasing and related forms of risk shifting between payers and providers. It seems entirely plausible that VA in the future might want to experiment with similar contractual approaches, based on advanced definitions of

10 Regarding performance-based, bundled payment contracting innovations being explored by CMS and others, see, for example, Shelton, Ondra, \& Levin (2015) and McKesson Health Solutions (2014). 
episodes of care, and the aggregation of its relationships with outside providers into large contracts that (presumably) would be subject to the full weight of FAR and VAAR formal review and procedures. There is not a single "right" approach to federal contracting for VA purchased care, or to the procurement rules under FAR and VAAR. Rather, VA might obtain different advantages when it pursues different approaches to contracting, such as economies of scale, or more sophisticated approaches that enable VA to pay for Veteran outcomes (instead of quantity of services). Ultimately, policy-makers may need to reflect on the overall strategy behind purchased care contracting practice, and what VA purchased care is intended to achieve, to select and refine an optimal path for the "units of purchase" and, consequently, the appropriate treatment of any such contracts under FAR and VAAR. Figure 5-1 illustrates the strategic trade-off between two different approaches to purchased care contracting under FAR and VAAR.

In May 2015, a senior VA procurement official came forward with allegations of widespread misconduct and violations of procurement rules under FAR and VAAR, particularly regarding the purchase of outside medical services under the Fee-Based Care program (the latter being another name for traditional purchased care; see Frye, 2015). It is beyond the scope of this report to review those allegations in detail. ${ }^{11}$ Nevertheless, the allegations reflect a similar duality in VA contracting practice to what we have described here, as well as considerable disagreement within VA about how best to work within FAR and VAAR acquisition framework to appropriately purchase care for Veterans. At present, VA has some authority to engage in local-level contracting for purchased care for services of small value, under

Figure 5-1

Alternative Approaches to Purchased Care Strategy for Procurement

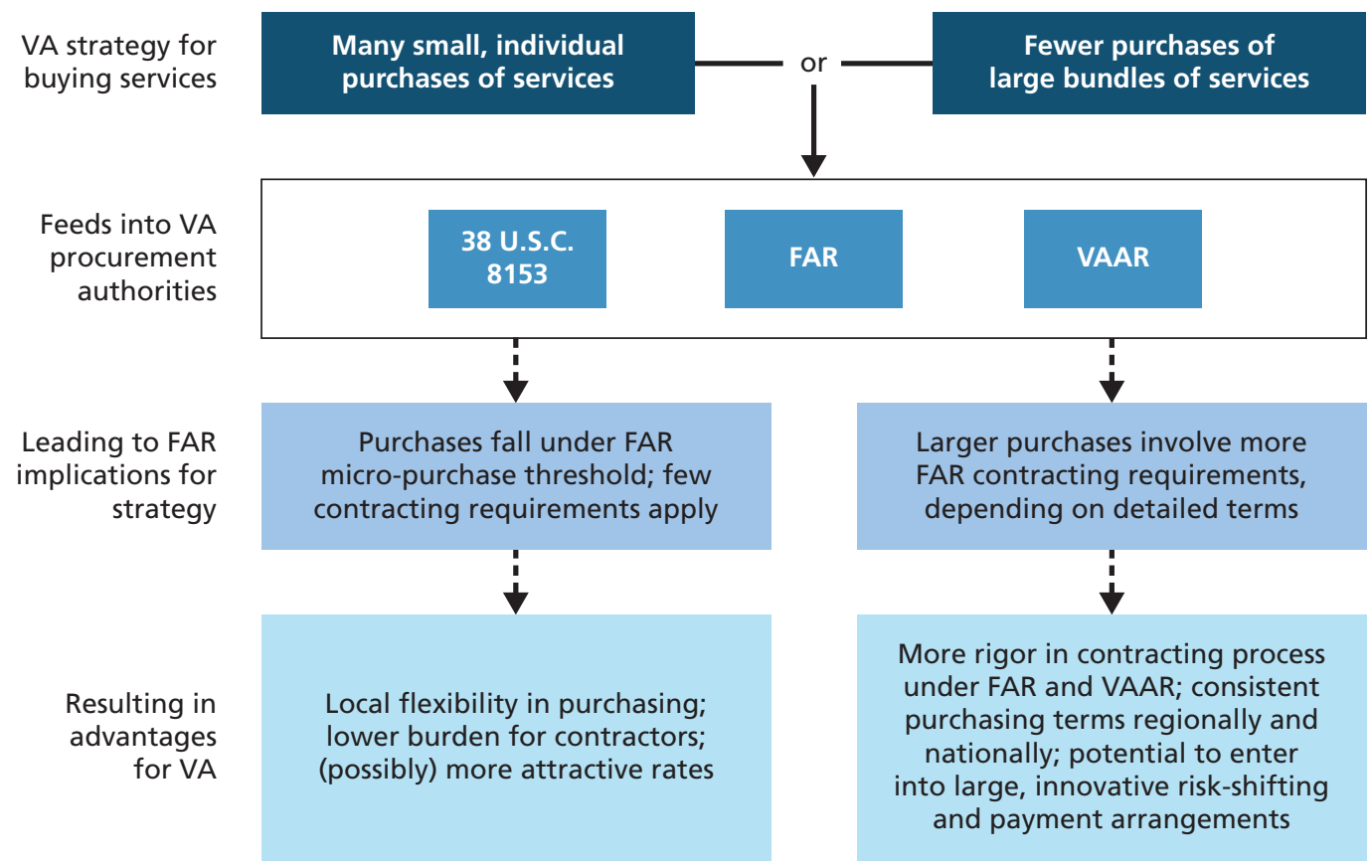

RAND RR1165z3-5.1

11 See the Assessment J report, on pharmaceuticals, medical and surgical supplies, and medical devices (McKinsey, 2015a), for a more lengthy discussion of the allegations contained in the Frye memo and the implications both for contracting and senior management within VA. 
streamlined FAR requirements, and carries out significant activity under this authority. Meanwhile, VA is also involved in pursuing much larger purchased care contracts, subject to the full requirements of FAR and VAAR. It remains for policy-makers to determine whether the benefits of less formal contracting for local, small-value purchases of care are worth preserving (or even extending) and, if so, how this will fit with the future trajectory of VA purchased care contracting writ large.

\subsubsection{Why Is Procurement Important to Purchased Care Strategy?}

Ultimately, purchased care involves VA in contracting with outside providers and exchanging payment for medical services received. Assuming that VA has good reason to engage in purchased care in the first place, procurement rules and strategy help to determine what VA is buying and both the terms and processes that are involved in buying it. For stakeholders, some basic questions about procurement approaches follow. Is the primary aim to maximize efficiency in VA purchasing or rigor in competitive bidding through the use of large-scale, aggregated contracting approaches? Is the aim to preserve VA flexibility in contracting for individual services to Veterans on a local basis? Or is the aim to encourage innovation in VA contracting and to shift the units of purchase and the terms of payment in ways that might enhance both quality and efficiency down the line? Different answers to these questions might lead to very different approaches to VA purchased care and to different proposals for modifying procurement processes and authority.

\subsection{VA's Approach to "Episodes of Care"}

The Veterans Choice Act mandate for Section 201, Assessment C, includes the task of addressing "the authorities and mechanisms under which the Secretary may furnish hospital care, medical services, and other health care at non-Department facilities, including whether the Secretary should have the authority to furnish such care and services at such facilities through the completion of episodes of care" [emphasis added]. Episode of care is a key term in this mandate, and also a key term in any discussion about VA purchased care policy.

\subsubsection{Defining the Episode Under the Veterans Choice Act}

As we first explained in Chapter Three, the Veterans Choice Act requires VA to allow a Veteran to obtain "hospital care and medical services from [the non-VA] health care provider through the completion of the episode of care," which includes "all specialty and ancillary services deemed necessary as part of the treatment recommended in the course of such hospital care or medical services" (Sec. 101(h)). The Veterans Choice Act does not define episode of care, though it does limit the provision of care from any health care provider under a single Choice authorization to a maximum of 60 days (Sec. 101(h)). Thus, whatever the Veterans Choice Act considered an episode of care to be, Choice would only cover the first 60 days thereof without follow-up authorizations.

Although the meaning of episode of care might not be clear from the act's language, its use within VA predates the Veterans Choice Act. Almost three decades ago, for example, it was simply the "period of consecutive days . . . beginning with the first day on which a veteran is furnished hospital or nursing home care; and ... ending on the day of the veteran's discharge from the hospital or nursing home facility, as the case may be" (Pub. L. 99-272, Sec. 19011(f) 
(2)(C), 1986). A later regulation, related to VA's provision of temporary lodging rather than non-VA care, defined the term as "a course of outpatient treatment, or a period of hospitalization, during which a veteran receives health care under 38 U.S.C. chapter 17, or 38 U.S.C. 8111 or 8153 ." It included a list of examples, such as "[e]xtended outpatient treatment, such as treatment associated with organ transplant, chemotherapy, or radiation" (38 C.F.R. 60.2). A 2012 internal directive stated that episode of care "as it pertains to VHA Non-VA programs refers to a set of clinically related healthcare services for a specific unique illness or condition (diagnosis and/or procedure) provided by an authorized non-VA provider during a defined authorized period of time" (VHA Chief Business Office, 2012).

In its November 2014 final interim rule, VA defined episode of care as "a necessary course of treatment, including follow-up appointments and ancillary and specialty services, which lasts no longer than 60 days from the date of the first appointment with a non-VA health care provider" (38 C.F.R. 17.1505). While the regulation appears to track the language in Section 101(h) of the Veterans Choice Act, there are some important differences. Prior VA use of episode of care simply described what can be characterized as a set of related services ("a course of outpatient treatment, or a period of hospitalization," "a set of clinically related healthcare services for a specific unique illness or condition"), and the interim final rule does incorporate "course of treatment" into the new definition. However, VA's final interim rule also included the modifier "necessary," suggesting that not all potential courses of treatment for a condition could be regarded as an episode of care. The comments to the interim final rule indicate that VA gave significant weight to the language in Section 101(h) of the Veterans Choice Act, which provides guidance on the types of services that might be provided in an episode of care:

$[T]$ he Secretary shall ensure that ... the veteran receives such hospital care and medical services from such health care provider through the completion of the episode of care (but for a period not exceeding 60 days), including all specialty and ancillary services deemed necessary as part of the treatment recommended in the course of such hospital care or medical services. [Emphasis added.]

One plausible interpretation for this passage is that Congress was calling on VA to ensure that a Veteran eligible for Choice due to distance or time in fact received whatever treatment was recommended by the non-VA provider, including any specialty and ancillary services that the non-VA provider deemed necessary. In other words, Section 101(h) can be seen as conferring a heightened level of discretion to non-VA health care providers to manage the course of treatment once the referral was made. ${ }^{12}$ Under VA's interpretation, however, it would be VA alone that would determine what types of services are necessary for a Veteran's care under the Choice program. ${ }^{13}$ As the comments to the interim final rule indicated, "We believe that the language 'deemed necessary' authorizes VA to make such determinations" (79 Fed. Reg. 65571). In arguing for the need for VA determinations of medical necessity in all instances, the comments to the interim final rule cite a passage from the Conference Report:

\footnotetext{
12 This interpretation is supported by the title of Section 101(h), "Follow-Up Care," which suggests that the original congressional intention was to address medical care and services subsequent to the initial contact with a non-VA provider. Put another way, Section 101(h) requires VA to ensure that non-VA providers are given the opportunity to control the delivery of care and services after the initial contact.

13 VA's interpretation may also trace back to the language of 38 U.S.C. 1703(a), which empowers the Secretary to purchase care when VA facilities are "not capable of furnishing the care or services [that are] required" [emphasis added].
} 
When coordinating care for eligible veterans through the Non-VA Care Coordination program, the Department should attempt to ensure when an appointment is authorized, the eligible veteran receives care within an appropriate time period, as defined by medical necessity as determined by the referring physician, or a mandatory time period established by the Secretary when the request for care is not initiated by a physician, that all medical fees are appropriately paid and health care records are returned to the Department within the prescribed time. (House Report 113-564, 2014, p. 56)

Given that the passage appears to speak almost exclusively to the issue of time rather than types of services, one interpretation of the conferees' original intent was that VA should ensure that a Veteran's care is delivered within a time period that is based on "medical necessity as determined by the referring physician" or within a mandatory time period as established by VA.

Regardless of how an episode of care is defined, the Veterans Choice Act is clear that VA must specifically authorize, at least initially, the provision of hospital care or medical services by non-VA providers or facilities as part of the Choice program. ${ }^{14}$ The interim final rule underscores this requirement by stating that VA will only pay for an episode of care that it has specifically authorized (38 C.F.R. 17.1535(c)). The comments to the interim final rule characterize the permission being requested as an authorization from VA to schedule an appointment with a non-VA provider. ${ }^{15}$ The need for prior authorization is one reason why VA specifically excluded emergency room visits and unscheduled visits to a clinic from the type of "authorized and scheduled encounter with a health care provider" that would take place under the Choice program (38 C.F.R. 17.1505). ${ }^{16}$ Moreover, the rule puts the onus on the provider to contact VA for additional permission to provide care or services that go beyond the scope of the initial authorization. Given that a covered episode of care is limited in duration to 60 days, authorization must again be issued should the Veteran need continuing treatment beyond the twomonth ceiling. Thus, it is certainly conceivable that a six-month course of treatment provided by a non-VA health care professional might involve multiple instances in which VA would need to revisit the authorization decision.

\subsubsection{What Are Episodes, and Why Does the Definition Matter for Purchased Care?}

In the section above, we briefly discussed the legal contours of episodes of care as VA authority currently defines these episodes. However, the legal discussion sidesteps a more basic, conceptual explanation of what an episode of care actually is. Put simply, an "episode" involves a coherent and clinically meaningful trajectory of care, tied to an underlying medical condition for which treatment is sought. Moreover, definition of the episode is also administratively important. Among other things, the boundaries of the "episode" determine how many services can be considered under a single referral and authorization for outside care. A broader definition for the episode would make it easier for a Veteran to obtain more services outside of VA,

\footnotetext{
${ }^{14}$ For example, Section 101(c)(1)(B) indicates that one of the options available to an eligible Veteran is to have VA authorize Choice care and services.

15 "In short, if a veteran visits a non-VA health care provider without seeking authorization from VA to schedule such an appointment, VA cannot use Program funds to pay for the services delivered and cannot provide reimbursement after the fact" (79 Fed. Reg. 65574).

16 As the commentary to the interim final rule indicates, such events "are not scheduled encounters and cannot be authorized in advance" (79 Fed. Reg. 65574).
} 
once having obtained an authorization for that episode, and in that sense might be viewed as widening the aperture for purchased care (with the potential trade-offs in utilization and cost). A narrower definition for the episode (say, limited to a single outpatient appointment) is inherently more restrictive, in the sense that it imposes a greater limit on how much outside service can be obtained under a single referral and authorization. By corollary, a narrower definition of the episode may give VA more granular control over the purchase of outside services and more operating responsibility for monitoring and approving such services.

VA has used the phrase episode of care in various contexts, often to place an outer boundary on the length of time for which a Veteran can receive a particular benefit or type of care. In the context of purchased care, an episode is defined by VHA as "a set of clinically related healthcare services for a specific unique illness or condition (diagnosis and/or procedure) provided by an authorized non-VA provider during a defined authorized period of time" (VHA Chief Business Office, 2012). Section 101(h) of the Veterans Choice Act states that VA will not pay for external medical services for an "episode of care" if it [the episode] extends beyond 60 days without reauthorization. Subsequent regulations adopted by VA under 38 C.F.R. 17.1505 provided the following definition for episode of care: "a necessary course of treatment, including follow-up appointments and ancillary and specialty services, which lasts no longer than 60 days from the date of the first appointment with a non-VA health care provider."

There is an inborn tension between quality control and oversight in the authority to purchase episodes of care. The 60-day threshold mandated in Choice is used to ensure that the authorized care is the necessary course of treatment. If an episode of care lasts longer than 60 days, then the Veteran must be reauthorized to receive treatment and services, either within VA or through a non-VA provider. Since VA is responsible for ensuring both that Veterans receive high-quality care and that the Department delivers care efficiently and effectively, the 60-day bookend allows VA to assess patients' status and match their needs with the best available resources. While the reauthorization process is an additional step, which may be inherently inefficient, its overarching purpose is to embed consideration of cost and oversight of quality of care into purchased care authorization. Medicare provides an example of a slightly different approach to the role of a payer vis-à-vis quality control and oversight. It is increasingly monitoring provider performance and monetarily rewarding or punishing providers based on the quality of care provided.

In practice, episodes may be constructed in narrow or increasingly broad ways with respect to providers, settings, and time period. A narrow construction might involve services offered by one provider in one setting, such as the provider and hospital services for a specified inpatient course of treatment. An intermediate construction could include all providers in one setting, such as all necessary provider and hospital services for an inpatient stay. A broader episode construction could also include all providers for an inpatient post-acute stay. While episodes of acute care typically begin and end at discrete times (for example, the day of a procedure or of the last follow-up visit), episodes for chronic events typically capture all treatment over an established time period, perhaps ranging from 60 days to as long as 12 months.

How an episode of care is defined is critical to how VA purchased care operates in practice today. For example, in our interviews, some local VA hospital personnel stated that ambiguity and inconsistency in defining episodes of care present a significant challenge for the system. One VISN director noted that the definition of episode of care under the Veterans Choice Act is confusing for serious ailments that require such treatments as chemotherapy and for which it is clear from the outset that treatment will last longer than 60 days and will necessitate new 
authorizations. In a related vein, a senior VA official brought up continuity of care issues, pointing out that the definition of episode of care under the Veterans Choice Act "has a potential to undermine the Veteran's comfort with the care they are receiving."

Figure 5-2 illustrates the time frames for five different episodes of care. As the figure shows, episodes of care may vary greatly in duration. Depending on the nature of treatment sought, an episode may be much shorter or longer than the 60-day reauthorization period used in the Choice program.

Lack of clarity in how to define episodes appears to have led some VAMCs to adopt narrower policies than others, in terms of the breadth of their referrals and authorizations for outside care and in the amounts of outside services that a Veteran can access in connection with a single referral. Presumably, this is a challenge that affects both ease of access to care outside VA and related costs.

Apart from current VA practice, the definition of episode of care is also intimately tied a new and emerging set of payment reforms in the United States more broadly. These reforms involve bundled payment and performance metrics based on clinical episodes, rather than traditional fee-for-service practice. In the future, new definitions of episode of care might become the basis for a new generation of payer-provider relationships and contracts in the broader U.S. health care market. With regard to VA, redefining the episode of care in line with broader market trends could have a major impact on what VA purchases, the terms on which it does so, and related efforts connected with monitoring the quality of care. It seems likely that VA purchased care practice may need to evolve over time to keep up with the outside state of the art in defining what constitutes an episode of care.

\subsubsection{External Models for Episodes of Care}

Episode of care is a commonly used concept in health care. One of the earliest definitions was offered by Hornbrook, Hurtado, \& Johnson (1985, p. 171) to define the boundaries around

Figure 5-2

Episode of Care Duration for Various Types of Care

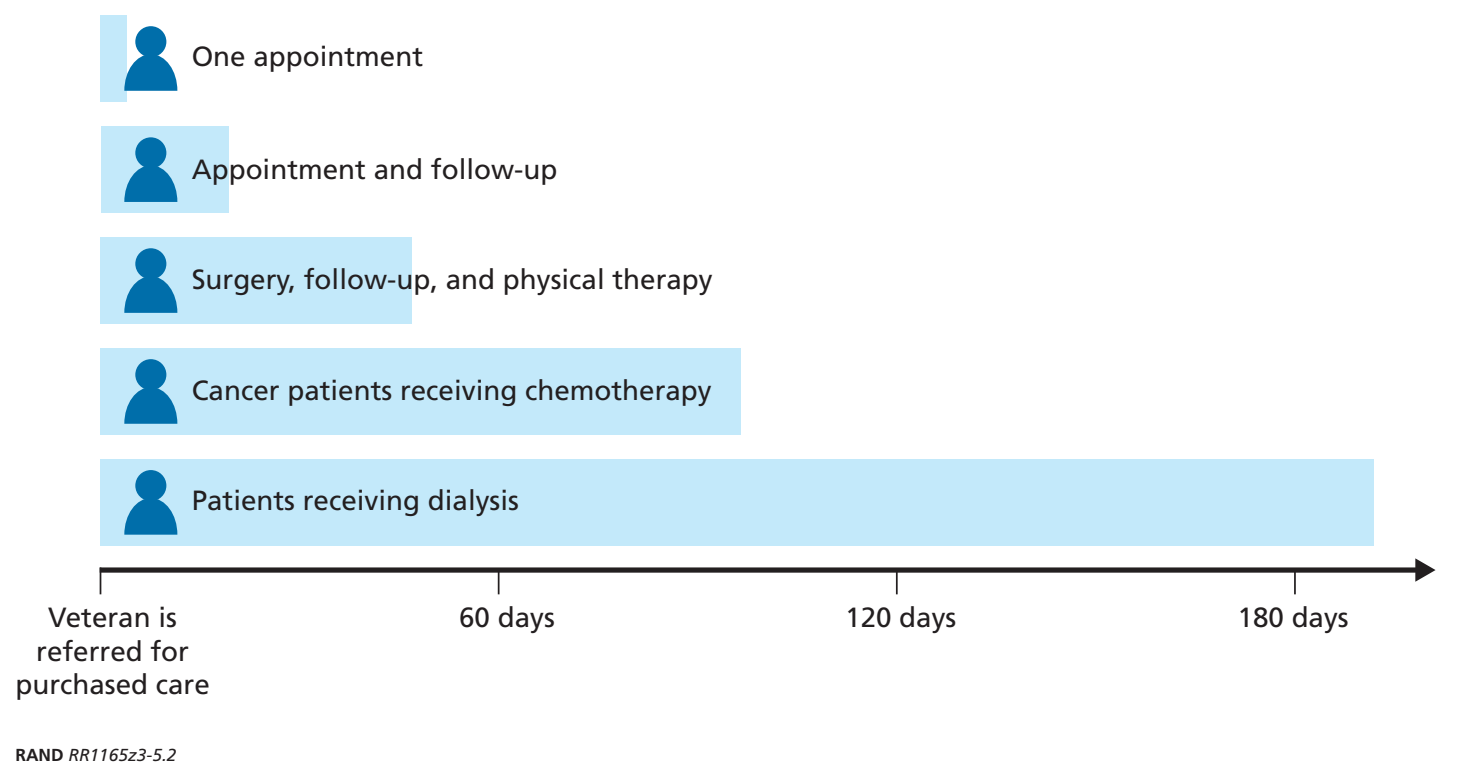


medical care for purposes of economic analysis: "A series of temporally contiguous healthcare services related to the treatment of a given spell of illness or provided in response to a specific request by the patient or other relevant entity." The authors aptly point out that episodes can be viewed from the perspective of the patient ("spell of illness"), the provider ("course of disease"), or the payer ("bundle of service").

A series of tools has been used to operationalize episodes of care in the private sector. Episode "groupers," such as the OptumInsight Symmetry Episode Treatment Groups product, the 3M Patient Focused Episode grouper, the Truven Medstat Medical Episode Grouper, the Health Care Incentives Institute's Prometheus, and the Cave grouper, are software tools that create condition-specific episodes from administrative claims data. These products use different methodologies to group and analyze services delivered by providers into episodes over a defined period of time and for specific clinical conditions. They have been used by commercial insurers and managed care organizations, health systems, and other payers in various ways connected to purchasing arrangements, coordination of care, and quality measurement.

The use of episodes of care (and corresponding tools and definitions for the episode) has been motivated by the desire to improve provider performance and care coordination while better controlling health care costs. A 2007 Institute of Medicine report, Rewarding Provider Performance: Aligning Incentives in Medicare (Committee on Redesigning Health Insurance Performance Measures, Payment, and Performance Improvement Programs, 2007), laid the groundwork, recommending that "CMS ... build towards an ultimate vision of aggregating funds for rewards into one integrated pool that would accommodate shared accountability and encourage coordination of care" and that the current measure sets "should evolve over time to provide more comprehensive and longitudinal assessments of provider and system performance." One important step toward achieving these goals involves the refinement of new performance measurement capabilities that are congruent with the episode of care (however defined). Another step involves linking payments directly to the episode, rather than to a fee-for-service invoice of all the services delivered within the episode. Both of these innovations depend on the deployment of valid, useful standards for bounding the episode of care, as a basis for subsequent optimization both of performance measurement and of payment.

Since the IOM recommendations, numerous reports have advocated for the adoption of episodes as the basis of performance measurement and/or payment (Medicare Payment Advisory Commission, 2008; Miller, 2010; Schoen et al., 2013). The Affordable Care Act has also spurred experimentation with related alternative payment models, including bundled payment. We offer a brief summary below, describing the application of episodes of care in both the performance measurement and payment contexts.

\subsubsection{Applications of Episodes of Care}

\subsubsection{Performance Measurement}

It is widely accepted that performance measurement is a key strategy for efforts to improve the quality and value of health care, and several public and private payers have adopted an episodebased approach to performance measurement and quality improvement. As an example, both Medicare and commercial health plans are profiling physicians on measures of health care cost and quality and feeding that information back to the physicians to encourage improvements in the quality of care. Medicare's reporting efforts in this vein are illustrative, particularly regarding the tie between performance measurement and the episode of care. Medicare's Supplemental Quality and Resource Use Reports involve "confidential feedback reports provided to medical group practices with payment-standardized, risk-adjusted cost information 
on the management of their Medicare fee-for-service patients based on episodes of care" (CMS, 2015b). Although there is some concern that current-point-in-time quality measures that apply to discrete clinical settings and a single condition rather than multiple comorbid conditions may be insufficient for episode-based measurement, efforts are actively under way to fill the measurement gaps (Damberg et al., 2009).

Public reporting of quality and cost information offers another lever to improve the value of health care, and some organizations are notably employing episode-based measurement in their public reporting of resource use. Several regional health care alliances with large claims databases have been experimenting with reporting episode-based measures across providers for comparison purposes. As an example, the Wisconsin Collaborative for Healthcare Quality (2011) has reported variations in resource use for episodes of care for asthma, diabetes, hypertension, and pregnancy with delivery. Additionally, the Health Care Cost Institute has recently introduced a new consumer-focused website called Guroo (n.d.), which reports average costs for 70 "care bundles" or episodes. These reporting efforts are using episodes as a common unit of measurement to inform consumer and payer decision-making.

GAO has suggested that VA use episodes of care as the basis to monitor the cost of purchased care. In a 2013 report, it made the following recommendation:

VA can also improve its capability to more effectively monitor the fee basis care program. VA Central Office's monitoring efforts are limited by the inability to analyze fee basis care data by episode of care. Because information that would allow VA to pull together all services with a single office visit or inpatient stay is not available, VA Central Office cannot effectively monitor the payments made by fee basis care units or ensure that fee basis providers are billing VA appropriately for care. (GAO, 2013a, p. 33)

In 2014, VA officials responded to the $2013 \mathrm{GAO}$ report and indicated that they were making improvements to their data systems to allow for analysis of purchased care claims based on episodes of care, but they did not provide a time frame for completion of this initiative (Williamson, 2014).

Taken in sum, recent experience and practice outside VA has involved the development of new performance measurement techniques based on sophisticated episode of care definitions and the application of those techniques by payers to quality improvement and value monitoring among providers. In principle, VA could adopt a similar approach to its own purchased care practice in the future, potentially by building on episode of care definitions and related innovations developed independently and outside of VA.

\subsubsection{Bundled and Performance-Based Payment Approaches}

Episode-based or "bundled" payment is another strategy that is being implemented by both public and private payers to improve the value of care by creating a financial incentive for providers to eliminate services that are clinically ineffective or duplicative (Miller, 2009) and to encourage effective coordination of care among providers. One study estimated that widespread implementation of bundled payments could save Medicare $\$ 3$ billion to $\$ 15$ billion per year (Cutler \& Ghosh, 2012). Although the term bundled payment is relatively new, the first actual use of bundles involved the Diagnosis Related Groups adopted by CMS over 30 years ago, in connection with a new Inpatient Prospective Payment System mandated by Congress to control hospital costs. Prior to that time, providers retrospectively billed Medicare for all of their à la carte service costs connected to an episode of care. By contrast, Diagnosis Related 
Groups "bundle" the services that are typically needed to treat a patient with a particular condition, and CMS sets the corresponding rates based on its own analysis of the average costs associated with such care.

More recently, public and private payers and some self-insured employers have been experimenting with bundled payments to providers, on the basis of anticipated costs for clinically defined episodes. In theory, the payment for an episode may cover multiple provider types, settings, and services, but, in practice, the pilots have used fairly limited episode constructions to date. Although there has been some experimentation with bundled payments for chronic care, most of the experiments to date have been focused on acute care, and particularly on joint replacement, for which there are easily identifiable start and end dates to the episode. While many programs aspire to prospective payment, most of the models now in place are still using retrospective payment (Bailit \& Houy, 2014). These payment arrangements are typically accompanied by quality measures that may be specific to the episode (e.g., c-section rates for pregnancy episodes) or more generally applicable to acute care episodes in hospitals (e.g., readmissions, avoidable complications, patient education). For some bundled payment programs, the providers must meet some minimum standards on quality measures to participate. In other programs, provider "bonuses" are contingent on achieving predetermined levels on the quality measures. Quality measurement in these programs may also serve as an important deterrent to the underprovision of care.

Commercial health plans' use of bundled payment arrangements has been increasing but is still quite limited and was estimated to represent only 0.1 percent of commercial health plan payments as of September 30, 2014 (Catalyst for Payment Reform, 2014). However, there are some notable examples of successful implementation of bundled payment in the commercial sector. Geisinger Health Systems' "ProvenCare" model was originally developed to bundle payment for coronary artery bypass graft surgery in 2006. The model succeeded in achieving a 10-percent reduction in readmissions, shortening the average length of stay, and reducing hospital charges (Casale et al., 2007) and subsequently led Geisinger to develop bundled payment for elective coronary angioplasty, bariatric surgery, perinatal care, and treatment of some chronic conditions. United Healthcare ran a bundled payment pilot for oncology care between 2009 and 2012 that involved five sites and reportedly achieved a 34-percent cost savings without a negative impact on quality (Newcomer et al., 2014).

In a somewhat different approach in recent years, several health plans adopted the Prometheus ${ }^{17}$ model to implement bundled payment programs. The model assigns evidence-based case reimbursement rates to common conditions and procedures, with a single rate covering all inpatient and outpatient care associated with a given condition or procedure. The reimbursement rate is adjusted for the severity and complexity of each patient's condition. Starting as a pilot program in four sites, the Prometheus model has been adopted by other payers and plans, where it is in various stages of implementation. Blue Cross Blue Shield of North Carolina and Horizon Healthcare Services, Inc., have both moved from pilots to permanent reimbursement for hip and knee surgery. An evaluation of Prometheus at three pilot sites documented a series of challenges to the successful implementation of the bundled payment model. The challenges included defining the bundles, ${ }^{18}$ defining the payment method, implementing quality mea-

\footnotetext{
17 Prometheus Payment Inc. is a nonprofit initiative of Health Care Incentives Institute.

18 This would include defining episodes of care to which the bundles correspond.
} 
surement procedures, allocating payments among providers, and redesigning delivery (Hussey, Ridgely, \& Rosenthal, 2011).

Several common barriers to bundled payment implementation, and some unique ones related to California regulation of hospitals and health plans, arose in the Integrated Healthcare Association's Bundled Episode Payment and Gainsharing Demonstration. This project brought together a group of providers, health plans, and vendors to develop and implement a bundled payment program for orthopedic surgery in California, starting in 2010. Despite initial enthusiasm among all parties, three of six health plans dropped out of the project, and only two of eight hospitals signed contracts with the participating health plans (Ridgely et al., 2014). ${ }^{19}$ Delays in implementation, the drop-off in providers and payers, and the resulting small number of procedures completed under the new contracts prevented an evaluation of the impact of the payment model on quality and cost. An important lesson from these pilots is the need for a sufficient volume of episodes to justify the investment of resources required for implementation of bundled payment.

CMS has also been experimenting with episode-based payment, coupled with performance measurement, on an increasingly larger and broader scale. The first CMS foray into bundled payment was the Medicare Participating Heart Bypass Demonstration that took place between 1991 and 1996 and involved bundling physician and hospital payment for coronary artery bypass graft surgery at seven hospitals. ${ }^{20}$ It was estimated that Medicare realized savings of about 10 percent through the demonstration, with no negative impact on quality of care (Cromwell et al., 1998).

Medicare's next experiment with bundled payment was the Acute Care Episode Demonstration, which was implemented at five sites over three years and covered five acute care episode types. In addition to the new payment mechanism, the pilot emphasized enhanced coordination of care, cost-control incentives, adoption of standardized clinical protocols, and quality improvement activities (IMPAQ International, 2013). Cost savings for Medicare Parts $\mathrm{A}$ and $\mathrm{B}$ were estimated at $\$ 7.3$ million ( $\$ 585$ per episode) across sites, though there was significant variation in cost savings across the types of episodes and the sites, as well as some increases in post-acute care spending that reduced the net Medicare savings per episode to $\$ 319$. There were no significant changes in quality under the demonstration, however.

In 2013, CMS introduced a new demonstration, Bundled Payment for Care Improvement, ${ }^{21}$ which provides an opportunity to test bundled payment across 48 potential episode types. All four payment models offered to providers are triggered by an acute care stay, but the services and providers included and the payment type (retrospective or prospective) vary (CMS, n.d.-b). Nearly 6,500 providers entered an exploratory stage of the program, but it is not clear how many will move to the next stage of implementation. In interviews with organizations that have withdrawn from the program, providers indicated that the potential costs outweighed the potential benefits (Koenig et al., 2015). Finally, in February 2015, CMS introduced its first bundled payment model for specialty care, the Oncology Care Model. CMS has offered to enter into new payment agreements with physician practices administering chemotherapy to cancer patients with the goal of providing higher-quality, more coordinated cancer care at

19 Two ambulatory surgery centers also executed contracts with one health plan.

20 The demonstration began with four hospitals in 1991, and three hospitals were added in 1993.

21 For additional details, see the program overview on the CMS website (CMS, n.d.-b). 
a lower cost to Medicare (CMS, n.d.-b). This is Medicare's first bundled payment program for non-acute care.

Several state Medicaid programs have also been experimenting with bundled payment. The Arkansas Medicaid program, together with two commercial payers, is implementing episode-based payment for 15 acute and chronic episodes, including some conditions that are new for this payment model, such as attention deficit hyperactivity disorder and asthma. It is the first mandatory multipayer demonstration model of bundled payment in the country, and the Ohio and Tennessee Medicaid programs are in the early stages of implementing similar programs (Golden et al., 2015).

Finally, a handful of large self-insured employers ${ }^{22}$ are utilizing bundled payment as part of centers of excellence programs for employee medical care. In this model, the employer negotiates a fixed price (bundled payment) for a procedure (i.e., an acute care hospital episode based on a major clinical intervention) with one or several centers of excellence. The bundled payment, in this model, covers the entire cost of the employee's care, as well as travel and lodging for the employee and a caregiver. Procedures covered by the programs include cardiac care, spine surgery, and transplants. The goal for employers is higher-quality care, quicker employee returns to work, lower costs due to lower complication rates, and greater predictability of costs. The motivation for health system participation is the potential for new, non-local sources of patients.

Several employer coalitions are also coordinating centers of excellence programs that utilize bundled payment. A group of large companies (including Lowe's and Walmart) is collaborating with the Pacific Business Group on Health to form the Employers Centers of Excellence Network to offer knee and hip replacement and spinal surgeries at no cost to employees if they receive care through one of four designated health systems, starting in January 2014 (Pacific Business Group on Health, 2014). Under this program, the network qualifies both the hospitals and individual surgeons based on volume, complication rates, training and experience, and patient satisfaction. Additionally, centers of excellence must report to a joint replacement registry and incorporate shared decision-making with patients. These employer models are voluntary such that employees may choose to receive care from local providers and incur routine costs. Travel and care management are handled by Health Design Plus, a health care management company. Centers of excellence also provide a health care navigator who works with the patient's home physician on evaluation prior to surgery and follow-up post-surgery. The Employers Health Coalition, a group of 300 small employers, also established a travel surgery program in 2014.

Studies of the results of employer-based centers of excellence programs utilizing bundled payment are not yet available. However, Cleveland Clinic reported performing about 200 cardiac surgeries over the first three years of the Lowe's program, with 3-4 percent of patients readmitted to any hospital, compared with a rate of 9-13 percent for heart surgeries nationally (Chen, 2014). Walmart reported that savings from its spine surgery program have mainly come in the form of avoiding surgeries that physicians at the centers of excellence have determined to be inappropriate (Gawande, 2015)

In sum, although there has been a great deal of enthusiasm for the adoption of bundled payment reforms, experimentation to date has been limited in scope, and there is little evidence

22 Lowe's, Walmart, PepsiCo, Boeing, and Kroger have each established centers of excellence programs. 
about the impact on the cost and quality of care. Additionally, there are significant issues that may act as barriers to effective bundled payment arrangements. Hussey and colleagues (2009) describe several, including threshold decisions about the design of the episode (e.g., number of settings, number of conditions, and variation within episode types) and regarding the attribution of responsibility and distribution of payment to multiple providers involved in an episode. Beyond the challenges in bundled payment design, even highly experienced payers and providers have encountered difficulties in implementation. In recent interviews with seven commercial and state payers involved in bundled payment arrangements, the payers interviewed described a series of challenges related to implementing bundled payment. These included finding providers who were willing to participate; covering the time and resources required for reconciliation of claims against a prospective budget (in the case of retrospective payment arrangements); and covering the staffing required for provider education, reporting, and quality improvement in bundled payment (Bailit \& Houy, 2014).

\subsubsection{How Might VA Use a Revised Approach to Episodes of Care in the Future?}

Given all of the ongoing developments around episodes of care in the U.S. health care system more broadly, VA has the potential to undertake a range of similar innovations going forward. We briefly reflect on some of the possibilities below.

\subsubsection{To Modify the Time Window That Bounds VA Authorizations}

VA may continue to define and use episodes of care as it does today with the intent of bounding the amount of time or the scope of services for which a Veteran is eligible to use outside providers, without compelling a reauthorization. Alternately, VA might seek to adopt a more sophisticated and clinically based set of standards to define what constitutes an episode. In principle, VA could either develop such standards on its own or else adopt from the emerging state of the art, drawing on the work of CMS, the Arkansas Medicaid program, and privatesector payers. Any such adoption by VA would likely involve moving away from a very simple formulation of the episode of care, such as the 60-day time window imposed under the Veterans Choice Act.

On a practical level, improved standards for episodes of care could help local VA administrators to address some of the confusion on how to define and apply episodes, as we described earlier in this chapter.

\subsubsection{As a Basis for Performance Measurement}

As we described above, GAO recommended (and VA agreed) that VA should develop a claimsbased analytic capability for performance measurement, drawing on appropriate episode of care standards, as applied to purchased care claims data. In principle, such a capability would enable better monitoring of cost and quality of purchased care and ideally might support performance comparisons across VA purchased care, care directly delivered by VA, and care in other delivery systems unrelated to VA. VA's ability to adopt appropriate episode-based performance measurement may be constrained by the extent to which measurement frameworks that take into account the existence of multiple chronic conditions are developed externally or internally. Any future version of performance measurement that VA might adopt will likely be sensitive to its initial choices in implementing more advanced and nuanced standards for the episode of care. 


\subsubsection{As a Basis for New Approaches to Purchasing and Payment}

Assuming that VA first implements more advanced, clinically based standards for an episode of care, it could, in theory, move toward adopting new innovations in value-based payment by purchasing care from non-VA providers on the basis of the quality and cost of episodes, rather than on a traditional fee-for-service basis. Future revisions to VA purchased care along these lines could benefit from the experimentation currently under way in Medicare, Medicaid, and the commercial market. Particularly if emerging models for episode-based payment outside of VA prove to favorably impact the quality and cost of care, VA may wish to pursue a similar path for its own purchased care operations, at least in a limited way. As Figure 5-3 shows, designing an episode-based payment system would require VA to address a series of strategic questions, beyond the definition of episodes, to make a future payment system work. Among the threshold issues that would need to be addressed are the selection of procedures and conditions for episode-based payment, selection of outside providers appropriate and willing to participate, and selection of an appropriate payment mechanism (e.g., prospective versus retrospective).

In the future, rather than attempting to negotiate complex episode-based payment contracts with numerous providers across the country, VA might plausibly consider establishing several regional centers of excellence for selected conditions or procedures or joining an established, episode-based payment network, such as the Employers Centers of Excellence Network. Joining an existing network would have the advantage of tapping a pool of experienced providers who have already been screened for high performance and who have worked through many of the implementation challenges to episode-based payment, as described earlier.

Figure 5-3

Design Considerations for VA in Developing Episode-Based Payment Mechanisms
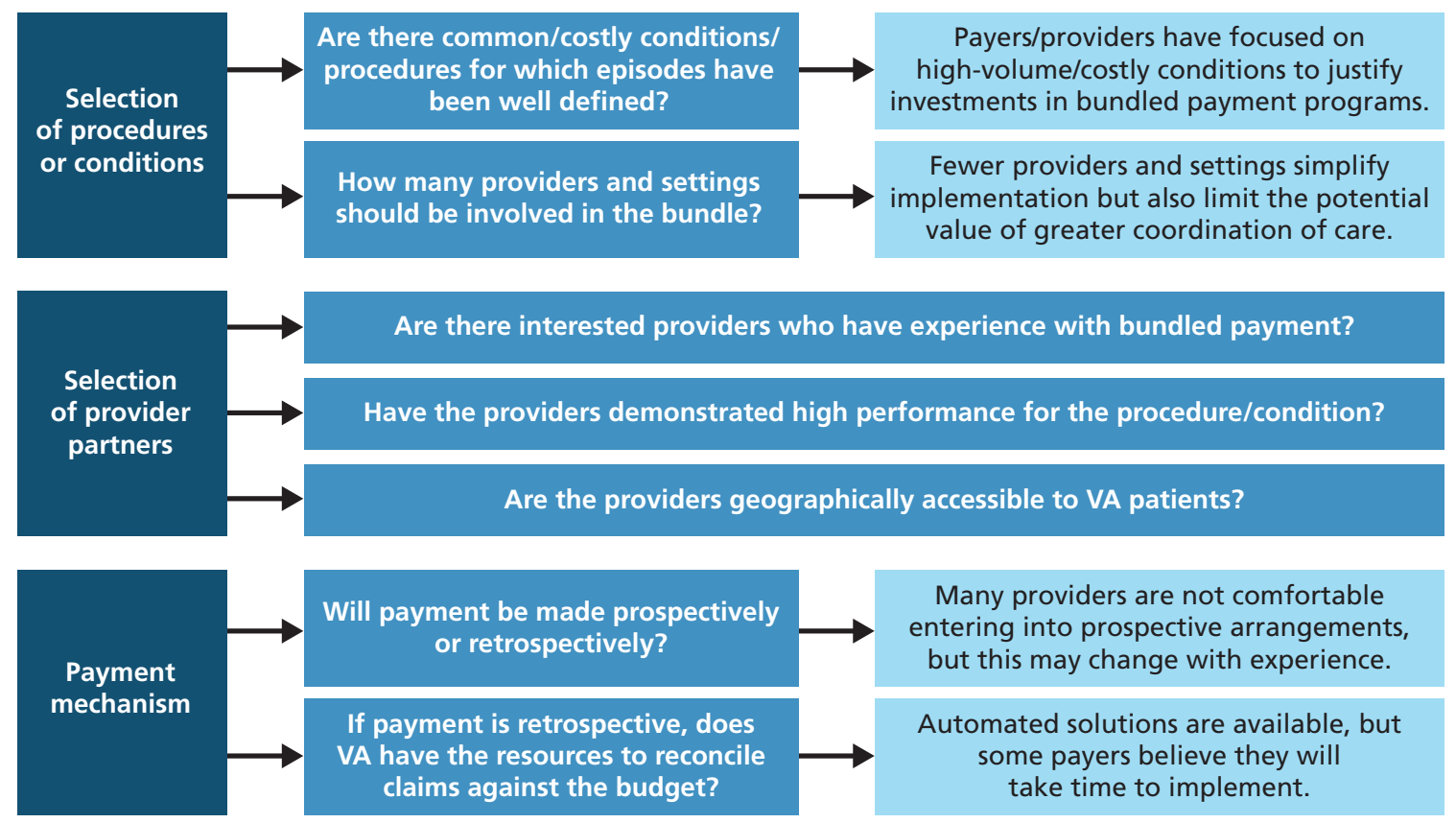

RAND RR1165z3-5.3 


\subsection{Discussion}

In sum, both VA's procurement policies and its standards for episodes of care are key to how the VA purchased care system actually operates. For VA to purchase outside services, it has to enter into some kind of contractual relationship with an outside provider, in which money is exchanged in return for services rendered. Any such contractual relationship, in turn, requires some foundational agreement over what the "standard units" being purchased actually are. In the future, new standards for the episode of care could be applied to VA contracting in ways that might radically shift the units of purchase, with a cascade of downstream implications for payment and risk-sharing, efficiency, performance measurement, quality assurance, and procurement practice.

For procurement, a key consideration for VA involves the link between rigorous, FARbased contracting requirements that tend to apply to large contracts, as opposed to the much more streamlined contracting requirements that apply to micro-purchases of service under FAR. Advocates of rigor in contracting may favor the formal approach and, by implication, higher-value umbrella contracts that cover networks of providers and large amounts of service on a regional or national basis. By contrast, advocates for local flexibility in contracting may favor the opposite approach. Setting aside the details of the federal procurement laws, VA must decide on a strategy for purchased care and how much emphasis ought to be placed on large contractual vehicles that draw on regional or national networks to provide outside services to large numbers of Veterans. The choice of strategic approach might be influenced by advantages of ensuring that the full requirements of FAR apply. Alternately, the strategy might be more heavily influenced by other considerations, such as ensuring access and/or efficiency through an appropriate approach to contracting.

The evolution of new standards for episodes of care could become another important, strategic consideration for VA in its approach to purchased care contracting. In the future and outside of VA, it seems likely that sophisticated standards for the episode of care could become a new platform for anchoring many payer-provider relationships. By corollary, bundled payment arrangements based on episodes would modify the units of purchase in health care, with corresponding risk-shifting between payers and providers, as through payment incentives to improve quality and the coordination of care and to control costs over the course of an "episode." Current state of the art in defining clinically meaningful episodes, and building performance measures and bundled payment contracts based on those definitions, is still in early in its development. However, as we have suggested here, intensive efforts are under way in Medicare and the private sector to try to scale up bundled payment arrangements and performance measurement, based on expanded and refined definitions of the episode of care.

In the future, VA should consider adopting similar innovations in bundled payment and performance measurement, based on more sophisticated and clinically nuanced standards for episodes of care. Plausibly, VA could develop such standards in house or else adopt them from work being done by other federal payers (e.g., CMS) or in the private sector. Regardless, new and expanded definitions for the episode of care could offer a platform for a new VA contracting approach to purchased care, such that the units of purchase would shift toward episodes and toward value-based payment and away from a more traditional fee-for-service framework. Here again, it seems likely that any such shift would move VA toward consolidating much of its purchase activity under larger, aggregate contractual vehicles that would cover many outside providers and large quantities of service. Strategically, that might be an attractive thing 
for VA to do, if episode-based purchasing can be shown to fulfill the promises of improving efficiency and quality in the procurement of outside services. Further evidence and experience with episode-based purchasing will need to accumulate before the merits of this approach for VA will become fully clear.

In the meantime, it is also important to note that a shift toward episode-based purchasing by VA might be undertaken as a stand-alone reform or, alternately, as a complement to an increased emphasis on purchased care by VA as a basic part of VA's health care mission. Other commentators on VA purchased care have offered opinions regarding what the balance should be between VA's provider and payer functions and whether VA should move more heavily in the direction of serving as payer in the future (e.g., Concerned Veterans for America, 2015). Without weighing in on the merit of this argument, it seems likely that an expanded emphasis on purchasing care might very well build on episode-based payment in the future and on the latest standards for defining episodes. Once again, these possibilities for the future invoke deep strategic considerations about what VA purchased care is for and how it ought to fit into VA's broader health care mission.

With all of this being said, what advice and insights can we offer to policy-makers about procurement and episodes of care? First, federal procurement rules are complex but are designed to ensure rigorous contracting processes and competitive bidding in purchasing. These are desirable things to achieve in the context of VA purchased care, but they are not the only strategic consideration for how to structure contracts to purchase services. Policy-makers may need to weigh other factors in determining an optimal strategy, including providers' willingness to contract with VA under more formal and burdensome requirements and the competing merits of local flexibility versus large-scale national contracting. Second, emerging standards for episodes of care may play directly into VA's contracting approach and strategy in the future by shifting the units of purchase and, consequently, the ways that VA might pursue quality and efficiency when purchasing outside care in the future.

Rather than approaching these issues as narrowly technical problems in existing authority, policy-makers instead will need to consider them in a broader, more forward-looking way in developing a coherent strategy for purchased care in the future. We will return to this point, and implications for VA policy, in Chapter Eight of this report. 



\section{PART III \\ Considerations for Future VA Purchased Care Authorities and Mechanisms}

This part examines future VA purchased care authorities and mechanisms and covers three chapters: Chapter Six, "A Review of Whether the Secretary Needs New Authorities for Purchased Care"; Chapter Seven, "Alternative Government Health Care Payer Models"; and Chapter Eight, "Conclusions and Recommendations." In Chapter Six, we discuss the objectives that influence potential changes in purchased care, the steps used to implement those changes, and the extent to which revisions would be needed in the Secretary's authorities. This analysis forms the basis for an integral theme of the report, which is the necessity of defining a purchased care strategy and objectives. In Chapter Seven, we explore how Medicare and the Military Health System can serve as potential models for purchasing care. This comparison offers lessons learned for policy-makers and VA concerning the mechanisms that support purchased care. Based on the culmination of our analysis in Parts I, II, and III, we respond to the assessment questions formally posed by Congress under Section 201(a)(1)(C) of the Veterans Choice Act and synthesize findings to support our assertions about purchased care and recommended changes to authorities and mechanisms. 

CHAPTER SIX

\section{A Review of Whether the Secretary Needs New Authorities for Purchased Care}

Overview of Methods and Data for Analysis of the Secretary's Need for New Purchased Care Authorities

- We drew on input from subject-matter experts and discussions with VA stakeholders to derive a series of potential objectives for policy changes to VA purchased care and to define illustrative implementing steps broadly responsive to these objectives.

- We then examined the authority implications of each of the implementing steps, building on existing VA legal authorities, policies, and guidance.

- We relied particularly on the existing language in applicable statutes and regulations when examining the authority implications of each implementing step.

Under Section 201(a)(1)(C), the statutory text of the Veterans Choice Act defines the focus of this assessment to include " $\mathrm{t}]$ he authorities and mechanisms under which the Secretary may furnish hospital care, medical services, and other health care at non-Department facilities, including whether the Secretary should have the authority to furnish such care and services at such facilities through the completion of episodes of care" [emphasis added]. The latter part of the assessment mandate poses a normative question: Broadly speaking, Congress has asked whether the Secretary should have more or less authority to furnish health care services at non-VA facilities than he has today, through the completion of "episodes of care." This normative question focuses on the desirability of a future change in the status quo of practice and authority and is inclusive rather than exhaustive-i.e., it invites comment on a somewhat broader array of potential policy changes.

The simple answer to this normative question depends, at least in part, on what Congress and VA most want to accomplish through purchased care practice. Determining whether it is a good idea to modify VA legal authority, or VA procedures that derive from that authority, requires identifying what policy-makers hope to achieve with respect to purchased care and their underlying assumptions, recognizing that those objectives might lead them to choose different targets for future policy changes.

To investigate the authority implications associated with a range of different possible policy changes to purchased care, we employed a method derived from scenario analysis. See Figure 6-1.

Starting from the set of objectives that VA or Congress might bring to changing purchased care, we define a series of illustrative implementing steps that they might choose to pursue and that are broadly responsive to one or more of these objectives. For the purposes of

1 See Chapters Three and Four for a detailed discussion of the meaning of episode of care. 
Figure 6-1

Objectives, Implementing Steps, and Implications for the Secretary's Authorities



this discussion, we group these implementing steps according to different aspects of purchased care (e.g., changes in the way that purchased care is managed). We then examine the implications for the Secretary's authorities (specifically, the need for legislative action, formal rulemaking by VA, or revisions to VA guidance or policy documents) in connection with each of the potential implementing steps. The objectives and steps comprise the elements for building many different potential scenarios for reforming purchased care. Our goal in this chapter is to offer insights into the revisions required in the Secretary's authorities by potential changes in purchased care. Therefore, we define the illustrative implementing steps rather than the scenarios themselves.

\subsection{Objectives for Policy Changes in Purchased Care}

We recognize that there could be a broad set of potential objectives for modifying the purchased care landscape, and so we define some that are currently being raised in the debate over VHA's future. We drew on a variety of sources for these objectives: congressional testimonies and hearings, articles and commission reports on the future of VA, and our interviews with purchased care stakeholders. ${ }^{2}$ We also discussed potential objectives with an internal RAND advisory panel, which included individuals with substantive knowledge in the areas of health care policy, health care financing, and Veterans' policy issues, as well as subject-matter expertise concerning VA as an institution. ${ }^{3}$

2 For some of the ideas in the debate on the future of purchased care, see Miller, 2014; Carrato, 2014; O'Hanlon, 2014; Weeks et al., 2009; Bandow, 2014; Frist \& Marshall, 2015; and Concerned Veterans for America, 2015.

3 Two members of the panel previously held senior executive service-level appointments as VA officials; a third is well known as an independent (non-RAND) expert in the area of VA health care policy; a fourth is an expert on Veteran mental health policy and was the co-lead on RAND's seminal study Invisible Wounds of War: Psychological and Cognitive Injuries, 
Table 6-1 captures a range of these potential objectives, which could lead to different choices for policy change and different implications for VA purchased care authority. It is important to note that these are not the only potential objectives for policy changes and that they are not mutually exclusive.

The objective for the first policy change would involve addressing a short-term mismatch between VA provider capacity and the demand for services by expanding purchased care initiatives, or by increasing Veteran access to existing initiatives, as a way to bridge the "gap." In principle, a future short-term "gap" could look similar, in some important respects, to the problems in access to care that prompted the passage of the Veterans Choice Act in 2014 (e.g., acute problems in the timeliness of scheduling appointments in particular locations, associated with underlying gaps in VA staff capacity or facilities). Alternatively, such a gap could involve another type of transient mismatch between the provider resources available within VA and demand for corresponding services (e.g., a shift in demand for specialty care in particular regions, together with an associated time lag in VA's ability to respond with new staffing or facilities). An important feature of short-term gaps is that they might appear with little warning, requiring VA to have an agile and flexible response capability. Given any short-term gap in the future, VA capacity could, in principle, be temporarily "patched" with purchased care until VA is able to address the gap by modifying its in-house provider resources and capabilities.

A second objective for policy change in purchased care could be to respond to a long-term mismatch between VA provider capacity and demand for services by Veterans. This objective differs from the first in that the hypothetical gaps would be structural in nature, and remedying them would involve long-term investments and enduring changes to VA practice. Purchased care would be undertaken to fill such a gap permanently. In principle, such gaps could arise in many different aspects of VA health care services and, depending on the particular

Table 6-1

Objectives for Policy Changes in Purchased Care

\begin{tabular}{|c|c|}
\hline Objective & Description \\
\hline $\begin{array}{l}\text { Address short-term gaps in VA health care } \\
\text { capacity through a temporary surge in } \\
\text { purchased care }\end{array}$ & $\begin{array}{l}\text { "Short-term gaps" could be those that exist today (i.e., in the } \\
\text { timeliness of appointments), or they could involve a future } \\
\text { mismatch between VA resources and demand for specialty care. }\end{array}$ \\
\hline $\begin{array}{l}\text { Address long-term gaps in VA health care } \\
\text { capacity through the use of purchased care } \\
\text { permanently }\end{array}$ & $\begin{array}{l}\text { Gaps could arise in any aspect of VA health care service capacity } \\
\text { that cannot be filled feasibly or efficiently by VA capacity } \\
\text { development. }\end{array}$ \\
\hline $\begin{array}{l}\text { Improve value of health care for Veterans } \\
\text { through purchased care }\end{array}$ & $\begin{array}{l}\text { From the perspective of government, purchased care could be } \\
\text { provided where doing so would lead to improvements in such } \\
\text { areas as clinical quality of care or cost-effectiveness. }\end{array}$ \\
\hline $\begin{array}{l}\text { Expand or enhance purchased care to } \\
\text { increase Veterans' choices }\end{array}$ & $\begin{array}{l}\text { Veterans could be offered more choice to seek coverage and care } \\
\text { outside of the traditional VHA system (e.g., via private providers } \\
\text { or other government facilities, such as those run by DoD). }\end{array}$ \\
\hline $\begin{array}{l}\text { Redefine the concept of VA health care by } \\
\text { aggressively outsourcing VA care }\end{array}$ & $\begin{array}{l}\text { The nature of VA health care activities could be transformed by } \\
\text { making purchased care much more focal as a primary mechanism } \\
\text { for delivering specific health care services to Veterans or for } \\
\text { delivering health care services to specific groups of Veterans. }\end{array}$ \\
\hline
\end{tabular}

Their Consequences, and Services to Assist Recovery; and a fifth served on multiple Presidential commissions and task forces on VA health care issues. 
nature of such a shortfall in resources, might reasonably be filled permanently by purchased care as an alternative to expanding VA's internal provider capabilities.

A third objective for policy change could involve seeking to improve the value of health care services delivered to Veterans via purchased care. Value (or cost-effectiveness), from VA's perspective, may involve a balanced consideration of several factors, including clinical quality of care, efficiency in service delivery, and timeliness of Veteran access. Broadly speaking, policy changes that might improve purchased care performance according to all these criteria-or according to one criterion without eroding performance in the other areas-could plausibly fit into this objective.

A fourth objective for policy change in purchased care would be involve seeking to expand Veterans' choices to seek coverage and care outside the traditional VHA system. This could be achieved via private providers or other government facilities, such as those run by $\mathrm{DoD}$, with the goal of enhancing Veteran satisfaction, access, or quality of care through the expansion of VA purchased care activities.

A fifth objective for policy change in purchased care could involve redefining the concept of VA health care, and the social contract between Veterans and VA, around more aggressive outsourcing of VA care. Reasons could include a desire to reduce government involvement in the direct provision of health care service. The result would be that purchased care would become much more focal as a primary mechanism for delivering specific types of services to Veterans or delivering services to specific groups of Veterans.

\subsection{Steps to Implement Policy Changes and Implications for Authorities}

Our goal is to offer insights into the revisions required in the Secretary's authorities (legislation, regulations, and internal VA policies) by potential changes in purchased care. We went beyond our list of objectives and defined a series of implementing steps involving concrete policy changes in purchased care. ${ }^{4}$ While these steps do not line up one to one with the objectives, they are broadly responsive to the objectives and are independent of each other. The steps address different aspects of purchased care; for ease of presentation, we grouped them into the following four categories:

- Expand and enhance relationships with providers outside VA.

- Modify Veterans' eligibility for purchased care.

- Change the way that purchased care is managed.

- Improve contracting for purchased care.

We are not recommending these implementing steps, nor did we assess their feasibility. We defined them to assess the implications for authorities. How policy-makers in VA or Congress might translate their objectives for changing purchased care into a package of specific implementing steps may or may not be straightforward, but it would likely involve difficult choices and judgments.

4 In defining our implementing steps, we once again drew on input from our internal advisory panel, the literature reviews, and our qualitative interviews with VA officials, both locally (e.g., at VAMCs across the country) and nationally (e.g., at VHA's Chief Business Office), as well as from VSOs, outside provider groups that contract with VA, officials from other federal health programs, officials involved with TRICARE, and independent subject-matter experts. 
We then analyzed each implementing step, determining how much formal intervention by either Congress or VA might be needed to carry it out. Some of the implementing steps would require new legislative action or a change to federal law by Congress. These sorts of changes could reflect a significant departure from the authority that the VA Secretary has today, or even a basic redesign of some of the structural features of VA and its purchased care programs. Some implementing steps may not require legislative change but might involve the Secretary modifying formal VA regulations. Finally, some other implementing steps might not require either new legislation or modified regulations. VA could execute those steps within the contours of existing authority simply by shifting its operating practice or modifying its internal guidance documents to reflect the changes.

In general, it is likely that any legislative change made to VA purchased care would also require a downstream amendment to current VA regulations or the promulgation of new ones to conform formal administrative authority to congressional mandates. In turn, it is also likely that any revision made to formal VA regulations would trigger corresponding changes downstream in VA internal policies and practices as well..$^{5}$ In all the summary tables and discussions of authority in this chapter, we characterize an implementing step as requiring a change in current regulations only if the step could be achieved to some degree by regulatory amendment alone; if the change need not be preceded by either congressional action or a formal VA regulatory amendment, we characterize the implementing step as requiring a change to current internal VA policies.

In addition, our assessment is based solely on the existing language in applicable sources of authority and assumes that all relevant stakeholders are of one mind when it comes to putting each implementing step into play. For example, assume that a particular step could be achieved solely by changing a VA regulation, without any need to address the matter through legislation. The summary tables below would reflect that assessment: legislation = no, regulation $=$ yes.

This analysis of authorities draws heavily on our findings from Chapters Three through Five of this report, on our literature review and legal analysis concerning the contours of VA's authority for purchased care initiatives, and on our qualitative interviews and investigation of local-level purchased care policies within VA.

\subsubsection{Implementing Steps: Expand and Enhance Relationships with Private Providers}

In this section, we describe implementing steps to expand and enhance relationships with private providers and, for each, the implications for authorities. Table 6-2 summarizes the steps and implications.

\subsubsection{Build New Relationships with Private-Sector Providers for Specific Types of Care}

In essence, this step envisions that VA would enter into new or revised contractual relationships to build or expand outside (i.e., nongovernment) preferred provider networks on a regional or national basis, with a particular focus on expanding clinically defined health care services for which VA wants to address a capacity gap. One of the implications of building these sorts of non-VA "clinical relationships" is that VA would wind up outsourcing more services-and a greater proportion of Veterans' demand for services - in at least some clinically specified domains. This kind of outsourcing could take on more than one form in the future. The sim-

5 This assumes that any new or modified regulations do not simply mirror existing VA policies or practices. 
Table 6-2

Implementing Steps: Expand and Enhance Partnerships with Private Providers

\begin{tabular}{|c|c|c|c|}
\hline Steps & Legislation Needed? & $\begin{array}{l}\text { Change in } \\
\text { Regulations } \\
\text { Needed? }\end{array}$ & $\begin{array}{l}\text { Change in Internal } \\
\text { VA Policies Needed? }\end{array}$ \\
\hline $\begin{array}{l}\text { Build new relationships with private-sector } \\
\text { providers for specific types of care (e.g., } \\
\text { specialty, primary) }\end{array}$ & No & No & Yes \\
\hline $\begin{array}{l}\text { Expand and enhance the national network of } \\
\text { outside providers for purchased care }\end{array}$ & No & No & Yes \\
\hline $\begin{array}{l}\text { Improve medical record and information } \\
\text { sharing across VA and non-VA organizations } \\
\text { and include effective channels for feedback }\end{array}$ & No & No & Yes \\
\hline
\end{tabular}

plest version of this step would essentially leave intact the current purchased care mechanisms for referring Veterans out of the system. It would merely facilitate such referrals by making available new (or newly expanded), domain-specific provider networks while strengthening the contractual foundation for the referrals. More ambitious versions of this step could also involve (1) shifting internal resourcing within VA to deemphasize the direct provision of related clinical services, (2) enhancing Veteran access to the outside networks for these service lines by streamlining or reducing current administrative requirements to obtain referrals from VA, (3) adopting an innovative contractual approach to purchasing related services and moving toward a bundled payment or capitated payment relationship between VA and its outside providers, or (4) more fully integrating purchased care providers into the VA system (such as by linking electronic health records) to facilitate smoother movement by Veterans between VA and non-VA providers and facilities.

\subsection{Implications for Authorities}

This implementation step can be understood to have an impact on two types of "authority." First, it involves creating new or revised contractual networks with outside service providers. Second, it involves supporting modifications to the administration of purchased care or to clinical service resourcing within VA itself. For the simplest version of this step, our analysis suggests that there are no fundamental legislative barriers to VA moving in this contractual direction, and, indeed, building public-private partnerships is already authorized by statute. The need for a regulatory amendment to build new, specialized provider networks is likely to be minimal as well. There are no current regulations, for example, that specifically control the administration of the PC3 program and its use of provider networks. As such, this appears to be an area in which VA could modify its practice in a relatively straightforward manner through internal policy changes. Note that a more ambitious version of the step-particularly one involving the streamlining of administrative requirements for purchased care or radically adjusting the resourcing for direct clinical services-would be much more likely to trigger a need for regulatory or statutory changes as well.

\subsubsection{Expand and Enhance the National Network of Outside Providers for Purchased Care}

VA has already taken steps to expand and enhance its national network of outside care providers through PC3 and its contractor relationships with Health Net and TriWest thereunder. In 
principle, each of the PC3 contractors is responsible for establishing a broad provider network covering a large part of the United States in support of VA purchased care activity. In practice, however, the PC3 contractors have had only limited time in which to build their networks; participating provider coverage is reportedly spotty in some parts of the country, and the terms of network participation may not be attractive to some providers. This step would involve VA (possibly through TPAs) establishing a stronger, deeper national provider network (similar in breadth to that which currently exists under DoD's TRICARE system), which would become the default mechanism for all purchased care activity, absent a compelling reason for using some other contractual route to purchase care in a specific instance. Likely elements of this step would involve enhancing the attractiveness of provider participation in the network, in part by accelerating claims processing activity and by making the rates paid to providers competitive and attractive. The step might also involve enhancing ongoing VA efforts and incentives to compel local VA officials to use the national network mechanism for purchasing care, rather than other contractual mechanisms, whenever possible.

\subsection{Implications for Authorities}

Only VA internal policies and practices would need to change. Existing statutory and regulatory authority would not bar VA from strengthening its networks of providers under the PC3 mechanism, or from creating new network mechanisms, as long as the criteria for provider participation do not contradict what is already required in VA's enabling statutes.

\subsubsection{Improve Medical Record and Information Sharing Across VA and Non-VA Organizations, and Include Effective Channels for Feedback}

The focal point for this step involves strengthening the coordination and oversight of care through the sharing of medical records back to VA during and following a referral of a Veteran through any mechanism for purchased care. At present, consistent with the industry norm, record-sharing requirements under some existing VA purchased care contracts (including the PC3 mechanism) are relatively unsophisticated and in many instances may involve faxing of paper records back to VA following an outside treatment episode.

Given the status quo, there are multiple reasons why improved record sharing could be beneficial to VA and to the Veterans that it serves. Improved access to outside records could facilitate VA in coordinating care across multiple outside providers and between VA and non-VA providers. Through its Virtual Lifetime Electronic Record initiative, VA has pursued electronic health information exchange with community providers. In the future, as more community providers develop the capability to share information electronically, VA may want to direct its referrals to these providers and incorporate incentives in its contracting mechanisms for prompt exchange of electronic information through the Veteran Lifetime Electronic Record. In the meantime, receiving records describing care provided in the community, in forms that are both readable by VA and easy for outside providers to comply with, is a high priority. The latter point is notably important in this context, so as not add to the burdens of outside providers in purchased care, hence reducing their potential for dissatisfaction with participating in VA purchased care mechanisms.

\subsection{Implications for Authorities}

Setting aside broader federal restrictions that apply to the exchange of identifiable health records under the Health Insurance Portability and Accountability Act, putting this step into place would likely only require changes in VA internal policies and practices to standardize and 
facilitate the sharing of medical records by outside providers. While some VA statutes already mandate the return of the medical record to VA by the external provider once the treatment has been completed, ${ }^{6}$ these would not conflict with what is being proposed here. As a matter of VA practice, medical record-sharing provisions have already become a standard, contractually based requirement for providers seeking to join PC3 networks, even in the absence of explicit statutory or regulatory mandates. Carrying out this step in practice would likely depend more on improved contractual provisions, and on investment and infrastructure support to outside providers that want to participate in the Veteran Lifetime Electronic Record, than it would on changes to legislation or formal VA regulations.

\subsubsection{Implementing Steps: Modify Veterans' Eligibility for Purchased Care}

In this section, we describe implementing steps to modify the eligibility of Veterans for purchased care and, for each, the implications for authorities. Table 6-3 summarizes the steps and implications.

\subsubsection{Enhance Access to Purchased Care by Renewing or Extending the Veterans Choice Act}

This step would seek to enhance access to non-VA providers in a targeted way, in situations where VA's internal providers cannot deliver timely or economical service, moving beyond the contours of any of VA's existing, permanent initiatives for purchased care. Beyond simply removing or modifying Choice's current termination triggers, different versions of this step could involve funding the renewed program either as a part of VA's budget or separately and as either a discretionary or mandatory program. The results of a simple version of this step might look very similar to the 2014 incarnation of the Veterans Choice Act. Alternately, a more complicated version of this step might be tailored differently, as by making access to outside pro-

Table 6-3

Implementing Steps: Modify Veterans' Eligibility for Purchased Care

\begin{tabular}{|c|c|c|c|}
\hline Steps & Legislation Needed? & $\begin{array}{l}\text { Change in } \\
\text { Regulations } \\
\text { Needed? }\end{array}$ & $\begin{array}{l}\text { Change in Internal } \\
\text { VA Policies Needed? }\end{array}$ \\
\hline $\begin{array}{l}\text { Enhance access to purchased care by } \\
\text { renewing or extending the Veterans Choice } \\
\text { Act }\end{array}$ & Yes & * & * \\
\hline $\begin{array}{l}\text { Use priority groups to help determine } \\
\text { the allocation of purchased care and the } \\
\text { scheduling and authorization of purchased } \\
\text { care appointments }\end{array}$ & Yes & * & * \\
\hline $\begin{array}{l}\text { Expand the availability of purchased care to } \\
\text { Veterans when purchased care is more cost- } \\
\text { effective }\end{array}$ & No & No & Yes \\
\hline $\begin{array}{l}\text { Create a VA subsidy for Veterans to obtain } \\
\text { health insurance coverage through ACA } \\
\text { exchanges or other sources }\end{array}$ & Yes & * & * \\
\hline
\end{tabular}

NOTE: Asterisks in the table indicate where changes in authority would likely occur but would cascade from a preceding change at a higher level of authority. Thus, a change in legislation (marked "Yes") might also lead to a downstream change in corresponding regulation (marked with an asterisk).

6 See, for example, Section 101(l) of the Veterans Choice Act. 
viders easier to obtain or more widely available to Veterans, ${ }^{7}$ or by targeting the step to expand access only to those medical specialties or services which comprise a future capacity gap.

\subsection{Implications for Authorities}

Congressional action would be needed to extend Choice beyond the current legislative cutoff points (i.e., either an exhaustion of the Veterans Choice Fund or three years following the enactment of the Veterans Choice Act). Legislation would also be needed if the criteria for Veteran eligibility, provider qualifications, the mandatory or discretionary nature of the program, or other key aspects of Choice were changed in any material way from the language in the 2014 act. However, some functional expansion of Choice eligibility and other features as currently implemented by VA might be realized though the promulgation of new or modified regulations. ${ }^{8}$ VA would always have the capability to change its current internal policies in connection with the Choice program—for example, to expand the pool of eligible providers. ${ }^{9}$

\subsubsection{Use Priority Groups to Help Determine the Allocation of Purchased Care and the Scheduling and Authorization of Purchased Care Appointments}

Access to VA facilities and direct providers might be treated as a scarce resource by VA, either globally or with regard to specific clinical capabilities and lines of service. One way to prioritize access to purchased care plausibly could involve making purchased care resources more readily available as a choice to Veterans in lower- or higher-priority groups, with the aim of easing demand on VA's direct-care system and thereby increasing the availability of direct care resources for others. Different versions of this step could involve different adjustments to the rules for purchased care access to make purchased care more readily available to Veterans or more attractive to them as an option. For example, access to purchased care might be made a default assumption for access to selected services by selected groups of Veterans, in much the same way that wait time and driving distance are default criteria for access under the Choice program. Regardless, any version of this step would involve tying the priority group scheme to purchased care so that Veterans in the highest priority groups would have enhanced access to outside services.

\subsection{Implications for Authorities}

While there is existing authority for VA to prioritize the provision of medical care to certain classes of Veterans, a shift in approach of this magnitude would clearly require congressional action (see 38 U.S.C. 1710). No current authority allows access to purchased care solely on the basis of a Veteran characteristic unrelated to medical need or issues regarding access to VA medical facilities. This implementing step would also create a need to promulgate modified regulations, given that existing administrative guidance addresses the prioritization of scheduling appointments, rather than prioritization of external care referrals (see 38 C.F.R. 17.49).

\footnotetext{
7 There are many hypothetical ways that Veteran access to non-VA providers could be expanded in the future. One simple example would involve replacing the " 30 -day/40-mile" rule with a "21-day/30-mile" rule. The consistent implication of such reforms is that they would presumably increase both the utilization and cost of outsourced health care services for VA, all other factors being held equal.

8 The recent regulatory change from geodesic distance to driving distance as VA's yardstick for measuring distance from a Veteran's residence to a VA medical facility is one example of such a process.

9 For example, VA could move toward a policy in which the maximum payment for services allowable by statute is the default standard used for compensating providers, rather than pushing for negotiated percentages of Medicare rates.
} 


\subsubsection{Expand the Availability of Purchased Care to Veterans When Purchased Care Is More Cost-Effective}

Under the existing core authority for purchased care (at 38 U.S.C. 1703), the Secretary may contract to purchase care when "Department facilities are not capable of furnishing economical hospital care or medical services because of geographical inaccessibility or are not capable of furnishing the care or services required." In principle, this provision leaves discretion to the Secretary in deciding when VA facilities are either "not capable" of furnishing service or not capable of doing so "economically" because of geographic inaccessibility. In practice under the traditional purchased care program, much of the discretion gets carried out locally and at the front line of VA encounters with Veterans, with VA clinicians and administrators determining the appropriateness of purchased care referrals on a case-by-case basis. This step would involve VA in issuing centralized guidance and directives about lines of VA health care service which would broadly be deemed "uneconomical" or capacity-limited and for which purchased care access might therefore be granted to Veterans on an expedited basis by local VA officials. More ambitious versions of this step might be combined with shifting VA's internal provider resources to focus on areas of specialization and strength, while channeling some other types of demand for services broadly toward purchased care.

\subsection{Implications for Authorities}

At least for the simple version of this step, only internal VA policies and practices would need to change. Existing statutory and regulatory authority would not bar VA from centralizing and clarifying guidance to designate some lines of service as being "uneconomical" or capacitylimited on a regional or national basis and, hence, appropriate for expedited access to purchased care.

\subsubsection{Create a VA Subsidy for Veterans to Obtain Health Insurance Coverage Through ACA Exchanges or Other Sources}

The idea here would be to shift some Veteran demand for VA health care services into outside facilities and alternative payer mechanisms. Rather than directly providing or paying for care, VA under this step would pay a subsidy directly to Veterans, who would then use the money to purchase health insurance coverage, either through the health care exchanges established by the Affordable Care Act, through traditional private health coverage, or through other insurance mechanisms (including Medicare). The details of exactly what the subsidy program would look like might be complex. Presumably, selected groups of Veterans would either be encouraged or mandated to participate, and the result would be to shift at least some Veterans out of VA care entirely. If the aim were to make the subsidy program both cost neutral and benefit neutral (that is, no incremental cost to government above status quo, and no shift in the health benefits that a Veteran would otherwise be entitled to at status quo), then significant VA controls would need to be imposed on who could obtain the subsidy, what kinds of insurance plans they could buy with it, and what they would be giving up in return for the subsidy. Regardless, any version of this step would involve VA in operating a subsidy program that is entirely outside its current scope of operation, and plausibly could involve a change in the Department's structure, to facilitate such a change in mission. There would be significant cultural challenges in undertaking such subsidies because any version of the step would involve shifting some Veterans away from VA, both in its capacity as a direct provider of, and as a direct payer for, medical services. 


\subsection{Implications for Authorities}

There is some precedent within VA in facilitating the acquisition of private health-related insurance by Veterans. For example, Section 510 of the Caregivers and Veterans Omnibus Health Services Act of 2010 (Pub. L. 111-163, May 5, 2010) established a pilot program in which VA would contract with private dental insurance carriers that in turn would offer coverage to eligible Veterans. While no direct subsidy is involved, it was VA's expectation that since "a large number of enrollees can assist with keeping premiums, copayments, and other administrative costs low," VA would "conduct the Federal contracting process anticipating this large number of expected enrollees and attempt to secure reasonable premium and copayment pricing" (78 Fed. Reg. 32128). Similar legislative authorization would be needed to move toward the goal described in this implementing step, though the scope of such statutory change would be increased markedly if participation were mandatory for Veterans in priority groups based on the most extensive service-connected disabilities. Regulatory change or modification of existing VA internal policies and procedures, by itself, would not provide sufficient authority for carrying out the kind of subsidy program that is envisioned by this step. In addition, such a step would require coordination outside of VA with CMS, the Department of Health and Human Services, and the Internal Revenue Service.

\subsubsection{Implementing Steps: Change the Way Purchased Care Is Managed}

In this section, we describe implementing steps to change the way purchased care is managed and, for each, the implications for authorities. Table 6-4 summarizes the steps and implications.

\section{Table 6-4}

Implementing Steps: Change the Way Purchased Care Is Managed

\begin{tabular}{lccc}
\hline Steps & Legislation Needed? & $\begin{array}{c}\text { Change in } \\
\text { Regulations } \\
\text { Needed? }\end{array}$ & $\begin{array}{c}\text { Change in Internal } \\
\text { VA Policies Needed? }\end{array}$ \\
\hline $\begin{array}{l}\text { Improve resourcing and management } \\
\text { decision-making through better data } \\
\text { collection and new analytic models }\end{array}$ & No & Yes \\
$\begin{array}{l}\text { Remove or modify "to be seen first" practice } \\
\text { under purchased care }\end{array}$ & Maybe & Maybe & Yes \\
$\begin{array}{l}\text { Incorporate all VA purchased care activities } \\
\text { into a single program within VA }\end{array}$ & Maybe \\
$\begin{array}{l}\text { Remove or modify specific VA purchased care } \\
\text { requirements that impede access to outside } \\
\text { providers }\end{array}$ & Yes & Yes \\
$\begin{array}{l}\text { Separate VA's payer and provider functions } \\
\text { into discrete organizations }\end{array}$ & Yes & $*$ \\
$\begin{array}{l}\text { Standardize and strengthen front-end VA } \\
\text { processes for purchased care }\end{array}$ & No & $*$ \\
\hline
\end{tabular}

NOTE: Asterisks in the table indicate where changes in authority would likely occur but would cascade from a preceding change at a higher level of authority. Thus, a change in legislation (marked "Yes") might also lead to a downstream change in corresponding regulation (marked with an asterisk). 


\subsubsection{Improve Resourcing and Management Decision-Making Through Better Data Collection and New Analytic Models}

This step would involve an improved data collection effort that builds on VA's existing purchased care ecosystem by aggregating claims and payment data across all of the various contractual and programmatic mechanisms by which VA outsources care. This step would seek to fill gaps in current data and recordkeeping, with the aim of giving decision-makers much better visibility into purchased care use and expenditures, as a foundation for achieving new efficiencies and for better allocating scarce purchased care resources to meet demand. More ambitious versions of this step might also seek to design new VA analytic models on resourcing for purchased care, so as to be able to estimate utilization and resource needs in the future, as a basis for budget planning. As a longer-term goal, such models and data could be used in conjunction with the information that is already available in VA health care records to inform strategic decisions as to when to provide health care inside or outside VA.

\subsection{Implications for Authorities}

Because improving data collection practices in purchased care lies well within VA's existing authorities to operate generally, it is highly unlikely that VA would require new statutory or regulatory authority to undertake this step. Likewise, modifying VA's approach to resource decision-making through analytic modeling for purchased care seems unlikely to transgress any specific, existing VA statutes or regulations or to require new authorities. On its face, implementing this step (i.e., collecting better data and/or implementing new resourcing models in purchased care) would only require changes to internal VA policies and practices and not changes in legislation or formal VA regulations.

\subsubsection{Remove or Modify the "To Be Seen First" Practice Under Purchased Care}

Currently, a Veteran typically first receives an appointment within VA for treatment, prior to receiving a referral and authorization for specialized purchased care out of the system. ${ }^{10}$ Although the core authority for purchased care per 38 U.S.C. 1703 does not explicitly mandate an initial appointment within VA as a requirement for all Veterans prior to their referral out of the system, in practice, the determination that a needed service cannot feasibly be provided within the system has typically involved decisions made by local VA providers and administrators, based on an initial clinical contact with a Veteran within VA's direct care system. Moreover, for at least some Veterans who fall into a narrow, statutory category established by 38 U.S.C. 1703(a)(2), VA's authority to purchase care is tied to the Veteran having already received related care or medical services through VA.

Under some circumstances, the practice of requiring an initial medical appointment within VA has reportedly resulted in catch-22 situations, such that a Veteran who cannot obtain a threshold appointment within VA for treatment for a specific problem also cannot receive a referral out for purchased care, for lack of the initial work-up that would specify and justify the referral. In practice, this implementing step would institute a broad fix within purchased care, to ensure that access to outside providers cannot be bottled up indefinitely based on lack of timely access to a gateway appointment within VA's direct provider system.

10 Note however that under the 40-mile provision under Choice, a Veteran who lives in an isolated geographic locale removed from any VA facilities might qualify automatically to obtain services through purchased care without the need for any initial screening appointment within VA. 


\subsection{Implications for Authorities}

For many Veterans, only VA internal policies and practices would need to change to address this problem. For this group, existing statutory and regulatory authority would not bar VA from eliminating the need to be seen by a VA doctor prior to scheduling an outside, purchased care appointment. A more ambitious fix for the "to be seen first" problem might also revise the statutory category established under 38 U.S.C. 1703(a)(2), which restricts VA's authority to purchase care for a defined subset of Veterans, based on their already having received medical treatment through VA. The latter fix would require legislative intervention by Congress.

\subsubsection{Incorporate All VA Purchased Care Initiatives into a Single Program Within VA}

The simplest version of the step would keep intact the defining contours of the various existing VA initiatives for purchased care (e.g., the 30-day/40-mile rule for Choice) and would retain local control over the front-end processes associated with purchased care, but would combine all of the existing programs and initiatives for purchased care under a single VA administrative umbrella, with manualized standards and improved guidance for VA personnel in how to carry out purchased care activities. More ambitious versions of this step could involve refining and harmonizing the current portfolio of VA purchased care initiatives to reduce their complexity or to craft a unified VA approach to purchased care while optimizing administrative processes and oversight. In principle, combining programs for purchased care could help foster greater efficiency in the administration of purchased care and improve understanding among VA staff of the availability of existing purchased care resources (i.e., available outside providers and alternative contracting vehicles).

To implement this step, the Chief Business Office could be elevated within VHA and explicitly given these responsibilities, or a new program office for purchased care could be established. The office would be responsible for capturing best practices in the different programs, organizing standardized training programs and combined processes for implementing various aspects of purchased care, and finding ways to foster innovation in purchased care, perhaps through the use of new standards for episodes of care.

\subsection{Implications for Authorities}

The extent to which this implementing step attempts to bring the many different types of purchased care programs under one programmatic "roof" will drive the manner in which appropriate authority would be made available. Much could be accomplished through changes in regulations and internal policies, if the goal were limited to unifying the command structure for overall administration of purchased care. Streamlining or standardizing procedures for requesting external care or compensating providers are also likely to be tasks within VA's sole discretion. However, matters related to consolidating or simplifying eligibility requirements for purchased care or shifting the existing responsibilities of the Chief Business Office or the NVCC unit would likely require congressional action, particularly to the extent that those issues are currently addressed by statute. The Veterans Choice Act, for example, specifically requires VA to coordinate the furnishing of care and services under Choice through the NVCC unit. Unless the implementing step is accomplished by moving all management authority for all programs under NVCC, the act would have to be amended. A similar need would flow from any attempt to change the source of payment for care furnished by non-VA providers away from the Chief Business Office, because the Veterans Choice Act specifically assigns that responsibility to the Chief Business Office. 


\subsubsection{Remove or Modify Specific VA Purchased Care Requirements That Impede Access to Outside Providers}

For purposes of illustration, we focus here on several examples of VA requirements that sometimes operate as impediments to Veteran access to purchased care. One such impediment involves the "60-day window" for an episode of care under the Choice program, pursuant to which a referral and authorization for purchased care services cannot last for more than 60 days without reauthorization by VA. For many acute health care problems, a 60-day limit on the episode of care may be more than sufficient to carry out treatment and to resolve the problem. For more-chronic conditions or primary care for Veterans not served by a VA facility, a 60-day episode of care may not correspond well to the nature of services being provided or the conditions being treated. In some instances, an arbitrary time limit placed on the episode of care may hamper coordination of care efforts that might otherwise take place among outside providers and may make it more difficult for Veterans to obtain the services they need in a timely and coherent way. This step would involve doing away with the 60-day window as a defining feature for an episode of care in favor of authorizing the Secretary to establish a more elastic set of episode guidelines for all purchased care to accommodate appropriate treatment trajectories and purchased care practices for a range of clinical conditions.

Another illustrative impediment involves the language in Section 101(b) of the Veterans Choice Act, which establishes that a Veteran may be eligible for service under the Choice program if he or she "resides more than 40 miles from the medical facility of the Department, including a community-based outpatient clinic, that is closest to the residence of the veteran." In instances in which a Veteran requires specialized services that are not available through the VA facility nearest his or her residence, the eligibility language of the 40-mile rule may not be responsive to the reality that the Veteran lives more than 40 miles away from the nearest VA facility with the ability to meet his or her specific treatment needs. In this instance, the implementing step would involve modifying the 40-mile rule to calculate the distance based on the nearest VA medical facility that offers the services required by the Veteran. ${ }^{11}$

A third illustrative impediment is the purchased care access filter that is imposed by 38 C.F.R. 17.53, which further restricts the broad eligibility afforded by 38 U.S.C. 1703 to utilize purchased care inpatient services when needed. The regulation restricts inpatient treatment by external providers to instances in which VA facilities are "not feasibly available." This step would apply a more liberal interpretation of 38 U.S.C. 1703 that would place the emphasis on the Veteran's best interests.

\subsection{Implications for Authorities}

The exact nature of what changes in authority might be needed would depend on what specific impediments in VA purchased care are chosen as the object of reform. Given the three illustrative examples we spotlight above, however, it is likely that a combination of revisions to the Veterans Choice Act, to regulations, and to VA internal policies would be required. ${ }^{12}$

\footnotetext{
11 Note that a very recent Senate bill has proposed instituting a very similar change to the Choice program. See S. 1463 , Access to Community Care Act for Veterans, passed by the Senate on May 22, 2015.

12 Table 6-4 suggests that legislative change would be needed to implement this step, based specifically on implementing the identified fixes to the 60-day window and 40-mile rule under Section 101 of the Veterans Choice Act.
} 


\subsubsection{Separate VA's Payer and Provider Functions into Discrete Organizations}

The idea here is to reorganize the way that VA manages Veteran health care risk and pays for medical services by standing up within VA a new, dedicated payer organization, which would become responsible for all health care funding and contracting/payment activity for VA. At the same time, VA's direct-provider network would be separated out as its own distinct organization, removed from the payer function, and solely dedicated to operating hospitals and providing medical services to Veterans. In principle, such a reorganization might mean that the new VA payer entity would contract with the VA provider entity, with the latter becoming the primary provider network for delivering benefits. Meanwhile, the VA payer entity would presumably also engage in contracts with other, outside provider networks and would make decisions about how to allocate resources and pay providers to best implement VA health benefits. ${ }^{13}$ In some ways, this step might logically complement a shift in the balance between payer and provider functions within VA, such that VA would put a much stronger emphasis on purchasing care, and VA provider facilities might be shifted to specialized aspects of clinical service where they have greatest comparative advantage and value. However, any version of this step would ramp up VA's payer expertise and capabilities and would manage VA health care funding in a manner similar to a traditional insurance entity.

\subsection{Implications for Authorities}

It is difficult to imagine undertaking such a deep shift in VA's mission and operations without making extensive amendments to Chapter 17, Title 38, of the U.S. Code. More specifically, if Congress authorized VA to form a new and distinct payer entity, it could also provide the Secretary with a detailed statutory blueprint for how that payer entity would be organized, exactly what functions it would perform, how it would receive funding from Congress and pay for outside health care services, how it would interact with VA's provider side, and how the new payer entity would fit into a broader strategy for VA purchased care. Related changes would almost certainly be required to VA regulations and internal policy directives as well.

\subsubsection{Standardize and Strengthen the Front-End VA Processes for Purchased Care}

Section 106 of Veterans Choice Act is noteworthy for having consolidated the back-end administrative processes (particularly, claims processing) associated with purchased care by shifting those processes (and the personnel associated with them) to control by VHA's Chief Business Office and away from the control of the local VAMCs that had previously been responsible for them. Loosely speaking, the logic behind this centralization was to enhance administrative efficiency, to make VA patients more attractive to outside providers, and thereby to enhance Veteran access. In principle, an additional step could be undertaken to enhance the frontend processes associated with purchased care (particularly referral and authorization) and to streamline and enhance the consistency of these processes across VAMCs through revised directives and guidance, together with stronger oversight from VHA's Chief Business Office (and more specifically, the NVCC unit and/or the purchased care offices thereunder). In principle, such a step would aim to make local VA staff more agile, effective, and consistent in their referral and authorization practices.

\footnotetext{
13 Splitting VA's payer and provider functions is not a new idea and has been proposed elsewhere (see, for example, Concerned Veterans for America, 2015). See Hosek \& Cecchine (2001) for a systematic analysis of the organizational implications of splitting the payer and provider functions in the Military Health System. That report addresses the underlying rationale and advantages to such a policy step in more detail.
} 


\subsection{Implications for Authorities}

Administrative aspects of modifying the front end of the purchased care process can largely be addressed through regulatory rulemaking and internal policy-making. To some extent, the current NVCC initiative attempts to accomplish some of these same goals, and much of that effort has moved forward solely through internal VA policy changes. Presumably, an expanded and enhanced effort along these lines could proceed by similar means. With this being said, a more ambitious version of this step that shifts the standardization of front-end processes away from the NVCC unit, and to some other programmatic office within VA, might require some technical statutory changes to implement as well. ${ }^{14}$

\subsubsection{Implementing Steps: Improve Contracting for Purchased Care}

In this section, we describe implementing steps to improve contracting for purchased care and, for each, the implications for authorities. Table 6-5 summarizes the steps and implications.

\subsubsection{Use Revised Definitions for Episodes of Care as a Basis for Improved Purchased Care Contracting}

In this step, the idea would be to build new or revised contractual relationships with outside provider networks, based on bundled payment innovations and sophisticated definitions of episodes of care. Such innovations could help to improve the quality of care for Veterans while also helping to control related costs to VA. By extension, the bundled payment arrangements envisioned by this step would become the fulcrum for an expanded emphasis on purchased care by VA. What would make such arrangements unique, by contrast with current VA practice, is that they would involve shifting financial risk from VA to outside providers, in connection with the delivery of coordinated packages of service. In practice, actually implementing bundled payment in purchased care contracting would be very complex and would depend on

Table 6-5

Implementing Steps: Improve Contracting for Purchased Care

\begin{tabular}{|c|c|c|c|}
\hline Steps & Legislation Needed? & $\begin{array}{l}\text { Change in } \\
\text { Regulations } \\
\text { Needed? }\end{array}$ & $\begin{array}{l}\text { Change in Internal } \\
\text { VA Policies Needed? }\end{array}$ \\
\hline $\begin{array}{l}\text { Use revised definitions for episodes of care } \\
\text { as a basis for improved purchased care } \\
\text { contracting }\end{array}$ & No & Maybe & Yes \\
\hline $\begin{array}{l}\text { Change the requirements imposed on VA by } \\
\text { FAR to improve VA's ability to contract for } \\
\text { purchased care }\end{array}$ & No & Yes & * \\
\hline $\begin{array}{l}\text { Institute long-term, Veteran-level contracts } \\
\text { for purchased care, particularly for long-term } \\
\text { service-connected conditions }\end{array}$ & No & No & Yes \\
\hline $\begin{array}{l}\text { Use revised definitions for episodes of care } \\
\text { as a basis for improving purchased care } \\
\text { coordination }\end{array}$ & Yes & * & * \\
\hline
\end{tabular}

NOTE: Asterisks in the table indicate where changes in authority would likely occur but would cascade from a preceding change at a higher level of authority. Thus, a change in legislation (marked "Yes") might also lead to a downstream change in corresponding regulation (marked with an asterisk).

14 See the immediately preceding footnote and the example of the Veterans Choice Act and its mandate to have the NVCC unit act as the coordinator for furnishing care outside of VA. 
the implementation of clinically meaningful standards for episodes of care and for the bundling of services. These standards are not currently well developed, nor does the infrastructure exist to support the bundling of services.

\subsection{Implications for Authorities}

Changing the current definition of episode of care as found in the Veterans Choice Act would require legislative action. However, the language in the act is broad, and VA's regulations implementing the act give the department considerable latitude in shaping the specific details of the term. Episodes of care for other VA purchased care initiatives are not defined by statutory law, and VA could clarify the term simply by modifying its internal policies and the way that it purchases episodes of care. This would provide a more stable foundation for moving forward with this kind of shift. In a similar vein, VA could undertake bundled payment contracting simply by modifying its internal policies and without recourse to legislative or formal regulatory changes.

\subsubsection{Change the Requirements Imposed on VA by FAR to Improve VA's Ability to Contract for Purchased Care}

Current VA contracting with outside providers for purchased care, particularly on a local basis, may at times be impeded by some of the technical requirements for procurement and contracting that are embedded in FAR. A related theme was raised in some of our qualitative interviews with VA officials and was also addressed in a recent VA budget proposal to Congress, which sought to revise VA authorities to "streamline and speed the business process for purchasing care for an individual Veteran that is not easily accomplished through a more complex contract with a private provider" (VA, Office of Budget, 2015, p. 14).

In line with these observations and the current VA procurement approach to purchased care, the most basic version of this step would affirm and strengthen the validity of local VA practices in the micro-purchase of medical services using purchase orders, consonant with the streamlined FAR requirements that apply under the micro-purchase threshold. More ambitious versions of this step might seek to clarify or to expand on the kinds of medical services that are appropriate for VA to outsource by using the micro-purchase mechanism or, alternately, the simplified acquisition procedures that apply under FAR's simplified acquisition threshold. The most extreme version of this step could involve crafting a new exception to the application of FAR to VA purchased care to enhance VA's ability to enter into related contracts without the formality of full FAR-based procurement processes. Any version of this step would protect or enhance VA's ability to engage in local-level contracting for medical services on a patient-bypatient basis, in part by streamlining FAR requirements that might otherwise apply (e.g., with regard to competitive bidding) and in part by making the prospect of contracting less onerous and more appealing to local providers.

\subsection{Implications for Authorities}

This implementing step contemplates modifying, or at least clarifying the application of, federal procurement laws to VA purchased care practice. The relevant procurement laws include FAR and VAAR (which interpret and expand on FAR). Both sets of rules appear in Title 48 of the C.F.R.

The most basic versions of this implementing step might not change any of the current FAR or VAAR rules but would simply clarify through guidance that the rules are consistent with the current VA procurement practice of local purchasing for individual services for Veter- 
ans, under the FAR micro-purchase thresholds. Presumably the latter could be accomplished simply as a matter of internal VA policy. A more aggressive version of this step might involve amending some of the formally promulgated acquisition rules-particularly the simplified acquisition procedures under Part 813 of VAAR - to clarify the appropriateness of flexible VA purchased care practices under the simplified acquisition procedures or the micro-purchase threshold. Any such changes would likely implicate a formal regulatory process, however, which would be more burdensome for VA to undertake. The most extreme version of this step would involve Congress undertaking a statutory modification to 38 U.S.C. 8153 to explicitly exempt some aspects of VA purchased care contracting from FAR and VAAR coverage. For our purposes, the middle-ground approach of modifying the federal procurement regulations would likely be sufficient to protect current VA contracting practices in purchased care, particularly the use of small, local contracts for services to an individual Veteran under the FAR micro-purchase threshold. ${ }^{15}$

\subsubsection{Institute Long-Term, Veteran-Level Contracts for Purchased Care, Particularly for the Treatment of Long-Term Service-Connected Conditions}

The concept here would be to structure some VA purchased-care contracts around specified clinical conditions, such that the entire episode of care could be outsourced to an external care provider or network selected for quality and cost. Presumably, the Secretary would undertake any such purchased-care contracting in clinical service lines for which direct provision of services by VA is deemed uneconomical or where VA capabilities are limited. In principle, this implementing step could be built on advanced definitions for episodes of care for clinically specific conditions and could further use those definitions to implement bundled payment innovations, such that the contractual providers would be paid by the episode rather for individual services, and with a corresponding shifting of risk from VA to the contractual provider. This kind of contracting could also build in advanced performance metrics and incentives, again based on contractually defined episodes of care. These sorts of innovations might build on the growing experience of recent bundled-payment demonstrations, including those sponsored by Medicare and private-sector payers.

\subsection{Implications for Authorities}

Authority already exists for moving forward with long-term contracts on either an individual Veteran basis and/or for specific conditions. Developing such contracts would involve a refocusing of internal VA policies and purchasing strategy to some extent, but no regulatory or legislative action would be needed to enter into such contracts per se.

\subsubsection{Use Revised Definitions for Episodes of Care as a Basis for Improving Purchased Care Coordination}

The premise here is to shift the way that VA defines episodes of care in practice to make episodes better correspond to clinically meaningful baskets and trajectories of connected health care services, which can usefully be lumped as a group when VA purchases services from outside. In principle, better-defined episodes could be helpful in improving the coordination of care with outside providers, since such episodes could facilitate the "bundling" of a package of relevant services to an outside provider, without the need to split some aspects of the episode

15 Table 6-5 reflects this "middle-ground" assumption, suggesting that the authority change needed for this step would involve modifying VA regulations. 
between VA and that provider, and without the need to seek repeated authorization from VA for episodes with durations longer than 60 days. In practice, the advantages in coordination that might accrue with revised standards for episodes of care would likely depend on the details of the new standards, the ease with which VA can apply them, and the impact of those standards on the front-end referral and authorization processes for purchased care.

\subsection{Implications for Authorities}

Changing the definition of episode of care as articulated in the Veterans Choice Act would require legislative action. However, the language in the act is broad, and regulations implementing the act give VA considerable latitude in defining an episode, within the constraint of the 60-day window. Episodes of care for other purchased care programs are not defined by statutory law, and VA could clarify the term simply by modifying its internal policies.

\subsection{Discussion}

In the Veterans Choice Act, Congress posed the question of "whether the Secretary should have the authority to furnish [health] care and services at [non-Department] facilities through the completion of episodes of care." The answer to this question is, at least in part, that it depends. If the aim is to maintain or expand VA purchased care, then clearly this kind of authority (which the Secretary already has) is needed and may indeed need to be expanded in specific ways. If the aim is to move VA in the direction of new contracting approaches for episodes of care and bundled payment arrangements, so as to mirror innovations in payment in other parts of the U.S. health care system, then, again, this kind of authority is needed, and the authority may need to be modified or expanded in specific ways.

On the other hand, if the primary aim is to address short-term gaps in VA capacity, or to protect and enhance VA's internal provider network and capability, then that could easily lead to the conclusion that the Secretary does not need more authority than he or she has today, with regard to "providing service at non-Department facilities through the completion of episodes of care." Ultimately, the normative question here depends on a strategic vision of what purchased care is for, how it fits into the larger VA mission, and how the Secretary can best accomplish those ends.

Given the many possible objectives for the future of purchased care, VA and Congress could find themselves considering a range of changes to purchased care. These changes could include enhancing relationships with private providers, making modifications in the eligibility of Veterans for purchased care, changing how purchased care is managed, or improving contracting for purchased care.

Our analyses incorporated these objectives and potential changes in purchased care in different ways. Our aim is not to urge VA or Congress to adopt any of these changes but to offer insights into what would be required in terms of the Secretary's authorities to implement potential policy changes (i.e., in legislation, regulations, or internal VA policies). Not surprisingly, the types of changes in the Secretary's authorities would depend on the specific characteristics of the policies themselves. Nevertheless, we offer some basic observations drawn from the analyses presented here and elsewhere in this report: 
- The Secretary has considerable statutory flexibility and discretion under Title 38 for purchasing care outside of VA, consistent with the traditional goal of responding to future short-term gaps in capacity. It bears repeating that the Secretary already has, and has had for some time, basic statutory authority to engage in purchased care activity, particularly where VA facilities are not capable of furnishing the care required. Some important aspects of purchased care, such as the strategy for contracting and building outside networks of providers or enhancing quality in the care that is purchased, lie largely within the discretion of the Secretary and are unlikely to require formal legislative or regulatory revisions to carry out. As such, improvements in the Secretary's tools for managing and resourcing purchased care would also not require legislative or regulatory revisions.

- The Secretary would likely need new authority through legislation for policy reforms that involve new types of funding for VA purchased care, basic changes in VA's mission pertaining to purchased care (e.g., in redefining VA's role as a payer versus a provider), changes in the fundamental eligibility requirements for Veteran health benefits, or reforms that would alter the Veterans Choice Act. Because any of these modifications would touch directly on existing statutory authority for VA and/or on the role of Congress in how it chooses to fund VA, these are aspects of the purchased care landscape for which revision would require additional legislative involvement by, and input from, Congress.

- Some specific impediments to VA purchased care access would require legislative interventions to fix. Specific examples discussed in this chapter include revisions to the 40-mile rule and the 60-day window under the Veterans Choice Act. Not all such impediments, however, involve statutes. For example, the need for Veterans "to be seen first" by a VA provider prior to a purchased care appointment does not (in all instances) flow directly from VA's statute and could be at least partly addressed by the Secretary without regard to legislative change or formal regulatory reform.

- Modifying the way that VA purchases episodes of care in the future may require new legislation (particularly in connection with the Veterans Choice Act) but, more importantly, will require internal VA policy changes to be made by the Secretary. Future reforms around episodes of care will likely involve the development of a new VA strategy for adopting bundled payment practices, based on emerging standards and definitions for episodes of care from outside sources. The Secretary already has discretion to move in this direction under current statutes and regulations, but VA internal policies and guidance would need to change in support of such movement, as would existing purchased care contracts.

- Some plausible policy changes that policy-makers might consider would involve very significant, sweeping statutory changes - for example, if VA or Congress were to undertake radical changes to VA's mission or function in connection with purchased care. Such changes might also require involvement by Congress in new legislation to establish the blueprint for change. Some examples along these lines could include a shift to greatly expand VA's role as payer organization, to move significant numbers of Veterans into purchased care and out of direct care through VA, or to make VA the operator of a subsidy program for outside health insurance, as an alternative to obtaining other sorts of health benefits through VA. 


\section{Alternative Government Health Care Payer Models}

\section{Overview of Methods and Data for Alternative Health Care Payer Models}

- We drew on the experiences of other large government health care payers to derive lessons for VA purchased care. The analysis of program structure, claims processing, contracting procedures, and other characteristics draws on a review of current and historical program documentation, GAO reports, and other literature.

- We compared and contrasted VA and two large programs (TRICARE and Medicare) along several dimensions, an analysis supported by a review of each program's structure and governing statutes.

As described in Chapter Three, VA currently has authority to purchase care, but within a limited scope and secondary to its primary function as a provider. As a result, there are both structural and financial limitations on VA's ability to marginally expand its role as payer. VA also lacks any clear direction for what or how much care to purchase, beyond seeking to remedy those situations in which it cannot provide needed care directly.

An avenue for reflecting on possible reforms to VA purchased care involves considering the experience of other large government health care payers and, in particular, the Military Health System and Medicare. In theory, both of these government payers represent potential models that VA could follow or learn from, in regard to various aspects of acting as a payer for outside health care services.

While VA purchases care in specific situations and for specific Veterans, Medicare and the Military Health System (through TRICARE) either purchase large quantities of care or all care for the populations they serve. As Figure 7-1 shows, these (and other) government payers vary in the degree to which they serve as direct providers of care, versus paying for outside health care services. For example, Medicare does not provide any health care services directly, while IHS provides nearly all care from in-house providers. ${ }^{1}$

TRICARE shares some important similarities with VA, in the sense that TRICARE involves the direct provision of care through military treatment facilities (MTFs) and purchased care services when necessary. Medicare, unambiguously and by contrast, involves a very large government health insurance program. Table 7-1 details the basic benefit structure of the main TRICARE and Medicare variants, compared with VA. The fundamental purpose

\footnotetext{
1 IHS is an agency within the U.S. Department of Health and Human Services that is responsible for providing federal health services to roughly 2 million American Indians and Alaska Natives who are members of 566 federally recognized tribes. While IHS serves as a notable benchmark on the continuum of care that is purchased or directly provided, the agency is very different from VA in size and scope and is thus not discussed further in this comparison of alternative government health care payer models.
} 
Figure 7-1

Spectrum of Provide-Versus-Purchase Care

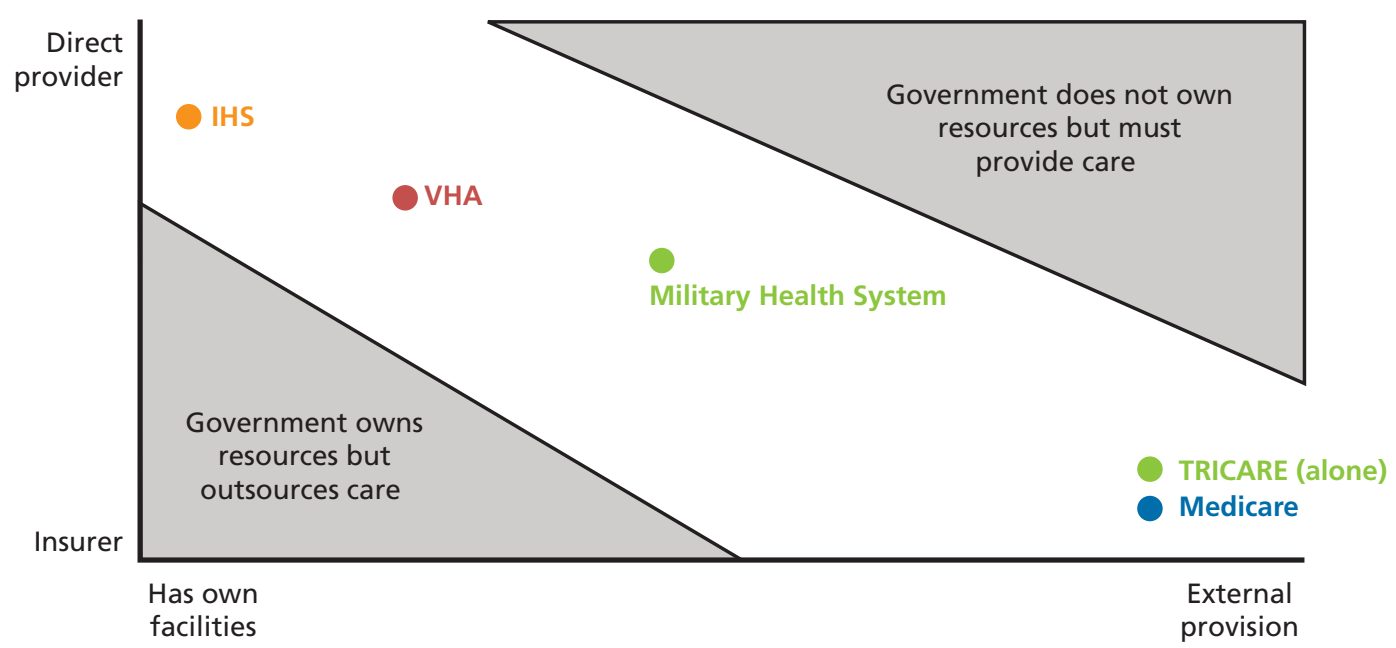

RAND RR1165z3-7.1

of TRICARE and Medicare, and their corresponding mechanisms and characteristics, distinguish them from VA and VA purchased care and highlight that there may be some limitations in looking to these other organizations as models for VA.

This chapter reflects on the similarities and differences between TRICARE, Medicare, and VA as government payers and seeks to draw some useful lessons for VA in regard to purchasing care. In support of these aims, we draw on a combination of document review supplemented with interviews from a variety of stakeholders involved in VA purchased care, TRICARE, and Medicare.

\subsection{Key Similarities Across VA, TRICARE, and Medicare}

Broadly speaking, VA operates as both a direct provider of health care services and as a payer for outside services. As we described in Chapter Three, VA engages in purchased care under an elaborate set of authorities, programs, and mechanisms. Three related observations are worth repeating here. First, the core authority for VA purchased care, under 38 U.S.C. 1703, establishes that the Secretary may purchase outside medical care when VA is unable to provide the same service and when certain other criteria are met. Second, the Veterans Choice Act compels access for eligible Veterans to purchased care when wait-time or driving distance criteria are met. Third, all VA purchased care authorities and operations fall under VA's primary health care function, which involves operating a national network of provider facilities and delivering medical services directly to Veterans.

As such, health care for TRICARE beneficiaries living near MTFs offers a natural comparison for VA, since the military, like VA, is involved both in the direct provision of health care services and the purchase of health care services in the private sector. TRICARE's experience in arranging for care for beneficiaries not living near a military facility may have parallels to care for Veterans in remote areas. DoD established TRICARE to control cost increases and improve access to health care (GAO, 1998). Also, like VA, TRICARE uses purchased care 
Table 7-1

Basic Program Structures of TRICARE, Medicare, and VA

\begin{tabular}{|c|c|c|c|c|c|}
\hline Feature & TRICARE Prime ${ }^{a}$ & $\begin{array}{l}\text { TRICARE Standard/ } \\
\text { Extra }\end{array}$ & $\begin{array}{l}\text { Traditional } \\
\text { Medicare } \\
\text { (A and B) }\end{array}$ & $\begin{array}{l}\text { Medicare } \\
\text { Advantage }\end{array}$ & VA \\
\hline Type of plan & $\begin{array}{l}\text { Health } \\
\text { maintenance } \\
\text { organization } \\
(\mathrm{HMO})\end{array}$ & $\begin{array}{l}\text { Preferred provider } \\
\text { organization (PPO) }\end{array}$ & Fee for service & HMO or PPO & $\begin{array}{l}\text { Staff model } \\
\text { HMO }\end{array}$ \\
\hline $\begin{array}{l}\text { Monthly premium } \\
\text { (individual) }\end{array}$ & $\begin{array}{l}\text { Retirees: } \$ 23.17 \\
\text { Active duty: None }\end{array}$ & None & $\$ 104.90^{\mathrm{b}}$ & $\begin{array}{l}\text { Average } \\
\$ 135-\$ 168\end{array}$ & None \\
\hline $\begin{array}{l}\text { Deductible } \\
\text { (individual) }\end{array}$ & Yes for retirees & $\begin{array}{l}\$ 50 / \$ 150 \text { (varies by } \\
\text { rank and beneficiary } \\
\text { group) }\end{array}$ & $\begin{array}{l}\text { Part B: } \$ 147 / \text { year } \\
\text { Part A: } \$ 1,260 \text { per } \\
\text { benefit period }\end{array}$ & Varies by plan & None \\
\hline Direct care & $\begin{array}{l}\text { Active duty: Use of } \\
\text { MTFs mandatory } \\
\text { Others: May be } \\
\text { assigned to MTFs } \\
\text { for primary care }\end{array}$ & $\begin{array}{l}\text { Yes, but only if space } \\
\text { available at MTFs }\end{array}$ & No & $\mathrm{No}^{\mathrm{C}}$ & Yes \\
\hline $\begin{array}{l}\text { Purchased care } \\
\text { network }\end{array}$ & Yes & Yes & No & Yes & Yes \\
\hline Cost sharing & Yes for retirees & Yes & Yes & Varies by plan & $\begin{array}{l}\text { Yes, some } \\
\text { priority } \\
\text { groups }\end{array}$ \\
\hline $\begin{array}{l}\text { Referral } \\
\text { authorization } \\
\text { required }\end{array}$ & $\begin{array}{l}\text { Yes for specialty } \\
\text { care }\end{array}$ & $\begin{array}{l}\text { No, some prior } \\
\text { authorization }\end{array}$ & No & Yes & Yes \\
\hline $\begin{array}{l}\text { Access standards in } \\
\text { purchased care }\end{array}$ & $\begin{array}{l}\text { Yes, time and } \\
\text { distance }\end{array}$ & No & N/A & $\begin{array}{l}\text { Yes, time and } \\
\text { distance }\end{array}$ & $\begin{array}{l}\text { Yes, } \\
\text { time and } \\
\text { distance }\end{array}$ \\
\hline
\end{tabular}

a For simplicity and ease of comparison, the table does not list fees for family members. TRICARE Standard and Extra are essentially one option with different cost sharing for in- and out-of-network providers.

b High-income beneficiaries pay higher premiums, up to $\$ 335.70$ per month (Medicare.gov, n.d.).

' Some Medicare Advantage plans are staff model HMOs and would therefore provide direct care, but Medicare itself is not. Medicare Advantage plans combine services for Parts A, B, and (often) D.

to fill gaps in its direct care system. ${ }^{2}$ In several ways, VA has followed a similar trajectory to TRICARE in its development of purchased care. Similar to VA, in implementing TRICARE, DoD faced challenges with establishing provider networks, provider payment backlog, and balancing direct and purchased care in different regions of the country to fulfill the need for care. ${ }^{3}$

DoD's direct care system has never been sized to serve all military health beneficiaries, so its purchased care program is long-standing and large. The program has also grown incrementally over the years. DoD's first purchased care program was established in 1956 when Congress passed the Dependents Medical Care Act (Pub. L. 84-569). The legislation formalized rules allowing active duty dependents, retirees, and dependents of retirees to receive medical care at

2 According to stakeholder interviews.

3 According to stakeholder interviews. 
MTFs and authorized DoD to purchase civilian health care services for active-duty dependents for the first time (Jansen, 2014). This legislation was followed by the Military Medical Benefits Amendments in 1966, which authorized DoD to extend outpatient care to certain dependents and retirees by contracting with civilian health care providers. These amendments authorized the establishment of the Civilian Health and Medical Program of the Uniformed Services (CHAMPUS) as a supplement to direct care in MTFs (TRICARE, 2009). TRICARE, the health plan for DoD beneficiaries, replaced CHAMPUS in 1994; unlike CHAMPUS, TRICARE includes both direct care and purchased care.

There are several key parallels in the development of VA purchased care and TRICARE. Both VA purchased care and TRICARE carried out congressionally mandated pilot programs to assess alternative methods for purchased care (GAO, 1998). TRICARE was preceded by two managed care pilot programs, the CHAMPUS Reform Initiative and the Catchment Area Management Program, in the late 1980s. The CHAMPUS Reform Initiative, launched in California and Hawaii in 1988 (Hosek, 1993), contracted out administrative functions and offered beneficiaries a choice of two options: (1) a new HMO, CHAMPUS Prime, or (2) the existing fee-for-service CHAMPUS Standard program, which was converted to a PPO with a new CHAMPUS Extra option. In 1994, Congress expanded the initiative and made it permanent by transforming CHAMPUS into TRICARE. ${ }^{4}$ TRICARE was again expanded in 2001 to include supplemental Medicare insurance and, in 2005, to make coverage available to eligible deactivated reservists (Rhem, 2001; TRICARE, 2005).

Today, TRICARE is administered through four regional contractors in four regions: domestically in the North, South, and West and overseas. These contractors work under the supervision of TRICARE regional offices to manage purchased care and to coordinate care between the direct and purchased arms of the TRICARE system. The current regional contractors have been in place since 2013, and most are incumbent contractors (GAO, 2014d). While VA and TRICARE are similar in several key ways, the funding structures of the two entities are notably different, particularly regarding entitlement status. An entitlement program, in contrast to a discretionary program, creates a right to the benefit-in this case, medical care: a right that obligates the federal government to pay related costs. VA's health care benefits, and particularly those involving purchased care, have not traditionally been regarded as an entitlement. By contrast, the authorizing statute for TRICARE, under 10 U.S.C. 1074, establishes that "a member of a uniformed service . . . is entitled to medical and dental care in any facility of any uniformed service" (emphasis added). The unified medical budget (of which TRICARE is part) is prepared annually and includes resources for all non-deployment-related medical expenses under DoD's control (Jansen, 2014). The funding for this is appropriated through several sources, including annual defense appropriations bills (Jansen, 2014). 5 While defense health programs essentially have a discretionary budget, DoD is obligated to pay for the health services, making it similar to an entitlement program. In sum, DoD's funding

\footnotetext{
432 C.F.R. 199.17 sets forth the regulations governing the TRICARE program itself.

5 The complete list of sections are as follows: (1) a defense appropriations bill section, "Defense Health Program," provides operation and maintenance, procurement, and research, development, test, and evaluation funding; (2) a defense appropriations bill section on "Military Personnel" provides funding for military medical personnel (doctors, corpsmen, and other health care providers) and TRICARE for Life accrual payments; (3) the military construction and VA appropriations bill provides funding for medical military construction; (4) the Medicare supplemental plan is funded through an accrual charge levied on active-duty military personnel; and (5) third-party collections are authorized by 10 U.S.C. 1097b(b) and a number of other reimbursable program and transfer authorities.
} 
streams for TRICARE may offer both solutions and challenges not present with more simply structured, fixed-budget discretionary programs, such as VA's health care function.

Medicare differs from both TRICARE and VA in that it is exclusively a payer for, and not a provider of, health care services. In fact, Medicare has never been a direct provider of services and from its earliest days used outside contractors to administer some aspects of the program. Like TRICARE (but unlike VA), Medicare is also a federal entitlement program. Medicare was enacted in 1965, as Title XVIII of the Social Security Act (Pub. L. 89-97), which simultaneously created the Medicaid program. ${ }^{6}$ Section 426 of Title 42 specifically establishes the hospital insurance benefits under Medicare as an entitlement program. Because the spending formula and beneficiary eligibility are defined in law, Medicare spending is considered mandatory and not discretionary (Costantino \& Schwabish, 2014). As such, all those eligible to participate in a federal program funded by mandatory spending will receive payment or services with no cap on related spending by the government. This statutory authority does give entitlement programs some nimbleness: Medicare can be efficient programmatically yet surge to meet patient demand, because it is not tied to an annual budget appropriation. In this respect, Medicare is very different from VA's health care operations, for which spending is tied to an annual budget appropriation by Congress.

To some extent, TRICARE and (by extension) the Military Health System, VA, and Medicare serve overlapping populations at different points in their lives. TRICARE and VA are specifically focused on offering care for military populations of service members and Veterans, respectively. The Military Health System serves a large population of military retirees and family members, but, at age 65, these beneficiaries transition to Medicare (with supplemental coverage from DoD).

\subsection{Lessons for VA from TRICARE and Medicare}

TRICARE and Medicare each bring decades of experience to the table, in refining and carrying out purchased care functions and operations within their respective domains. TRICARE's TPAs (or managed care support contractors) have built a national network of outside providers, and the contractual framework to support them, to augment DoD's long-standing role in providing direct care to beneficiaries. Medicare, by contrast, has been deeply involved in refining and experimenting with methods for managed utilization and cost reduction.

Drawing broadly on the experience of both TRICARE and Medicare, we believe that the most obvious lessons for VA fall into three categories:

- Outsourcing administrative functions

- Instituting contractor incentives

- Managing utilization.

We address each of these points in the sections that follow.

6 See 42 U.S.C. 1395 et seq. for the current statutory basis for Medicare. 


\subsubsection{Outsourcing Administrative Functions}

Over time, major government payers outside of VA have outsourced a variety of administrative functions to private contractors, often with performance incentives attached. Important functions that have been outsourced have included provider network maintenance, claims processing, and call center or other support for enrollees.

TRICARE acquires health care services through Managed Care Support Contracts in three domestic regions. Contractor functions include establishing and maintaining provider networks, third-party billing, claims processing, specialty care referrals, and enrollment (GAO, 2014a). The contractors for the three regions, UnitedHealth, Humana Military, and Health Net, also conduct medical management, customer service activities, and data collection. One interview respondent described TRICARE's relationship with its contractors as a way to increase the efficiency of the system: "We don't contract directly with providers. We use Humana, Health Net, and United to build networks and ... [to operate as] fiscal intermediaries to pay claims - all the mechanics that go with it, enrollment, referrals, all that. We contract with United, they get paid an administrative fee and make a profit, and they go build a network with providers." For the military, the contracting arrangements under TRICARE mean that they do not have to have staff internally to find providers or manage billing. As another interview respondent said, "I don't know how we would have enough people to go to every zip code in America. These companies already have networks; I don't know how we would have the expertise or people to do that ... [or why we would want to] . . when they already have that expertise."

Like TRICARE, CMS makes extensive use of outside contractors in administering the Medicare program. From 1966 until the Medicare Prescription Drug Improvement and Modernization Act of 2003, Part A fiscal intermediaries and Part B carriers were the primary administrative processing intermediaries between CMS and providers (CMS, 2015c). The legislation led to a series of contracting reforms, most notably by creating the Medicare Administrative Contractors system, which is the central point for much of Medicare's operational functions (e.g., processing claims and applications, hearing appeals, providing call centers, and supporting educational efforts; see CMS, 2015a, and CMS, n.d.-a). Beyond these core functions, CMS contracts out other aspects of its operations, including beneficiary contact centers, enterprise data centers, health care integrated general ledger and account systems, Medicare secondary payer recovery contractors, zone program integrity contractors, qualified independent contractors, quality improvement organizations, and recovery auditors (CMS, n.d.-a). Under the Medicare Administrative Contractors system, the contractors are responsible for providing services to their assigned geographic area (CMS, 2015a).

By contrast with both TRICARE and Medicare, VA purchases a limited volume of care and employs a different approach, at least in some of its programs. VA uses two contractors to develop and maintain the provider networks for PC3 and Choice (analogous to the provider networks for TRICARE). The VA TPAs, Health Net and TriWest, manage provider networks for Veterans to access primary care, inpatient specialty care, outpatient specialty care, mental health care, limited emergency care, and limited newborn care for enrolled female Veterans following birth of a child at non-VA providers (VHA Chief Business Office Purchased Care, 2015). However, the TPAs for VA handle only the administrative functions that the contractors for TRICARE and Medicare handle for the PC3 and Choice programs. For the larger volume of care currently purchased through the traditional VA purchased care program, authorizations and claims payments are handled largely in house at VA. By contrast, both 
TRICARE and Medicare use contractors to perform these functions for all purchased care. In the future, if VA enforces its policy to rely more on PC3 and Choice, its TPAs will bear more of the administrative responsibility, particularly for such functions as authorization and claims payments, in line with TRICARE and Medicare.

\subsubsection{Claims Processing}

One of the major administrative functions for Medicare and TRICARE contractors is claims processing, which enables DoD and Medicare to put into place financial incentives for quicker turnarounds and systems for curbing improper or fraudulent claims. VA is less experienced in its outsourcing of the claims processing functions under PC3.

As of fall 2013, TRICARE processed about 4.6 million claims every week (TRICARE, 2013). The contractors who carry out the work do not publicly report claims processing costs separately from the provider costs. However, the contractors report that about 75 percent of the claims processing is fully automated - that is, not requiring human intervention. The contractors also reported to the study team a processing cost per claim of $\$ 2.25-\$ 2.50$ for electronic claims and $\$ 3.50$ for paper-based claims. Presumably, automation of claims processing through outside contractors is one of the areas where VA might usefully emulate the practice of TRICARE in pursuit of greater efficiency.

Meanwhile, program integrity officials within TRICARE are charged with oversight of improper payments. Over time, TRICARE has had to build a fraud and abuse system to combat improper payments. A 1999 GAO report found that DoD was not very good at identifying fraud (GAO, 1999). DoD subsequently built in incentive payments for contractors to identify fraudulent billing practices. TRICARE has tried to create contracts that push some "program risks" to the contractors and has created a robust Program Integrity Office with clearly defined criteria and staff consisting of lawyers, statisticians, physicians, and registered nurses. This office directs contractors in identifying and limiting fraud and abuse throughout the program. The fraud office also deals with improperly paid claims. As a result, TRICARE reportedly now has a very low payment error rate (less than 0.5 percent for billed charges and about 1-2 percent of actual amounts paid) (National Academy of Public Administration, 2011; Jones, 2012). However, a 2015 GAO report found that the improper payment rate was likely higher than reported; it recommended that TRICARE adopt Medicare's system of analyzing the underlying medical record for a sample of claims to determine whether services were properly coded (GAO, 2015).

The claims processing contracts include financial penalties or incentives to encourage payment accuracy. Overpayments identified during the Managed Care Support Contracts' annual health care cost compliance review audit are extrapolated to the audit universe, and the contractors are liable for the entire extrapolated overpayment error amount, providing a built-in incentive for contractors to continually monitor and improve their claims processing. Meanwhile some contracts also allow the contractor to earn financial incentives for exceeding the contractual performance baseline on overpayments. To minimize improper payments, both pre- and post-payment controls, including claims auditing software, documentation policies, and audits, are built into both contract requirements and contractors' claims processing systems (Defense Health Agency, n.d.). Here again, VA could in principle seek to model TRICARE in its approaches to using outside contractors to reduce erroneous overpayment and fraud in claims processing. 
As with TRICARE, Medicare's claims processing is also completely outsourced, as are many of its other administrative support functions. Historically, provider groups nominated "fiscal intermediaries" in a non-competitive bidding process. In 2003, CMS was granted the ability to use competitive bidding to award outside contracts for a variety of services, including claims processing (GAO, 2014b). Under this set of reforms, CMS also instituted cost-plusfee payment arrangements, which allow contractors to win incentive payments for meeting performance metrics. Over time, CMS contractors have been slowly improving their performance, but they still do not yet meet all performance targets (GAO, 2010). Notably, there are still problems in ensuring that claims are paid correctly the first time (GAO, 2014f). Just over 10 percent of Medicare's fee-for-service claims were improperly paid in 2013 (GAO, 2015). Medicare's fraud and abuse system uses a different set of contractors to police claims, the zone program integrity contractors. Medicare also uses models with algorithms to identify potentially fraudulent claims (GAO, 2012). A 2012 GAO study found that the system had the ability to curb fraudulent billing from providers and to save money by identifying fraudulent practices before claims were actually paid. However, the report noted that Medicare's contractors had not yet implemented the system consistently (GAO, 2012).

In contrast with TRICARE and Medicare, VA still processes a significant portion of its purchased care claims in house, rather than through outside contractors (in connection with claims that arise under traditional purchased care and outside of the PC3 and Choice mechanisms). Under the traditional VA purchased care program, the processing of claims by VA is handled at the VAMC or VISN level, which has contributed to a lack of standardization in processes across facilities/VISNs. The Veterans Choice Act notably imposed a mandate on VA to create a new system to pay these claims and to centralize funding through VHA's Chief Business Office. Previously, internal guidance for processing claims through the NVCC had been passed down by VA, but one official interviewed for this study noted, "We know from audits that not everyone implements [this in] the same way."

Moreover, as we noted in Chapter Four, VA has continued to experience some problems in carrying out its claims payment function, including improperly paid claims, authorizations for patients to access purchased care that are not justified or properly authorized, and lack of data for calculating the cost of the services in an episode of care. Again and in principle, shifting the claims payment function more fully to outside contractors, while ensuring appropriate automation and implementing incentive payments tied to reducing improper payments and other outcomes, could offer some advantages for VA to pursue, in seeking to draw useful lessons from the experience of TRICARE and Medicare.

\subsubsection{Instituting Contractor Incentives}

Financial incentives built into contracting arrangements can encourage adherence to various quality, efficiency, or processing standards, beyond their use in claims processing. Over their evolution, both Medicare and TRICARE have developed incentive payments to align quality and cost savings measures between the programs and the contractors, though the process has not always worked perfectly. VA requires non-VA providers to return medical record information before payment can be issued. Although this is not an incentive in the usual sense, it can be a lesson for the other payers.

Under current TRICARE contract provisions, contractor performance is encouraged through semiannual award fee and performance guarantees (GAO, 2014e). There are also several other financial incentives built into TRICARE contracts for controlling the level of ancil- 
lary services use. Managed care support contracts receive 10 percent of provider discount savings above a government-set threshold, encouraging them to steer beneficiaries to in-network providers who should be more efficient. There are penalties if the network share of Prime claims falls below the government-specified standards. In addition, costs for Prime beneficiaries who have civilian primary care providers (as opposed to those assigned for primary care to the MTF) are compared to the per capita trend reported in National Health Expenditures accounts; the contractor is responsible for 30 percent of the differential if the Managed Care Support Contracts' cost trend is higher (DoD, 2014).

As part of the previously mentioned Medicare Modernization Act, the contractors administering fee-for-service Medicare now have incentive payments for high-quality work beyond their contractual obligations. The award fee system allows contractors to earn bonus payments for performance metrics, including beneficiary service, overall performance on the contract, and appeals processing (CMS, 2014b).

VA has very few pay-for-performance incentives for its contractors. In the Project HERO pilot, the contractors were paid a "value reimbursement" for coordinating appointments and returning clinical information to VA after a private-sector appointment in a fixed-fee-perservice arrangement (Panangala, 2010). According to our interviewees, the process for obtaining information from network providers is still undergoing standardization at the VA facility level. One contractor said that returning the records could be a challenge when VA facilities have different standards: "What is 'complete' varies from facility to facility. Sometimes, it [the record] is not legible. This is particularly problematic for optometry. They have their own symbols that they use, and a VA nurse who is not an optometrist may not understand it."

In the future, VA might consider instituting additional performance incentives into its contracting framework for purchased care, similar to those under TRICARE and Medicare. Presumably, steps along these lines might make particular sense if VA expands its outsourcing of administrative functions in the future, and likewise if VA shifts more of its purchased care activity to TPA arrangements, as under PC3 and Choice.

\subsubsection{Managing Utilization and Controlling Costs}

At present, VA has only limited traditional features (e.g., authorization requirements and processes) to reduce unnecessary utilization and costs. By contrast, Medicare and TRICARE have followed somewhat different pathways in the attempt to control costs and utilization when purchasing care. VA could add some additional mechanisms for managing utilization for Veterans receiving care in the community.

TRICARE was originally developed in response to increasing cost pressures and concerns over access in CHAMPUS, the program's predecessor (GAO, 1998). While the original intent was to impose more control on utilization for the dependents and retirees not receiving care in the MTFs, recent studies have shown that TRICARE does not take advantage of such techniques as financial incentives or reimbursement systems based on value. In constant 2013 dollars, while the typical private health insurance premium increased by 76 percent between 2002 and 2013, the TRICARE premium for retirees actually declined by 10 percent (Defense Health Agency, 2015). Recently, the Military Compensation and Retirement Modernization Commission cited significantly higher use of health care services, both inpatient and outpatient, by TRICARE beneficiaries than in civilian HMOs, due to a lack of incentives, such as cost sharing, that would deter utilization (Military Compensation and Retirement Modernization Commission, 2015). 
Unlike TRICARE or VA, Medicare is not a direct provider of services. Medicare is an insurance program that pays providers for the care delivered to Medicare beneficiaries (CMS, 2014a). ${ }^{7}$ Traditional Medicare has no formal provider networks, and any willing provider can apply to join. With Medicare, a beneficiary can receive care from any health care provider that accepts the insurance. With this structure, in the past there was traditionally only limited utilization control in traditional Medicare, save through copayments to deter overutilization (Medicare.gov, n.d.). The cost sharing in Medicare is quite high for some services, so a market for plans that cover just the cost sharing in Medicare developed (called Medigap plans). These plans distort the financial incentives that would otherwise control utilization. In sum, this system is very different from the VA purchased care context.

Medicare employs some mechanisms for enhancing quality and controlling costs in its feefor-service side and is piloting other innovative approaches that VA could potentially include in its purchasing arrangements. Originally, Medicare paid only "reasonable costs" to hospitals or "usual, customary, and reasonable charges" to doctors and other medical providers (Davis et al., 2013). However, after costs exceeded projections, Medicare replaced its "reasonable costs" and "usual, customary, and responsible charges" standard with a predetermined fee-for-service model during reforms during the 1980s and 1990s (Davis et al., 2013). Under the Diagnostic Related Group (DRG) system, hospitals were given a lump sum for a given episode of care, instead of allowing the hospitals to individually charge for every service performed during the patient's stay. More recently, the Affordable Care Act funded demonstration projects for a variety of payment and care delivery changes in the fee-for-service Medicare environment, with the express purpose of better aligning incentives to control utilization and spending. These alternative payment models, like bundled payments and accountable care organizations, are set up to pay for "value" instead of for "volume," as in the traditional fee-for-service model (U.S. Department of Health and Human Services, 2015).

As we discussed in more detail in Chapter Four, bundled-payment arrangements based on episodes of care offer an important avenue for potential reform by VA, and a way in which payment innovations now being tested by Medicare might be useful as a model to VA in the future. TRICARE initially relied on utilization review for cost containment, an approach that was employed in the private sector at the time but has not proved to be effective. VA could institute a variety of these mechanisms to manage utilization and coordinate purchased care for Veterans.

\subsection{Experience with Third-Party Contracting for Purchased Care Administration}

Many of the lessons learned in the previous sections have focused primarily on the outsourcing of various functions to the private sector. However, it should be noted that heavy reliance on contractors for managing purchased care is not without drawbacks, which can range from losing oversight on day-to-day administrative functions to problems associated with the competitive bidding process itself. Both TRICARE and Medicare have had issues with their bid-

\footnotetext{
7 Funding for Medicare hospital insurance comes through payroll taxes, paid by both employers and employees, per 26 U.S.C. 3101 and 3102. Regulations governing Medicare are contained in Title 42 of the C.F.R., Chapter IV, Parts 405-600.
} 
ding processes. For its part, VA has also had issues with its contracting processes for support services.

During the most recent process to award TRICARE Managed Care Support Contracts for the three domestic regions, all three contract awards were protested by unsuccessful bidders (as were some earlier awards). ${ }^{8}$ Ultimately, new award decisions were made in all three regions, which triggered further, though unsuccessful, protests. This protracted process delayed initiation of the new contracts, misaligned the performance periods of the finalized Managed Care Support Contracts, and is expected to lead to increased costs (GAO, 2014a). In addition, the transition to a new contractor in the West region led to physician reports of delays in the processing of authorizations and referral requests, long hold times for telephone queries and support, website problems, and other deficiencies in support. Many commentators indicated that these problems had a negative impact on patient care (California Medical Association, 2013). DoD ultimately held the incoming contractor accountable for not meeting some requirements, through corrective action requests and financial penalties. However, GAO also found that DoD lacked a process for holding its contractors accountable and that inadequate guidance and insufficient oversight contributed to problems with health care delivery (GAO, 2014e). These concerns, along with complaints about inadequate access to care and limited choice, led the Military Compensation and Retirement Reform Commission to recommend eliminating TRICARE entirely, and replacing it with a program offering beneficiaries a selection of commercial insurance plans administered through OPM and paid for by a nontaxable allowance (Military Compensation and Retirement Modernization Commission, 2015).

Medicare's durable medical equipment contracts have recently suffered similar concerns over the transparency of the process. Medicare was required to start bidding out contracts to provide durable medical equipment, such as prosthetics or oxygen supplies (CMS, 2015b). The program has been widely criticized by patient advocates as potentially disruptive if a new company in a given region were to win the new contract, thus changing procedures or even types of equipment offered (Japsen, 2013). GAO reported in 2014 that the process led to savings and that the process did not adversely affect beneficiaries, contrary to media reports (GAO, 2014c). The report also recommended ongoing monitoring of the process.

VA also has a contracting process in place, for services other than the major contracts to provide health services. VA's Office of Inspector General monitors and audits the contracting process for all VA agencies (VA Office of Inspector General, 2014c, 2013). In one audit for VHA support services in 2014, the VA Office of Inspector General found that VA lacked a rigorous internal process for the entire spectrum of contract lifespan from developing and awarding a contract to monitoring performance post-award (VA Office of Inspector General, 2014d).

In summary, all three organizations have had issues with bidding out contracts to the private sector for various services. Any competitive bidding and appeals process for these functions would need to be managed carefully and thoughtfully, so as to minimize the risk of any interruption to ongoing operations.

\footnotetext{
8 A former administrator of the Office of Federal Procurement Policy has argued that, across the federal government, protests yield benefits that outweigh the costs they impose (Gordon, 2013).
} 


\subsection{Discussion}

TRICARE and Medicare can both offer some lessons on how to efficiently purchase care from outside contractors. Perhaps most notable in this regard, TRICARE and Medicare outsource many of the administrative functions in paying for care, such as claims processing and fraud tracking, and they often do so with structured performance incentives for the outside contractors. In principle, policy-makers could draw on these lessons in strengthening VA's approach to purchased care contracting in the future-either in the context of expanding VA's emphasis on purchased care or in the context of improving efficiency and quality within VA's current approach to purchased care. Regardless, policy-makers would be well served by developing a clear strategy for VA purchased care as an antecedent to improving related processes and standards for outsourcing.

More broadly, the relevance of TRICARE and MEDICARE as models for VA depends in part on whether policy-makers agree on a clear strategy for VA purchased care programs, and particularly so if an ambitious path to reform is undertaken, by refashioning VA's function and mission to look much more like that of TRICARE or Medicare than it does today. Even stopping short of this possibility, a well-articulated strategy for VA purchased care could nevertheless help to foster more effective resource administration, increase capacity development, and improve the performance of VA purchased care programs. We expand on the latter point in Chapter Eight of this report. 


\subsection{Summary of Assessment Findings}

One of VA's core functions as an agency involves providing health care services to eligible Veterans. Although VA has traditionally carried out this role primarily by operating a national network of hospitals and other facilities, it also purchases health care services from outside providers. VA purchased care evolved primarily to address situations in which VA's direct care resources were unable to offer needed services. Although purchased care has accounted for only a small fraction of VA's health care budget over the past decade, that fraction is growing. In the wake of the recent crisis in access to care through VA facilities, stakeholders and policy-makers are revisiting the role and performance of VA purchased care. Specifically, they are considering whether modifications to VA's purchased care approach might be appropriate or desirable, given broader goals of expanding access to care, enhancing and developing trusted partnerships, and improving VA operations to deliver high-quality health care to eligible Veterans.

Pursuant to Section 201(a)(1)(C) of the Veterans Access, Choice, and Accountability Act of 2014 (Veterans Choice Act), Congress mandated an independent assessment of VA specifically to address "[t]he authorities and mechanisms under which the Secretary may furnish hospital care, medical services, and other health care at non-Department facilities, including whether the Secretary should have the authority to furnish such care and services at such facilities through the completion of episodes of care." Put another way, the congressional assessment mandate poses a few basic questions about purchased care. First, what authorities and mechanisms does VA have to purchase care? Second, does VA have the appropriate authorities and mechanisms to purchase care? Third, should VA have the authority to purchase care through the completion of episodes of care?

In answering these questions throughout this report, we observed that the Secretary already has considerable authority to furnish purchased care. In fact, that authority and related practice are long-standing. However, current VA authority and policy for purchasing care are complicated. They are structured around core provisions that establish what the Secretary may do, rather than what he or she must do, in purchasing care. Meanwhile, related eligibility criteria for Veterans, contracting parameters, and administrative mechanisms (for example, for authorizations and claims processing) involve a patchwork of interlocking rules and policies, which can be confusing even for VA personnel. In the discussion that follows, we offer some suggestions for how current purchased care authorities and policy might be modified to reduce this complexity and improve coherence, while empowering VA staff and facilitating VA operations. 
Beyond the recommendations that we articulate here, we also identified many other possible revisions that might be made to purchased care authorities in the future. ${ }^{1}$ Whether any of these changes are actually wise depends on what policy-makers and stakeholders hope to achieve by reforming purchased care. Different objectives could easily lead to different packages of reforms. An important priority for the future will involve forging consensus on the objectives for revising purchased care and on a corresponding strategy for purchased care policy consistent with VA's broader health care mission.

\subsubsection{VA Has a Complex Set of Authorities to Purchase Care, Reflecting Tension Among Implicit Aims}

The core authorities that govern VA purchased care activities are scattered across many different statutory and regulatory provisions. Central examples include 38 U.S.C. 1703 (contracts for medical care service with non-VA facilities), 38 U.S.C. 1725 and 1728 (reimbursement of emergency care), 38 U.S.C. 8153 (sharing of health care resources), and Section 101 of the Veterans Choice Act (defining the parameters of the Choice program). These statutory authorities are the foundation for a corresponding set of regulatory provisions. Collectively, the statutes and regulations form a complicated landscape for when and how the Secretary may purchase care and, by extension, which Veterans are permitted to obtain purchased care services.

Although the basic grant of authorities to the Secretary for purchased care is expansive in some respects, it is not unlimited. Both Congress and VA have imposed significant controls over the types of Veterans who can take advantage of external health care resources, the medical conditions that may be treated, and the procedures that must be followed to obtain a referral or reimbursement for an independent purchase of services. Such controls also govern how the existing availability and capabilities of VA personnel and facilities should be taken into account, the need for prior VA approval to access external providers, the process for contracting with outside providers and the substance of those contracts, and the length of time that purchased care can be obtained without additional authorization.

Moreover, the underlying intent of these varied controls implicitly reflects several interests beyond simply providing Veterans with access to outside care. One such interest is to limit the need for and costs of purchased care. Another is to balance VA's primary health care function as a direct provider of services with a more limited secondary function of paying for outside services when gaps arise in VA's direct-provider capacity. Finally, the controls may also be intended to ensure some degree of local-level VA discretion regarding the optimal mix of internal and external resources for allocating care in the field.

In sum, not only are VA's authorities for furnishing purchased care complex and scattered, but they also embody more than one aim, and those aims may operate in tension with each other.

\subsubsection{The Episode of Care Defines the "Unit" of VA Authorization and Helps Shape the Purchased Care in Practice}

In Section 201(a)(1)(c) of the Veterans Choice Act, Congress posed the question of whether the Secretary should have the authority to furnish care at non-VA facilities through the completion of episodes of care. As discussed throughout this report, the Secretary already has significant authority to purchase care, but that authority is not explicitly tied to formal standards for

1 See, in particular, Chapter Six. 
episodes, beyond particular program requirements for authorization (for example, as specified under the Veterans Choice Act). Detailed clinical standards for defining episodes of care are still in development, both within VA and across the U.S. health care system. Regardless, how these episodes are defined is important in purchased care because the episode conceptually bounds a clinical problem for which a Veteran may require outside services, so it might therefore may make sense to outsource as a coherent "unit."

As discussed in Chapter Five, revised standards for episodes of care may well become the basis for new forms of contracting, bundled-payment innovation, and purchasing of services in the future, inside and outside of VA. Likewise, new episode-of-care standards will likely become the foundation for important new techniques in performance measurement and quality improvement.

Given the ongoing changes within the U.S. health care system, which may include the future development of well-defined episode-of-care standards, sophisticated bundled payment arrangements, and robust episode-based performance measurement, the Secretary of VA should have more authority (and more responsibility) to build purchased care contracts around these developments. Specifically, the 60-day authorization period for purchased care through the Choice program (and established under the Veterans Choice Act) should be modified to accommodate the more effective use of bundled payment arrangements and other advancements in episode-of-care standards. Furthermore, it is clear that further refinements in defining episodes of care, along with an authority framework that allows the Secretary to adopt such refinements, will be critical to supporting VA in any move toward episode-based payment mechanisms in the future.

\subsubsection{The Purchased Care Landscape Is Already in the Midst of Transformation}

As of this writing (in the summer of 2015), numerous changes to VA's authorities and mechanisms for purchasing care were being proposed, planned, and implemented. VA, Congress, and the TPAs were collaborating to develop pilots in local areas to test new processes for administering Choice and PC3. These stakeholders were also reviewing the performance of VAMCs to determine whether local facilities were meeting demand through both direct and purchased care. According to recent congressional testimony and our own interviews, stakeholders and policy-makers are acutely aware of the variation in purchased care SOPs across the enterprise and are actively working to address it. Major changes along these lines are anticipated in the coming months.

Meanwhile, several related changes to the Choice program were under way. In May 2015, the Senate Veterans' Affairs Committee suggested that high costs may be associated with changes to the 40 -mile rule to access care through the Veterans Choice Act-particularly if the rule were modified to take into account driving distance to the most appropriate facility for the treatment required (Exploring the Implementation and Future of the Veterans Choice Program, 2015). Both the House and Senate Veterans' Affairs committees are working closely with the Congressional Budget Office to assess these costs and the feasibility of possible changes to the 40-mile rule. On May 1, 2015, VA submitted a legislative proposal that included "major improvements to VA's authority to use provider agreements for the purchase of community care" (Exploring the Implementation and Future of the Veterans Choice Program, 2015). As of this writing, full details of that proposal were not available.

As of early June 2015, there was lingering uncertainty about the future of the Choice program. The Veterans Choice Act was enacted as a temporary bill, terminating on "the date 
on which the Secretary has exhausted all amounts deposited in the Veterans Choice Fund ... or the date that is three years after the date of the enactment of this Act, whichever occurs first." Many stakeholders interviewed believed that the Veterans Choice Act would likely be extended. Beyond possible extension or termination, changes to the program's funding and eligibility may be on the horizon. VA has indicated that it would like to use Choice funds to support other purchased care programs, as well as hepatitis $\mathrm{C}$ treatment (Exploring the Implementation and Future of the Veterans Choice Program, 2015). In addition, VA has called for changes to eligibility restrictions that impede it from offering obstetrics, dentistry, and longterm care services under the Choice program (Exploring the Implementation and Future of the Veterans Choice Program, 2015). Various stakeholders have discussed the possibility, benefits, and challenges of merging purchased care programs and their associated funding streams. As of this writing, these issues continued to echo in congressional conversations about the future of VA purchased care programs (Assessing the Promise and Progress of the Choice Program, 2015; Exploring the Implementation and Future of the Veterans Choice Program, 2015).

With these facets of purchased care authorities and practice in flux, the landscape of VA purchased care is not just complicated, but dynamically so. Moreover, while the proposed policy changes seek to address many problems and issues, their sheer multiplicity suggests the drawbacks of a piecemeal approach to reform and the lack of guiding orientation and strategy for VA's purchased care enterprise as a whole.

\subsection{Limitations of the Assessment}

Our research approach in this assessment was subject to several basic limitations, deriving largely from our use of qualitative and legal research methods to answer the questions posed by Congress. As described in Chapter Two, one of our primary data collection activities involved stakeholder interviews. We interviewed several dozen stakeholders over the course of this study about many different aspects of VA purchased care policy and practice. This method offered the advantage of tapping the insights and expertise of highly knowledgeable individuals regarding how purchased care works in practice. However, it also involved soliciting the perspectives of a limited sample of stakeholders whose experience and perspectives may have been imperfect or biased. As discussed in Chapter Two, we sought to mitigate this limitation by speaking with multiple respondents from each of several different stakeholder vantage points, validating our interview data against data from other sources when possible, and focusing our interviews on collecting basic factual and institutional information about purchased care.

Somewhat different limitations applied to our request for local purchased care policy documents. Our request for documents was sent to all 141 VAMC administrative parents and 21 VISNs in the country, and the overall response rate was an impressive 86.4 percent (with 125 of 141 VAMC administrative parents and 15 of 21 VISNs responding). However, we have no independent way of confirming whether we received every relevant document from every entity responding to the request; whether local institutions had consistent assumptions about what was relevant and within the scope of our request; or whether nonresponses reflected the absence of relevant policies at the local level, confusion regarding the nature of the request, or an inability to respond within a relatively short time frame. Another limitation of this research involved defining the scope of purchased care authorities. Per the assessment mandate, we focused on the authorities and mechanisms that govern purchased care. However, we note 
that if purchased care ramps up substantially, then VA will need to realign resources, which could require changes to authorities and mechanisms that are not directly related to purchased care. Such shifts in VA resources might include changes to a range of different dimensions of organizational capacity, including staffing, information technology, fiscal resources, and facilities. For example, VA might need to accommodate an increase in purchased care utilization through a reduction in its medical personnel and facilities. These organizational shifts would likely require changes to authorities, which could limit the time frame and circumstances under which the VA Secretary may undertake administrative reorganization, including consolidating, eliminating, abolishing, or redistributing VA functions, offices, facilities, or activities.

The limitation of this study's scope to the authorities and mechanisms that are directly related to purchased care reflects the constraints of the available data. A main theme of this report is that changes to authorities and mechanisms depend largely on policymakers' objectives for the purpose and trajectory of purchased care. Through a literature review, interviews, and an analysis of purchased care utilization data and budget allocations, we identified a clear trend toward increased usage of purchased care. However, even in interviews with senior VA leadership and other key stakeholders in which we directly asked about the future of purchased care, we were unable to distinguish the vision for purchased care in the immediate or long term. Without knowing the scale or direction of purchased care, it is impossible to analyze the full extent of potential changes to authorities and mechanisms that may be required as a result of shifts in VA organization. As such, we focused the scope of our assessment on authorities and mechanisms that clearly answer the research questions posed in the assessment mandate. Other dimensions of VA health care that may shift as a result of a dramatic reorientation toward purchased care are covered in greater detail in other assessments mandated by the Veterans Choice Act.

\subsection{Recommendations}

Our findings and analyses indicate that the challenges now facing VA purchased care can be best understood not only in terms of the Secretary's authorities, but also through the interplay among those authorities, mechanisms, and institutional management practices. Consequently, the solutions to the challenges are likely to involve a similar mix of reforms to authorities, mechanisms, and management practices. In the recommendations that follow, we suggest eliminating inconsistencies in authorities and changing the definition of episode of care. We also recommend that VA develop an explicit strategy and improved management structure for purchased care while allocating responsibility for related activities to the appropriate levels of management and administration within VA.

Because we view our recommendations as complementary in addressing a complex problem, we have not attempted to rank or prioritize them, nor do we propose an ideal timeline for implementation. Clearly, VA might undertake some internal policy changes in purchased care unilaterally, and it would not need to await congressional action before proceeding. On the other hand, our first recommendation involves developing an overarching strategy for purchased care. We recommend this in part because such a strategy could help script other responsive revisions to purchased care authorities and practice downstream. 
Collectively, these recommendations seek to move VA toward a more holistic vision for purchased care, to align authorities and mechanisms in support of that vision, and to ameliorate some of the entangled problems that constrain purchased care administration.

\subsubsection{Define a Strategy for Purchased Care}

Working together, Congress and VA should articulate a clear strategy and set of goals for purchased care and how it fits into VA's broader health care mission. Moreover, VA and Congress should establish benchmarks for success in the adoption of related purchased care reforms.

Policy-makers might reasonably approach purchased care with a range of objectives for change. If the aim is to maintain or expand VA purchased care permanently, that might lead to one set of conclusions about modifying authorities. If the aim is simply to address shortterm capacity gaps, that might lead to another set of conclusions. Finally, if the aim is to enhance the quality of purchased care services, Veterans' access to such services, or Veterans' care choices, that might lead to a third set of conclusions about modifying authorities. Given the link between the objective and the specific steps for carrying it out, the objective and the broad strategic vision for purchased care should be determined before any concrete policy options are pursued. In turn, that objective and vision will determine the best combination of future policies.

VA is now at a crossroads regarding how to modify and whether to expand its purchased care programs. It already has the authority to purchase care, but with a limited scope that is secondary to VA's primary health care function in operating as a direct provider of services. Some stakeholders would like to see the greater use of purchased care at VA. Others would like VA to maintain its direct-care organization and core health care delivery capabilities. Congress has chosen a middle pathway with the Veterans Choice Act, providing more funding both for purchased care and for hiring in-house providers. These competing visions for VA make it difficult to reach consensus about the path forward.

In principle, a coherent strategy for VA purchased care should guide both the organizational ethos and the actions of those implementing purchased care programs. The strategy should offer a foundation for new rules and procedures with flexibility to support growth in demand, extenuating circumstances, and Veteran-centered care. ${ }^{2}$ The strategy should also provide clear direction for when and how VA should purchase care, as well as the roles and responsibilities of key stakeholders. More focused changes to authority and guidance, and to program management and performance monitoring, would then follow from the strategy.

Ultimately, without a basic strategy for purchased care, questions about what authorities the Secretary should have become much harder to answer, and future purchased care reforms are more likely to be fragmented, incremental, and less focused in their effects.

\subsubsection{Address Cost Control More Directly and Systematically}

Cost control is one of the implicit design features of VA purchased care authorities. The existing authorities limit the amount of funding for purchased care and set priorities regarding which Veterans receive access (e.g., pursuant to the 40-mile rule under Choice). As discussed in Chapter One, any proposal to modify purchased care authorities that focuses only on improving

2 Note that the concept of "Veteran-centered care" implies that providers actively engage with the Veteran in decisionmaking about individual options for treatment. 
Veterans' access neglects the secondary goal of limiting spending on purchased care, particularly in the context of discretionary funding and annual appropriations for VA health benefits.

The role of the tiered access structure in permitting and gating access to care within a discretionary budget is critical. A pillar of the authorities governing VA purchased care, 38 U.S.C. Section 1710 identifies service-connected and other specific injuries and illnesses for which the department shall provide health care services. Section 1710 also indicates that illnesses and injuries not specified in the list of those that VA shall treat will be treated at the discretion of the Secretary, contingent on available resources.

Much of the relevant authority for cost control has been filled in by regulations and programmatic guidance. These regulations and guidance create mechanisms that give significant control and responsibility to personnel in the field charged with making decisions about whether to refer and authorize purchased care on a patient-by-patient basis. ${ }^{3}$ This means that cost control in VA purchased care involves local decision-making that indirectly affects resourcing, when policy-makers have been unable or unwilling to make those resourcing decisions more directly.

We recommend that VA and Congress address cost control in purchased care more explicitly and systemically. Specific cost-control steps that might reasonably be implemented could include rigorous performance evaluation and auditing of current purchased care contracts (including PC3 contracts) and more systematic data collection on various costs associated with purchased care programs and administrative activities (e.g., network development, credentialing, training, claims processing). VA should also consider more aggressive deployment of traditional cost-control and cost-sharing mechanisms in health insurance, including copays, deductibles, and utilization review. Finally, VA can also address cost control more directly through adopting innovations in bundled payments, value-based contracting, and performance incentives for contractors.

\subsubsection{Collect Better Data to Accurately Estimate Demand and Use of Purchased Care}

VA should systematically collect data on purchased care processes and outcomes. Like TRICARE, VA needs to establish demand for purchased care and then design its outside provider networks to meet that need. The structure and success of purchased care are contingent on understanding the demand for care and shifts in demand for care over time. For example, Veterans who spend their winters in Phoenix, Arizona, reportedly increase demand for services in that area by a multiplier of eight to 10 during the winter. ${ }^{4}$ Given the legacy approach to purchased care that is in place, VA should use direct care to meet demand while reserving purchased care to address treatment areas where there are gaps in capacity to meet demand.

VA lacks systematic data on purchased care arranged at the local facility level. VA patient experience surveys collect Veterans' assessments of their access to care, but that information lacks specificity. Furthermore, the surveys are collected too infrequently and response rates are too low to meaningfully inform purchased care planning and implementation. Previous assessments by the National Academy of Public Administration and GAO align with our conclusion that more systematic data collection should be embedded in purchased care processes,

\footnotetext{
3 For example, 38 U.S.C. 1710 says that the Secretary shall furnish hospital care and medical services that he or she "determines to be needed." The determination of "need" presumably involves clinical judgment in any given case, together with an economic judgment about the most appropriate way to meet a clinical need.

4 According to a stakeholder interview.
} 
and both VA and its contractors should be able to analyze this data as needed to plan for and operate the purchased care program cost-effectively. A strong base of data would allow VA to regularly monitor purchased care outcomes (e.g., improved access, quality, coordination, cost) and make targeted adjustments to policies and processes as needed.

\subsubsection{Develop a Stronger Management Structure for Purchased Care and Allocate Responsibility and Authority to the Most Appropriate Levels}

There is a need for improved program management of VA purchased care activities. Furthermore, program management for purchased care should allocate responsibility and authority for purchasing care to the most appropriate level within VA's administrative hierarchy. For example, referrals should be managed locally, while large contracts (such as PC3 and Choice) should be managed centrally. The role of senior leadership (and of VA) should be to clearly articulate the expected outcomes of the purchased care programs and enterprise. Senior leadership should also establish performance measures to determine whether those outcomes have been accomplished. The leadership can use these metrics to ensure that the purchased care provided to Veterans is both high quality and cost-efficient. Moreover, senior leadership should issue clear policies and procedures for the field to follow and audit field performance at the facility level, drawing on both headquarters-level performance data reviews and site visits by program experts. Finally, there should be sanctions for noncompliance with approved policies and procedures.

A stronger program management structure should also facilitate appropriate flexibility in the field and at the local level. VA health care operations are far too complex and geographically varied to support a one-size-fits-all approach to purchased care. Better program management would help ensure that leadership is aware of and has input on local deviations from system-wide standards. If a significant deviation from approved policies is required, VA leadership should approve it beforehand. At the local level, VAMCs should offer better guidance on their SOPs, provide training on purchased care options and program implementation, and collect data on purchased care activities. Local program management should have a strong enough presence and priority to assist key decision-makers (like chiefs of staff) in addressing problems as they arise. Central program management should facilitate local administration and offer guidance as appropriate.

\subsubsection{Evaluate the Third-Party Contractors Administering the PC 3 and Choice Programs}

As the PC3 and Choice programs continue to grow, VA should implement a process for evaluating the performance of the TPAs administering these programs. Performance evaluation should be based on a series of explicit criteria, including network strength, process efficiency, and Veterans' experiences. To assess network strength, VA should consider whether the TPAs have built provider networks to adequately address the needs of Veterans living in the regions covered by the TPA, including whether Veterans have a choice of providers and whether network providers are able to provide timely access to care. VA should also assess the efficiency and accuracy of claims processing, the timeliness and ease of referral processes, and other key outcomes related to technical performance. Finally, it should examine Veterans' experiences with accessing care through these programs. Evaluation of the TPAs should be routine and ongoing, implemented as part of a process of continuous quality improvement. 


\subsubsection{Develop Clear and Consistent Guidance and Training on VA's Authority to Purchase Care}

While VA has a range of legacy manuals and directives on health care operation and procedures, the organization does not have a current, comprehensive manual that offers clear guidance on purchased care authorities and SOPs. Existing VA guidance on purchased care is scattered, outdated in parts, and inconsistent in setting clear standards for local VA officials to follow. Our research indicates that, as a consequence, local VAMCs have struggled with ambiguity when developing their own policies and procedures for purchased care.

VA should create a consolidated manual on purchased care, together with associated training and messaging that explains VA's authority to purchase care and clarifies eligibility and administrative processes for Veterans, VA staff, TPAs, and other stakeholders. Figure 8-1 shows how VA could translate statutes and regulations to internal and external audiences, clarify guidance, and improve processes and coordination.

In the midst of ongoing shifts in purchased care and a barrage of messaging to Veterans and other stakeholders about the Choice program, enhanced coordination and communication will be pivotal to the success of purchased care programs. The combination of improved internal processes and external messaging will be critical to reducing confusion, clarifying roles and responsibilities, and, ultimately, improving performance of VA staff members, VA providers, private providers, and TPAs.

\subsubsection{Ensure That Purchased Care Contracts Include Requirements for Data Sharing, Quality Monitoring, and Care Coordination}

To provide better oversight and ensure the quality of care for Veterans receiving health care in the community, VA should incorporate into its contracts with non-VA providers and TPAs requirements for data sharing, routine quality-of-care reporting, and collaborative coordination of care. VA is a leader in quality-of-care measurement and improvement, yet it has lim-

Figure 8-1

VA's Approach to Informing Internal and External Stakeholders About Authorities

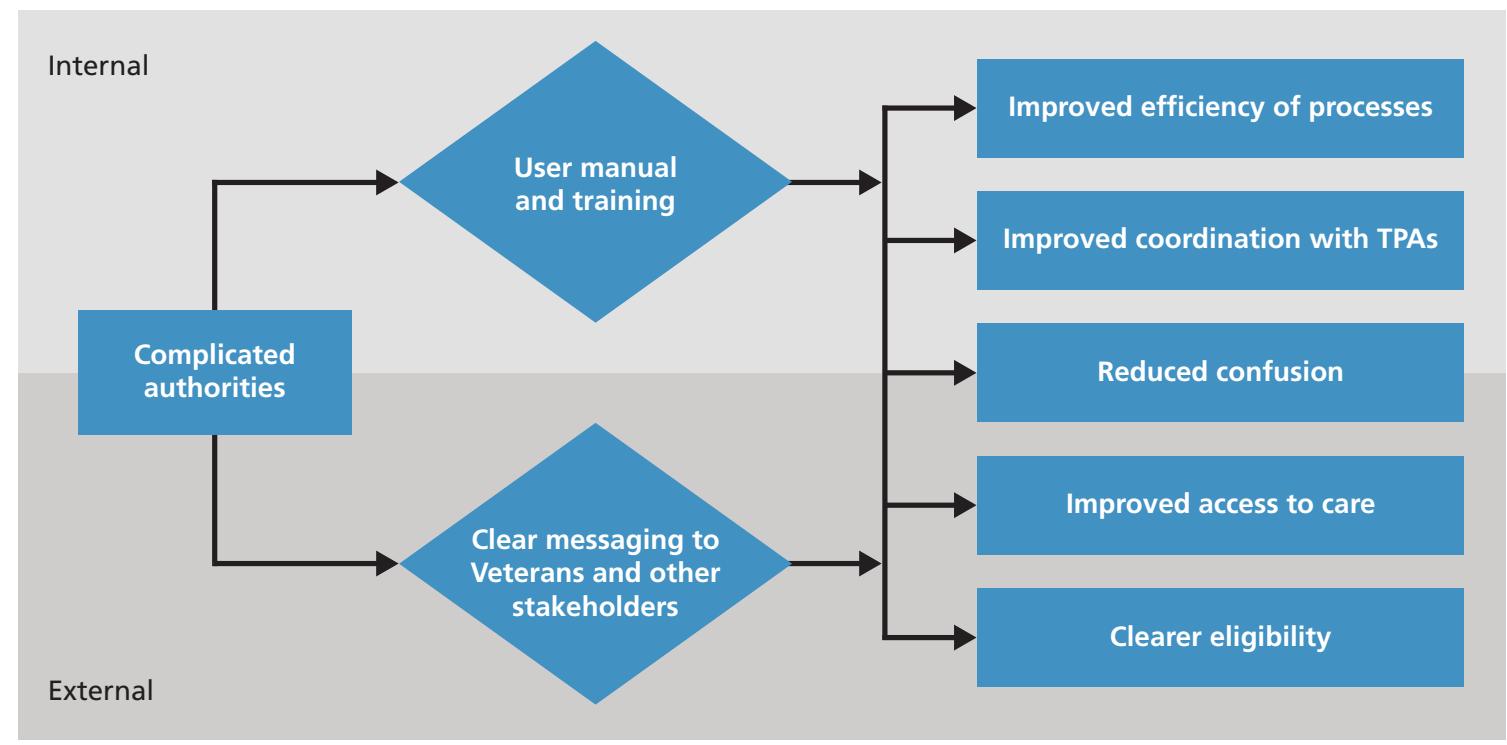


ited visibility into the quality of care provided to Veterans through purchased care programs. Oversight entities have examined the quality of outside care provided to Veterans, but VA does not have sufficient internal data collection mechanisms to track the performance of purchased care administration and inform necessary adjustments. In developing contracts with non-VA providers and TPAs, VA should require routine reporting of quality measures to ensure that the quality of care that Veterans receive through non-VA providers matches the quality of care offered by VA. Such contracts should also make explicit how non-VA providers will communicate and coordinate with VA counterparts.

\subsubsection{Consider Adopting Innovative (but Tested) Ways to Purchase Care}

TRICARE and Medicare offer some lessons for efficiently purchasing care that VA could adopt regardless of whether policy-makers decide to expand its purchased care footprint or simply improve its current purchased care programs. Specifically, TRICARE and Medicare outsource many of their administrative functions, such as claims processing and fraud tracking, often providing performance incentives to outside contractors. VA should consider incorporating the same approach into its current purchased care programs as well, particularly if policy-makers decide to expand the scope and size of VA purchased care.

\subsubsection{Eliminate Inconsistencies in Current Authorities and Provide Flexibility for VA to Implement a Purchased Care Strategy}

A key theme of this report is that the appropriate authority structure for purchased care depends, in part, on policy-makers' objectives for what purchased care should accomplish. That is, Congress and VA must first decide on a strategy for purchased care and then implement specific policy changes to carry out that strategy. Regardless of the specific direction of any new VA strategy for purchased care, Congress and VA can still eliminate inconsistencies in current authorities, which can improve care for Veterans. Aside from pursuing specific policy goals, these authorities should be clear, harmonious, and coherent.

We found several points of tension and confusion within existing authorities (for example, inconsistencies in VA standards for episodes of care, the subjective nature of some elements of 38 U.S.C. 1703, differences in definitions of geographic inaccessibility and wait times, and conflict between the language and intent of what constitutes a "medical facility" for applying the 40-mile rule under Choice). Beyond resolving these sorts of conflicts within the authorities, VA and Congress should also ensure that purchased care authorities are not so prescriptive that they restrict VA's ability to innovate, adopt new best practices, and surge to meet emerging needs.

VA already has basic authorities and mechanisms for purchasing care, but they are overly complex. The authorities are a relic of the evolution of purchased care over many years, and the mechanisms are not constructed or coordinated in a way that is easily navigated by Veterans, VA staff, TPAs, or other stakeholders. There are also many different rules about eligibility, reporting requirements, reimbursement rates, and authorization.

Beyond eliminating specific inconsistencies in purchased care authorities, a more ambitious step toward reducing confusion and ambiguity could involve consolidating and harmonizing VA's purchased care authorities, potentially by bringing together related programs under a single operating umbrella. Any such approach to consolidation would certainly involve significant political and practical challenges for Congress and VA, particularly in deciding how to harmonize existing authorities and how much revision to do in the process of consolidating 
them. As discussed in Chapter Six, different versions of consolidation could look very different from one other, depending on exactly how Congress and VA choose to approach such a move. Regardless, policy-makers should at least consider the merits of simplifying the existing structure of authorities and programs through this kind of consolidation effort.

\subsubsection{Revise How Episodes of Care Are Defined to Better Accommodate Veterans' Needs}

Under Section 101(h) of the Veterans Choice Act, the Secretary is obligated to allow Veterans who use the Choice program to seek outside services through the completion of an episode of care, "but for a period not in excess of 60 days." This narrow authority constraint on the Choice program forces the reauthorization of an episode after a defined period of time. In practice, this requirement may run contrary to evolving clinical practices and standards for episodes of care in the broader health care sector. It seems likely that the intent of Section 101(h) was to impose a basic resourcing gate on services purchased thereunder and to give VA both the authority and the responsibility to periodically review the Choice program's use of outside services to ensure that it is appropriate. In health care practice elsewhere, however, the term episode of care is much more flexible, accommodating clinical situations with either very short episodes (for example, the treatment of a minor, acute condition) or very long episodes (for example, the treatment of a chronic illness).

The episode of care construct is important clinically and administratively in helping to coordinate related services for an underlying medical problem. Outside the VA context, new standards for episodes, built around specific clinical conditions, have been focal points for emerging innovations in payment practice for purchased care. The 60-day requirement under Section 101(h) of the Veterans Choice Act and regulations interpreting that section are less than optimal for monitoring and coordinating care or for purchasing outside services in a manner that meaningfully corresponds to an episode. For policy-makers, our recommendation is to revise the current authority on episodes under the act, to support VA monitoring of episodes of care in a more flexible and nuanced way in the future.

\subsubsection{Adopt a Consistent Strategy for Reimbursement Rates Across Purchased Care Initiatives}

This report reviewed some basic challenges to establishing reimbursement rates for VA purchased care. For example, the establishment of TPA provider networks has reportedly been hampered in some regions because providers are reluctant to accept Medicare (or subMedicare) rates for their services. In these regions, some specialty providers may be able to make more money by accepting patients with private insurance over Veteran patients. By extension, when VA reimbursement rates become unattractive to outside providers, purchased care may become a less effective way to address shortfalls in internal capacity.

Another challenge in purchased care involves the potential for intra-VA competition between different purchasing mechanisms. The competition is driven by the fact that VA pays various reimbursement rates to providers (as shown in Table 8-1). Notably, providers who otherwise meet eligibility requirements might choose among several different contracting arrangements, including (1) joining a TPA network under PC3, (2) joining a TPA network under Choice, or (3) avoiding joining a network and instead accepting VA patients on a case-bycase basis through individual agreements with local VAMCs or the Choice TPAs. Each of these options has the potential to generate a different reimbursement rate for outside providers. Holding other factors equal, higher reimbursement rates would presumably be more attractive 
Table 8-1

Provider Reimbursement Rates, by Purchased Care Mechanism

\begin{tabular}{llcll}
\hline Feature & ARCH & PC3 & $\begin{array}{c}\text { Traditional VA Purchased } \\
\text { Care }\end{array}$ & Choice \\
\hline $\begin{array}{l}\text { Typical } \\
\text { reimbursement } \\
\text { rate }\end{array}$ & $\begin{array}{l}\text { \% of or full } \\
\text { Medicare rate }\end{array}$ & $\%$ of Medicare rate & $\begin{array}{l}\text { VA fee schedule, } \\
\text { Medicare rate, or } \\
\text { contracted rate }\end{array}$ & $\%$ of Medicare rate \\
\hline
\end{tabular}

for outside providers to pursue. VA should avoid influencing outside provider behavior as a result of the multiplicity of its purchasing channels and mechanisms.

To address these types of reimbursement problems, we recommend that VA and policymakers adopt a coherent strategy for reimbursement across VA purchased care initiatives, balancing considerations of cost against those of ensuring access. The strategy should be clear in its application, with the determination of purchasing mechanism based first on ensuring access to services by Veterans and with the appropriate reimbursement rate then following. VA can and should secure lower rates where outside providers are highly competitive in a given local market. But in an uncompetitive local market, the rates need to be sufficient to ensure access to needed services. VA mechanisms and contracts for purchasing care should reflect this reality in the setting of outside reimbursement rates.

Establishing a more effective strategy for reimbursement rates may require revisions to current VA authorities. As we explained in Chapter Three, current VA purchased care laws tend to set upper bounds on provider reimbursement rates while establishing no floor. ${ }^{5}$ However, in the context of a local market in which the pool of outside providers is very limited, such ceilings may actually be counterproductive and could undercut VA's ability to obtain needed services through purchased care.

Revisions to VA policy guidance will likely be equally important in adopting a more coherent approach to reimbursement rates. As discussed in Chapter Four, for some VA staff, simply determining which program or mechanism to use for purchasing care for a given Veteran-while considering the various options in the appropriate order-involves considerable complexity and ambiguity. To ensure better decisions about when and how to purchase care, we suggest revisions to VA policy, training, messaging, and oversight to bring the overall strategy on reimbursement rates into congruence and to reconcile alternative mechanisms for providers to seek appropriately competitive reimbursement.

\subsection{Conclusions}

Providing direct services for Veterans at VA facilities is a long-standing pillar of the VA health care system. At the center of this direct-care model is the nation's dual recognition that Veter-

5 Under Section 101(d)(2)(B) of the Veterans Choice Act, for example, provider reimbursement rates generally cannot be higher than the Medicare fee schedule rates (except for care for Veterans residing in counties with population densities of less than seven persons per square mile). In the context of outpatient services under Section 1703 purchased care, for example, reimbursements can be based on the terms of any existing contract or agreement between the provider and VA. If no such contract or agreement exists, the reimbursement would be the lower of the Medicare rate, the rate available through repricing (in which contractors offer VA discounted health care through a network of providers), or the amount the provider bills the general public for similar services. 
ans have unique health care needs and that VA should ensure that Veterans have timely access to high-quality care. While the nation's commitment to serving Veterans' unique health care needs is unwavering, the means to achieve this goal are shifting. As such, utilization of purchased care has increased significantly in recent years to supplement VA's capacity, given the increase in demand for care. ${ }^{6}$

Symptomatic of the widening gap between supply and demand for VA health care, the waitlists and the access issues at Phoenix and other medical centers signified a confluence of problems with VA health care. Per the Veterans Choice Act assessment mandate, we investigated the following research questions regarding VA purchased care:

1. What authorities and mechanisms does VA have to purchase care?

2. Does VA have the appropriate authorities and mechanisms to purchase care?

3. Should VA have the authority to purchase care through the completion of episodes of care?

We found that VA has a range of authorities to purchase care, but they are overly complicated. The authorities are complex, and they reflect various interests regarding the purpose, utilization, oversight, and limits of purchased care. Such interests include cost control, balancing direct and outsourced care, and ensuring surge capacity to meet emerging care needs. While VA has the authorities to purchase care, policy-makers must eliminate inconsistencies in the statutory and regulatory framework to reduce confusion and increase consistency of purchased care implementation. For instance, changes should be made to reduce inconsistencies in VA standards for episodes of care, the subjective nature of some elements of 38 U.S.C. 1703, differences in definitions of geographic inaccessibility and wait times, and conflict between the language and intent of what constitutes a "medical facility" for applying the 40 -mile rule under Choice.

While we found that changes are needed to reconcile the inconsistencies in authorities, we also found that the issues with purchased care mechanisms pose even greater challenges for stakeholders. Through ad hoc addition of pilots and programs, purchased care mechanisms have grown evolutionarily, and, as a result, navigating the multitude of options for outsourcing care is difficult for Veterans, VA staff, private providers, and TPAs. VA purchased care lacks the appropriate vision, strategy, and management structure to guide implementation. To improve management of purchased care, VA needs to develop clear and consistent guidance on SOPs and regularly communicate with stakeholders about the purpose of purchased care and its rules and requirements. In addition, VA should address cost controls more directly, through rigorous performance evaluation and auditing of contracts, systematic data collection on costs, more aggressive deployment by VA of such traditional cost controls as copays and deductibles, and adoption of innovations in bundled payments, value-based contracting, and performance incentives for contractors. Furthermore, to better assess purchased care processes and outcomes, VA must collect better data on processes and evaluate TPA performance in implementing PC3 and Choice contracts.

Beyond changes to purchased care management, VA should modify authorities and mechanisms to position the Department to adopt best practices and make strategic decisions

6 The Assessment A report discusses how demand for VA services has been steadily increasing, despite a decline in the overall Veteran population (RAND Health, 2015a). 
about outsourcing care in the long term at both the local and enterprise levels. Per the second research question posed, we assert that VA should have the authority to purchase care through the completion of episodes of care. However, the Department needs to revise how episodes of care are defined to better accommodate Veterans' needs. Under the Veterans Choice Act, VA must allow Veterans who use the Choice program to seek outside services through the completion of an episode of care, "but for a period not in excess of 60 days." The legal requirement for a fixed-term reauthorization of an episode runs contrary to evolving clinical practice and standards in the broader health care sector. A revision of this authority would improve monitoring of episodes of care and reduce the administrative burden on VA staff and Veterans.

\subsection{Looking Toward the Future}

VA not only operates one of the largest health care systems in the world (VA, 2015a), but it is also widely renowned for the quality of its work in many areas of care, research, and development. For example, VA is a world leader in research and development in prostheticsrelated care (VA, Office of Research and Development, 2015), and it excels in the care and treatment of spinal cord injuries, geriatric conditions, polytrauma, traumatic brain injury, and posttraumatic stress disorder (McDonald, 2014a). In addition, VA consistently receives high marks on customer satisfaction (VHA, 2012; U.S. Department of Veterans Affairs, Office of Public and Intergovernmental Affairs, 2014), and it continues to hone its capabilities in health information technology, physical infrastructure, and other areas. VA's excellence in providing quality care to Veterans in a culturally sensitive manner has been widely touted, and Veterans and stakeholders recognize the value of the VA system. According to VA Secretary Robert McDonald,

In the past nine months, I've learned that there is no substitute for VA. Veterans need VA, and Americans everywhere benefit from VA-from VA research contributing to major breakthroughs in medical science (three Nobel Prizes, seven Lasker Awards, the implantable cardiac pacemaker, the first successful liver transplants, and the nicotine patch to help smokers quit); from VA training of doctors, nurses, and other medical professionals, including 70 percent of America's physicians; and from VA's highly specialized expertise in delivering clinical and rehabilitative services to wounded warriors. (McDonald, 2015)

The VA system has built a reputation for the strengths of its size, progress, and innovation, which are backed by decades of experience and success in serving Veterans. While Veterans and other key stakeholders widely acknowledge the success of many facets of the VA enterprise, they also recognize that the Department faces significant organizational challenges and that, in some important respects, the operations and identity of the VA system are still evolving. Furthermore, in the case of purchased care, related operations within the VA system have evolved more rapidly than the patchwork of authorities and mechanisms that support them.

Improving the authorities and mechanisms for purchased care offers an enormous opportunity for VA. Synchronizing legal guidelines and supporting structures in support of a wellarticulated objective and coherent strategy could empower the organization in the future in more effectively growing its provider network, improving its administration and processes, and 
fostering creative solutions for communicating and coordinating with private providers at both the federal and local levels.

The recommendations in this report aim to facilitate VA's adoption of best practices in purchased care, drawing on the collective experience of the wider health care community. Outside advancements in administrative functions, payment structures, performance management, standardization, and managed utilization can offer VA a blueprint for long-term gains in organizational efficiency and effectiveness. Defining and implementing improved standards for episodes of care is another way to improve internal processes and leverage VA's connections with the private health care community. Adopting some combination of these recommendations could help lift VA to new levels of organizational performance and, ultimately, improve the health and the lives of Veterans. 



\section{Growth in Purchased Care Utilization Rates and Authorizations}

About 10 percent of VA's entire health care budget goes to purchased care. Pursuant to a request from RAND, VHA's Chief Business Office estimated that the total tab in FY 2014 for purchased care was $\$ 5.6$ billion, after steady and significant increases year after year (Figure A-1; VA, 2014c). Other VA sources have provided different estimates of purchased care expenditures during this time frame, with Deputy VA Secretary Sloan Gibson testifying before the Senate Veterans' Affairs Committee on May 12, 2015, that VA had spent more than $\$ 8.5$ billion on community care in FY 2014 (Exploring the Implementation and Future of the Veterans Choice Program, 2015). The difference in these estimates is likely because Deputy Secretary Gibson included Civilian Health and Medical Program of Veterans Affairs (CHAMPVA) costs in his totals. Using another metric of purchased care utilization, Deputy Secretary Gibson noted that Veterans completed 55.04 million appointments at VA facilities and 16.2 million appointments in the community in FY 2014 (Exploring the Implementation and Future of the Veterans Choice Program, 2015).

Figure A-1

Growth in VA Purchased Care, FYs 2002-2014

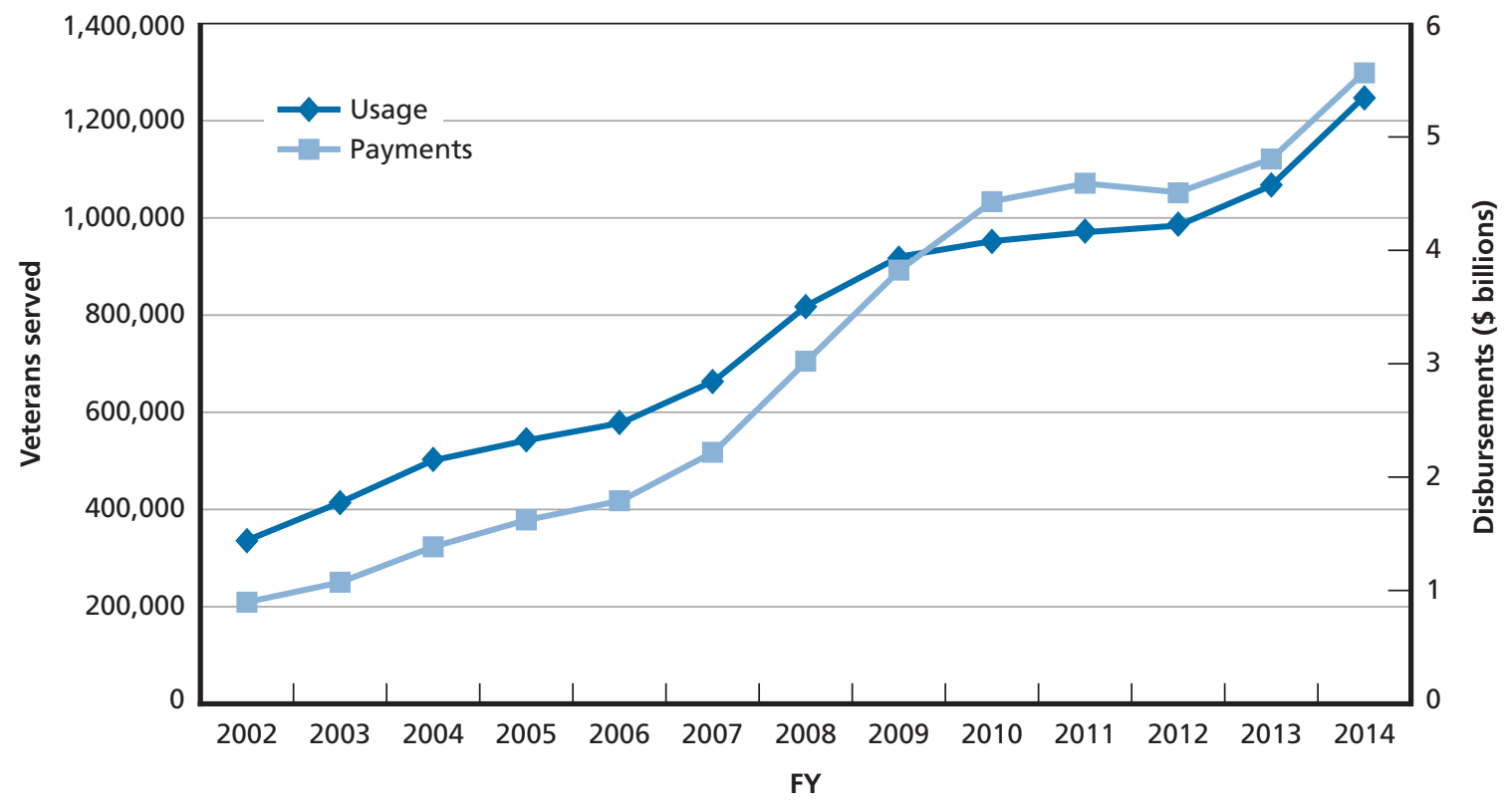

SOURCE: Data obtained through a request to the VHA Chief Business Office, May 12, 2015, and originally derived from VA Central Office fee payment files.

RAND RR1165z3-A.1 
The use of purchased care spiked in the wake of the Phoenix scandal and during implementation of the Choice Program. VHA has used purchased care to meet surge demands and reduce backlogs. As shown in Figure A-2, from FY 2013 to FY 2014, the rate of purchased care utilization by VHA enrollees increased from 12 to 14 percent. And, as the figure shows, purchased care was already increasing.

As Table A-1 indicates, more than half of all expenditures for purchased care from FY 2008 through FY 2012 were for nonemergency inpatient and outpatient care.

Figure A-2

Purchased Care Utilization by VHA Enrollees, FYs 2002-2014

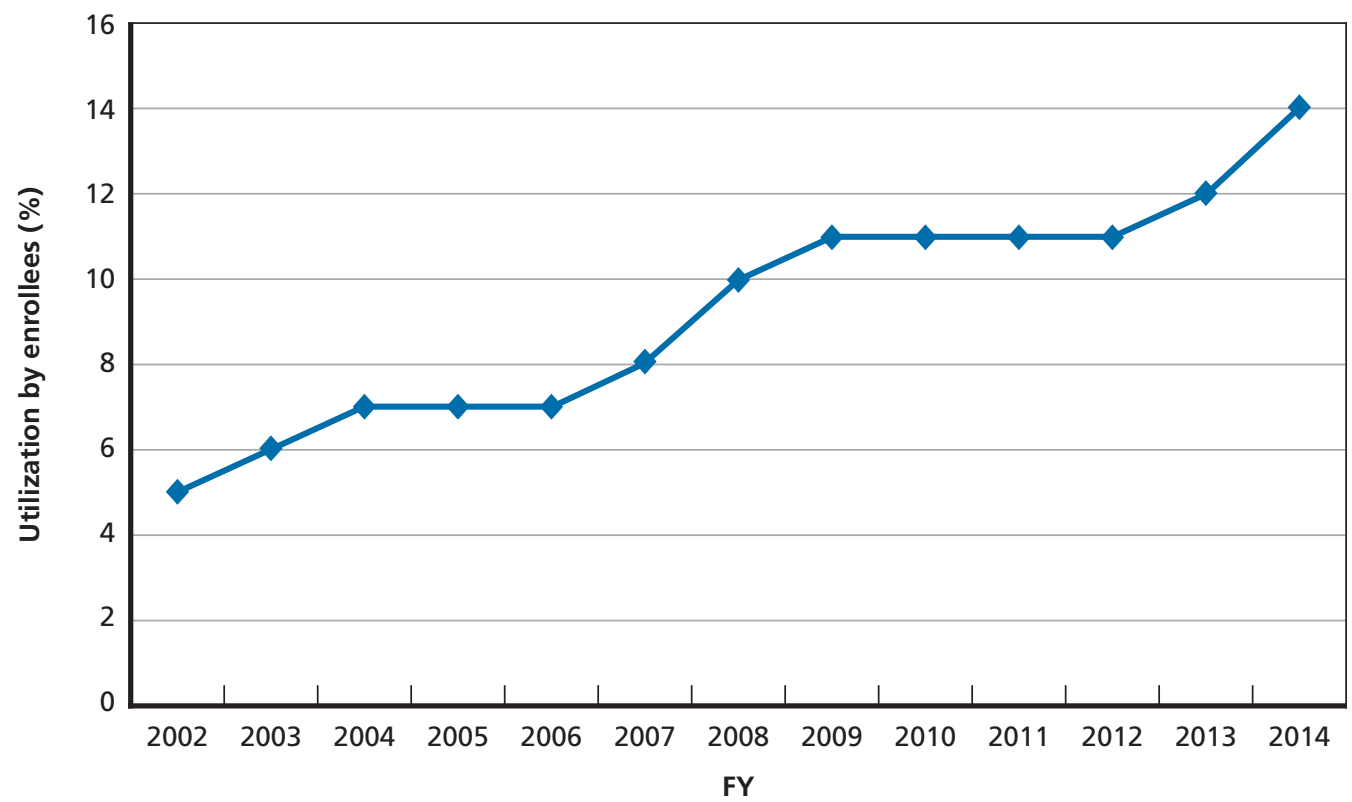

RAND RR1165z3-A.2

Table A-1

VA Spending and Utilization, by Purchased Care Category, FYs 2008-2012

\begin{tabular}{llc}
\hline External Service & \multicolumn{1}{c}{ Type of Care } & $\begin{array}{c}\text { \% of All VA Purchased } \\
\text { Care Expenditures }\end{array}$ \\
\hline & Preauthorized inpatient & 22.7 \\
& Preauthorized outpatient, medical & 36.3 \\
Broad-based & Preauthorized outpatient, dental & 1.8 \\
& Emergency care for Veterans with service-connected conditions & 4.5 \\
& Emergency care for Veterans with non-service-connected & 8.8 \\
Conditions & 13.3 \\
& Home health & 12.3 \\
\hline
\end{tabular}

SOURCE: GAO (2013a, p. 38, Table 2). 
We also obtained VA purchased care utilization data for 24 individual VAMCs through our request for documents. The data showed interesting variations in the use of purchased care. ${ }^{1}$ Although we collected data on only a subsection of the VAMCs across the United States, our analysis shows that some VAMCs are much more likely than others to employ VA purchased care mechanisms. For instance, while all VAMCs seemed to be in line with the national trend of increasing utilization of purchased care mechanisms over time, it appears that-among the 24 sites included in this segment of our analysis - utilization was highest in VAMC B, VAMC I, VAMC R, VAMC V, VAMC W, and VAMC X. Of those, VAMC W's utilization was particularly high, almost double that of the other high-utilization sites shown in Figure A-3.

Additionally, we obtained VA purchased care authorization data for a different set of VAMC sites. The data showed both authorizations for all VA purchased care and those specifically for PC3 from FY 2013 through FY 2014. Again, as shown in Figure A-4, the data correspond with the trends highlighted in Figure A-3, indicating overall increases in purchased care disbursements over time. However, there is also significant variation in such authorizations across VAMCs, even though the sites included in Figure A- 4 are different from those included in Figure A-3.

While we were unable to clearly discern the reason for such variation in VA purchased care utilization and authorizations, one cause may be that funding allotments for VA purchased care differed by VISN during this time frame. The Veterans Choice Act mandated that responsibility for funds for purchased care be centralized in VHA's Chief Business Office beginning in the October-November 2014 time frame, but prior to this centralization, each VISN managed its own purchased care budget. Many VISN directors with whom we spoke indicated that they based their planning for their VISN's use of purchased care on their budget for such care each year.

Variations in the permissiveness and tone of purchased care SOPs across the VAMCs provide us with another working hypothesis to explain this variation in utilization, though such local-level policies may have ultimately been shaped by the knowledge of overarching budgetary constraints in a given region. As noted above, the RAND team coded all SOPs received through the data call with regard to their apparent focus and tone pertaining to utilizing internal VA care if at all possible, as opposed to being permissive regarding utilization of VA purchased care. The results were strikingly varied, with 70 SOPs containing language focused on keeping Veterans within the VA system and utilizing purchased care only as a temporary, last-resort option. Meanwhile, 102 SOPs were much more permissive in tone regarding the utilization of purchased care; while they still tended to note that such care should serve as only a temporary solution, they were set up to facilitate the ease of use of the purchased care mechanism(s) in question. The remaining SOPs were deemed to be too neutral in tone to code either way. Nonetheless, the variation in tone across VAMCs regarding how permissive to be

\footnotetext{
1 We obtained VA purchased care cost and authorization data (total and PC3) from detailed VAMC site visit documents. Months in which fiscal years started and stopped varied by VAMC. We did not have access to numerical data on FY 2013 total authorizations and all costs for all VAMCs, so some of this information had to be imputed from bar graphs. We used the software program WebPlotDigitizer to compare the height of labeled y-axis ticks to the heights of bar graph columns and to impute the value of those columns. To check the robustness of the data imputed with WebPlotDigitizer, we matched FY 2014 imputed authorization values with real authorization values for sites that provided both a graph and the true value (both were available in site visit documents). In the case of one VAMC, for instance, the imputed number of FY 2014 authorizations was 40,945, whereas the real number was 40,679, showing a relatively minimal difference of 266 , or an 0.65 -percent deviation from the real value.
} 
Figure A-3

Purchased Care Utilization Across VAMC Sites, FYs 2012-2015




Figure A-4

Total Purchased Care Authorizations and PC3 Authorizations Across Specific VAMC Sites, FYs 2013-2014

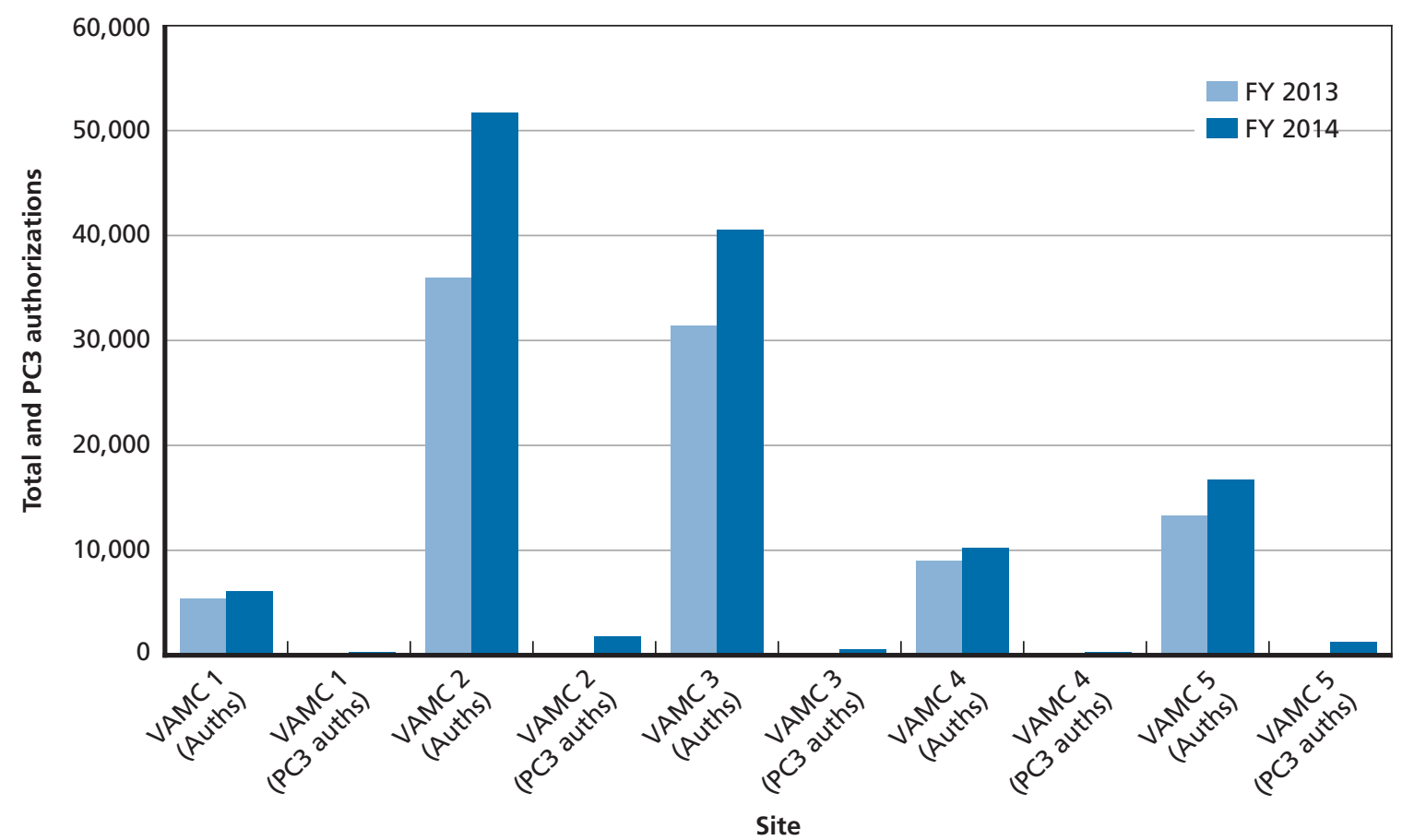

RAND RR1165z3-A.4

when authorizing purchased care services provides one possible explanation for the variance in actual utilization of VA purchased care mechanisms across sites.

The facility survey data also provide an interesting perspective on the frequency with which purchased care options are exercised. The survey asked respondents, "How frequently do you refer Veterans to fee-basis or contracted care?" It also directed respondents to use their best judgment to answer this question, specifying that they were not required to pull data from their administrative parent records to respond. Responses varied substantially, as shown in Figure A-5, with similar fractions of respondents (25-30 percent each) indicating that they referred Veterans to fee-basis or contracted care 2-4 percent of the time, 5-10 percent of the time, and over 10 percent of the time. Sixteen percent of respondents indicated that they referred Veterans to fee-basis or contracted care 1 percent or less of the time. 
Figure A-5

Frequency with Which VA Facilities Refer Veterans to Fee-Basis or Contracted Care

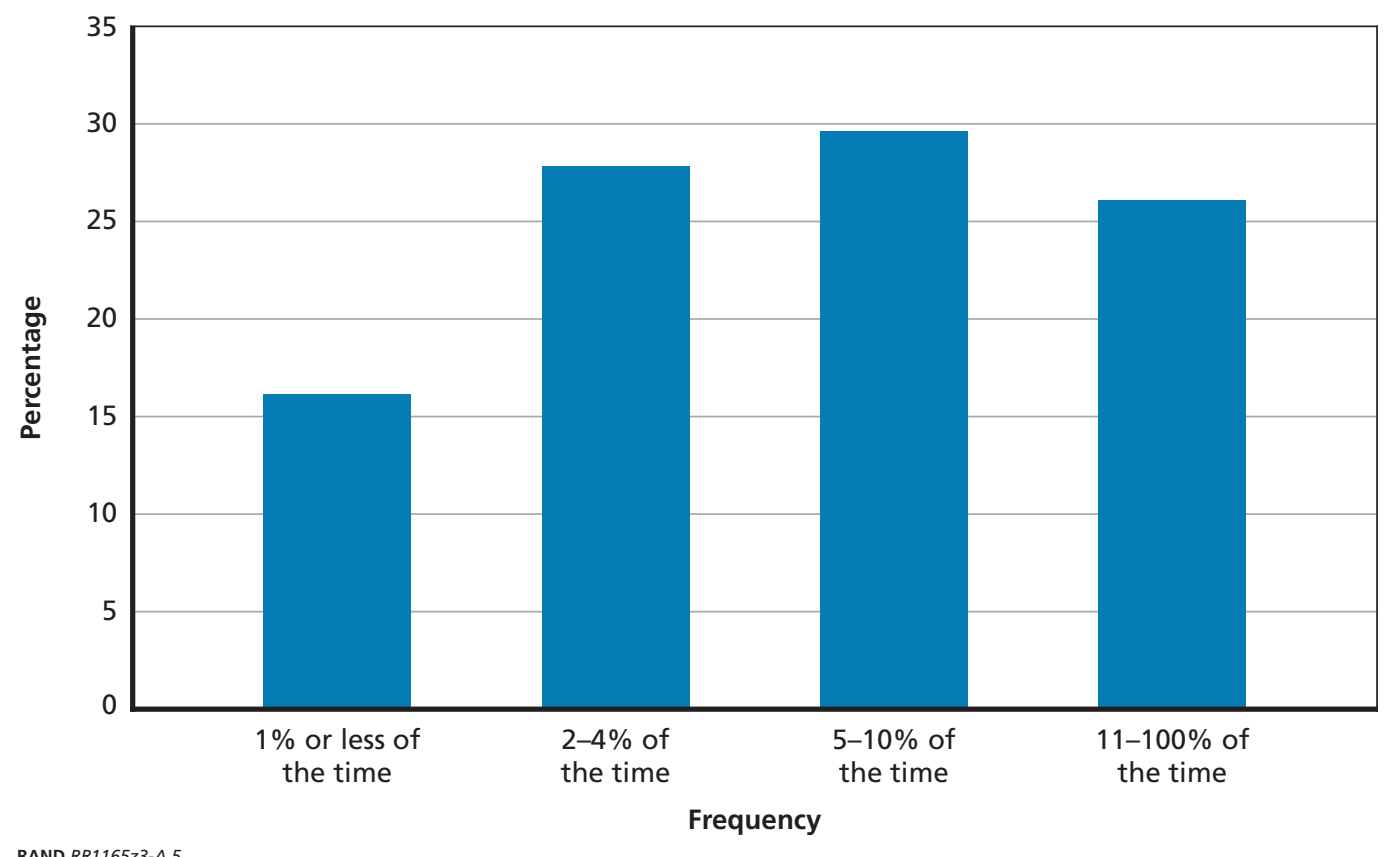

RAND RR1165z3-A.5 


\section{Statutory and Regulatory Authorities for the Provision of Purchased Care to Veterans}

Title 38 of the U.S. Code (Veterans' Benefits), enacted law that has not been codified, and Title 38 of the C.F.R. (Pensions, Bonuses, and Veterans' Relief) contain the existing law and regulations that create, govern, and regulate VA. These collections of law and regulation are the core repositories of the formal authorities granted by Congress to VA and the product of VA's rulemaking authority to implement congressional direction. Below, we outline the relevant provisions relating to the use of non-VA provided health care for Veterans. This listing is meant as a reference and a roadmap of the law and regulation. Following this roadmap, we provide a lengthier discussion of how the law and policy play out in practice in the non-VA health care programs used by the Department.

\section{B.1. Statutory Provisions Relating to Purchased Care}

Title 38 of the U.S. Code contains enactments by Congress that create and establish the legal groundwork for VA and enumerate some of the benefits for which Veterans are eligible. These provisions outline several programs for Veterans, including compensation, pensions, insurance, housing, and burial benefits. Health care benefits are addressed in Chapter 17 of the U.S. Code. Chapter 17, "Hospital, Nursing Home, Domiciliary, and Medical Care," authorizes the Secretary to provide hospital care and medical services to Veterans. It details the hospital care and medical services to which Veterans are entitled, who is eligible for such care and services, and how the Secretary is to administer such care and services. Beyond Title 38, a small number of U.S. Code sections in Titles 10, 25, 26, 31, 41, and 42 directly or indirectly address issues related to purchased care.

In addition, Congress has enacted many bills that have never been formally codified, often because the nature of the legislation is temporary, such as would be true for an appropriations act addressing a single fiscal year. The Veterans Choice Act is an example of enacted law that was never codified because of its temporary status, though it does appear as a statutory note to 38 U.S.C. 1701.

The U.S. Code sections and enacted legislation that has never been codified that are most relevant to purchased care are summarized in Table B-1. The primary sections that pertain to the department's ability to work with non-VA providers are Section 1703 and Section 1710. Section 1703 reads, in pertinent part,

When Department facilities are not capable of furnishing economical hospital care or medical services because of geographical inaccessibility or are not capable of furnishing the care 
or services required, the Secretary, as authorized in section 1710 of this title, may contract with non-Department facilities in order to furnish any of the following. . . .

The statute then lists the types of care available under contracting arrangements, including hospital care, medical services for disability treatments, medical emergencies, hospital care for female Veterans, diagnostic services, and outpatient dental services.

Table B-1

Statutory Provisions Relevant to Purchased Care

\section{Citation}

10 U.S.C. 1074

10 U.S.C. $1097 b$

25 U.S.C. 1645

26 U.S.C. $3101-3102$

31 U.S.C. 3901-3907

38 U.S.C. 1151

38 U.S.C. 1701

38 U.S.C. 1703

38 U.S.C. 1705

38 U.S.C. 1706

38 U.S.C. 1710

38 U.S.C. $1710 A$

38 U.S.C. $1710 \mathrm{~B}$

38 U.S.C. 1712

\section{Description}

"Medical and Dental Care for Members and Certain Former Members"; core authorizing statute for TRICARE, a health benefit plan for active-duty and retired military personnel and their dependents.

"TRICARE program: Financial Management"; allows reimbursement of providers at rates higher than authorized under certain conditions.

"Sharing Arrangements with Federal Agencies"; authorizes the IHS to enter into arrangements for sharing medical facilities and services with tribal governments, DoD, and VA.

"Rate of Tax," "Deduction of Tax Through Wages"; authorization for payroll taxes to be paid by both employers and employees for Medicare insurance.

Prompt Payment Act; imposes time limits for paying proper invoices submitted to the federal government, along with interest and statutory penalties for delay under certain conditions.

"Benefits for Persons Disabled by Treatment or Vocational Rehabilitation"; treats compensation available to Veterans disabled as part of medical treatment or rehabilitation in the same way as if the disability was service-connected.

"Definitions"; core terms specified and defined.

"Contracts for Hospital Care and Medical Services in Non-Department Facilities"; authorizes the VA Secretary to contract with non-VA facilities to furnish inpatient and outpatient treatment and qualifying non-emergent and emergent care when VA facilities are not capable of furnishing economical hospital care or medical services because of geographical inaccessibility or are not capable of furnishing the care or services required.

"Management of Health Care: Patient Enrollment System"; describes VA's patient enrollment and priority system. Under Section 1705, no care can be provided if the Veteran is not enrolled (with the exception of disabled Veterans in a 12-month period after discharge from service).

"Management of Health Care: Other Requirements"; states that the VA Secretary shall, to the extent feasible, design, establish, and manage health care programs in such a manner as to promote cost-effective delivery of health care services in the most clinically appropriate setting.

"Eligibility for Hospital, Nursing Home, and Domiciliary Care"; authorizes the VA Secretary to maintain an eligibility and ranking system for Veterans receiving hospital care and medical services. In addition, Section 1710(f) authorizes the Secretary to set copayment amounts and collect copayments.

"Required Nursing Home Care"; authorizes the VA Secretary to provide nursing care to eligible Veterans.

"Extended Care Services"; authorizes the VA Secretary to contract with community-based facilities to provide extended care services to eligible Veterans.

"Dental Care; Drugs and Medicines for Certain Disabled Veterans; Vaccines"; authorizes the VA Secretary to provide purchased care dental services to Veterans, subject to the requirements of Section 1703. 
Table B-1-Continued

\begin{tabular}{ll}
\hline Citation & \multicolumn{1}{c}{ Description } \\
\hline 38 U.S.C. 1712A & "Eligibility for Readjustment Counseling and Related Mental Health Services"; notes that \\
in furnishing counseling and related mental health services under subsections (a) and \\
(b) of this section, the VA Secretary has the same authority to enter into contracts with \\
private facilities that is available to the Secretary under Sections 1703 (a)(2) and 1710 (a)(1) \\
(B). This section is relevant to recently discharged Veterans.
\end{tabular}

38 U.S.C. 1716

"Hospital Care by Other Agencies of the United States"; authorizes the VA Secretary to reimburse the Departments of Health and Human Services (Public Health Service), Army, Navy, Air Force, or Interior for hospital care "when so specified in an appropriation or other Act."

38 U.S.C. $1717 \quad$ "Home Health Services; Invalid Lifts and Other Devices"; authorizes the VA Secretary to furnish home health services to eligible Veterans.

38 U.S.C. 1718 "Therapeutic and Rehabilitative Activities"; authorizes the VA Secretary to enter into contracts for therapeutic and rehabilitative services for Veterans who suffer from a chronic illness and whose care is primarily home-based.

38 U.S.C. $1720 \quad$ "Transfers for Nursing Home Care; Adult Day Health Care"; authorizes VA to transfer Veterans and service members to non-VA nursing homes under certain conditions.

38 U.S.C. 1720D "Counseling and Treatment for Sexual Trauma"; authorizes the VA Secretary to enter into contracts with qualified mental health professionals for counseling and treatment for sexual trauma.

38 U.S.C. 1720G "Assistance and Support Services for Caregivers"; authorizes the VA Secretary to establish programs to provide instruction, training, and support to in-home caregivers.

38 U.S.C. 1722A "Copayment for Medications"; sets rules and rates for medication.

38 U.S.C. 1724 "Hospital Care, Medical Services, and Nursing Home Care Abroad"; authorizes the VA Secretary to provide hospital care and medical services outside the United States under certain circumstances.

38 U.S.C. 1725

38 U.S.C. 1728

"Reimbursement for Emergency Treatment"; authorizes the VA Secretary to provide reimbursement to a Veteran directly or to the health care provider for emergency treatment under specified circumstances.

"Reimbursement of Certain Medical Expenses"; authorizes the VA Secretary to reimburse a Veteran for emergency treatment under specified circumstances.

38 U.S.C. $1741 \quad$ "Criteria for Payment"; authorizes the VA Secretary to contribute to the per diem costs incurred by Veterans residing in state-run nursing homes or receiving domiciliary care or adult day health care from such facilities.

38 U.S.C. $1803 \quad$ "Health Care"; requires the VA Secretary to provide health care to a child of a Vietnam War Veteran who is suffering from spina bifida.

38 U.S.C. $1813 \quad$ "Health Care"; requires the VA Secretary to provide health care to a child of a Vietnam War Veteran who is suffering from certain birth defects.

38 U.S.C. 1821

38 U.S.C. 7302

"Benefits for Children of Certain Korea Service Veterans Born with Spina Bifida"; authorizes the VA Secretary to provide health care to a child of a Korea War Veteran who is suffering from spina bifida under certain circumstances.

"Functions of Veterans Health Administration: Health-Care Personnel Education and Training Programs"; mission statement for VHA with regard to assuring the adequacy of the nation's supply of health professionals.

38 U.S.C. $7409 \quad$ "Contracts for Scarce Medical Specialist Services"; authorizes the VA Secretary to enter into contracts with certain persons and institutions for the provision of scarce medical specialist services.

38 U.S.C. $8111 \quad$ "Sharing of Department of Veterans Affairs and Department of Defense Health Care Resources"; requires the VA and DoD secretaries to enter into agreements for coordinating, using, and exchanging each department's respective health care resources. 
Table B-1-Continued

\begin{tabular}{ll}
\hline Citation & \multicolumn{1}{c}{ Description } \\
\hline 38 U.S.C. 8153 & $\begin{array}{l}\text { "Sharing of Health-Care Resources"; authorizes the Secretary to enter into contracts } \\
\text { or other agreements for the mutual use, or exchange of use, of health care resources } \\
\text { between VA and any provider. }\end{array}$
\end{tabular}

41 U.S.C. 1903

"Special Emergency Procurement Authority"; authorizes federal agencies to use simplified acquisition procedures under certain conditions.

41 U.S.C. 253

"Competition Requirements"; requires the use of full and open competition for federal procurement except under certain circumstances.

42 U.S.C. 1395- "Health Insurance for Aged and Disabled"; the statutory basis for Medicare.

1395b-10, Parts A-E

Pub. L. 84-569,

70 Stat. 250 (1956)

Pub. L. 85-56, 71 Stat. 83 (1957)

Pub. L. 93-82, 87 Stat. 183 (1973)

Dependents Medical Care Act of 1955; DoD's first purchased care program.

Pub. L. 99-272, 100 Stat. 108 (1986)

Veterans' Benefits Act of 1957; Sec. 501 et seq. provides the foundation for modern VA health benefit provision, including the use of non-VA providers and facilities.

Veterans Health Care Expansion Act of 1973; Section 106 provides the current basis for reimbursement of emergency medical care from non-VA medical resources.

Consolidated Omnibus Budget Reconciliation Act of 1985; Sec. 19012 ("Technical Revision of Authority to Contract for Hospital Care and Medical Services") sets forth much of what is now 38 U.S.C 1703; Sec. 19011 ("Eligibility for Health Care of Veterans with Non-ServiceConnected Disabilities") provides an early definition of "episode of care."

Pub. L. 104-262, Veterans' Health Care Eligibility Reform Act of 1996; expanded the services VA could offer 110 Stat. 3179 (1996) Veterans, required VA to establish priority categories and operate a patient enrollment system, and enhanced VA's sharing authority.

Pub. L. 106-117, Veterans Millennium Health Care and Benefits Act; Sec. 111 expanded reimbursement 113 Stat. 1563 (1999) for non-VA emergency treatment to non-service-connected medical issues under certain circumstances.

Pub. L. 108-183, Veterans Benefits Act of 2003; Sec. 308 allows sole-source contracts under certain 117 Stat. 2661 (2003) conditions.

Pub. L. 109-114, Military Quality of Life and Veterans Affairs Appropriations Act, 2006; relevant to 119 Stat. 2380 (2005) purchased care due to the publication of House Report 109-305 (2005) during its deliberation, which laid the foundation for Project HERO.

Pub. L. 110-387, Veterans' Mental Health and Other Care Improvements Act of 2008; Sec. 402 expanded 122 Stat. 4110 (2008) reimbursement for non-VA emergency care; Sec. 403 required the Secretary to conduct a pilot program to facilitate the use of non-VA providers by highly rural Veterans (later referred to Project $A R C H$ ).

Pub. L. 111-137, To amend title 38, United States Code, to expand veteran eligibility for reimbursement by 123 Stat. 3495 (2010) the Secretary of Veterans Affairs for emergency treatment furnished in a non-Department facility, and for other purposes; allowed reimbursement of emergency care for nonservice-connected issues even if a Veteran could receive partial payment from third-party source.

Pub. L. 111-163, Caregivers and Veterans Omnibus Health Services Act of 2010; Sec. 303 authorized the VA 124 Stat. 1174 (2010) Secretary to conduct demonstration projects to test alternative approaches for expanding care to Veterans in rural areas; Sec. 308 modified the eligibility requirements for Project $\mathrm{ARCH}$; Sec. 510 required the Secretary to establish a pilot program in which VA would contract with private dental insurance carriers.

Pub. L. 113-146, Veterans Access, Choice, and Accountability Act of 2014; Sec. 101 created the Veterans 128 Stat. 1754 (2014) Choice Program; Secs. 102 and 103 expanded opportunities for collaboration with the IHS and Native Hawaiian health care systems; Sec. 104 extended the operational life of Project $\mathrm{ARCH}$ and addressed scheduling matters; Sec. 105 addressed prompt payment issues; Sec. 106 transferred local authority for purchased care to the VHA Chief Business Office. 
Table B-1-Continued

\begin{tabular}{ll}
\hline Citation & \multicolumn{1}{c}{ Description } \\
\hline $\begin{array}{l}\text { Pub. L. 113-175, } \\
128 \text { Stat. 1901 (2014) }\end{array}$ & $\begin{array}{l}\text { Department of Veterans Affairs Expiring Authorities Act of 2014; Sec. 409 made a number } \\
\text { of technical amendments in regards to contracting to the Veterans Choice Act and the } \\
\text { Veterans' Mental Health and Other Care Improvements Act of 2008 (Project ARCH). }\end{array}$ \\
$\begin{array}{ll}\text { Pub. L. 113-235, } \\
\text { 128 Stat. 2130 (2014) }\end{array}$ & $\begin{array}{l}\text { Consolidated and Further Continuing Appropriations Act, 2015; Sec. 242 created } \\
\text { exceptions to the standard rules for provider reimbursement under the Veterans Choice } \\
\text { Act that include care or services furnished in Alaska or in states with an all-payer model } \\
\text { agreement in place. }\end{array}$ \\
$\begin{array}{l}\text { Pub. L. 114-19, } \\
\text { 129 Stat. 215 (2015) }\end{array}$ & $\begin{array}{l}\text { Construction Authorization and Choice Improvement Act; Sec. 3 amended the Veteran } \\
\text { Choice Act to (1) change the basis for measuring distance between a Veteran's residence } \\
\text { and VA medical facilities from straight line to driving distance, and (2) redefine "unusual } \\
\text { or excessive burden." }\end{array}$ \\
\hline
\end{tabular}

Section 1710, which is referenced in Section 1703, is a broader provision that directs the Secretary to provide hospital, nursing home, and domiciliary care. The conditions under which such care can be provided are related to a host of factors, including service-connected disabilities, receipt of disability compensation, prisoner-of-war status, and financial hardship.

Taken together, Congress has rather explicitly granted the Secretary the authority to contract with non-VA health care providers. The conditions under which this authority can be exercised are those situations when Department facilities are not capable of furnishing economical hospital care or medical services because of geographical inaccessibility or are not capable of furnishing the care or services required. Beyond this broad authority to contract for care, there are more specialized authorities for contracting for certain types of care (such as counseling for sexual trauma in Section 1720D and for therapeutic and rehabilitative services in Section 1718).

In short, even before the Veterans Choice Act legislation strengthened and expanded VA purchased care, the Secretary had the authority to engage non-VA practitioners to provide health care to Veterans. Chapter Three of this report provides detailed descriptions of the programs VA has used to provide purchased care. From an authorities perspective, Congress has given very clear language authorizing VA to contract for care at non-VA facilities. Decisions about contracting have been delegated to the Secretary and, as discussed in the next section, the Department has responded to the statutory language by developing regulation to implement Chapter 17's authorizations.

\section{B.2. Regulatory Provisions Relating to Purchased Care}

The statutes found in the U.S. Code, as well as non-codified enacted legislation, do not explain in great detail what procedures are to be followed to carry out their provisions for the care of Veterans. Regulations such as Title 38 C.F.R.are the product of the rulemaking process for implementing congressional authorizations. Title 38 C.F.R. explains how the provisions of Title 38 U.S.C., as well as non-codified enacted legislation, are to be carried out. Whereas Congress creates the statutory foundation, VA creates the provisions of Title 38 C.F.R. These regulations constitute, then, a first look at how VA intends to implement the purchased care program. 
Title 38 of the C.F.R., "Pensions, Bonuses, and Veterans' Relief," is divided into two chapters. Chapter 1 relates to VA, and Chapter 2 relates to the Armed Forces Retirement Home. Chapter 1, Part 17 ("Medical"), is the important part for our purposes. Some other regulations scattered throughout the C.F.R., such as those in Titles 5, 32, and 48, are also of interest. Table B-2 lists the regulations that are most relevant to purchased care.

Generally, 38 C.F.R. Part 17 tracks the statutory language in 38 U.S.C. and noncodified enacted legislation. The most relevant development of the statutorily authorized non-VA program is located in Section 17.52. That section states that "when VA facilities or other government facilities are not capable of furnishing economical hospital care or medical services because of geographic inaccessibility or are not capable of furnishing care or services required, VA may contract with non-VA facilities." That language mirrors 38 U.S.C. 1703. The regulations expand on that authority in sections 17.53 and 17.54 by creating a system allowing admission of any Veteran to a private or public hospital at VA expense only with prior authorization. Sections 17.55 and 17.56 detail the financial and contracting procedures for payment of public or private hospital care.

Both statutory and regulatory authority allow for wide discretion and ample programmatic development at the department level through programs and policies that operate outside of the federal rulemaking process. 
Table B-2

Regulatory Provisions Relevant to Purchased Care

Citation Description

5 C.F.R. $1315.1-$

1315.20

32 C.F.R. 199.17

38 C.F.R. 17.30

38 C.F.R. $17.36-$ 17.40

38 C.F.R. 17.41 and 17.42

38 C.F.R. $17.43-$

17.49

38 C.F.R. 17.50 and 17.51

38 C.F.R. 17.52 17.56

38 C.F.R. $17.57-$ 17.60

38 C.F.R. 17.80 17.83

38 C.F.R. 17.85

38 C.F.R. $17.92-17.98$

atient Services." Sec. 17.93 states that "[i]f the needed medical services are not available at a VA facility or Department of Defense facility, the VA shall arrange for care on a fee basis, but only if the veteran is eligible to receive medical services in non-VA facilities under § 17.52." Sec. 17.96 states that "[a]ny prescription, which is not part of authorized Department of Veterans Affairs hospital or outpatient care, for drugs and medicines ordered by a private or non-Department of Veterans Affairs doctor of medicine or doctor of osteopathy duly licensed to practice in the jurisdiction where the prescription is written, shall be filled by a Department of Veterans Affairs pharmacy or a non-VA pharmacy in a state home under contract with VA for filling prescriptions for patients in state homes," subject to conditions detailed in the section.

38 C.F.R. $17.108-$ 17.111

"Prompt Payment"; covers payments by executive branch agencies to vendors and contractors.

"TRICARE Program"; establishes TRICARE, defines its

"Definitions"; core terms specified and defined for VA medical regulations.

"Enrollment Provisions and Medical Benefits Package." These sections detail how to enroll benefits package" available to enrolled Veterans. Sec. 17.38 states that the "medical benefits package" includes "emergency care in VA facilities; and emergency care in non$17.53,17.54,17.120-132 . "$

"Examinations and Observations and Examinations." These sections detail categories of persons eligible for hospitalization for observation and physical examination.

"Hospital, Domiciliary, and Nursing Home Care"; details who is eligible for such care. Sec. $\mathbf{1 7 . 4 6}$ provides authority to admit a Veteran to a hospital on a contract basis if authorized by 38 U.S.C. 1703 and 38 C.F.R. 17.52.

"Use of Department of Defense, Public Health Service, or Other Federal Hospitals." Sec. 17.50 states that hospital facilities operated by any agency of the U.S. government may be used for the care of VA patients pursuant to agreements between VA and the department or agency operating the facility. Sec. 17.51 states that hospital care in facilities operated by any agency of the U.S. government may be authorized during an emergency.

"Use of Public and Private Hospitals." Sec. 17.52 states that "when VA facilities or other government facilities are not capable of furnishing economical hospital care or medical services because of geographic inaccessibility or are not capable of furnishing care or services required, VA may contract with non-VA facilities." Sec. 17.53 states that admission of any Veteran to a private or public hospital at VA expense will be authorized only when VA health care facilities are not feasibly available. Sec. 17.54 states that "[t]he admission of a veteran to a non-Department of Veterans Affairs hospital at Department of Veterans Affairs expense must be authorized in advance." Sections 17.55 and 17.56 detail care in a contract public or private nursing home facility under conditions detailed in the section. Sec. 17.60 authorizes the extension of nursing care in a public or private nursing section.

"Use of Services of Other Federal Agencies"; provides detail on the requirements and procedures for contracts for outpatient services.

"Research-Related Injuries"; states that "if a research subject needs treatment in a medical emergency for a condition covered by this section, VA medical facility directors shall provide reasonable reimbursement for the emergency treatment in a non-VA facility."

"Copayments." Sec. 17.111 sets forth requirements regarding copayments for extended care services provided to Veterans by VA (either directly by VA or paid for by VA). 
Table B-2-Continued

\begin{tabular}{ll}
\hline Citation & \\
\hline $\begin{array}{l}\text { 38 C.F.R. 17.120- } \\
17.132\end{array}$ & $\begin{array}{l}\text { "Payment and Reimbursement of the Expenses of Medical Services Not Previously } \\
\text { Authorized"; describes rules for reimbursing emergency medical services from non-VA } \\
\text { providers. }\end{array}$ \\
$\begin{array}{l}\text { 38 C.F.R. 17.140- } \\
17.142\end{array}$ & $\begin{array}{l}\text { "Delegations of Authority." Sec. 17.142 states that the Under Secretary for Health is } \\
\text { delegated authority to enter into sharing agreements, contracts for scarce medical } \\
\text { specialist services, and contracts for other medical services. }\end{array}$ \\
38 C.F.R. 17.160- & $\begin{array}{l}\text { "Dental Services"; describes eligibility for dental care provided by VA, as well as the rules } \\
\text { 17.169 }\end{array}$ \\
$\begin{array}{l}\text { surrounding the dental insurance program. } \\
\text { 17.242 C.F.R. 17.230- }\end{array}$ & $\begin{array}{l}\text { "Sharing of Medical Facilities, Equipment, and Information." Sec. 17.230 states that } \\
\text { "[d]uring a period in which the Secretary is authorized to furnish care and services to } \\
\text { members of the Armed Forces under paragraph (a) of this section, the Secretary may } \\
\text { authorize VA facilities to enter into contracts with private facilities for the provision } \\
\text { during such period of hospital care and medical services for certain veterans." Sec. 17.240 } \\
\text { states that the Under Secretary for Health may enter into agreements for sharing medical } \\
\text { resources with other hospitals, including State or local, public or private hospitals or other } \\
\text { medical installations subject to provision in the section. }\end{array}$
\end{tabular}

38 C.F.R. $17.270-$ 17.278

38 C.F.R. $17.400-$ 17.410

38 C.F.R. $17.700-$ 17.730

38 C.F.R. $17.1000-$ 17.1008

38 C.F.R. $17.1500-$ 17.1540

38 C.F.R. 60.2

48 C.F.R. $801.670-3$

48 C.F.R. 813.307

48 C.F.R. 853.213

48 C.F.R. 873.101 873.118
"Civilian Health and Medical Program of Veterans Affairs (CHAMPVA)"; describes program for medical care for survivors and dependents of certain Veterans.

"Hospital Care and Medical Services for Camp Lejeune Veterans and Families"; describes eligibility for special program to treat those who may have become ill at a North Carolina Marine Corps facility.

"Purpose and Scope"; establishes grant program for transportation alternatives for highly rural Veterans.

"Payment or Reimbursement for Emergency Services for Non-Service-Connected Conditions in Non-VA Facilities"; describes rules for approving payment or reimbursement for emergency medical services.

"Expanded Access to Non-VA Care Through the Veterans Choice Program." Sec. 17.1510 details the eligibility criteria for care through the Veterans Choice Program. Sec. 17.1515 states that a Veteran eligible for the Veterans Choice Program may choose to schedule an appointment with a VA health care provider or select a non-VA provider if that entity or health care provider meets the requirements of Sec. 17.1530. Sec. 17.1530 details the conditions under which an entity or provider is eligible to deliver care under the Veterans Choice program.

"Definitions"; describes an early VA definition of episode of care, albeit in the context of temporary lodging.

"Medical, Dental, and Ancillary Service"; describes rules for acquisition of health care services when the dollar amount is under a specific floor.

"Forms"; identifies certain forms that must be used when using simplified acquisition methods.

"Simplified Acquisition Procedures (SFs 18, 30, 44, 1165, 1449, and OF's 336, 347, and 348)"; identifies certain forms that must be used with simplified acquisition methods.

"Simplified Acquisition Procedures for Health-Care Resources"; describes rules that apply to the acquisition of health-care resources consisting of commercial services or the use of medical equipment or space. 
In coordination with MITRE, we issued a request to all $141 \mathrm{VA}$ administrative parents of the VAMCs to share any available guidance or policy documents from the VAMC and VISN levels describing SOPs for conducting purchased care activities at the local or regional level. A total of 664 files were provided to the RAND study team in response to the request (see Figure C-1).

\section{Figure C-1}

Local Purchased Care Policy Documents Received

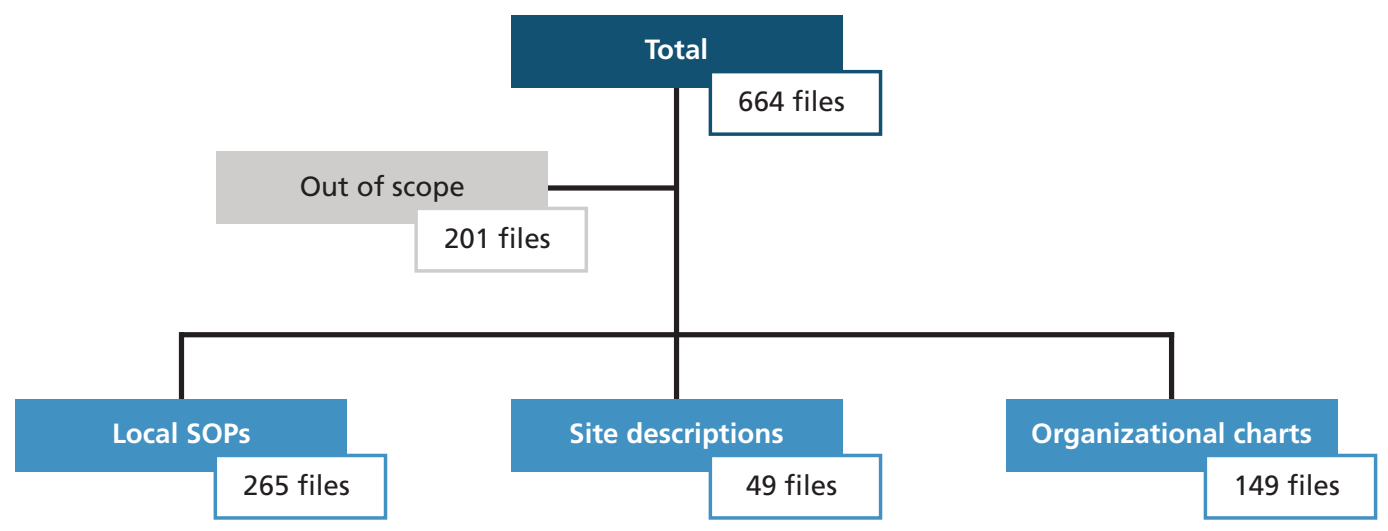

RAND RR1165z3-C.1

\section{C.1. Response Rate}

RAND received responses from 79 separate entities (78 VAMCs and one VISN) containing a total of 265 SOPs, as well as responses from 48 separate entities (47 VAMCs and one VISN) containing a total of 49 detailed VAMC site descriptions, and responses from 109 separate entities (94 VAMCs and 15 VISNs) containing a total of 149 organizational charts. Overall, RAND received an SOP, site description, or organizational chart from 140 of 162 total entities (125 of 141 VAMC administrative parents and 15 of 21 VISNs) to which the request was sent, resulting in an overall response rate of 86.4 percent. The response rate for SOP documents was 48.8 percent. The response rate for site descriptions was 29.6 percent, and the response rate for organizational charts was 67.3 percent (see Figure C-2). 
Figure C-2

Response Rates for Local Purchased Care Policy Documents
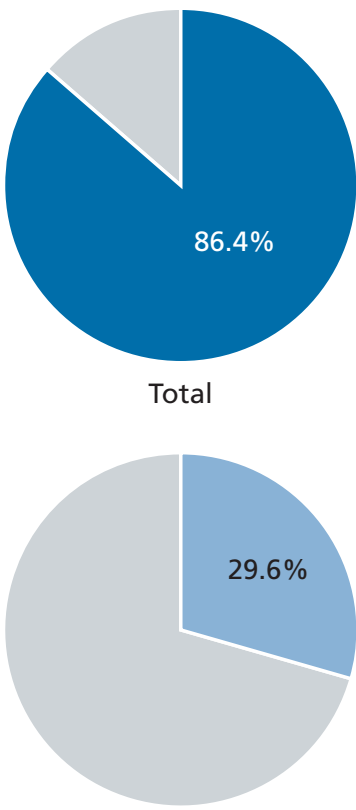

Site descriptions

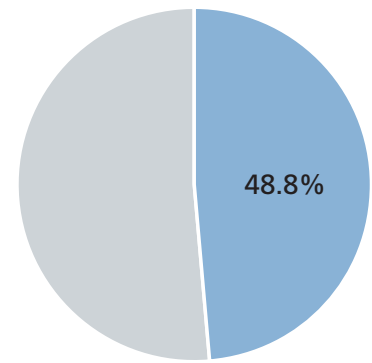

Local SOPs

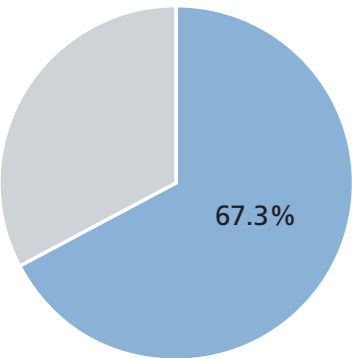

Organizational charts

\section{C.3. Dates of Local VA Policies}

It is worth noting that 205 of the 664 total documents included a date, and the vast majority of these predated the August 2014 passage of the Veterans Choice Act and the November 2014 establishment of the Veterans Choice Act program. Figure C-3 illustrates the breakdown of dates of the policies received through our request for data, showing that they spanned from January 2008 to April 2015, with the majority having been promulgated in 2012 and 2013. Moreover, the bulk of those documents post-dating the establishment of the Veterans Choice Act program were quite short and deemed by the study team as less useful for the purposes of elaborating key policies, processes, and SOPs on VA purchased care. For instance, many of these consisted of one-page documents simply containing screen shots of how to enter a purchased care consult request into various computing systems, with little to no accompanying text.

In assessing the documents received through the request for data, we coded all SOPs by the following criteria: date; whether they were useful or not useful for understanding VA purchased care policies and procedures; the number of pages they comprised; the terminology used to refer to VA purchased care; the authorities cited by each; their level of detail; whether they urged VA staff to encourage the use of VA purchased care or, alternatively, staying within the VA system if at all possible; which VA staff were listed as being responsible for various steps in the purchased care referral and authorization processes; and whether and to what extent they discussed "episodes of care." 
Figure C-3

Distribution of Dates of Local VA Policies Received

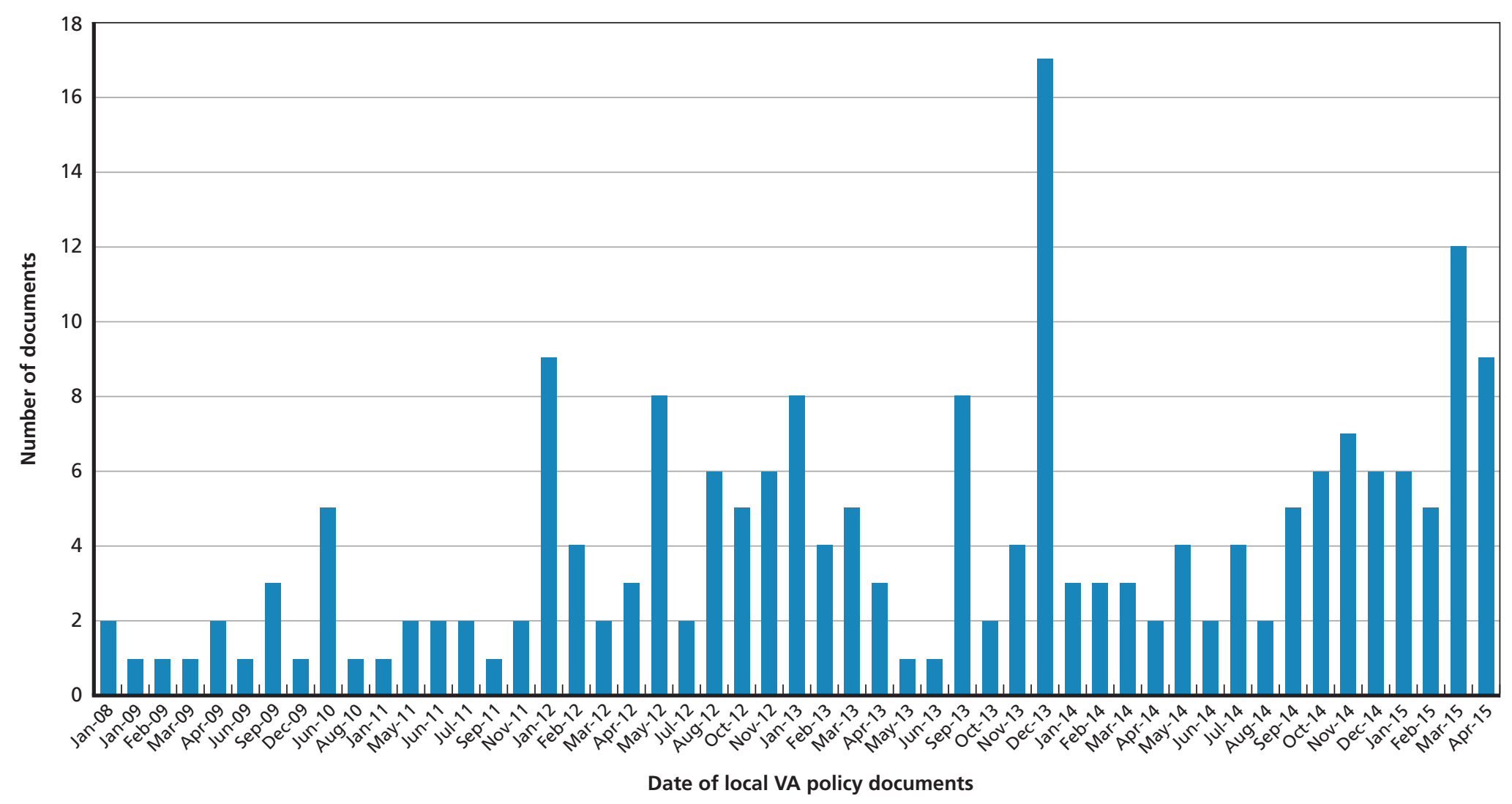




\section{C.4. Local SOP Document Length}

SOPs received through the data request ranged from one to more than 20 pages in length. While most fell at the shorter end of the spectrum, with 150 documents ranging from one to five pages, many other SOPs were longer (see Figure C-4). Fifty-eight documents ranged from five to 10 pages, 19 documents ranged from 10 to 20 pages, and 13 documents contained more than 20 pages. Document length was a fairly good (though not foolproof) indicator of the level of policy detail contained therein, with 57 SOPs found to be highly detailed, 86 SOPs found to be moderately detailed, and 94 SOPs found to be minimally detailed.

\section{C.5. SOP Terminology}

Moreover, there was little consistency in the terminology used to describe VA purchased care across these SOPs: Some were specific to particular purchased care mechanisms (such as the Veterans Choice Act program or PC3), while others referred to "non-VA care," "purchased care," "fee basis," "fee authority," "community based services," or "non-VA fee consults." Still others referred to specific services in this context, such as dialysis, home health services, mammograms, and physical therapy. Most SOPs contained a section delineating responsibilities for particular staff members to fulfill in the VA purchased care referral and authorization process, but they varied widely in terms of both the staff positions listed and the responsibilities of each staff member.

\section{Figure C-4}

Page Ranges for SOP Documents Received

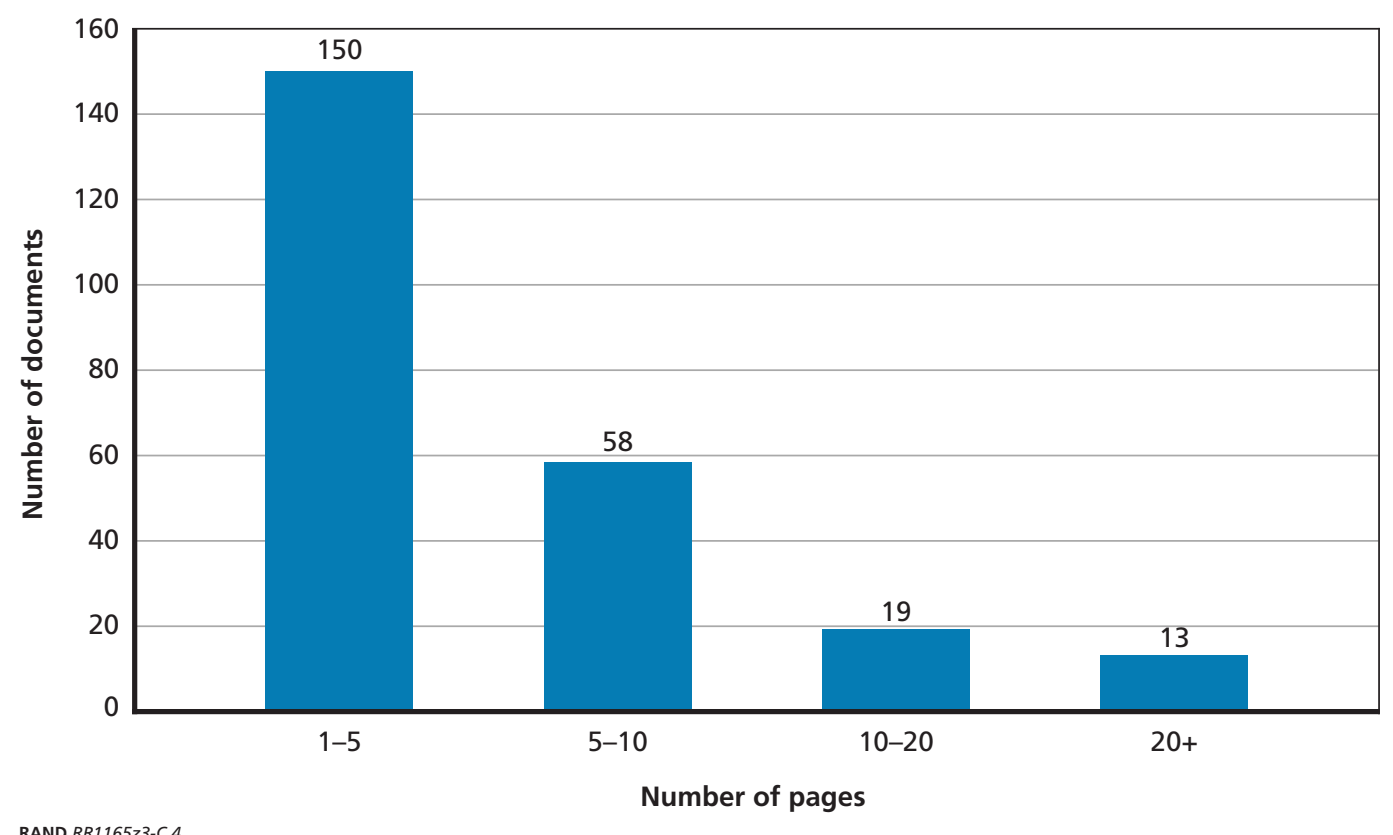

RAND RR1165z3-C.4 


\section{C.6. Organizational Chart Analysis}

Not only do VA facilities' purchased care policies and procedures vary, but their categorization and placement of VA purchased care within their organizational structure also vary. As noted above, RAND received 253 organizational charts from VAMCs and VISNs across the country as part of the request for data. On these 253 organizational charts, just 12 organizations (one at the VISN level) identified a separate non-VA care function or office. The dates of these 12 charts varied widely, from January 2012 to February 2015. Nine predated the implementation of the Veterans Choice Act in November 2014, and three were dated after its implementation. Offices relevant to VA purchased care at these organizations went by a variety of names:

- Four facilities and one VISN listed a "non-VA care" office.

- One facility listed a "non-VA care coordination/fee" office.

- Two facilities listed a "non-VA care coordination" office.

- One facility listed a "chief dental care/non-VA care" office.

- One facility listed a "fee basis, community care referral team."

- One facility listed an "integrated fee/non-VA care" office.

- One facility listed a "purchased care" office.

To gain a better understanding of where VA purchased care offices were located within the organizations, we recorded the degrees of separation between the office and the VAMC or network director for the 10 charts displaying the VAMC or VISN organizational structures. For example, if the VA purchased care office reported to the associate director, who reported to the VAMC director, we counted two degrees of separation. If the office reported to a manager who reported to the associate director, who then reported to the VAMC director, we counted three degrees of separation. On average, we found 2.5 degrees of separation between the facility director and the VA purchased care office across the 12 organizations that listed a separate purchased care function or office on their organizational charts.

In the 12 organizations examined, purchased care offices reported through a variety of management channels. Two offices reported to the VAMC associate director for patient care services, three reported to the VAMC associate director, one reported to the VAMC assistant director of facility support, two reported to the VAMC chief of staff, and one reported to the VISN deputy network director. There appeared to be little standardization in VA purchased care reporting chains within the organizations examined.

Two of the charts showed the organizational structures of the VA purchased care offices. They were not placed in the context of the larger organization, so we were unable to determine the degrees of separation between these offices and the VAMC director. These two examples were very different from one another. A program management officer led the smaller office of the two examples (25 full-time-equivalent staff) and oversaw a clinical care coordination group and an administrative care coordination group. The larger office (52.5 full-time-equivalent staff) had a small business management team and large authorization and case management teams. Although additional examples would be needed to draw definite conclusions, it appears from these two preliminary examples that there is not a standard organizational model for VA purchased care offices or divisions. 


\section{C.7. Facilities Responding to Request for Data}

Table C-1 characterizes the facilities that responding to our request for policy documents and the types of materials each provided.

\section{Table C-1}

Facilities Responding to Request for Data

\begin{tabular}{|c|c|c|c|c|c|c|}
\hline VISN & Administrative Parent & City & VAMCs & SOPs & $\begin{array}{c}\text { Site } \\
\text { Descriptions }\end{array}$ & $\begin{array}{l}\text { Org. } \\
\text { Charts }\end{array}$ \\
\hline 1 & $\begin{array}{l}\text { VA Boston HCSW Roxbury, Brockton, } \\
\text { Jamaica Plains }\end{array}$ & West Roxbury & 3 & $x$ & $x$ & $x$ \\
\hline 1 & Togus (Maine) VAMC & Augusta & 1 & $x$ & $x$ & $x$ \\
\hline 1 & Providence VAMC & Providence & 1 & $x$ & & \\
\hline 1 & $\begin{array}{l}\text { Edith Nourse Rogers Memorial Veterans } \\
\text { Hospital }\end{array}$ & Bedford & 1 & $x$ & & \\
\hline 1 & Manchester VAMC & Manchester & 1 & $x$ & $x$ & $x$ \\
\hline 1 & VA Central Massachusetts HCS & Northampton & 1 & $x$ & & \\
\hline 2 & Albany Stratton VAMC & Albany & 1 & & & $x$ \\
\hline 2 & $\begin{array}{l}\text { VA Western New York HCS Buffalo, } \\
\text { Batavia }\end{array}$ & Buffalo & 2 & & & $x$ \\
\hline 2 & Syracuse VAMC & Syracuse & 1 & $x$ & & $x$ \\
\hline 2 & Bath VAMC & Bath & 1 & $x$ & & $x$ \\
\hline 2 & Canandaigua VAMC & Canandaigua & 1 & $x$ & $x$ & $x$ \\
\hline 3 & VA New Jersey HCS East Orange, Lyons & East Orange & 2 & $x$ & & \\
\hline 3 & James J. Peters VAMC & Bronx & 1 & $x$ & & \\
\hline 3 & $\begin{array}{l}\text { VA NY Harbor HCS Brooklyn, } \\
\text { Manhattan }\end{array}$ & New York Harbor & 2 & $x$ & & \\
\hline 3 & Northport VAMC & Northport & 1 & $x$ & $x$ & $x$ \\
\hline 3 & $\begin{array}{l}\text { VA Hudson Valley HCS Montrose, } \\
\text { Castle Point Wappinger Falls }\end{array}$ & Montrose & 1 & $x$ & & \\
\hline 4 & Altoona-James E. Van Zandt VAMC & Altoona & 1 & $x$ & & \\
\hline 4 & Coatesville VAMC & Coatesville & 1 & $x$ & $x$ & \\
\hline 4 & Erie VAMC & Erie & 1 & $\mathrm{x}$ & & \\
\hline 4 & Lebanon VAMC & Lebanon & 1 & $\mathrm{x}$ & & \\
\hline 4 & Philadelphia VAMC & Philadelphia & 1 & $x$ & $x$ & \\
\hline 4 & VA Pittsburgh HCS Heinz, Pittsburgh & Pittsburgh & 2 & $x$ & & $x$ \\
\hline 4 & Wilkes-Barre VAMC & Wilkes-Barre & 1 & $x$ & & \\
\hline 4 & Clarksburg-Louis A. Johnson VAMC & Clarksburg & 1 & $x$ & & \\
\hline 5 & $\begin{array}{l}\text { VA Maryland HCS Baltimore, } \\
\text { Loch Raven, Perry Pt }\end{array}$ & Baltimore & 3 & & $x$ & $x$ \\
\hline
\end{tabular}


Table C-1-Continued

\begin{tabular}{|c|c|c|c|c|c|c|}
\hline VISN & Administrative Parent & City & VAMCs & SOPs & $\begin{array}{c}\text { Site } \\
\text { Descriptions }\end{array}$ & $\begin{array}{l}\text { Org. } \\
\text { Charts }\end{array}$ \\
\hline 5 & Martinsburg VAMC & Martinsburg & 1 & $\mathrm{x}$ & $\mathrm{x}$ & \\
\hline 6 & Asheville VAMC & Asheville & 1 & & $x$ & $x$ \\
\hline 6 & Durham VAMC & Durham & 1 & $x$ & $x$ & $x$ \\
\hline 6 & Fayetteville VAMC & Fayetteville & 1 & & & $\mathrm{x}$ \\
\hline 6 & Hunter Holmes McGuire VAMC & Richmond & 1 & & & $x$ \\
\hline 6 & Salem VAMC & Salem & 1 & & & $x$ \\
\hline 6 & Beckley VAMC & Beckley & 1 & & & $x$ \\
\hline 7 & Birmingham, Alabama, VAMC & Birmingham & 1 & $x$ & & $x$ \\
\hline 7 & $\begin{array}{l}\text { Central Alabama Veterans HCS } \\
\text { Tuskegee, Montgomery }\end{array}$ & Montgomery & 2 & & $x$ & \\
\hline 7 & Tuscaloosa VAMC & Tuscaloosa & 1 & $x$ & & $x$ \\
\hline 7 & Atlanta VAMC & Atlanta & 1 & $\mathrm{x}$ & & $x$ \\
\hline 7 & Charlie Norwood VAMC & Augusta & 1 & $\mathrm{x}$ & & $\mathrm{x}$ \\
\hline 7 & Carl Vinson VAMC & Dublin & 1 & & & $\mathrm{x}$ \\
\hline 7 & Ralph H. Johnson VAMC & Charleston & 1 & & & $\mathrm{x}$ \\
\hline 7 & Wm. Jennings Bryan Dorn VAMC & Columbia & 1 & $\mathrm{x}$ & & $x$ \\
\hline 8 & C.W. Bill Young VAMC & Bay Pines & 1 & & $x$ & $x$ \\
\hline 8 & Malcom Randall VAMC & Gainesville Lake City & 1 & & $x$ & $x$ \\
\hline 8 & Miami VA HCS & Miami & 1 & & $x$ & $x$ \\
\hline 8 & Orlando VAMC & Orlando, Viera & 1 & $x$ & $x$ & $x$ \\
\hline 8 & $\begin{array}{l}\text { James A. Haley VAMC, Primary Care } \\
\text { Annex }\end{array}$ & Tampa & 2 & & & $x$ \\
\hline 8 & West Palm Beach VAMC & West Palm Beach & 1 & $x$ & & $x$ \\
\hline 8 & VA Caribbean HCS & San Juan & 1 & $x$ & $x$ & $x$ \\
\hline 9 & Lexington VAMC Cooper, Leestown & Lexington & 2 & $\mathrm{x}$ & & \\
\hline 9 & Robley Rex VAMC & Louisville & 1 & $\mathrm{x}$ & & \\
\hline 9 & $\begin{array}{l}\text { Tennessee Valley HCS Murfreesboro, } \\
\text { Nashville }\end{array}$ & Nashville & 2 & $x$ & & \\
\hline 10 & Chillicothe VAMC & Chillicothe & 1 & $\mathrm{x}$ & & $\mathrm{x}$ \\
\hline 10 & Chalmers P. Wylie ACC & Columbus & 1 & & & $\mathrm{x}$ \\
\hline 10 & Cincinnati VAMC & Cincinnati & 1 & $x$ & $x$ & $x$ \\
\hline 10 & Louis Stokes Cleveland VAMC & Cleveland & 1 & $x$ & & $x$ \\
\hline 10 & Dayton VAMC & Dayton & 1 & $x$ & & $x$ \\
\hline 11 & VA Illiana HCS & Danville & 1 & & & $x$ \\
\hline
\end{tabular}


Table C-1-Continued

\begin{tabular}{|c|c|c|c|c|c|c|}
\hline VISN & Administrative Parent & City & VAMCs & SOPs & $\begin{array}{c}\text { Site } \\
\text { Descriptions }\end{array}$ & $\begin{array}{l}\text { Org. } \\
\text { Charts }\end{array}$ \\
\hline 11 & $\begin{array}{l}\text { VA Northern Indiana HCS Marion, Fort } \\
\text { Wayne }\end{array}$ & Marion & 2 & $x$ & & $x$ \\
\hline 11 & Richard L. Roudebush VAMC & Indianapolis & 1 & $x$ & $x$ & $x$ \\
\hline 11 & VA Ann Arbor HCS & Ann Arbor & 1 & $\mathrm{x}$ & $\mathrm{x}$ & $x$ \\
\hline 11 & Battle Creek VAMC & Battle Creek & 1 & $x$ & $x$ & $x$ \\
\hline 11 & John D. Dingell VAMC & Detroit & 1 & $x$ & $x$ & $x$ \\
\hline 11 & Aleda E. Lutz VAMC & Saginaw & 1 & $x$ & & $x$ \\
\hline 12 & Jesse Brown VAMC & Chicago & 1 & $x$ & & $x$ \\
\hline 12 & Edward Hines Jr. VA Hospital & Hines & 1 & $x$ & & $x$ \\
\hline 12 & $\begin{array}{l}\text { Captain James A. Lovell Federal Health } \\
\text { Care Center }\end{array}$ & North Chicago & 1 & & & $x$ \\
\hline 12 & $\begin{array}{l}\text { William S. Middleton Memorial } \\
\text { Veterans Hospital }\end{array}$ & Madison & 1 & & & $x$ \\
\hline 12 & Oscar G. Johnson VAMC & Iron Mountain & 1 & & $x$ & $x$ \\
\hline 12 & Clement J. Zablocki VAMC & Milwaukee & 1 & $x$ & & $x$ \\
\hline 12 & Tomah VAMC & Tomah & 1 & $x$ & & \\
\hline 15 & $\begin{array}{l}\text { VA Eastern Kansas HCS Colmery-O'Neil, } \\
\text { Dwight D. Eisenhower }\end{array}$ & Topeka & 2 & $x$ & & \\
\hline 15 & Robert J. Dole VAMC & Wichita & 1 & $x$ & & $x$ \\
\hline 15 & Harry S. Truman Memorial & Columbia & 1 & $x$ & & \\
\hline 15 & Kansas City VAMC & Kansas City & 1 & $x$ & & $x$ \\
\hline 15 & Marion VAMC & Marion & 1 & & & $x$ \\
\hline 15 & John J. Pershing VAMC & Poplar Bluff & 1 & & & $\mathrm{x}$ \\
\hline 15 & $\begin{array}{l}\text { VA St. Louis HCS Jefferson Barracks, } \\
\text { John Cochran }\end{array}$ & St. Louis & 2 & $x$ & $x$ & $x$ \\
\hline 16 & Veterans HCS of the Ozarks & Fayetteville & 1 & $x$ & & $x$ \\
\hline 16 & $\begin{array}{l}\text { Central Arkansas Veterans HCS } \\
\text { Eugene J. Towbin, John L. McClellan } \\
\text { Memorial }\end{array}$ & Little Rock & 1 & $x$ & & $x$ \\
\hline 16 & Alexandria VA HCS & Alexandria & 1 & $x$ & & $x$ \\
\hline 16 & Southeast Louisiana Veterans HCS & New Orleans & 1 & $x$ & $x$ & \\
\hline 16 & Overton Brooks VAMC & Shreveport & 1 & $x$ & & $x$ \\
\hline 16 & Gulf Coast Veterans HCS & Biloxi & 1 & $x$ & $x$ & $x$ \\
\hline 16 & G.V. (Sonny) Montgomery VAMC & Jackson & 1 & $x$ & $x$ & $x$ \\
\hline 16 & Jack C. Montgomery VAMC & Muskogee & 1 & & & $x$ \\
\hline 16 & Oklahoma City VAMC & Oklahoma & 1 & $x$ & & $x$ \\
\hline
\end{tabular}


Table C-1-Continued

\begin{tabular}{|c|c|c|c|c|c|c|}
\hline VISN & Administrative Parent & City & VAMCs & SOPs & $\begin{array}{c}\text { Site } \\
\text { Descriptions }\end{array}$ & $\begin{array}{l}\text { Org. } \\
\text { Charts }\end{array}$ \\
\hline 16 & Michael E. DeBakey VAMC & Houston & 1 & & & $\mathrm{x}$ \\
\hline 17 & $\begin{array}{l}\text { Dallas VAMC Sam Rayburn Memorial } \\
\text { Veterans Center }\end{array}$ & Dallas & 2 & & $x$ & \\
\hline 17 & South Texas Veterans HCS & San Antonio & 1 & & $x$ & $x$ \\
\hline 17 & $\begin{array}{l}\text { Central Texas Veterans HCS Temple, } \\
\text { Marlin, Waco }\end{array}$ & Temple & 3 & $x$ & $x$ & $x$ \\
\hline 18 & Phoenix VA HCS & Phoenix & 1 & & $x$ & $x$ \\
\hline 18 & Northern Arizona VA HCS & Prescott & 1 & & & $x$ \\
\hline 18 & Southern Arizona VA HCS & Tucson & 1 & & & $x$ \\
\hline 18 & New Mexico VA HCS & Albuquerque & 1 & & $\mathrm{x}$ & $x$ \\
\hline 18 & Amarillo VA HCS & Amarillo & 1 & & & $x$ \\
\hline 18 & West Texas VA HCS & Big Spring & 1 & & & $x$ \\
\hline 19 & VA Eastern Colorado HCS & Denver & 2 & $x$ & $x$ & $x$ \\
\hline 19 & Grand Junction VAMC & Grand Junction & 1 & & & $x$ \\
\hline 19 & VA Montana HCS & Fort Harrison & 1 & & $x$ & $x$ \\
\hline 19 & VA Salt Lake City HCS & Salt Lake City & 1 & $x$ & $x$ & $x$ \\
\hline 19 & Cheyenne VAMC & Cheyenne & 1 & & & $\mathrm{x}$ \\
\hline 20 & Alaska VA HCS & Anchorage & 1 & $x$ & & \\
\hline 20 & Boise VAMC & Boise & 1 & $\mathrm{x}$ & $x$ & $\mathrm{x}$ \\
\hline 20 & VA Portland HCS & Portland & 1 & $x$ & $x$ & $x$ \\
\hline 20 & VA Roseburg HCS & Roseburg & 1 & $\mathrm{x}$ & & $\mathrm{x}$ \\
\hline 20 & $\begin{array}{l}\text { VA Puget Sound HCS Seattle, } \\
\text { American Lake }\end{array}$ & Seattle & 3 & $x$ & & \\
\hline 20 & Mann-Grandstaff VAMC & Spokane & 1 & $\mathrm{x}$ & & \\
\hline 21 & Central California VA HCS & Fresno & 1 & & $\mathrm{x}$ & $\mathrm{x}$ \\
\hline 21 & $\begin{array}{l}\text { VA Northern California HCS Martinez, } \\
\text { Sacramento }\end{array}$ & Martinez, East & 2 & & $x$ & $x$ \\
\hline 21 & VA Palo Alto HCS & Palo Alto & 3 & & $x$ & $\mathrm{x}$ \\
\hline 21 & San Francisco VA HCS & San Francisco & 1 & & $x$ & $\mathrm{x}$ \\
\hline 21 & VA Pacific Islands HCS & Honolulu & 1 & $\mathrm{x}$ & & \\
\hline 21 & VA Sierra Nevada HCS & Reno & 1 & & $x$ & $x$ \\
\hline 22 & VA Loma Linda HCS & Loma Linda & 1 & & & $x$ \\
\hline 22 & VA Long Beach HCS & Long Beach & 1 & & $x$ & \\
\hline 22 & VA Greater Los Angeles HCS & Los Angeles & 1 & & & $\mathrm{x}$ \\
\hline 22 & VA San Diego HCS & San Diego & 1 & & $x$ & \\
\hline
\end{tabular}


Table C-1-Continued

\begin{tabular}{|c|c|c|c|c|c|c|}
\hline VISN & Administrative Parent & City & VAMCs & SOPs & $\begin{array}{c}\text { Site } \\
\text { Descriptions }\end{array}$ & $\begin{array}{l}\text { Org. } \\
\text { Charts }\end{array}$ \\
\hline 22 & VA Southern Nevada HCS & Las Vegas & 1 & & & $x$ \\
\hline 23 & VA Nebraska-Western lowa HCS & Omaha & 3 & $x$ & & \\
\hline 23 & VA Central lowa HCS & Des Moines & 1 & $x$ & & $x$ \\
\hline 23 & lowa City VA HCS & lowa City & 1 & $x$ & $x$ & $x$ \\
\hline 23 & Minneapolis VA HCS & Minneapolis & 1 & $x$ & $x$ & $x$ \\
\hline 23 & Fargo VA HCS & Fargo & 1 & & $\mathrm{x}$ & $\mathrm{x}$ \\
\hline 23 & $\begin{array}{l}\text { VA Black Hills HCS Hot Springs, } \\
\text { Fort Meade }\end{array}$ & Fort Meade & 1 & $x$ & & $x$ \\
\hline 23 & Sioux Falls VA HCS & Sioux Falls & 1 & & & $x$ \\
\hline 23 & St. Cloud VA HCS & St. Cloud & 1 & $x$ & & $x$ \\
\hline \multicolumn{2}{|c|}{ Total VAMCs } & & & 78 & 47 & 94 \\
\hline \multicolumn{2}{|c|}{ Total VISNs } & & & 1 & 1 & 15 \\
\hline \multicolumn{2}{|l|}{ Total } & & & 79 & 48 & 109 \\
\hline \multicolumn{2}{|c|}{ Response rate } & & & $48.8 \%$ & $29.6 \%$ & $67.3 \%$ \\
\hline
\end{tabular}

NOTE: HCS = healthcare system. 


\section{Facility Survey Questions and Frequency Response Data}

We included the following seven questions in the chief of staff module of the 2015 Survey of VA Capabilities and Resources, which was sent to the chiefs of staff at all VAMCs in the United States. A description of the methodology for developing the questions can found in Chapter Two of this report.

The invitation to participate in the survey was sent via email directly to each administrative parent's chief of staff. The email included instructions, links to the survey modules, and a signed letter from VA's Interim Under Secretary for Health encouraging VA employees to complete the survey. The web-based survey included nine modules. Each chief of staff was responsible for completing the chief of staff module, identifying the most appropriate individual to complete each of the clinical condition modules, and overseeing the completion and return of all survey modules. Of the 141 administrative parents to which the survey was sent, 117 started the survey and submitted a response. However, several respondents chose to discontinue the survey before answering every question, leaving 111 respondents -78 percent of the total sample_-answering those questions pertaining to purchased care.

9. How frequently do you refer Veterans to fee-basis or contracted care?

$1 \%$ or less of the time

$2-4 \%$ of the time

$5-10 \%$ of the time

$11-100 \%$ of the time

\begin{tabular}{llc}
\hline Response & N & $\%$ \\
\hline $1 \%$ or less of the time & 18 & $16.2 \%$ \\
$2-4 \%$ of the time & 31 & $27.9 \%$ \\
$5-10 \%$ of the time & 33 & $29.7 \%$ \\
$11-100 \%$ of the time & 29 & $26.1 \%$ \\
\hline
\end{tabular}


10. On a scale from 1 to 4 , where 1 is the most important reason and 4 is the least important reason, please rank which of the following are the most important reasons for referring Veterans to fee-basis care.

\begin{tabular}{lcccc}
\hline Response & $\begin{array}{c}\text { N (answering } \\
\text { question) }\end{array}$ & $\begin{array}{c}\text { N (\%) Ranking } \\
\text { Importance as 1 }\end{array}$ & $\begin{array}{c}\text { N (\%) Ranking } \\
\text { Importance as 2 }\end{array}$ & $\begin{array}{c}\text { N (\%) Ranking } \\
\text { Importance as 3 }\end{array}$ \\
\hline $\begin{array}{l}\text { a. Lack of clinical services } \\
\text { available at VA facilities }\end{array}$ & 111 & $86(77.5 \%)$ & $14(12.6 \%)$ & $11(9.9 \%)$ \\
$\begin{array}{l}\text { b. Veteran travel distance to VA } \\
\text { facilities }\end{array}$ & 111 & $12(10.8 \%)$ & $51(45.9 \%)$ & $48(43.2 \%)$ \\
$\begin{array}{l}\text { c. Veteran wait times at VA } \\
\text { facilities }\end{array}$ & 111 & $15(13.5 \%)$ & $46(41.4 \%)$ & $50(45.0 \%)$ \\
\hline
\end{tabular}

NOTE: Some participants ranked more than one response.

10D. Are there other important reasons why your local health care system refers Veterans to fee-basis or contracted care?

Yes -- > Please describe your reason(s) in the comments box.

$\square$ No

\begin{tabular}{llc}
\hline Response & N & $\%$ \\
\hline Yes & 37 & $33.3 \%$ \\
No & 74 & $66.7 \%$ \\
\hline
\end{tabular}

11. Please mark "yes" or "no" for the following questions.

\begin{tabular}{|c|c|c|c|}
\hline Question & $\begin{array}{c}\mathbf{N} \\
\text { (answering } \\
\text { question) }\end{array}$ & $\begin{array}{l}\text { Yes: } \\
\text { N (\%) }\end{array}$ & $\begin{array}{c}\text { No: } \\
\text { N (\%) }\end{array}$ \\
\hline $\begin{array}{l}\text { a. Has your local health care system implemented the } \\
\text { Non-VA Care Coordination (NVCC) internal referral } \\
\text { management program? }\end{array}$ & 111 & $106(95.5 \%)$ & $5(4.5 \%)$ \\
\hline $\begin{array}{l}\text { b. At your local health care system, are Veteran } \\
\text { priority ratings and the service-connection of } \\
\text { the injury or illness considered when scheduling } \\
\text { appointments? }\end{array}$ & 111 & $45(40.5 \%)$ & 66 (59.5\%) \\
\hline $\begin{array}{l}\text { c. Does your local health care system "bump" } \\
\text { a Veteran from a scheduled appointment to } \\
\text { accommodate the appointment needs of a Veteran of } \\
\text { a higher priority group? }\end{array}$ & 111 & $2(1.8 \%)$ & $109(98.2 \%)$ \\
\hline
\end{tabular}


12. How often does your local health care system do the following things?

\begin{tabular}{lccccc}
\hline & N (answering & $\begin{array}{c}\text { All of the } \\
\text { Time: } \\
\text { N (\%) }\end{array}$ & $\begin{array}{c}\text { Most of the } \\
\text { Time: } \\
\text { N (\%) }\end{array}$ & $\begin{array}{c}\text { Some of the } \\
\text { Time: } \\
\text { Q (\%) }\end{array}$ & $\begin{array}{c}\text { None of the } \\
\text { Time: } \\
\text { N (\%) }\end{array}$ \\
\hline $\begin{array}{l}\text { a. Share records with non-VA } \\
\text { health care providers in electronic } \\
\text { format? }\end{array}$ & 110 & $5(4.5 \%)$ & $10(9.1 \%)$ & $43(39.1 \%)$ & $52(47.3 \%)$ \\
$\begin{array}{l}\text { b. Collect data about how long } \\
\text { Veterans wait for appointments at } \\
\text { non-VA health care providers? }\end{array}$ & 111 & $15(13.5 \%)$ & $23(20.7 \%)$ & $45(40.5 \%)$ & $28(25.2 \%)$ \\
\end{tabular}

13A. If you have to refer Veterans out for non-VA care, and the care requires more than one visit, do they need a referral for each visit?

$\square$ Separate referral for each visit

$\square$ One referral will cover all related visits to this specialist within 60-day time frame

$\square$ Other (please describe in the comments section for question 13A).

\begin{tabular}{lcc}
\hline Response & N & $\%$ \\
\hline Separate referral for each visit & 9 & 8.1 \\
$\begin{array}{l}\text { One referral will cover all related } \\
\text { visits to this specialist within 60- } \\
\text { day time frame }\end{array}$ & 51 & 45.9 \\
Other & 51 & \\
\hline
\end{tabular}

13B. What if the Veteran requires more than one visit to this specialist for his/ her broken leg, but the care is anticipated to span a period longer than 60 days (e.g., seven months)? Does he/she need a referral for each visit?

Separate referral for each visit

One referral will cover all related visits to this specialist regardless of time frame

$\square$ Other (please describe in the comments section for question 13B).

\begin{tabular}{lcc}
\hline Response & N & $\%$ \\
\hline Separate referral for each visit & 23 & 20.7 \\
$\begin{array}{l}\text { One referral will cover all related } \\
\text { visits to this specialist regardless of } \\
\text { time frame }\end{array}$ & 41 & 36.9 \\
Other & 47 & \\
\hline
\end{tabular}





\section{Veteran Health Benefits and Priority Grouping}

\section{E.1. VHA Enrollment and Priority Group Status}

Veteran eligibility for health care services has evolved significantly over the years, reflecting changes in the relative capacity of VA health care and demand from Veterans. Over time, Congress has expanded or limited access to VA health care based on the conditions facing VA at that time, imposing various systems for the allocation of health care resources. In the most significant of these, and in an attempt to balance access and efficiency concerns (Panangala, 2006), Congress passed the Veterans' Health Care Eligibility Reform Act of 1996 (P.L. 104262). This statute expanded the services that VA could offer Veterans and required VA to establish priority categories and operate a patient enrollment system to manage access. In response, VA established eight enrollment priority groups based on service-connected disabilities or exposures, prisoner-of-war status, receipt of a Purple Heart or Medal of Honor, and income (see Table E-1). Although all "Veterans," as that term is defined in federal law, are eligible to obtain VA health care services, including a basic medical package, this priority system determined which Veterans could access such services and also set rules for copayments for services and eligibility for additional health benefits. It is important to note that health benefits are not an "entitlement"; they are dependent on discretionary appropriations. Further, under VA's statutory health care mandates, the Secretary may increase cost sharing or suspend enrollment as needed to balance the agency's budget and serve those Veterans at the top of the priority group list.

Table E-1

VA Priority Groups

Priority

Group

1

2

3

Eligibility Requirements

- Veterans with VA-rated service-connected disabilities $50 \%$ or more disabling

- Veterans determined by VA to be unemployable due to service-connected conditions

- Veterans with VA-rated service-connected disabilities $30 \%$ or $40 \%$ disabling

- Veterans who are former prisoners of war

- Veterans awarded a Purple Heart medal

- Veterans whose discharge disability was incurred or aggravated in the line of duty

- Veterans with VA-rated service-connected disabilities $10 \%$ or $20 \%$ disabling

- Veterans awarded special eligibility classification under 38 U.S.C. 1151, "benefits for individuals disabled by treatment or vocational rehabilitation"

- Veterans awarded the Medal of Honor 
Table E-1-Continued



4 - Veterans who are receiving aid and attendance or housebound benefits from VA

- Veterans who have been determined by VA to be catastrophically disabled

- Non-service-connected Veterans and noncompensable service-connected Veterans rated $0 \%$ disabled by VA with annual income below VA and geographically (based on resident zip code) adjusted income limits

- Veterans receiving VA pension benefits

- Veterans eligible for Medicaid programs

- Compensable $0 \%$ service-connected Veterans

- Veterans exposed to ionizing radiation during atmospheric testing or during the occupation of Hiroshima and Nagasaki

- Project 112/SHAD participants

- Veterans who served in the Republic of Vietnam between January 9, 1962, and May 7, 1975

- Veterans who served in the Persian Gulf War between August 2, 1990, and November 11, 1998

- Veterans who served on active duty at Camp Lejeune for not fewer than 30 days between January 1, 1957, and December 31, 1987

- Veterans who served in a theater of combat operations after November 11, 1998, as follows: Currently enrolled Veterans and new enrollees discharged from active duty on or after January 28,2003 , are eligible for the enhanced benefits for five years post-discharge.

- Combat Veterans who were discharged between January 2009 and January 2011 and did not enroll in the VA health care during their five-year period of eligibility have an additional year to enroll and receive care. The additional one-year eligibility period began February 12, 2015, with the signing of the Clay Hunt Suicide Prevention for America Veterans Act. ${ }^{b}$

- Veterans with gross household income below the geographically adjusted income limits for their resident location and who agree to pay copays

- Veterans with gross household income above VA and geographically adjusted income limits for their resident location and who agree to pay copays

- Veterans eligible for enrollment: Noncompensable $0 \%$ service-connected and:

- Subpriority a: Enrolled as of January 16, 2003, and who have remained enrolled since that date and/or placed in this subpriority due to changed eligibility status

- Subpriority b: Enrolled on or after June 15, 2009, whose income exceeds the current VA or geographic income limits by $10 \%$ or less

- Non-service-connected and:

- Subpriority c: Enrolled as of January 16, 2003, and who have remained enrolled since that date and/or placed in this subpriority due to changed eligibility status

- Subpriority d: Enrolled on or after June 15, 2009, whose income exceeds the current VA or geographic income limits by $10 \%$ or less

- Veterans not eligible for enrollment: Veterans not meeting the criteria above:

- Subpriority e: Noncompensable $0 \%$ service-connected (eligible for care of their serviceconnected condition only)

- Subpriority g: Non-service-connected

SOURCE: VHA (2015b)

a While eligible for priority group 6 , until system changes are implemented, the Veteran would be assigned to priority group 7 or 8 , depending on income.

${ }^{b}$ At the end of the enhanced enrollment priority group placement time period, Veterans will be assigned to the highest-priority group for which their unique eligibility status qualifies at that time. 


\section{E.2. VA Health Care Benefits}

VA provides a wide array of health care benefits to eligible Veterans. These include inpatient, primary, and specialty care through VA facilities and contractors; supporting services (such as home health care and hospice care); medical device support; medications; and linkages between VA health care services and other VA programs, such as educational benefits, support to homeless Veterans, and cemetery benefits. This section summarizes VA health care benefits and programs, providing basic information about the nature of the benefit, the population served, and the potential cost to Veterans.

\section{E.2.1. Basic Medical Benefits Package}

VA provides basic medical care to enrolled Veterans through the VA health care system and contracted care providers. ${ }^{1}$ The standard medical benefits package includes the following:

- Inpatient care includes medical, surgical, mental health, dialysis, and acute care services.

- Preventive/primary care services include but are not limited to periodic exams, immunization, genetic counseling, and health and nutrition education. VA also offers three wellness programs to enrolled Veterans. In addition to clinic-based primary care, VA may provide home-based care for Veterans with complex health care needs. Home-based services are provided by an interdisciplinary treatment team.

- Gender-specific care is provided to female Veterans, including gynecological care, breast and reproductive oncology, infertility treatment, maternity care, and newborn care for up to seven days if the Veteran delivers in a VA or VA-contracted facility.

- Mental health and substance abuse care are provided in inpatient and outpatient settings, and specialized programs are offered, such as intensive case management for Veterans with serious mental illness and military sexual trauma counseling for Veterans with trauma resulting from sexual physical assault or battery while in the military.

- Skilled home health care is offered to Veterans who need skilled services, case management, assistance with activities of daily living, or assistance with instrumental activities of daily living on a short-term basis. Services are provided by community-based home health agencies under contract with VA.

- Hospice care is provided to Veterans with a terminal condition with six months or less to live and is offered either in the home, community, outpatient, or inpatient setting.

- Palliative care does not require that the Veteran have a terminal condition and is offered in the home, community, outpatient, or inpatient setting.

- Respite care is for Veterans who need skilled services, case management, and assistance with activities of daily living or instrumental activities of daily living; who are isolated; or who have a caregiver who is experiencing burden. Veterans can receive respite care at home or in an inpatient or outpatient setting.

- Adult day health care primarily offers an opportunity for recreation and social interaction for Veterans who need skilled services, case management, and assistance with activities of daily living or instrumental activities of daily living; however, health services from nurses, therapists, and social workers may be available. The program may be offered at VAMCs, state veterans homes, or community organizations.

1 See, generally, 38 C.F.R. 17.38 for an authoritative summary of VA's medical benefits package. 
- Rehabilitation services are available for blindness in inpatient and outpatient settings, for spinal cord injuries through spinal cord injury centers located throughout the country, and for amputation through regional and polytrauma/amputation sites. Additionally, residential rehabilitation and treatment services are available for Veterans with multiple and severe medical conditions, mental illness, addiction, or psychosocial deficits through the combined domiciliary and mental health residential rehabilitation and treatment programs.

- Medical equipment and prosthetic items are provided to Veterans receiving care for any condition.

- Eyeglasses and hearing aids are provided under certain circumstances and only to Veterans who are otherwise receiving VA care or services. VA does not provide eyeglasses and hearing aids for "normal" vision or hearing loss.

- Medications are provided for prescriptions written by a VA provider and included in the VA National Drug Formulary.

\section{E.2.2. Other Health Care-Related Benefits and Services}

In addition to the basic medical package described above, VA offers other health-related programs and services to Veterans and their family members, some of which are available to all Veterans (e.g., peer-to-peer readjustment counseling) and some of which are based on eligibility criteria (e.g., dental care)

- CHAMPVA (Civilian Health and Medical Program of the Department of Veterans Affairs) is a health care benefits program that provides coverage to the spouse or widow(er) and to the dependent children of a qualifying Veteran or service member or the primary caregiver. The program pays for medical care from non-VA providers. Additionally, primary family caregivers of eligible Veterans who have no other health insurance may also receive counseling, training, and mental health services.

- Dental care. The eligibility requirements for dental care differ from the medical care requirements. Veterans are categorized into six classes that then determine the scope of treatment available. Dental care may be provided at VA facilities or by non-VA providers. VA is also operating a national pilot program to make private dental insurance available at reduced cost to enrolled Veterans and family members through CHAMPVA.

- The Children of Women Vietnam Veterans program under 38 U.S.C. 1813(b) covers external medical expenses from approved providers related to certain birth defects in children born after their mothers began duty in Vietnam. Similarly, the Children of Veterans Born with Spina Bifida program under 38 U.S.C. 1803(b) and 38 U.S.C. 1821(a) covers external medical expenses from approved providers related to spina bifida in the children of parents exposed to herbicides during duty in Vietnam or the Korean demilitarized zone. ${ }^{2}$

- Peer-to-peer readjustment counseling. In addition to the mental health care services described above, VA runs a system of approximately 300 "Vet Centers." These are communitybased storefront centers that are staffed by Veterans who are part of the Readjustment Counseling Service. VA provides mental health and readjustment care through these centers to all Veterans, regardless of service characterization, priority grouping, or existence

\footnotetext{
2 We include these programs because they are used by VA to purchase or acquire, either directly or indirectly, medical services from non-VA sources, even though the recipients of those services are not Veterans.
} 
of a VA-rated service-connected disability, and does so at no cost to the Veteran. Veterans need not enroll with the VA health care system to access care at Vet Centers, and this care is not considered part of VA's basic medical care package.

- Veterans Crisis Line. A confidential toll-free hotline, online chat, or text service is available 24 hours a day, seven days a week for Veterans, family members, and friends.

- Travel reimbursement is available for travel related to obtaining health care services for Veterans in specified circumstances. VA may also pay the cost of overnight travel associated with obtaining health care services.

- Family caregivers program. VA provides mental health services, access to health insurance, and other non-health-related services to caregivers of post-9/11 Veterans and service members who were medically discharged.

\section{E.2.3. Specialized External Services and Specialized Veteran Populations}

There are many VA programs that could be characterized as types of purchased care, in that they rely on external providers and resources to deliver health care to Veterans. As we can see from the following program descriptions, however, their utility as a means of expanding a wide range of non-VA health care services to Veterans is generally limited:

- Indian Health Service/Tribal Health Program Reimbursement Agreements Program. These agreements reimburse IHS and Tribal Health Program health facilities for services provided to American Indian and Alaska Native Veterans. Authority for the agreements can be found in 38 U.S.C. 8153 (which provides for mutual use or exchange of use of health care resources between VA and external agencies and providers), as well as Section 405(c) of the Indian Health Care Improvement Act (requiring reimbursement of IHS, tribes, and tribal organizations for health services to Veterans). ${ }^{3}$

- Scarce medical specialist services contracts. Under 38 U.S.C. 7409, VA has the authority to enter into contracts with medical and nursing schools, "clinics," and "any other group or individual" for the provision of "scarce medical specialist services." The enabling statute requires that the services be provided "at Department facilities."

- Services outside of the United States. Through the Foreign Medical Program under 38 U.S.C. 1724, VA is responsible for reimbursing medical expenses incurred by Veterans with service-connected disabilities (or, in some circumstances, Veterans receiving vocational rehabilitation assistance) who are residing or traveling abroad.

- Long-term care programs. VA also has a number of programs to provide long-term care in inpatient and at-home settings using non-VA resources:

- The State Veterans Home Per Diem Program under 38 U.S.C. 1741 allows VA to contribute to the per diem costs incurred by Veterans residing in state-run nursing homes or receiving domiciliary care or adult day health care from such facilities.

- Community Nursing Homes under 38 U.S.C. 1720 are contracted public or private nursing homes.

- Purchased Home Health Care Services is the umbrella term for two programs under 38 U.S.C. 1710. ${ }^{4}$ The first is Skilled Home Health Care Services, which contracts with

3 Section 405(c) of the Indian Health Care Improvement Act (2010) was amended by the Affordable Care Act, specifically at 25 U.S.C. 1645(c).

4 Additional descriptions of these programs can be found in VHA Handbook 1140.6 (VHA, 2006). 
community-based home health agencies to provide short-term services, such as nursing, physical therapy, and speech pathology, to homebound or remotely located Veterans. ${ }^{5}$ The second is the Homemaker and Home Health Aide Services program, which uses contracted public and private health care agencies to provide in-home services and to pay stipends to family members.

- Other programs. There are other instances in which VA pays at least some of the cost of health care services provided by non-VA personnel or facilities, though such programs fall outside the scope of the mandate for this assessment:

- The Home Hospice Care Program uses personnel from community hospice agencies.

- Veterans who do not meet the limited eligibility standards for VA-supplied dental care can purchase a discounted dental insurance policy, through a national pilot program.

- Examinations for VA disability compensation or pension benefits can be performed by external health care providers on a fee basis or under contract.

\section{E.2.4. Emergency Services}

As discussed in Chapter Three, services under 38 U.S.C. 1703 are often referred to as "preauthorized care" because the Veteran must receive explicit permission from VA prior to visiting external health care professionals or facilities or risk being personally liable for the costs of services rendered. In a crisis situation, however, obtaining appropriate VA approval prior to arriving at a hospital's emergency department or calling for paramedics may be impractical or put the Veteran's life or health at risk.

The first of two key statutes providing legislative authority for VA payment of external emergency care without prior approval is 38 U.S.C. 1728, under which VA will reimburse a Veteran for the costs of emergency treatment (or pay the provider directly) as long as the event was related to a service-connected disability (either directly or indirectly). Table E-2 describes various aspects of service-connected emergency care.

The other main avenue to reimbursed external emergency care is 38 U.S.C. 1725, which does not require a Veteran to have a service-connected disability (see Table E-3).

Table E-2

Key Features of Service-Connected Emergency Care

\begin{tabular}{|c|c|}
\hline Feature & Description \\
\hline Situational eligibility & $\begin{array}{l}\text { (1) "Prudent layperson" would have reasonably expected treatment delay to be } \\
\text { hazardous; and } \\
\text { (2) VA or federal health care facilities not "feasibly available"; and } \\
\text { (3) unreasonable or unwise to attempt to first utilize VA or federal facilities (or } \\
\text { prior attempts were refused) }\end{array}$ \\
\hline Status eligibility & $\begin{array}{l}\text { (1) Emergency treatment is related to a service-connected disability; or } \\
\text { (2) Veteran has total permanent service-connected disability }\end{array}$ \\
\hline $\begin{array}{l}\text { VA discretion to utilize or } \\
\text { pay for non-VA care }\end{array}$ & $\begin{array}{l}\text { VA shall reimburse Veteran or provider for emergency services rendered, but only } \\
\text { as per VA regulations }\end{array}$ \\
\hline $\begin{array}{l}\text { Provider qualifications or } \\
\text { requirements }\end{array}$ & None \\
\hline $\begin{array}{l}\text { Veteran input into } \\
\text { provider choice }\end{array}$ & Presumably unlimited \\
\hline
\end{tabular}

5 Skilled Home Health Care Services has also been known as "Purchased Skilled Home Care" and "fee-basis home care." 
Table E-2-Continued

\begin{tabular}{|c|c|}
\hline Feature & Description \\
\hline $\begin{array}{l}\text { Additional requirements } \\
\text { for inpatient treatment }\end{array}$ & None until point at which emergency ends \\
\hline $\begin{array}{l}\text { Additional requirements } \\
\text { for outpatient treatment }\end{array}$ & None until point at which emergency ends \\
\hline \multirow[t]{4}{*}{ Payments } & $\begin{array}{l}\text { "Usual and customary" charges according to statute, but regulations add the } \\
\text { following: }\end{array}$ \\
\hline & $\begin{array}{l}\text { If inpatient, "prospective payment system similar to that used in the Medicare } \\
\text { program" }\end{array}$ \\
\hline & If outpatient, \\
\hline & $\begin{array}{l}\text { (1) the amount described on any contract or negotiated agreement, or } \\
\text { (2) if no contract or agreement exists } \\
\text { (a) the "Medicare rate," } \\
\text { (b) the "repricer" rate, or } \\
\text { (c) amount the provider bills general public }\end{array}$ \\
\hline Direct payer of provider & VA or Veteran (who is later reimbursed by VA) \\
\hline $\begin{array}{l}\text { Medical record sharing } \\
\text { requirements }\end{array}$ & None \\
\hline Coverage & National \\
\hline $\begin{array}{l}\text { First year implemented or } \\
\text { authorized }\end{array}$ & 1973 \\
\hline Status & Active \\
\hline Key statutes or laws & 38 U.S.C. 1728 \\
\hline Key regulations & 38 C.F.R. $17.120-17.121$ \\
\hline
\end{tabular}

Table E-3 Key Features of Non-Service-Connected Emergency Care

\begin{tabular}{|c|c|}
\hline Feature & Description \\
\hline \multirow[t]{3}{*}{ Situational eligibility } & $\begin{array}{l}\text { (1) "Prudent layperson" would have reasonably expected treatment delay to be } \\
\text { hazardous; and }\end{array}$ \\
\hline & (2) VA or federal health care facilities not "feasibly available"; and \\
\hline & (3) unreasonable or unwise to attempt to first utilize VA or federal facilities \\
\hline \multirow[t]{3}{*}{ Status eligibility } & $\begin{array}{l}\text { (1) Must be "active" participant in VA health care receiving treatment in prior } \\
24 \text { months; }\end{array}$ \\
\hline & $\begin{array}{l}\text { (2) Veteran must not have any other health plans or coverage that could pay for } \\
\text { some of the bill; and }\end{array}$ \\
\hline & $\begin{array}{l}\text { (3) Veteran must not have any other collateral sources that could cover the entire } \\
\text { bill }\end{array}$ \\
\hline $\begin{array}{l}\text { VA discretion to utilize or } \\
\text { pay for non-VA care }\end{array}$ & $\begin{array}{l}\text { VA shall reimburse Veteran or provider for emergency services rendered, but only } \\
\text { as per VA regulations }\end{array}$ \\
\hline $\begin{array}{l}\text { Provider qualifications or } \\
\text { requirements }\end{array}$ & $\begin{array}{l}\text { Must be hospital emergency room or a similar facility held out as providing } \\
\text { emergency care }\end{array}$ \\
\hline $\begin{array}{l}\text { Veteran input into provider } \\
\text { choice }\end{array}$ & Presumably unlimited \\
\hline
\end{tabular}


Table E-3-Continued

\begin{tabular}{|c|c|}
\hline Feature & Description \\
\hline $\begin{array}{l}\text { Additional requirements } \\
\text { for inpatient treatment }\end{array}$ & VA suggests that inpatient providers contact VA within 48 hours of admission \\
\hline $\begin{array}{l}\text { Additional requirements } \\
\text { for outpatient treatment }\end{array}$ & None \\
\hline \multirow[t]{4}{*}{ Payments } & $\begin{array}{l}\text { "Reasonable value of emergency treatment" (secondary payer if third party } \\
\text { collateral source provides some contribution) but VA establishes maximum } \\
\text { amount payable by regulation: }\end{array}$ \\
\hline & Lesser of \\
\hline & (1) amount for which the Veteran is personally liable or \\
\hline & (2) 70 percent of Medicare fee schedule \\
\hline Direct payer of provider & VA or Veteran (who is later reimbursed by VA) \\
\hline $\begin{array}{l}\text { Medical record sharing } \\
\text { requirements }\end{array}$ & None \\
\hline Coverage & National \\
\hline $\begin{array}{l}\text { First year implemented or } \\
\text { authorized }\end{array}$ & 1999 \\
\hline Status & Active \\
\hline Key statutes or laws & 38 U.S.C. 1725 \\
\hline Key regulations & 38 C.F.R. $17.1000-17.1008$ \\
\hline
\end{tabular}

\section{E.3. Cost of Care to Veterans}

Veterans enrolled in VA health care do not pay premiums; however, they may be charged copayments based on the type of care provided, whether the condition being treated is serviceconnected, and the Veteran's enrollment priority group. Copayments are charged for four types of health care services, including inpatient care, outpatient care (except preventive care), outpatient medication, and long-term care services. Only those Veterans in Priority Group 1 are never charged copayments; those with higher incomes (Priority Groups 7 and 8) are billed for copays for all four types of service. Veterans in Priority Groups 2, 3, and 5 may be charged copays for outpatient medication, and those in Priority Group 5 have copayments for longterm care services. Assessment B's report details the cost of VA care to veterans, with data on various types of users, services, and insurance type.

VA is required by federal law to bill a Veteran's private insurance provider for health care services for any non-service connected condition, and it may also bill Medicare supplemental insurance plans. ${ }^{6}$ In FYs 2015 and 2016, VA plans to recoup $\$ 3.2$ billion in private payments for non-service-connected health care. Payments received from private insurers may be used to reduce Veterans' required copayments.

6 The Balanced Budget Act of 1997 (P.L. 105-33) required VA to establish the "Medical Care Collections Fund," and to seek reimbursement from Veterans and/or private insurers for non-service-connected health care services. Importantly, this statute also allowed VA to retain these funds instead of returning them to the U.S. Treasury and to roll them over to later fiscal years. See Panangala (2013, p. 10). 


\section{References}

Altarum Institute. (2015, January 30). VHA Project ARCH evaluation: Comprehensive assessment of Project $A R C H$. Ann Arbor, MI.

American College of Physicians. (2015, March 3). Letter to the Honorable Robert McDonald. Retrieved from http://www.aha.org/advocacy-issues/letter/2015/150302-cl-rin2900-ap24.pdf

American Hospital Association. (2015, March 2). Letter to the Honorable Robert McDonald.

American Legion. (n.d.). Review of VA contract health care Project HERO. Retrieved from http://www.legion.org/veteransbenefits/bulletins/6247/review-va-contract-health-care-project-hero

AMVETS, Disabled American Veterans, Paralyzed Veterans of America, \& Veterans of Foreign Wars of the U.S. (VFW). (2013). The independent budget for the Department of Veterans Affairs: Fiscal year 2014.

Assessing the Promise and Progress of the Choice Program. (2015, May 13). Hearing before the Committee on Veterans' Affairs, U.S. House of Representatives. 114th Congress.

Bailit, M., \& Houy, M. (2014, May). Key payer and provider operational steps for successfully implementing bundled payment. Health Care Incentives Improvement Institute. Retrieved from http://www.hci3.org/content/key-payer-and-provider-operational-steps

Bandow, D. (2014, June 2). Veterans need choice in choosing health care. Washington, DC: Cato Institute.

Byrne, B. (2014, August 8). Veterans deserve better health care options. Bradley's Blog. Retrieved from https://byrne.house.gov/media-center/columns/veterans-deserve-better-health-care-options

California Medical Association. (2013, May 21). TRICARE survey results. Retrieved from http://www.cmanet.org/files/assets/news/2013/05/tricare-survey-results-052113.pdf

Carrato, T. (2014, June 18). Testimony by Thomas Carrato, president, Health Net Services, before the Committee on Veterans' Affairs, U.S. House of Representatives. 113th Congress.

Casale, A., Paulus, R., Selna, M., Doll, M., Bothe Jr., A., McKinley, K. E., Berr, S., Davis, D., Gilfillan, R., Hamory, B., \& Steel Jr., G. (2007). ProvenCareSM: A provider-driven pay-for-performance program for acute episodic cardiac surgical care. Annals of Surgery, 246(4), 613-623.

Catalyst for Payment Reform. (2014). National scorecard on payment reform. Retrieved from http://www.catalyzepaymentreform.org/images/documents/nationalscorecard2014.pdf

Centers for Medicare \& Medicaid Services. (n.d.-a). Functional contractors overview. Retrieved from http://www.cms.gov/Medicare/Medicare-Contracting/Medicare-Administrative-Contractors/Downloads/ Functional-Contractors-Overview-2013.pdf

(n.d.-b). Bundled Payments for Care Improvement (BPCI) Initiative: General information. Retrieved from http://innovation.cms.gov/initiatives/bundled-payments

—. (2014a, July 25). Medicare program-General information. Retrieved from http:/www.cms.gov/Medicare/Medicare-General-Information/MedicareGenInfo/index.html

. (2014b, October 2). Award fee average MAC earned overall. Retrieved from http:/www.cms.gov/Medicare/Medicare-Contracting/Medicare-Administrative-Contractors/ Award-Fee-Average-MAC-Earned-Overall-.html 
(2015a, January 26). Better care. Smarter spending. Healthier people: Why it matters. Fact sheet. Retrieved from http://www.cms.gov/Newsroom/MediaReleaseDatabase/Fact-sheets/2015-Fact-sheets-items/ 2015-01-26-2.html

. (2015b, April 9). Competitive acquisition ombudsman. Retrieved from

http://www.cms.gov/Medicare/Medicare-Fee-for-Service-Payment/DMEPOSCompetitiveBid/

Competitive_Acquisition_Ombudsman.html

- (2015c, April 9). MAC jurisdictions. Retrieved from http://www.cms.gov/Medicare/ Medicare-Contracting/Medicare-Administrative-Contractors/MACJurisdictions.html

Chen, Caroline. (2014, March 7). Cheaper surgery sends Lowe's flying to Cleveland Clinic. Bloomberg. Retrieved from http:/www.bloomberg.com/news/articles/2014-03-07/cheaper-surgery-sends-lowe-s-flying-to-cleveland-clinic CMS — see Centers for Medicare \& Medicaid Services.

Committee on Redesigning Health Insurance Performance Measures, Payment, and Performance Improvement Programs. (2007). Rewarding provider performance: Aligning incentives in Medicare. Washington, DC: Institute of Medicine of the National Academies. Retrieved from http://www.nap.edu/catalog/11723/ rewarding-provider-performance-aligning-incentives-in-medicare-pathways-to-quality

Concerned Veterans for America. (2015, February 26). Fixing Veterans health care: A bipartisan policy taskforce. Arlington, VA.

Costantino, M., \& Schwabish, J. (2014, April). The federal budget of 2013: A closer look at mandatory spending. Washington, DC: Congressional Budget Office. Retrieved from https://www.cbo.gov/sites/default/files/45280-Budget_Mandatory_Final.pdf

Cromwell, J., Dayhoff, D. A., McCall, N. T., et al. (1998). Medicare participating heart bypass center demonstration. Health Care Financing Administration.

Cutler, D. M., \& Ghosh, K. (2012). The potential for cost savings through bundled episode payments. New England Journal of Medicine, 366(12), 1075-1077.

Damberg, C. I., Sorbero, M. E., Hussey, P. S., Lovejoy, S., Liu, H., \& Mehrotra, A. (2009). Exploring episode-based approaches for Medicare performance measurement, accountability and payment. Washington, DC: U.S. Department of Health and Human Services.

Davis, P. A., Talaga, S. R., Binder, C., Hahn, J., Kirchhoff, S. M., Morgan, P. C., \& Tilson, S. (2013, January 31). Medicare primer. Report R40425. Washington, DC: Congressional Research Service. Retrieved from https://www.fas.org/sgp/crs/misc/R40425.pdf

Defense Health Agency. (n.d.). FY 2014-2015 risk assessment, military health benefits program for improper payment reporting. Retrieved from http://comptroller.defense.gov/Portals/45/documents/gwipr/fy2014/ riskAssessment/DHA_Risk_Assessment_FY2014.pdf

. (2015, February 28). Evaluation of the TRICARE program: Access, cost, and quality. Retrieved from http://www.health.mil/Reference-Center/Reports/2015/02/28/

Evaluation-of-the-TRICARE-Program-Fiscal-Year-2015-Report-to-Congress

Dickson, V. (2014, August 14). VA expands new care program, but providers may balk at the low rates it pays. Modern Healthcare.

DoD_see U.S. Department of Defense.

EmpowerChiro. (2014, February 24). Preferred provider application. Retrieved from

http://www.empowerchiro.com/TriWest/TriWestApp.pdf

Exploring the implementation and future of the Veterans Choice program. (2015, May 12). Hearing before the Committee on Veterans' Affairs, U.S. Senate. 114th Congress.

Frist, B., \& Marshall, J. (2015, February 27). A bold blueprint for transforming Veterans health care. Washington Post. 
Frye, J. R. (2015, March 19). Letter to the Honorable Robert McDonald. Retrieved from http://m.govexec.com/media/gbc/docs/pdfs_edit/051415e1.pdf

GAO_ see U.S. Government Accountability Office.

Gawande A. (2015, May 11). Overkill. New Yorker. Retrieved from

http://www.newyorker.com/magazine/2015/05/11/overkill-atul-gawande

Gibson, S.. (2015, May 13). Transcript of remarks at a hearing on access under Veterans Choice program, Committee on Veterans' Affairs, U.S. House of Representatives. 114th Congress.

Golden, W., Thompson, J., Motley, M., Fendrick, A., Mathis, C., \& Chernew, M. (2015, May 19).

Arkansas Payment Improvement Initiative: Expanding episodes to other clinical areas. Health Affairs Blog.

Retrieved from http://healthaffairs.org/blog/2015/05/19/

arkansas-payment-improvement-initiative-expanding-episodes-to-other-clinical-areas

Gordon, D. I. (2013). Bid protests: The costs are real, but the benefits outweigh them. George Washington University Law School Public Law and Legal Theory Paper, No. 2013-41. Retrieved from

http://ssrn.com/abstract=2228748

Grant Thornton. (2015). Assessment I: Business Processes. Retrieved from

http://www.va.gov/opa/choiceact/documents/assessments/Assessment_I_Business_Processes.pdf

Guroo. (n.d.). Homepage. Retrieved from

http://www.guroo.com

Health Net Federal Services. (n.d.-a). About our PCCC preferred provider network. Retrieved from https://www.hnfs.com/content/hnfs/home/va/home/provider/options-for-providers/join-our-network.html

_ . (n.d.-b). Become a Veterans Choice participating provider. Retrieved from

https://www.hnfs.com/content/hnfs/home/va/home/provider/options-for-providers/

become-a-veterans-choice-participating-provider.html

—. (n.d.-c). For Veterans receiving care from a Health Net provider. Fact sheet.

_. (n.d.-d). VA Choice provider self registration. Retrieved from

http://www.healthnetpc3provider.com/p3c/?register=true

. (2014, November). Participation agreement for services under the Veterans Access, Choice and

Accountability Act of 2014. Retrieved from

https://www.hnfs.com/content/dam/hnfs/va/pccc/VeteransChoice/

Choice_Provider_Appl_Professional_Nov2014.pdf

Health Resources and Services Administration. (n.d.). What are federally qualified health centers (FQHCs)?

Retrieved from

http://www.hrsa.gov/healthit/toolbox/RuralHealthITtoolbox/Introduction/qualified.html

Hegseth, P. (2015, March 13). Breaking another promise to Veterans. Wall Street Journal.

Hicks, J. (2015, February 3). Obama budget seeks authority to shift funds from Veterans Choice program. Washington Post.

Hoffmeier, D. (2015, May 12). Testimony of Donna Hoffmeier, program officer, VA services, Health Net Federal Services, before the Committee on Veterans Affairs, U.S. Senate.

Hornbrook, M. C., Hurtado, A. V., \& Johnson, R. E. (1985). Health care episodes: Definition, measurement and use. Medical Care Review, 42(2), 163-218.

Hosek, J., Mattock, M., Schoenbaum, M., \& Eiseman, E. (2005). Placing a value on the health benefit for active-duty personnel. Santa Monica, CA: RAND Corporation. MG-385-OSD. Retrieved from http://www.rand.org/pubs/monographs/MG385.html

Hosek, S. (1993, May). The CHAMPUS reform initiative: Implications for military health care reform. Santa Monica, CA: RAND Corporation. CT-107. Retrieved from

http://www.rand.org/pubs/testimonies/CT107.html 
Hosek, S., \& Cecchine, G. (2001). Reorganizing the Military Health System: Should there be a joint command? Santa Monica, CA: RAND Corporation. MR-1350-OSD. Retrieved from http://www.rand.org/pubs/monograph_reports/MR1350.html

Hosek, S., \& Straus, S. (2013). Patient privacy, consent, and identity management in health information exchange: Issues for the Military Health System. Santa Monica, CA: RAND Corporation. RR-112-A. Retrieved from http://www.rand.org/pubs/research_reports/RR112.html

House Report 109-305. (2005, November 18). Making appropriations for military quality of life functions of the Department of Defense, military construction, the Department of Veterans Affairs, and related agencies for the fiscal year ending September 30, 2006, and for other purposes. Report to accompany H.R. 2528, 109th Congress, 1st Session.

House Report 113-564. (2014, July 28). Veterans Access, Choice, and Accountability Act of 2014. Report to accompany H.R. 3230, 113th Congress, 2nd Session.

Huelskamp: Kansas vets to receive their Choice Card soon. (2014, November 6). Salina Post. Retrieved from http://salinapost.com/2014/11/06/huelskamp-kansas-vets-to-receive-their-choice-card-soon

Humana Military. (2014, April). 2014 provider handbook, Tricare South region. Retrieved from http://www.humana-military.com/library/pdf/providerhandbook.pdf

Hussey, P. S., Sorbero, M. E., Mehrotra, A., Liu, H., \& Damberg, C. L. (2009). Episode-based performance measurement and payment: Making it a reality. Health Affairs, 28(5), 1406-1417.

Hussey, P. S., Ridgely, M. S., \& Rosenthal, M. B. (2011). The Prometheus bundled payment experiment: Slow start shows problems in implementing new payment models. Health Affairs, 30(11), 2116-2124.

IMPAQ International. (2013). Evaluation of the Medicare Acute Care Episode (ACE) demonstration: Final evaluation report. Centers for Medicare and Medicaid Services.

Jansen, D. J. (2014, January 2). Military medical care: Questions and answers. Report RL33537. Washington, DC: Congressional Research Service. Retrieved from https://www.fas.org/sgp/crs/misc/RL33537.pdf

Japsen, B. (2013, June 29). Obama administration not budging on Medicare competitive bidding. Forbes.

Johnson, B. S., Boudiab, L. D., Freundl, M., Anthony, M., Gmerek, G. G, \& Carter, J. (2013, July). Enhancing Veteran-centered care: A guide for nurses in non-VA settings. American Journal of Nursing, 113(7).

Jones, B. (2012, September 14). Testimony by Brad Jones, chief operating officer, Humana Veterans Healthcare Services, before the Subcommittee on Health, Committee on Veterans' Affairs, U.S. House of Representatives.

Kidston, M. (2015, January 21). Delay in VA program upsets Mineral County Health Center. Ravalli Republic.

Kime, P. (2015, February 9). N.H. senators move to protect Veterans Choice. Military Times.

Koenig, L., Doherty, J., Mather III, R. C., Nguyen, J., \& Sankaran, S. (2015). Is the Medicare Bundled Payments for Care Improvement Initiative designed to succeed? American Journal of Managed Care, 3(1).

McDermott, C. (2014, November 25). Ayotte, Shaheen seek answers from VA on "Choice Program." Concord Monitor.

McDonald, R. (2014a, October 20). Remarks by Secretary Robert A. McDonald at the Institute of Medicine annual meeting. Office of Public and Intergovernmental Affairs. Retrieved from http://www.va.gov/opa/bios/secretary.asp

. (2014b, November 5). An open letter to America’s Veterans from Secretary Bob McDonald. VAntage Point-Official Blog of the U.S. Department of Veterans Affairs. Retrieved from

http://www.blogs.va.gov/VAntage/15990/an-open-letter-to-americas-veterans-from-secretary-bob-mcdonald

(2015, May 7). Robert McDonald: Why we serve. Federal Times. Retrieved from

http://www.federaltimes.com/story/government/management/public-service/2015/05/03/

caring-veterans-higher-calling/26710321/

McIntyre, Jr., D. (2015, May 12). Testimony by David J. McIntyre, president and CEO, TriWest Healthcare Alliance, before the Committee on Veterans' Affairs, U.S. Senate. 114th Congress. 
McKesson Health Solutions. (2014). The state of value-based reimbursement and the transition from volume to value in 2014. Retrieved from http://mhsinfo.mckesson.com/rs/mckessonhealthsolutions/images/ MHS-2014-Signature-Research-White-Paper.pdf

McKinsey \& Company. (2015). Assessment J (Supplies). 2015a. Retrieved from http://www.va.gov/opa/choiceact/documents/assessments/Assessment_J_Supplies.pdf . (2015). Assessment K (Facilities). 2015b. Retrieved from http://www.va.gov/opa/choiceact/documents/assessments/Assessment_K_Facilities.pdf

Medicare.gov. (n.d). Medicare 2015 costs at a glance. Retrieved from http://www.medicare.gov/your-medicare-costs/costs-at-a-glance/costs-at-glance.html Medicare Payment Advisory Commission. (2008). Report to Congress: Medicare payment policy. Washington, DC: MedPAC.

Military Compensation and Retirement Modernization Commission. (2015, January 29). Final report of the Military Compensation and Retirement Modernization Commission. Washington, DC.

Miller, H. D. (2009). From volume to value: Better ways to pay for health care. Health Affairs (Millwood), 28(5), 1418-1428.

. (2010, June). Making reform a reality: Ways to facilitate better healthcare payment and delivery systems and lower healthcare costs. Network for Regional Healthcare Improvement, Center for Healthcare Quality and Payment Reform, and Robert Wood Johnson Foundation. Retrieved from http://www.rwjf.org/content/dam/farm/reports/reports/2010/rwjf61467

Miller, J. (2014, June 18). Statement by the Honorable Jeff Miller before the Committee on Veterans' Affairs, U.S. House of Representatives. 113th Congress.

Moran, J. (2014, December). Sen. Moran introduces bill directing VA to help Veterans still struggling with healthcare access under Choice Act. Press release.

Murray, E. (2015, June 1). Statement by Edward Murray, acting assistant secretary for management and interim chief financial officer, U.S. Department of Veterans Affairs, before the Subcommittee on Oversight and Investigations, Committee on Veterans' Affairs, U.S. House of Representatives. 114th Congress.

National Academy of Public Administration. (2011, September). Veterans Health Administration fee care program. Washington, DC.

National Association of Community Health Centers. (2015, March 5). Letter to director, regulation policy and management.

Newcomer, L. N., Gould, B., Page, R. D., Donelan, S. A., \& Perkins, M. (2014, July 8). Changing physician incentives for affordable, quality cancer care: Results of an episode payment model. American Society of Clinical Oncology.

Non-VA care: An integrated solution for Veteran access. (2014, June 18). Hearing before the Committee on Veterans' Affairs, U.S. House of Representatives. 113th Congress.

O'Hanlon, M. (2014, May 23). To help injured Veterans, bring in private sector help. Reuters.

Pacific Business Group on Health. (2014, December). Employers Centers of Excellence: Negotiating high-quality care at top performing centers. Fact sheet. Retrieved from http://www.pbgh.org/storage/documents/ECEN_Program_Summary1214.pdf

Panangala, S. V. (2006, October 26). Veterans' health care issues in the 109th Congress. Report RL32961. Washington, DC: Congressional Research Service.

- (2010, February 3). Veterans health care: Project HERO implementation. Report 7-5700. Washington, DC: Congressional Research Service.

. (2013, August 14). Veterans' medical care: FY2014 appropriations. Report R43179. Washington, DC: Congressional Research Service.

Philpott, T. (2015, April 2). Caution flag up on more easing VA "choice card" usage. Stars and Stripes. 
Project ARCH. (n.d.). Project ARCH frequently asked questions. Retrieved from http://www.wichita.va.gov/documents/Project-ARCH-FAQs.doc

RAND Health. (2015a). Current and projected characteristics and unique health care needs of the patient population served by the Department of Veterans Affairs. Santa Monica, CA: RAND Corporation,

RR-1165/1-VA. Retrieved from http://www.rand.org/pubs/research_reports/RR1165z1.html

- (2015b). Resources and capabilities of the Department of Veterans Affairs to provide timely and accessible care to Veterans. Santa Monica, CA: RAND Corporation, RR-1165/2-VA. Retrieved from http://www.rand.org/pubs/research_reports/RR1165z2.html

Rhem, K. T. (2001, September 20). TRICARE for Life ready to kick off Oct 1. American Forces Press Service. Retrieved from http://archive.defense.gov/news/newsarticle.aspx?id=44853

Ridgely, M. S., de Vries, D., Bozic, K. J., \& Hussey, P. S. (2014). Bundled payment fails to gain a foothold in California: The experience of the IHA bundled payment demonstration. Health Affairs, 33(8), 1345-1352.

Robinson, C. (2014, June 11). National Acquisition Center updates. Hines, IL: VA National Acquisition Center.

Schoen, C., Guterman, S., Zezza, M. A., and Abrams, M. K. (2013, January). Confronting costs: Stabilizing U.S. health spending while moving toward a high performance health care system, Washington, DC:

Commonwealth Fund Commission on a High Performance Health System.

Shelton, H. H., Ondra, S. L., \& Levin, P. L. (2015). Reforming the Military Health System. Retrieved from http://www.cnas.org/sites/default/files/publications-pdf/Reforming\%20DoD\%20Healthcare_021015.pdf

Tanielian T., Farris, C., Epley, C., Farmer, C. F., Robison, E., Engel, C. C., Robbins, M., \& Jaycox, L. H. (2014). Ready to serve: Community-based provider capacity to deliver culturally competent, quality mental health care to Veterans and their families. Santa Monica, CA: RAND Corporation. RR-806-UNHF. Retrieved from http://www.rand.org/pubs/research_reports/RR806.html

Task Force on the Future of Military Health Care. (2007, December). Final report. Washington, DC: U.S. Department of Defense. Retrieved from http://www.dcoe.mil/content/Navigation/Documents/

103-06-2-Home-Task_Force_FINAL_REPORT_122007.pdf

Tester, J. (2014, September 11). Letter to Carolyn M. Clancy, M.D., from Senator Jon Tester of Montana (copy on file with the authors).

TRICARE. (2005, second quarter). New TRICARE Reserve Select Health Plan launched April 26: Understanding your role. TRICARE Provider News. Retrieved from https://www.hnfs.com/content/dam/hnfs/tn/prov/news/pdf/PN\%202005/PN_Spring_2005_final.pdf

_. (2009). Module 1: Who we are and our history. Retrieved from http://www.tricare.mil/tricareu/pco_ppt/20091130/01_who_we_are_public_our_history.pdf . (2013, November 1). What is TRICARE? [Video]. Retrieved from https://www.youtube.com/watch?v=8d0619DAe_s

Trivedi, A., Matula, S, Miake-Lye, I., Glassman, P. A., Shekelle, P., \& Asch, S. (2011, January). Systematic review: Comparison of the quality of medical care in Veterans Affairs and non-Veterans Affairs settings. Medical Care, 49(1), 76-88.

TriWest Healthcare Alliance. (n.d.). Network provider fact sheet: VAPC3 and VACAA (Veterans Choice Program) comparison. Retrieved from https://www.triwest.com/en/vapc3-provider/Quick-Reference-Guides/

VACAA-VAPC3-Differences_Network-Provider.pdf

- (2014). Patient Centered Community Care. Retrieved from

https://vapccc.triwest.com/PCCCWeb/index.html\#/home

. (2015a). Provider registration. Retrieved from https://joinournetwork.triwest.com

(2015b). Provider registration. Retrieved from

https://joinournetwork.triwest.com/Forms/Request/Add.aspx 
Retrieved from

(2015c). Veterans Affairs Patient-Centered Community Care (VAPC3) network provider handbook.

https://www.triwest.com/en/VAPC3-Provider/Provider-Handbook/2013-HA-VAPC3-Provider-Handbook.pdf

U.S. Department of Defense. (2014). The Department of Defense ancillary services report to Congress and defense committees. Washington, DC.

U.S. Department of Health and Human Services. (2015, January 26). Better, smarter, healthier: In historic announcement, HHS sets clear goals and timeline for shifting Medicare reimbursements from volume to value. Press release. Retrieved from http://www.hhs.gov/news/press/2015pres/01/20150126a.html

U.S. Department of Veterans Affairs. (2006, August). Health care resources contracting-Buying (VA Directive 1663). Retrieved from http://wwwl.va.gov/vapubs/viewPublication.asp?Pub_ID=347

- (2010, July 23). Locations: California. Retrieved from

http://www.va.gov/directory/guide/state.asp?STATE=CA\&dnum=1

. (2013a, October). Invoice review and certification, vol. VIII, chapt. 1A. Retrieved from http://www.va.gov/finance/docs/VA-FinancialPolicyVolumeVIIIChapter01A.pdf

. (2013b, December 30). VHA site classifications and definitions (VHA Handbook 1006.02). Washington, DC.

. (2014a, January). NNPO non-VA medical care coordinationization fact sheet for pre-authorized care. Form 10-7078/10-7079. Retrieved from

http://www.va.gov/purchasedcare/docs/pubfiles/factsheets/nvc_authorizations.pdf

—. (2014b, April 1). About VA. Retrieved from http://www.va.gov/about_va/mission.asp

. (2014c, May 27). Accelerating Access to Care Initiative fact sheet. Washington, DC: Office of Public Affairs Media Relations. Retrieved from

http://www.va.gov/health/docs/052714AcceleratingAccessFactSheet.PDF

- (2014d, October 3). Report to Congress on the Veterans Choice program authorized by section 101 of the Veterans Access, Choice, and Accountability Act of 2014 (Pub. L. 113-146). Washington, DC.

- (2014e, November). Veterans Access, Choice, and Accountability Act of 2014, Title I: Choice program and health care collaboration. Fact sheet.

—. (2015a). History—VA history. Retrieved from http://www.va.gov/about_va/vahistory.asp

- (2015b). Medical programs and information technology programs, congressional submission FY 2015

funding and FY 2016 advance appropriations, vol. II. Washington, DC.

. (2015c, March 25). Expanding Choice program eligibility: What changes in the 40-mile calculation mean for Veterans. VAntage Point_-Official Blog of the U.S. Department of Veterans Affairs. Retrieved from http://www.blogs.va.gov/VAntage/18463/expanding-choice-program-eligibility/

. (2015d, April 24). VA expands Choice program eligibility, effective immediately. Press release.

U.S. Department of Veterans Affairs, Office of Budget. (2015, February). FY 2016 budget submission, vol. 1: Supplemental information and appendices. Retrieved from http://www.va.gov/budget/products.asp

U.S. Department of Veterans Affairs, Office of Inspector General. (2009, August 3). Audit of Veterans Health Administration's non-VA outpatient fee care program. Report 08-02901-185. Washington, DC.

. (2010, August 18). Veterans Health Administration: Audit of non-VA impatient fee care program. Report 09-03408-227. Washington, DC.

. (2012, March 14). Department of Veterans Affairs: Review of VA's compliance with the Improper Payments Elimination and Recovery Act. Report 12-00849-120. Washington, DC.

- (2013, September 27). Department of Veterans Affairs: Audit of VA's Technology Acquisition Center contract operations. Report 12-02387-343. Washington, DC.

- (2014a, August 12). Healthcare inspection: Improper closure of non-VA care consults, Carl Vinson VA Medical Center, Dublin, Georgia. Report 14-03010-251. Washington, DC. 
(2014b, August 26). Veterans Health Administration: Review of alleged patient deaths, patient wait times, and scheduling practices at the Phoenix VA Health Care System. Report 14-02603-267. Washington, DC.

. (2014c, September 26). Administrative investigation: Conduct prejudicial to the government and interference of a VA official for the financial benefit of a contractor, Veterans Health Administration, Procurement and Logistics Office, Washington, DC. Report 13-03065-304. Washington, DC.

- (2014d, November 19). Veterans Health Administration: Audit of support service contracts. Report 12-02576-40. Washington, DC.

. (2015, April 28). Review of VA's Patient-Centered Community Care (PC3) contracts' estimated cost savings. Report 14-02916-336. Washington, DC.

U.S. Department of Veterans Affairs, Office of Public and Intergovernmental Affairs. (2014, April 16). Independent 2013 survey shows Veterans highly satisfied with VA care. Press release. Retrieved from http://www.va.gov/opa/pressrel/pressrelease.cfm?id=2537

U.S. Department of Veterans Affairs, Office of Research and Development. (2015). VA research on prosthetics/limb loss. Retrieved from http://www.research.va.gov/topics/prosthetics.cfm

U.S. Government Accountability Office. (1998, February 26). Defense health care: Operational Difficulties and system uncertainties pose continuing challenges for TRICARE. Report GAO/T-HEHS-98-100. Washington, DC.

. (1999, July). Defense health care: Improvements needed to reduce vulnerability to fraud and abuse. Report GAO/HEHS-99-142. Washington, DC.

- (2008, March). Health care: Additional efforts to better assess joint ventures needed. GAO-08-399. Washington, DC.

. (2010, March). Medicare contracting reform: Agency has made progress with implementation, but contractors have not met all performance standards. Report GAO-10-71. Washington, DC.

. (2012, October). Medicare fraud prevention: CMS has implemented a predictive analytics system, but needs to define measures to determine its effectiveness. Report GAO-13-104. Washington, DC.

- (2013a, May). VA health care: Management and oversight of fee basis care need improvement. GAO-13-441. Washington, DC.

. (2013b, October). VA health care: Additional guidance, training, and oversight needed to improve clinical contract monitoring. Report GAO-14-54. Washington, DC.

—. (2014a, March). Defense health care: Acquisition process for TRICARE's third generation of managed care support contracts. Report GAO-14-195. Washington, DC.

. (2014b, March). Medicare: Contractors and private plans play a major role in administering benefits. Report GAO-14-417T. Washington, DC.

. (2014c, March). Medicare: Second year update of CMS's durable medical equipment competitive bidding program round 1 rebid. Report GAO-14-156. Washington DC.

- (2014d, March). VA health care: Actions needed to improve administration and oversight of Veterans' Millennium Act emergency care benefit. Report GAO-14-175. Washington, DC.

. (2014e, June). Defense health care: More-specific guidance needed for TRICARE's managed care support contractor transitions. Report GAO-14-505. Washington, DC.

. (2014f, July). Medicare program integrity: Increased oversight and guidance could improve effectiveness and efficiency of postpayment claims review. Report GAO-14-474. Washington, DC.

. (2015, February). Improper payments: TRICARE measurement and reduction efforts could benefit from adopting medical record reviews. Report GAO-15-269. Washington, DC.

VA—see U.S. Department of Veterans Affairs.

VA Central Western Massachusetts Health Care System. (2012, October 10). Non-VA Care Coordination (NVCC) appointment management process. Leeds, MA. 
VA crisis slowly changing health-care system for Veterans. (2014, March 10). Arizona Republic. Retrieved from http://www.azcentral.com/story/news/arizona/investigations/2015/03/11/

va-crisis-slowly-changing-health-care-system-veterans/24745045

VA fee basis care: Examining solutions to a flawed system. (2012, September 12). Transcript of hearing before the Subcommittee on Health, Committee on Veterans' Affairs, U.S. House of Representatives. 112th Congress.

Veterans of Foreign Wars of the U.S. (VFW). (2015a, March 2). Veterans Choice Program initial report. Kansas City, MO.

. (2015b, May 11). Veterans Choice Program second report. Kansas City, MO.

Veterans Health Administration. (various dates). Operations. Manual M-1. Washington, DC.

- (2006, July 21). Purchased home health care services procedures. VHA Handbook 1140.6. Washington, DC.

_ . (2012, February) Become a VA physician. Brochure. Retrieved from

http://www.vacareers.va.gov/assets/common/print/Physician_Brochure.pdf

. (2013a, January 23). VHA Directive 1601: Non-VA medical care program. Retrieved from http://www.va.gov/vhapublications/ViewPublication.asp?pub_ID=2859

- (2013b, December). Introduction to non-VA care consult/referral review process. Washington, DC.

. (2013c, December). Non-VA Medical Care Coordination (NVCC) process guide: Non-VA care consult/ referral review. Washington, DC.

. (2013d, December). Non-VA Medical Care Coordination (NVCC) process guide: Appointment and clinical documentation management. Washington, DC.

— . (2014a, October 7). VHA surgical complexity. Retrieved from http://www.va.gov/health/surgery

—. (2014b, December 15). Non-VA medical care program: Fact sheet for interested providersPatient-Centered Community Care and Veterans Access, Choice, and Accountability Act. Retrieved from http://www.va.gov/opa/choiceact/documents/FactSheets/Fact-Sheet-For-VACAA-Providers.pdf

- (2015a, April 13). Veterans Access, Choice, and Accountability Act update: Veterans Choice program. Washington, DC.

—. (2015b, July). Enrollment priority groups. IB 10-441. Washington, DC. Retrieved from

http://www.va.gov/healthbenefits/resources/publications/IB10-441_enrollment_priority_groups.pdf

Veterans Health Administration, Chief Business Office. (2012, October). Non-VA care. Washington, DC.

- (2013a, December). Appointment and clinical documentation management. Washington, DC.

- (2013b, December). Non VA Care Coordination (NVCC) administrative appeals management process. Washington, DC.

- (2014, September 22). Patient-Centered Community Care (PC3) contracts. Washington, DC.

Veterans Health Administration, Chief Business Office Purchased Care. (2015, June 3). Patient-Centered Community Care (PC3). Retrieved from

http://www.va.gov/PURCHASEDCARE/programs/veterans/nonvacare/pccc/index.asp

Veterans' Rural Health Advisory Committee. (2012, January 30). Meeting minutes. Washington, DC: VA Office of Rural Health. Retrieved from http://www.ruralhealth.va.gov/docs/VRHAC/january-2012-teleconference.pdf

VFW- see Veterans of Foreign Wars of the U.S.

VHA— see Veterans Health Administration.

Weeks, W. B., Wallace, A. E., Wallace T. A., \& Gottlieb D. J. (2009). Does the VA offer good health care value? Journal of Health Care Finance, 35(4), 1-12. 
Williamson, R. (2014, June 18). Statement by Randall B. Williamson, Director, Health Care, U.S. Government Accountability Office, before the Committee on Veterans' Affairs, U.S. House of Representatives. 113th Congress.

. (2015, June 1). Statement by Randall B. Williamson, Director, Health Care, U.S. Government Accountability Office, before the Subcommittee on Oversight and Investigations, Committee on Veterans' Affairs, U.S. House of Representatives. 114th Congress.

Wisconsin Collaborative for Healthcare Quality. (2011). A resource use primer. Middleton, WI. 